Arcabouço para recuperação de imagens por conteúdo visando à percepção do usuário 



\section{Arcabouço para recuperação de imagens por conteúdo visando à percepção do usuário ${ }^{1}$}

\section{Pedro Henrique Bugatti}

Orientadora: Profa. Dra. Agma Juci Machado Traina

Tese apresentada ao Instituto de Ciências Matemáticas e de Computação - ICMC-USP, como parte dos requisitos para obtenção do título de Doutor em Ciências - Ciências de Computação e Matemática Computacional. VERSÃO REVISADA.

\footnotetext{
${ }^{1}$ Este trabalho teve o apoio financeiro da FAPESP (Fundação de Amparo à Pesquisa do Estado de São Paulo), processo 2008/00485-6.
} 
Ficha catalográfica elaborada pela Biblioteca Prof. Achille Bassi e Seção Técnica de Informática, ICMC/USP, com os dados fornecidos pelo(a) autor(a)

Bugatti, Pedro Henrique
Arcabouço para recuperação de imagens por conteúdo
visando à percepça do usuário / Pedro Henrique
Bugatti; orientadora Agma Juci Machado Traina. --
São Carlos, 2012.
148 p.
Tese (Doutorado - Programa de Pós-Graduação em
Ciências de Computação e Matemática Computacional) --
Instituto de Ciências Matemáticas e de Computação,
Universidade de São Paulo, 2012.
1. recuperação de imagens por conteúdo. 2.
consultas por similaridade. 3. perfis de usuário. 4.
funçós de distância. 5. imagens médicas. I. Traina,
Agma Juci Machado, orient. II. Título.


Para meus pais, meu irmão Fábio

e minha noiva Priscila. 
"Life is like riding a bicycle. To keep your balance, you must keep moving."

Albert Einstein 


\section{Agradecimentos}

A Deus por permitir que eu tivesse saúde e perseverança para concluir o presente trabalho, e por todas as oportunidades de aprendizado.

Ao meu pai, Ildeberto, pelo apoio constante e por ser um exemplo de dedicação, dignidade e integridade, tanto na vida pessoal e familiar, quanto acadêmica.

À minha mãe, Ivani, por todo amor e carinho incondicionais despendidos e por sempre ensinar-me a persistir perante todos os percalços.

À minha noiva, Priscila, por dividirmos todos os momentos, por todo incentivo, compreensão, carinho e amor.

Ao meu irmão e melhor amigo, Fábio, pelos momentos de descontração, apoio e companheirismo.

À minha orientadora, profa. Dra. Agma Juci Machado Traina, pelo voto de confiança e por todos os ensinamentos transmitidos tanto na vida acadêmica como pessoal.

Ao prof. Dr. Caetano Traina Júnior pelas valiosas sugestões e revisões.

À toda minha família de São Carlos, em especial aos meus avós, minha tia Dirce e primas Fernanda e Télia.

A todos os amigos do Grupo de Bases de Dados e Imagens (GBdI). Foram tantos que passaram durante esses anos de mestrado e doutorado, que citar um ou outro seria injusto.

Ao Prof. Dr. Paulo Mazzoncini de Azevedo Marques e à profa. Dra. Ângela Delete Bellucci, ambos do departamento de Clínica Médica da Faculdade de Medicina de Ribeirão Preto (FMRP-USP), pelo auxílio nos experimentos no Hospital das Clínicas, bem como a todos os médicos radiologistas e residentes que despenderam tempo e conhecimento para as análises realizadas.

À FAPESP pelo apoio financeiro, bem como às outras agências de fomento (CAPES e CNPq) e ao ICMC-USP. 
Na última década observou-se grande interesse para o desenvolvimento de técnicas para Recuperação de Imagens Baseada em Conteúdo devido à explosão na quantidade de imagens capturadas e à necessidade de armazenamento e recuperação dessas imagens. A área médica especificamente é um exemplo que gera um grande fluxo de informações, principalmente imagens digitais para a realização de diagnósticos. Porém um problema ainda permanecia sem solução que tratava-se de como atingir a similaridade baseada na percepção do usuário, uma vez que para que se consiga um recuperação eficaz, deve-se caracterizar e quantificar o melhor possível tal similaridade.

Nesse contexto, o presente trabalho de Doutorado visou trazer novas contribuições para a área de recuperação de imagens por conteúdo. Dessa forma, almejou ampliar o alcance de consultas por similaridade que atendam às expectativas do usuário. Tal abordagem deve permitir ao sistema CBIR a manutenção da semântica da consulta desejada pelo usuário. Assim, foram desenvolvidos três métodos principais. O primeiro método visou a seleção de características por demanda baseada na intenção do usuário, possibilitando dessa forma agregação de semântica ao processo de seleção de características. Já o segundo método culminou no desenvolvimento de abordagens para coleta e agregação de perfis de usuário, bem como novas formulações para quantificar a similaridade perceptual dos usuários, permitindo definir dinamicamente a função de distância que melhor se adapta à percepção de um determinado usuário. O terceiro método teve por objetivo a modificação dinâmica de funções de distância em diferentes ciclos de realimentação. Para tanto foram definidas políticas para realizar tal modificação as quais foram baseadas na junção de informações a priori da base de imagens, bem como, na percepção do usuário no processo das consultas por similaridade. Os experimentos realizados mostraram que os métodos propostos contribuíram de maneira efetiva para caracterizar e quantificar a similaridade baseada na percepção do usuário, melhorando consideravelmente a busca por conteúdo segundo as expectativas dos usuários. 


\section{Abstract}

In the last decade techniques for Content-Based Image Retrieval (CBIR) have been intensively explored due to the increase in the amount of captured images and the need of fast retrieval of them. The medical field is a specific example that generates a large flow of information, especially digital images employed for diagnosing. One issue that still remains unsolved deals with how to reach the perceptual similarity. That is, to achieve an effective retrieval, one must characterize and quantify the perceptual similarity regarding the specialist in the field.

Therefore, the present thesis was conceived to fill in this gap creating a consistent support to perform similarity queries over images, maintaining the semantics of a given query desired by the user, bringing new contribuitions to the content-based retrieval area. To do so, three main methods were developed. The first method applies a novel retrieval approach that integrates techniques of feature selection and relevance feedback to perform demand-driven feature selection guided by perceptual similarity, tuning the mining process on the fly, according to the user's intention. The second method culminated in the development of approaches for harvesting and surveillance of user profiles, as well as new formulations to quantify the perceptual similarity of users, allowing to dynamically set the distance function that best fits the perception of a given user. The third method introduces a novel approach to enhance the retrieval process through user feedback and profiling, modifying the distance function in each feedback cycle choosing the best one for each cycle according to the user expectation. The experiments showed that the proposed methods effectively contributed to capture the perceptual similarity, improving in a great extent the image retrieval according to users' expectations. 
1 Introdução 1

1.1 Considerações Iniciais . . . . . . . . . . . . . . . . . . . . . . . 1

1.2 Motivação . . . . . . . . . . . . . . . . . . . 2

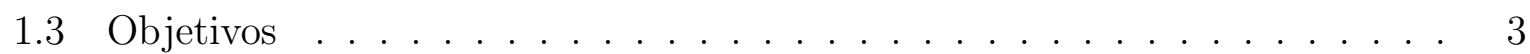

1.4 Organização do documento . . . . . . . . . . . . . . . . 4

2 Recuperação de Imagens Baseada em Conteúdo $\quad 7$

2.1 Introdução . . . . . . . . . . . . . . . . . . . 7

2.2 Extração de Características . . . . . . . . . . . . . . . . . . . . . 9

2.2 .1 Segmentação de Imagens . . . . . . . . . . . . . . . . . . . . . . 10

2.2 .2 Cor . . . . . . . . . . . . . . . . . 13

2.2 .3 Textura . . . . . . . . . . . . . . . 15

2.2 .4 Forma . . . . . . . . . . . . . . . . 16

2.3 Medidas de Similaridade . . . . . . . . . . . . . . . . . . . . . 17

2.3.1 Consultas por Similaridade e Espaços Métricos . . . . . . . . . . . . 18

2.3.2 Espaços Métricos . . . . . . . . . . . . . . . . 20

2.4 Estruturas de Indexação . . . . . . . . . . . . . . . . . . . . . . 21

2.5 Interação com o Usuário . . . . . . . . . . . . . . . . . . . . . 22

2.6 Realimentação de Relevância . . . . . . . . . . . . . . . . . . . . . . . 23

2.6.1 Sistema CBIR com Realimentação de Relevância . . . . . . . . . . 23

2.7 Avaliação de Desempenho . . . . . . . . . . . . . . . . . 27 
2.7.1 Precisão e Revocação . . . . . . . . . . . . . . . . . . . . . . . . . . 27

2.8 Considerações Finais . . . . . . . . . . . . . . . . . . . . . 30

3 Funções de Distância e Correlações

3.1 Introdução . . . . . . . . . . . . . . . . . . . . . . . . 31

3.2 Funções de Distância Consolidadas . . . . . . . . . . . . . . . . . . . 31

3.2.1 Distâncias Geométricas . . . . . . . . . . . . . . . . . . . 32

3.2 .2 Teoria da Informação . . . . . . . . . . . . . . . . . . . . 37

3.2 .3 Medidas Estatísticas . . . . . . . . . . . . . . . . . 38

3.3 Propostas de Funções de Distâncias . . . . . . . . . . . . . . . . . . . . . 39

3.3.1 Funções de Distância Métricas . . . . . . . . . . . . . . . . . . . . 41

3.4 Valores Limites de Funções de Distância . . . . . . . . . . . . . . . . . 42

3.5 Considerações Finais . . . . . . . . . . . . . . . . . . . . . . . . . 44

4 Seleção de Características por Demanda 47

4.1 Introdução . . . . . . . . . . . . . . . . . . . . . 47

4.2 Conceitos Relacionados . . . . . . . . . . . . . . . . . . . . . . . 49

4.2.1 Processo de Mineração de Regras . . . . . . . . . . . . . . . . . . 49

4.3 Método Proposto . . . . . . . . . . . . . . . . . . . . . . . 52

4.4 Experimentos . . . . . . . . . . . . . . . . . . 55

4.4.1 Descrição das Bases de Imagens . . . . . . . . . . . . . . . . . . 56

4.4.2 Metodologia Experimental . . . . . . . . . . . . . 57

4.4.3 Resultados . . . . . . . . . . . . . . . . . . 59

4.5 Considerações Finais . . . . . . . . . . . . . . . . . . . 66

5 Integrando Perfis de Usuário em Sistemas CBIR $\quad 67$

5.1 Introdução . . . . . . . . . . . . . . . . . . . . . . 67

5.2 Conceitos Relacionados . . . . . . . . . . . . . . . . . . . 68

5.2 .1 Análise de Imagens na Área Médica . . . . . . . . . . . . . . . . 68

5.2 .2 Perfis de Usuário . . . . . . . . . . . . . . . . . . . . . . 71

5.3 Método CBIR Orientado à Percepção . . . . . . . . . . . . . . . . . . . . . 73

5.3.1 Supervisão e Levantamento dos Perfis de Usuários . . . . . . . . . . 73

5.3.2 Avaliação de Similaridade Guiada pela Percepção . . . . . . . . . . 75

5.3.3 Integração de Perfis de Usuários em Sistemas CBIR . . . . . . . . . 77

5.4 Experimentos . . . . . . . . . . . . . . . . . . 80

5.4 .1 Descrição das Bases de Imagens . . . . . . . . . . . . . . . . 80

5.4 .2 Metodologia Experimental . . . . . . . . . . . . . . . . . . . 81

5.4 .3 Resultados . . . . . . . . . . . . . . . . . 83

5.5 Considerações Finais . . . . . . . . . . . . . . . . . . . . . . . . . 92 
6 Novas Políticas para Escolha de Funções de Distância 95

6.1 Introdução . . . . . . . . . . . . . . . . . . . . . . . . . 95

6.2 Método Proposto . . . . . . . . . . . . . . . . . . . . . . . . . . 96

6.3 Experimentos . . . . . . . . . . . . . . . . . . . 100

6.3.1 Resultados . . . . . . . . . . . . . . . . . . . 101

6.4 Considerações Finais . . . . . . . . . . . . . . . . . . . . . . . . 119

7 Arquitetura CBIR agregada a Perfis $\quad 121$

7.1 Introdução . . . . . . . . . . . . . . . . . . . . . . . . 121

7.2 Estilos Arquiteturais e Padrões de Projeto . . . . . . . . . . . . . . . . 122

7.3 Arquitetura Desenvolvida . . . . . . . . . . . . . . . . . . 124

7.4 Descrição do Sistema . . . . . . . . . . . . . . . . . . . . . . . . . . 124

7.4.1 Validação em Ambiente Real . . . . . . . . . . . . . . . . . . . 126

7.5 Considerações Finais . . . . . . . . . . . . . . . . . . . . . . . 128

8 Conclusões $r$

8.1 Considerações Finais . . . . . . . . . . . . . . . . . . . . . 129

8.2 Principais Contribuições . . . . . . . . . . . . . . . . . . 130

8.3 Publicações . . . . . . . . . . . . . . . . . . . . . 131

8.4 Propostas para Trabalhos Futuros . . . . . . . . . . . . . . . . 133

Referências Bibliográficas $\quad 135$ 


\section{Lista de Figuras}

2.1 Fluxo de dados em um sistema CBIR. . . . . . . . . . . . . . . . . . . 8

2.2 (a) Identificação de limiar por ponto de mínimo utilizando a técnica de Otsu; (b) exemplo de uma imagem de ressonância magnética e (c) sua segmentação aplicando a técnica de Otsu. . . . . . . . . . . . . . . . . . . . 11

2.3 (a) Imagem do pulmão obtida a partir de exame de tomografia computadorizada; (b) exemplo da aplicação do método de crescimento de região para segmentação do pulmão esquerdo. . . . . . . . . . . . . . . . . . . 1

2.4 Exemplo de segmentação realizada pela variação do método EM/MPM. (a) imagem original; (b) imagem segmentada em 5 classes; (c) região de classe 1 (fluido cérebro-espinhal); (d) região de classe 2 (massa cinzenta); (e) região de classe 3 (massa branca); (f) região de classe 4 (dura, medula óssea, gordura) (Balan, 2007). . . . . . . . . . . . . . . . 13

2.5 Exemplo de um histograma de níveis de cinza obtido a partir de uma imagem médica de ressonância magnética do cérebro. . . . . . . . . . . . . . . 14

2.6 Imagens visualmente distintas e com histogramas idênticos. . . . . . . . . . 14

2.7 Exemplos de imagens contendo nódulos tumorais: (a) nódulo benigno; (b) nódulo maligno. . . . . . . . . . . . . . . . . . . . . . 17

2.8 Consultas por similaridade em um domínio de pontos bidimensionais utilizando a função de distância Euclidiana como função de dissimilaridade. O objeto "central" preto $O_{q}$ é o objeto de consulta enquanto os respectivos objetos cinza constituem as respostas. (a) Ilustra uma Consulta por abrangência de raio $r_{q}$ e (b) ilustra uma Consulta pelos 5 vizinhos mais próximos.

2.9 Diagrama de um sistema CBIR com realimentação de relevância, explicitando o laço de realimentação . . . . . . . . . . . . . . . . . . . . . . . 25 
2.10 Exemplo da técnica de movimentação de centro de consulta. (a) Consulta Inicial (centro de consulta original). (b) Novo centro de consulta movimentado. . . . . . . . . . . . . . . . . . . 25

2.11 Conjunto de resultados possíveis para uma dada operação de busca. . . . . 28

2.12 Exemplo de um gráfico de medidas precision e recall. . . . . . . . . . . 29

2.13 Exemplo de gráficos de precisão e revocação. . . . . . . . . . . . . . . . . 30

3.1 Representação das formas geométricas geradas conforme a distância $L_{p}$ utilizada e em relação aos pontos eqüidistantes à distância $r_{q}$ a partir do objeto centro $o_{q} \ldots \ldots \ldots \ldots \ldots \ldots$

3.2 Incongruência da desigualdade triangular. . . . . . . . . . . . . . . . . . 41

3.3 Variação da abrangência das funções de distância de acordo com a translação do centro de consulta. . . . . . . . . . . . . . . . . . . . . . 43

4.1 Regiões de rejeição (Ribeiro et al., 2005). . . . . . . . . . . . . . . . . 52

4.2 Fluxo de Execução do Método Proposto . . . . . . . . . . . . . . . . 55

4.3 Exemplos de imagens de cada classe pertencentes ao conjunto de teste da base de imagens de ressonância magnética $M R I$. . . . . . . . . . . . 56

4.4 Exemplos de imagens de cada classe pertencentes ao conjunto de teste da base de imagens de ROIs de pulmão oriundas de exames de tomografia computadorizada CTROIsPulmão. . . . . . . . . . . . . . . . 57

4.5 Gráficos de curvas de precisão e revocação, utilizando (a) $L_{1}$, (b) $L_{2}$, e (c) $L_{\infty}$, obtidos a partir da base $M R I$ representada pelos descritores de Haralick comparando o comportamento da recuperação utilizando as características originais com o método proposto utilizando 3 ciclos de realimentação. . . .

4.6 Gráficos de curvas de precisão e revocação, utilizando (a) $L_{1}$, (b) $L_{2}$, e (c) $L_{\infty}$, obtidos a partir da base $M R I$ representada pelo histograma de níveis de cinza comparando o comportamento da recuperação utilizando as características originais com o método proposto utilizando 3 ciclos de realimentação. 60

4.7 Gráficos de curvas de precisão e revocação, utilizando (a) $L_{1}$, (b) $L_{2}$, e (c) $L_{\infty}$, obtidos a partir da base $M R I$ representada pelos momentos de Zernike comparando o comportamento da recuperação utilizando as características originais com o método proposto utilizando 3 ciclos de realimentação. . . .

4.8 Gráficos de curvas de precisão e revocação, utilizando (a) $L_{1}$, (b) $L_{2}$, e (c) $L_{\infty}$, obtidos a partir da base CTROIsPulmão representada pelos descritores de Haralick comparando o comportamento da recuperação utilizando as características originais com o método proposto utilizando 3 ciclos de realimentação. . . . . . . . . . . . . . . . . . . . . . . 
4.9 Gráficos de curvas de precisão e revocação, utilizando (a) $L_{1}$, (b) $L_{2}$, e (c) $L_{\infty}$, obtidos a partir da base CTROIsPulmão representada pelo histograma de níveis de cinza comparando o comportamento da recuperação utilizando as características originais com o método proposto utilizando 3 ciclos de realimentação. . . . . . . . . . . . . . . . . . . . . . . . .

4.10 Gráficos de curvas de precisão e revocação, utilizando (a) $L_{1}$, (b) $L_{2}$, e (c) $L_{\infty}$, obtidos a partir da base CTROIsPulmão representada pelos momentos de Zernike comparando o comportamento da recuperação utilizando as características originais com o método proposto utilizando 3 ciclos de realimentação.

4.11 Exemplo da execução de uma consulta $k$-NN $(k=7)$, utilizando a imagem no canto superior esquerdo como centro de consulta. (a) Utilizando as características originais. (b) Utilizando o método proposto. As imagens ressaltadas pela borda vermelha dizem respeito a falsos positivos. . . . . .

4.12 Gráficos de curvas de precisão e revocação, utilizando (a) $L_{1}$, (b) $L_{2}$, e (c) $L_{\infty}$, obtidos a partir da base SatImage comparando o comportamento da recuperação utilizando as características originais com o método proposto utilizando 3 ciclos de realimentação. . . . . . . . . . . . . . . . . .

4.13 Gráficos ilustrando o tempo de execução das consultas k-NN utilizando a distância $L_{2}$ obtido sobre o conjunto de imagens $M R I$ representado pelas características oriundas dos extratores de (a) Haralick; (b) histograma de níveis de cinza; e (c) momentos de Zernike, comparando o tempo de execução das consultas utilizando as características originais e o método proposto empregando os 3 primeiros ciclos de realimentação. . . . . . . . . . 65

5.1 Fluxo de execução do processo de levantamento do perfil dinâmico. . . . 75

5.2 Exemplo de cálculo do Fator de Percepção. . . . . . . . . . . . . . . . . . . 77

5.3 Integração da abordagem de perfis de usuários proposta para uma arquitetura típica de sistema CBIR. . . . . . . . . . . . . . . . 78

5.4 Autômato de pilha desenvolvido para o parsing dos perfis de usuário. . . . 78

5.5 Exemplos de cada classe de imagens da base MamaROIs: (a) calcificação, (b) massa. . . . . . . . . . . . . . . . . . . . . .

5.6 Gráficos ilustrando e comparando o comportamento das funções de distância que melhor se ajustam à percepção de cada usuário com base em seus perfis utilizando o APF, considerando os achados (a) Espessamento; (b) Vidro Fosco e (c) Favo de Mel. Quanto menor o valor do APF, mais adequada a função de distância à percepção do usuário. . . . . . . . . . . . . . 
5.7 Gráficos ilustrando e comparando o comportamento das funções de distância que melhor se ajustam à percepção de cada usuário com base em seus perfis utilizando o APF, considerando os achados (a) Espessamento; (b) Vidro Fosco e (c) Favo de Mel. Quanto menor o valor do APF, mais adequada a função de distância à percepção do usuário. . . . . . . . . . . . . 86

5.8 Gráficos ilustrando e comparando o comportamento das funções de distância que melhor se ajustam à percepção de cada usuário com base em seus perfis utilizando o APF, considerando os achados Calcificação e Massa descritos pelos: (a) histogramas de níveis de cinza, (b) descritosres de Haralick e (c) momentos de Zernike. Quanto menor o valor do APF, mais adequada a função de distância à percepção do usuário. . . . . . . . . . . . . . . . . . . 89

5.9 Gráficos comparando o impacto gerado pelas funções de distância com relação à percepção dos usuários, calculado agregando informações dos perfis de usuários, considerando as características obtidas a partir das bases CTROIsPulmão e MamaROIs em junção com as distâncias $L_{1}, L_{2}, L_{\infty}$ e

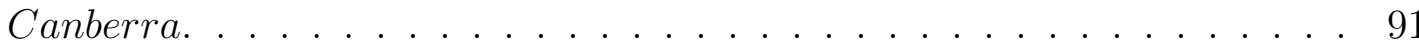

6.1 Arquitetura do método proposto . . . . . . . . . . . . . . . . 98

6.2 Exemplo do funcionamento da política proposta. . . . . . . . . . . . . . 100

6.3 Exemplos de imagens de cada classe pertencentes ao conjunto de teste da base de imagens Corel: (a) Africa; (b) Beach; (c) Buildings; (d) Buses; (e) Dinosaurs; (f) Elephants; (g) Flowers; (h) Food; (i) Horses e (j) Mountains. 101

6.4 Fenômeno local optimum trap (Liu et al., 2009). . . . . . . . . . . . . . . . 102

6.5 Gráficos de curvas de precisão média, gerados a partir de consultas aos k-vizinhos mais próximos e dos primeiros 3 ciclos de realimentação sobre a base de imagens $M R I$, comparando a utilização da técnica QPM com distâncias estáticas e QPM com a abordagem de mudança dinâmica de funções de distância proposta. Realimentação positiva, utilizando funções de distância da família Minkowski. (a) Cabeça Axial (b) Cabeça Coronal (c) Espinha Sagital (d) Cabeça Sagital. . . . . . . . . . . . . . . . . 104

6.6 Gráficos de curvas de precisão média, gerados a partir de consultas aos k-vizinhos mais próximos e dos primeiros 3 ciclos de realimentação sobre a base de imagens $M R I$, comparando a utilização da técnica QPM com distâncias estáticas e QPM com a abordagem de mudança dinâmica de funções de distância proposta. Realimentação positiva, utilizando funções de distância da família Minkowski, Canberra e $\chi^{2}$. (a) Cabeça Axial (b) Cabeça Coronal (c) Cabeça Sagital (d) Espinha Sagital. . . . . . . . . . . . 105 
6.7 Gráficos de curvas de precisão e revocação, gerados a partir de consultas aos k-vizinhos mais próximos sobre imagens da classe Crânio Coronal da base de imagens $M R I$ representadas por características de histogramas de níveis de cinza, comparando a política proposta em relação a manutenção da melhor distância da base. . . . . . . . . . . . . . . . . . . . . . . 107

6.8 Gráficos de curvas de precisão e revocação, gerados a partir de consultas aos k-vizinhos mais próximos sobre imagens da classe Crânio Coronal da base de imagens $M R I$ representadas por características oriundas dos momentos de Zernike, comparando a política proposta em relação a manutenção da melhor distância da base. . . . . . . . . . . . . . . . . . . . . . . 109

6.9 Gráficos de curvas de precisão média, gerados a partir de consultas aos k-vizinhos mais próximos e dos primeiros 3 ciclos de realimentação sobre imagens da classe Crânio Coronal da base de imagens $M R I$, representadas por características de histogramas de níveis de cinza, comparando a política proposta em relação a manutenção da melhor distância da base. . . . . . . . 110

6.10 Gráficos de curvas de precisão média, gerados a partir de consultas aos k-vizinhos mais próximos e dos primeiros 3 ciclos de realimentação sobre imagens da classe Crânio Coronal da base de imagens $M R I$, representadas por características oriundas dos momentos de Zernike, comparando a política proposta em relação a manutenção da melhor distância da base. . . 110

6.11 Gráficos de curvas de precisão e revocação, gerados a partir de consultas aos k-vizinhos mais próximos e dos primeiros 3 ciclos de realimentação sobre imagens da classe Espinha Sagital da base de imagens $M R I$, representadas por características oriundas dos momentos de Zernike, comparando a política proposta em relação a manutenção da melhor distância da base. . . 111

6.12 Gráficos de curvas de precisão e revocação gerados a partir de consultas aos k-vizinhos mais próximos e os primeiros 3 ciclos de realimentação sobre imagens da classe Enfisema da base de imagens CTRoisPulmão representadas por características oriundas dos descritores de Haralick aplicados às matrizes de co-ocorrência, comparando a política proposta em relação a manutenção da melhor distância da base. . . . . . . . . . . . . . . . . . . 113

6.13 Gráficos de curvas de precisão e revocação gerados a partir de consultas aos k-vizinhos mais próximos e os primeiros 3 ciclos de realimentação sobre imagens da classe Consolidação da base de imagens CTRoisPulmão representadas por características oriundas dos momentos de Zernike, comparando a política proposta (Canberra e Chi) em relação a manutenção da melhor distância da base $\left(L_{1}\right) \ldots$. . . . . . . . . . . . . . . . . . . . 114 
6.14 Gráficos de curvas de precisão e revocação gerados a partir de consultas aos k-vizinhos mais próximos e os primeiros 3 ciclos de realimentação sobre imagens da classe Africa da base de imagens Corel representadas por características oriundas dos histogramas de níveis de cinza, comparando a política proposta em relação a manutenção da melhor distância da base. . 116

6.15 Gráficos de curvas de precisão e revocação gerados a partir de consultas aos k-vizinhos mais próximos e os primeiros 3 ciclos de realimentação sobre imagens da classe Elephants da base de imagens Corel representadas por características oriundas dos histogramas de níveis de cinza, comparando a política proposta em relação a manutenção da melhor distância da base. . . 117

6.16 Gráficos de curvas de precisão e revocação gerados a partir de consultas aos k-vizinhos mais próximos e os primeiros 3 ciclos de realimentação sobre imagens da classe Horses da base de imagens Corel representadas por características oriundas dos histogramas de níveis de cinza, comparando a política proposta em relação a manutenção da melhor distância da base. . . 118

7.1 Diagrama Esquemático da Arquitetura Proposta. . . . . . . . . . . . . . 124

7.2 Interface do sistema. . . . . . . . . . . . . . . . . . . . 125

7.3 Interface do sistema - Menu. . . . . . . . . . . . . . . . . . . . . 127

7.4 Porcentagem de casos onde os usuários responderam que o sistema apresentou resultados de acordo com cinco escalas de satisfação: muito melhor, um pouco melhor, neutro/similar, um pouco pior e muito pior. (a) Usuários Especialistas; (b) Usuários Comuns. . . . . . . . . . . . . . . . . . . . . 127 


\section{Lista de Tabelas}

4.1 Valores Críticos de Z (Ribeiro et al., 2005). . . . . . . . . . . . . . 52

5.1 Tabela explicitando exemplos de achados clínicos em Tomografia Computadorizada de pulmão. . . . . . . . . . . . . . . . . . . . . . . . 70

5.2 Tabela comparando a precisão das consultas por similaridade e o APF em relação ao número de características visuais de um dado achado clínico representadas pelas características de textura, considerando a base CTROIsPulmão.

5.3 Tabela comparando a precisão das consultas por similaridade e o APF em relação ao número de características visuais de um dado achado clínico representadas pelas características de histogramas de níveis de cinza, considerando a base CTROIsPulmão. . . . . . . . . . . . . . . . . . 87

5.4 Tabela comparando a precisão das consultas por similaridade e o APF em relação ao número de características visuais de um dado achado clínico representadas pelas características de histogramas de níveis de cinza, considerando a base MamaROIs. . . . . . . . . . . . . . . . . . . . . . . . . . 88

5.5 Tabela comparando a precisão das consultas por similaridade e o APF em relação ao número de características visuais de um dado achado clínico representadas pelos descritores de Haralick, considerando a base MamaROIs. 90

5.6 Tabela comparando a precisão das consultas por similaridade e o APF em relação ao número de características visuais de um dado achado clínico representadas pelos momentos de Zernike, considerando a base MamaROIs. 90 


\section{Lista de Abreviaturas e Siglas}

$\begin{array}{ll}\text { AID } & \text { Attribute Interaction Distances. } \\ \text { APF } & \text { Average Perception Factor. } \\ \text { CBIR } & \text { Content-based Image Retrieval. } \\ \text { CT } & \text { Tomografia Computadorizada. } \\ \text { DBM-Tree } & \text { Density-Based Metric Tree. } \\ \text { DE } & \text { Distância Euclidiana. } \\ \text { DF-Tree } & \text { Distance Fields Tree. } \\ \text { DKL } & \text { Divergência de Kullback-Leibler. } \\ \text { DM } & \text { Distância Métrica. } \\ \text { DMH } & \text { Distância Mahalanobis. } \\ \text { DNA } & \text { Ácido Desoxirribonucléico. } \\ \text { DPF } & \text { Dynamic Partial Distance. } \\ \text { DQ } & \text { Distância Quadrática. } \\ \text { DTW } & \text { Dynamic Time Warping. } \\ \text { EM } & \text { Expectation and Maximization. } \\ \text { GWD } & \text { Global Warp Distance. } \\ \text { HCRP-USP } & \text { Hospital das Clínicas de Ribeirão Preto - USP. } \\ \text { IBM } & \text { International Business Machines. } \\ \text { ICMC-USP } & \text { Instituto de Ciências Matemáticas e de Computação - USP. } \\ \text { k-NN } & \text { Consulta aos } k \text {-Vizinhos mais próximos (k-Nearest Neighbors Query). } \\ \text { MA } & \text { Método de Acesso. } \\ \text { MAM } & \text { Metric Access Method (Método de Acesso Métrico). } \\ \text { PACS } & \text { Picture Anchiving and Communication System. } \\ \text { PDF } & \text { Probability Density Function. } \\ \text { PF } & \text { Perception Factor. } \\ \end{array}$




$\begin{array}{ll}\text { QBIC } & \text { Query by Image Content. } \\ \text { QPM } & \text { Query Point Movement. } \\ \text { RF } & \text { Relevance Feedback. } \\ \text { RM } & \text { Ressonância Magnética. } \\ \text { ROIs } & \text { Regions of Interest. } \\ \text { SAID } & \text { Strong Attribute Interaction Distance. } \\ \text { SAM } & \text { Spatial Access Method (Método de Acesso Espacial). } \\ \text { SGBDs } & \text { Sistemas Gerenciadores de Bases de Dados. } \\ \text { SIH } & \text { Sistemas de Informações Hospitalares. } \\ \text { SQL } & \text { Structure Query Language. } \\ \text { StARMiner } & \text { Statistical Association Rule Miner. } \\ \text { SVM } & \text { Support Vector Machine. } \\ \text { USP } & \text { Universidade de São Paulo. } \\ \text { WMD } & \text { Warp Metric Distance. } \\ \text { WAID } & \text { Weak Attribute Interaction Distance. }\end{array}$




\section{Capítulo \\ 1 \\ Introdução}

\subsection{Considerações Iniciais}

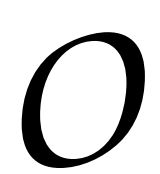

s Sistemas de Informações Hospitalares (SIH) processam informações relativas aos pacientes, destacando-se, entre elas, seu estado de saúde, os exames realizados e os procedimentos médicos adotados. Atualmente, a maioria desses sistemas armazenam dados textuais e numéricos, mas, em alguns casos, já é possível a associação das informações textuais com informações gráficas, provenientes de exames como raio-X, tomografia (CT ou RM), ultrassom, entre outros. Com a introdução dos sistemas PACS (Picture Archiving and Communication System) (Faggioni et al., 2011; Müller et al., 2004), cresceu o interesse por integrar num só sistema todas as informações dos pacientes (textos, imagens, gráficos, dados temporais, entre outros).

Infelizmente, os poucos sistemas PACS comerciais oferecidos atualmente são extremamente caros, e não contemplam todas as necessidades do centro médico (Hains et al., 2012; Sung et al., 2000). Dessa forma, o estado da arte na área resume-se ao desenvolvimento de soluções locais, muitas vezes restritas. Alguns centros médicos integrados a unidades de pesquisa optam, via de regra, por adquirir apenas alguns módulos do sistema, desenvolvendo e adaptando outros módulos e criando soluções próprias conforme sua necessidade. Assim, o custo é reduzido e contemplam-se necessidades e características próprias de cada ambiente.

Como os sistemas PACS organizam as imagens provenientes de exames efetuados sobre os pacientes, seria muito interessante que por meio desses sistemas fosse possível realizar consultas e recuperar tais imagens baseando-se apenas no conteúdo das mesmas. 
Por exemplo, pode ser necessário "recuperar todas as imagens, obtidas em exames de tomografia computadorizada de coração, similares a uma imagem dada". Nesse caso, o cruzamento das informações é independente das chaves de busca tradicionais, baseadas em dados numéricos e textuais, as quais associam exames e pacientes em um SIH tradicional. A facilidade de recuperação de dados baseada em seu conteúdo é um dos recursos mais almejados para incorporação aos sistemas PACS (Akgül et al., 2011). Através dessa facilidade, podem ser encontrados registros de pacientes cujas imagens associadas apresentam aspectos de similaridade (utilizando padrões gráficos), além de se obter correlações utilizando sintomas previamente registrados, tratamentos efetuados, etc (Huang, 2011; Lemke, 2011; Marsh, 1997). Pode-se notar que um sistema PACS é potencialmente uma ferramenta bastante eficaz no auxílio ao diagnóstico médico.

Um sistema PACS deve então ser capaz de responder a consultas por similaridade, isto é, questões do tipo: "quais são as 10 imagens mais semelhantes (próximas) de uma dada imagem" ou "quais são as imagens que diferem de até 5 unidades de uma imagem padrão". Vale notar que tanto as imagens quanto a função de distância (dissimilaridade) definida são usualmente dependentes do domínio dos dados e do interesse do que se considera "semelhante".

Imagens médicas são um tipo de dado complexo que traz por si só uma série de desafios. Devem ser tratadas por técnicas que não permitam a perda de informação, o que muitas vezes é relevado em algoritmos para extração de características de imagens tradicionais. Os sistemas de recuperação de imagens por conteúdo (Content-Based Image Retrieval CBIR) (Akgül et al., 2011) (Ghosh et al., 2011) podem ser uma ferramenta muito valiosa para auxiliar ao processamento de Consultas por Similaridade (Seção 2.3.1), e auxiliar o diagnóstico médico, pois retornará as imagens ou casos mais semelhantes àquele que o especialista médico está analisando. Porém, a recuperação pura e simples das imagens, que não considera as expectativas dos usuários (dada pelo perfil dos mesmos), e muitas vezes retorna imagens fora do padrão esperado pelo usuário, gera insegurança e não aceitação de sistemas computacionais que realizam tal tarefa. Desse modo, uma ferramenta que potencialmente seria muito útil para o benefício de pacientes e seu tratamento torna-se inviável. A presente tese visou diminuir essa lacuna, respondendo consultas por similaridade que atendam às expectativas dos usuários.

\subsection{Motivação}

Por mais de uma década, pesquisadores têm explorado a área de análise e recuperação de imagens por conteúdo. Entretanto, a maioria dos trabalhos encontrados preocupam-se com a proposta de novos extratores de características e negligenciam o inter-relacionamento entre as características e as funções de distância que as comparam, indicando o grau de similaridade entre as imagens. Desse modo, fazem uso das mais 
conhecidas e amplamente utilizadas funções de distância, sem explorar adequadamente se tais funções suportam a recuperação das imagens por conteúdo atendendo às expectativas dos usuários. Além disso, para que seja possível mensurar/atingir a similaridade perceptual entre duas imagens, é necessário o conhecimento prévio (perfil) do usuário que deverá utilizar o sistema, pois a similaridade depende de quais aspectos na imagem, que o usuário está buscando, devem-se comparar.

Para conseguir uma recuperação eficaz, que satisfaça às expectativas do usuário, é necessário quantificar e caracterizar o melhor possível a similaridade perceptual. No entanto, muitas vezes as funções de distância tradicionais não evidenciam imagens obviamente similares. É nessa direção que o presente trabalho foi elaborado: desenvolver um arcabouço que integre a calibração de funções de distância que permitam aproximar a noção perceptual do usuário com relação à similaridade entre imagens médicas, de modo a auxiliar o usuário a recuperar imagens por conteúdo atendendo às suas expectativas. Para isso, foi necessário integrar em um mesmo ambiente o conhecimento dos usuários, proveniente de levantamento e organização de seus perfis, bem como da inclusão de técnicas de realimentação de relevância para permitir calibrar as funções de distância além da junção com as características mais apropriadas para a classe de imagens que está sendo tratada. Nesse sentido, a presente tese visou aproximar o sistema computacional às expectativas do especialista médico.

\subsection{Objetivos}

Atualmente os sistemas CBIR embasam-se no paradigma denominado "One-size-fits-all", ou seja, não existe uma escolha personalizada de acordo com a expectativa perceptual do usuário com relação aos pares função de distância e características extraídas das imagens que melhor adequam-se ao mesmo. O ponto crucial de tal problema diz respeito a usuários diferentes muitas vezes requererem funções de distância distintas para atingirem suas expectativas, bem como, diferentes coleções de imagens também necessitarem de diferentes funções de distância.

Portanto, o objetivo da presente tese foi criar um suporte consistente para a realização de consultas por similaridade em imagens médicas, onde a manutenção da semântica de consulta desejada pelo usuário fosse contemplada. Para tanto, funções de distância foram calibradas e selecionadas automaticamente e de maneira transparente aos usuários com o intuito de quantificar mais apropriadamente a semelhança entre pares de imagens, buscando atender às expectativas dos mesmos.

A definição de uma distância que propicie o retorno de imagens por conteúdo contemplando a noção perceptual de similaridade dos usuários é uma tarefa muito complexa, e que depende também diretamente da qualidade dos vetores de características das imagens 
e das expectativas do usuário, que podem ser levantadas através de seu perfil de trabalho e conhecimento.

Dessa forma, a presente tese contemplou o desenvolvimento de novas técnicas, que atendem às expectativas dos usuários, com relação à similaridade em imagens médicas constituindo-se em uma contribuição inédita deste trabalho.

\subsection{Organização do documento}

Esta tese de doutorado apresenta a seguinte organização:

- No presente capítulo foram apresentadas considerações iniciais, a motivação para o desenvolvimento do trabalho, assim como os objetivos pertinentes para seu desenvolvimento e a organização do documento;

- No capítulo 2 são introduzidos os principais conceitos envolvidos no processo de recuperação de imagens baseada em conteúdo (CBIR), envolvendo fundamentalmente a extração de características, métricas de comparação, tipos de consulta, estruturas de indexação adequadas ao contexto abordado, técnicas de realimentação de relevância, assim como a avaliação de desempenho;

- No capítulo 3 é introduzido o conceito de função de distância, bem como realizado um estudo sobre inúmeras funções de distância, descrevendo o estado da arte para consultas por similaridade. Além disso, é realizada uma análise sobre a abrangência de determinadas funções de distância, como também com relação a homogeneidade destas no espaço de características e suas correlações;

- No capítulo 4 é apresentada a proposta e desenvolvimento de um novo método para seleção de características por demanda adaptativa e redução da dimensionalidade baseada na expectativa do usuário, assim como os experimentos realizados e resultados obtidos;

- No capítulo 5 é apresentado um novo método baseado na integração de perfis de usuário em sistemas CBIR com o intuito de responder consultas por similaridade perceptuais, ou seja, embasadas na percepção de cada usuário em questão. Além disso, são explicitados os experimentos realizados em ambiente real e com especialistas da área médica, bem como análise dos resultados obtidos;

- No capítulo 6 é apresentada a proposta e desenvolvimento de um novo método mediador para o emprego de políticas de escolha de funções de distância em diferentes ciclos de realimentação, bem como os experimentos realizados e resultados obtidos a partir destes; 
- No capítulo 7 é apresentada uma arquitetura para o desenvolvimento de sistemas CBIR agregados a perfis de usuários;

- No capítulo 8 são apresentadas as considerações finais, bem como uma síntese das principais contribuições do presente trabalho e propostas para trabalhos futuros. 


\section{Capítulo}

\section{2}

\section{Recuperação de Imagens Baseada em Conteúdo e Conceitos Relacionados}

\subsection{Introdução}

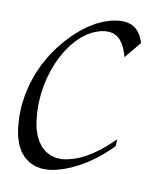

om o desfecho da primeira década do século 21, observa-se um grande aumento na demanda pela recuperação de dados multimídia, no caso em questão principalmente imagens, e, portanto, a necessidade de aplicações construídas sobre esta espinha dorsal.

Objetivando transpor as dificuldades e desvantagens apresentadas pela descrição textual das imagens, surgiu a abordagem de recuperação de imagens utilizando seu conteúdo pictórico. O principal desígnio foi o de estender as técnicas tradicionais de recuperação de imagens em bancos de dados multimídia, incluindo também informações visuais inerentes às imagens, possibilitando que essas pudessem ser obtidas por meio de um processo automático. As imagens a partir desse momento poderiam ser recuperadas por meio de seu conteúdo visual e não mais textual/descritivo. A essa abordagem, foi dado o nome de "Recuperação de Imagens Baseada em Conteúdo" (Content-Based Image Retrieval $C B I R)$. O objetivo principal dessa abordagem consiste em extrair informações das imagens que possam caracterizar adequadamente (idealmente univocamente) o conteúdo das mesmas.

Inúmeras áreas de aplicação fazem uso principalmente de técnicas de recuperação de imagens baseada em conteúdo (CBIR) para a manipulação de bases de imagens, dentre as quais a área de informática médica é uma das mais representativas. Müller et al. 
(2004) apresentam uma extensa revisão de trabalhos, mostrando o quanto as técnicas de recuperação de imagens por conteúdo têm sido aplicadas na área médica. Por exemplo, existem várias propostas de integração de CBIR aos PACS, tais como as apresentadas em Bueno et al. (2002) e Horii \& Ratib (2006).

Grande parte dos sistemas de recuperação de imagens baseada em conteúdo tem arquitetura similar, e envolve algumas etapas primordiais. Entre as principais etapas de um sistema CBIR estão o armazenamento, indexação e extração de características, e o cálculo de similaridade realizado por meio de uma métrica de similaridade (ou função de distância). Tais etapas são integradas por um mecanismo de recuperação de imagens que possibilita a realização de consultas baseadas em conteúdo.

O fluxo de dados em uma arquitetura genérica de um sistema CBIR é apresentado na Figura 2.1. Inicialmente as imagens são processadas e as características visuais das mesmas são extraídas, gerando-se uma representação matemática da imagem por meio de um conjunto de características que refletem diversas propriedades da imagem. Essa representação é denominada assinatura ou vetor de características da imagem. Para a construção da estrutura de índices, a similaridade entre as imagens da base é avaliada. As características da imagem de consulta são extraídas e comparadas com as características das demais imagens da base para a execução de uma consulta.

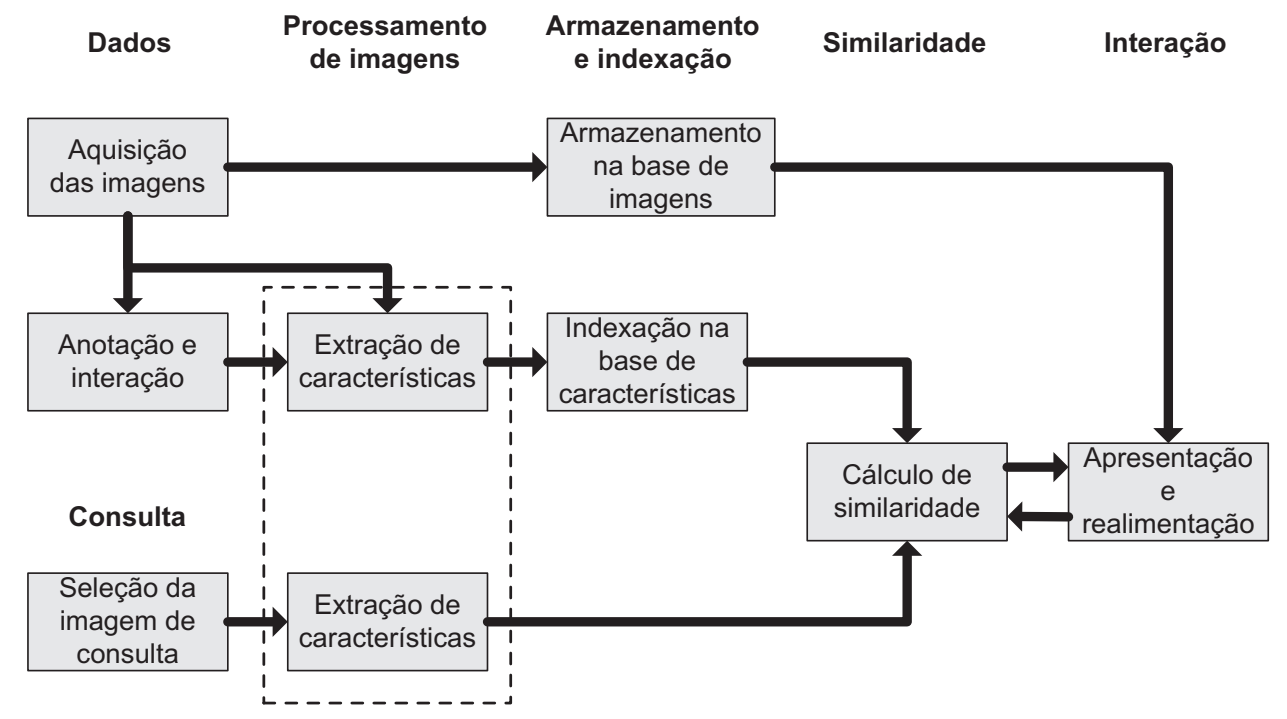

Figura 2.1: Fluxo de dados em um sistema CBIR. Adaptada de (Smeulders et al., 2000)

Na literatura pode-se verificar a proposta de alguns sistemas CBIR. O QBIC ( Query By Image Content) (Flickner et al., 1995) por exemplo foi o primeiro sistema comercial CBIR, o qual foi desenvolvido pela IBM e posteriormente acoplado ao SGBD IBM DB2. Além deste, outros sistemas que merecem destaque são o Virage (Bach et al., 1996), o qual viria a ser integrado ao SGBD Oracle, o Photobook (Pentland et al., 1996), o VisualSEEk (Smith \& Chang, 1996), o Netra (Ma \& Manjunath, 1997) o SIMPLIcity (Semantics-sensitive Integrated Region Matching for Picture Libraries) (Wang et al., 2001) 
e o MIRROR (MPEG-7 Image Retrieval Refinement based On Relevance feedback) (Wong et al., 2005). Em Smeulders et al. (2000) é explicitada uma ampla revisão bibliográfica sobre a área de CBIR até o final da década de 90 e em Datta et al. (2008) é apresentada uma revisão dos trabalhos mais recentes. Já em Müller et al. (2004) e Ghosh et al. (2011) é apresentada uma revisão das pesquisas com relação à área médica.

No entanto, apesar dos inúmeros avanços alcançados pela comunidade científica, as técnicas de CBIR ainda demandam muita pesquisa. A principal problemática diz respeito ao gap semântico existente entre as características de baixo nível extraídas automaticamente das imagens e a interpretação realizada pelo ser humano (Smeulders et al., 2000). Deserno et al. (2008) sugerem uma visão mais sistemática do conceito de gaps em CBIR para a área médica, classificando-os em quatro categorias: de conteúdo, de atributos, de desempenho e de usabilidade.

Pela natureza desta tarefa, as técnicas de CBIR têm se concentrado em alguns aspectos fundamentais: (i) como extrair características que descrevam matematicamente o conteúdo de uma imagem; (ii) como avaliar a similaridade entre imagens baseando-se em suas representações abstratas; (iii) como efetuar a recuperação de forma eficiente em grandes bases de imagens; e (iv) como realizar a interação do usuário com o sistema.

No presente capítulo são introduzidos e discutidos os conceitos envolvidos em cada etapa do processo de recuperação de imagens baseada em conteúdo, iniciando pela seção subseqüente (seção 2.2) a qual introduz o processo de extração de características.

\subsection{Extração de Características}

Dentre os principais componentes de um sistema de recuperação de imagens baseado em conteúdo está o processo de extração de características, uma vez que estas contêm a única informação disponível para diferenciação entre as imagens. No entanto, se as propriedades visuais que o usuário está interessado não forem capturadas por tais características, ou caso estas não estejam inseridas no contexto da consulta desejada pelo mesmo, o sistema CBIR não será capaz de alcançar as expectativas do usuário, não importa o quão sofisticadas tais características sejam.

A representação original das imagens é o primeiro problema a ser abordado para realização de CBIR, afinal uma matriz de pixels não possui informação semântica que corresponda à percepção visual humana. Inúmeras propostas de descrições matemáticas de imagens podem ser encontradas na literatura, visando extrair a semântica da cena retratada na imagem. Desta forma, a imagem passa a ser um elemento de um conjunto definido pelas suas características, que são medidas numéricas que capturam alguma propriedade visual da imagem.

Idealmente os extratores de características deveriam realizar a extração de características relevantes de uma dada imagem, de maneira similar a que um observador humano 
realizaria. Entretanto, apesar do amplo progresso obtido atualmente, tal preceito permanece ainda distante, devido ao pouco conhecimento referente à visão, cognição e emoção humana. Além disso, é necessária a melhor integração entre as características extraídas e uma função de distância adequada para compará-las com o intuito de atingir a recuperação desejada pelo usuário. Caso ambos, características e funções de distâncias, sejam utilizados a esmo (sem prévia análise), torna-se baixa a possibilidade de melhorar a eficiência da recuperação de imagens.

Portanto, a primeira etapa realizada para a análise de uma imagem é a extração de características. De maneira formal, na recuperação de imagens baseada em conteúdo, uma característica diz respeito a uma medida numérica que tem por objetivo capturar uma determinada propriedade visual da imagem, podendo ser de escopo global, ou seja, para a imagem como um todo, ou local onde foca-se pequenas regiões da imagem (regiões de interesse). Em meio às características mais utilizadas para descrever uma imagem de modo sucinto e comumentemente empregadas em CBIR estão, de fato, as características definidas como primitivas (Deselaers et al., 2008a) que são aquelas derivadas de três elementos fundamentais da imagem: distribuições de intensidades (cores), textura e forma. Em Penatti et al. (2012) e Kejia et al. (2011) é realizada uma extensa comparação entre diversos extratores de características baseados em tais elementos.

A representação de imagens baseada em regiões aproxima-se mais da percepção humana do que a representação de imagens inteiras (Jing et al., 2003). Desta forma, é possível identificar e destacar elementos visuais diferentes presentes na cena e estabelecer associações entre eles. Para obter assinaturas baseadas em região, o primeiro passo essencial é a segmentação das imagens.

\subsubsection{Segmentação de Imagens}

A segmentação é um processo que consiste na subdivisão de uma imagem em regiões distintas, a qual leva em consideração propriedades de homogeneidade e descontinuidade da imagem. Sendo assim, a segmentação é uma das principais etapas para a análise automática das imagens, visto que a partir de tal processamento torna-se possível delimitar os objetos de interesse para extração de padrões.

Uma segmentação ideal é aquela onde cada região obtida está relacionada de maneira direta com um objeto contido na imagem (pulmão, cerebelo, entre outros) (Balan, 2007). Na literatura existem taxonomias para a classificação de métodos de segmentação. Segundo Gonzalez \& Woods (2008) tais métodos são classificados em três categorias básicas: limiarização (thresholding), segmentação baseada em bordas e segmentação baseada em regiões.

A limiarização é um dos métodos mais simples e intuitivos de segmentação de imagens. A técnica consiste em classificar todos os pixels que estejam em uma mesma faixa de 
intensidade como pertencentes a uma mesma região. No entanto, a determinação dos limiares é um dos pontos problemáticos de tal técnica. Além da seleção manual empírica, onde o usuário com base na visualização do resultado da segmentação indica os limiares, existem também técnicas automáticas para a seleção dos mesmos. Grande parte dessas técnicas automáticas baseiam-se no histograma da imagem, identificando os pontos de mínimo deste (Sahoo et al., 1988). Porém, essa abordagem pode apresentar problemas caso exista uma depressão alongada no histograma, causando uma escolha arbitrária do limiar. Uma técnica largamente utilizada na literatura e que sobrepuja tais problemas é apresentada por Otsu (1979) a qual realiza a escolha do limiar baseada na maximização da variância entre duas partes do histograma. A Figura 2.2 ilustra a aplicação do método de Otsu.

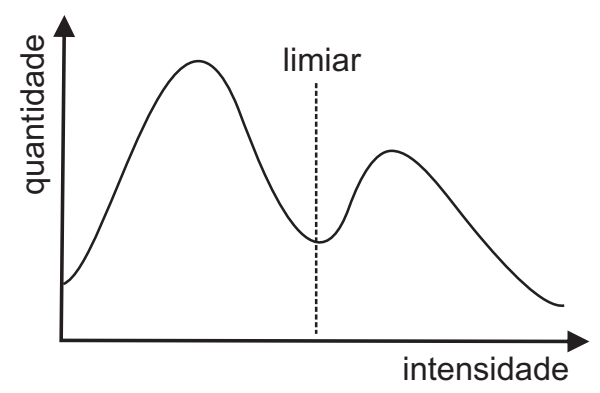

(a)

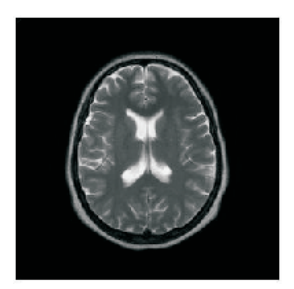

(b)

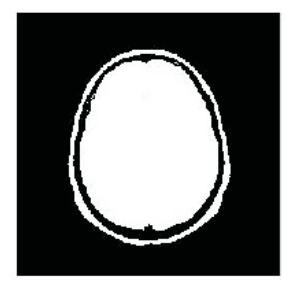

(c)

Figura 2.2: (a) Identificação de limiar por ponto de mínimo utilizando a técnica de Otsu; (b) exemplo de uma imagem de ressonância magnética e (c) sua segmentação aplicando a técnica de Otsu.

Quanto aos métodos de segmentação baseados em bordas, estes visam detectar regiões da imagem onde a variação dos tons de cinza ocorre de maneira relativamente abrupta, assim, detecta-se descontinuidades significativas nos níveis de cinza da imagem. Após a detecção das possíveis descontinuidades, aplica-se geralmente algum método capaz de conectar os fragmentos obtidos que geram contornos reais dos objetos. Tais algoritmos de conexão são denominados edge linking onde os principais são: a análise local, na qual procura-se formar fronteiras de pixels com características comuns, considerando apenas uma vizinhança pequena ( $3 \times 3$ ou $5 \times 5$, por exemplo); a análise baseada na transformada de Hough, que visa encontrar curvas específicas na imagem por meio do mapeamento dos pontos da imagem do espaço cartesiano para o espaço dos parâmetros da curva procurada; e os métodos de percurso em grafos, que consistem em representar segmentos de reta como arestas e encontrar caminhos de custo mínimo no grafo gerado, que representam contornos significativos na imagem (Gonzalez \& Woods, 2008).

Além dos algoritmos edge linking existe também o modelo de contornos ativos (snakes) proposto por Kass et al. (1987). As snakes são contornos ativos que são atraídos para as bordas dos objetos da imagem e adaptam-se a essas bordas em um processo de convergência. 
Os métodos de segmentação baseada em regiões procuram similaridade entre pixels, ao contrário dos métodos de limiarização e embasados em bordas que delimitam elementos considerando as diferenças nas tonalidades dos pixels. As técnicas mais tradicionais de segmentação baseada em regiões são: crescimento de região (region growing), na qual pixels iniciais são escolhidos e iterativamente verifica-se se os pixels da vizinhança devem ser agrupados aos conjuntos definidos pelos pixels iniciais; e divisão e fusão (split and merge), onde a imagem é recursivamente dividida em regiões menores, e, então, as regiões menores similares são gradativamente fundidas de acordo com algum critério de homogeneidade (Gonzalez \& Woods, 2008). A Figura 2.3 ilustra a aplicação do método de crescimento de regiões para segmentação do pulmão de uma imagem obtida por meio de um exame de tomografia computadorizada.

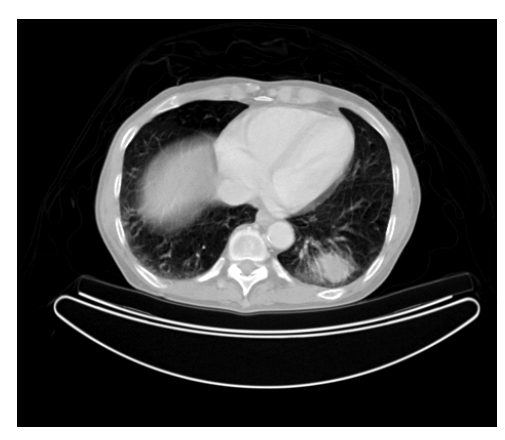

(a)

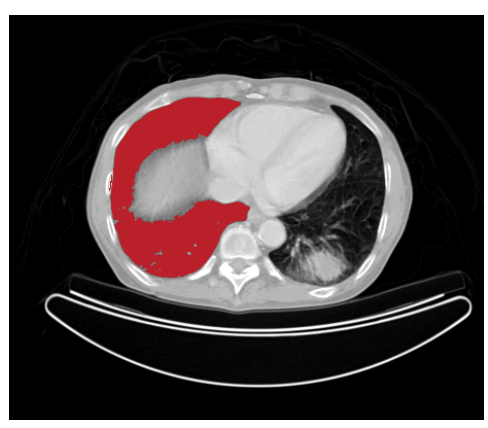

(b)

Figura 2.3: (a) Imagem do pulmão obtida a partir de exame de tomografia computadorizada; (b) exemplo da aplicação do método de crescimento de região para segmentação do pulmão esquerdo.

Além das técnicas descritas existem também aquelas baseadas em textura, as quais realizam a segmentação de acordo com as peculiaridades das diferentes texturas presentes nas imagens. Em Balan (2007) foi proposta uma variação do método EM/MPM (Comer \& Delp, 2000) a qual representa imagens médicas extraindo medidas estatísticas de regiões obtidas por meio da segmentação de uma dada imagem. Para tanto, o método proposto, como o próprio nome explicita, utiliza a combinação do algoritmo EM (Expectation and Maximization) para realizar o ajuste de um Modelo de Mistura Gaussiano (Gaussian Mixture Model) no histograma da imagem com um classificador baseado nos Campos Aleatórios de Markov, o qual incorpora o conceito de coerência espacial entre os pixels. A Figura 2.4 apresenta um exemplo dos resultados obtidos por meio da aplicação da variação do método EM/MPM para segmentação de uma imagem de cérebro, utilizandose 5 classes, incluindo a classe de pixels do plano de fundo (background). As regiões de textura obtidas também são mostradas separadamente para uma melhor visualização.

Em (Qian et al., 2002) a segmentação é utilizada para identificação de grupos de microcalcificações em exames de mamografia. Ainda com relação a métodos específicos para imagens médicas, Schilham et al. (2006) realizam a segmentação de imagens de 


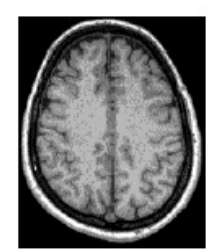

(a)

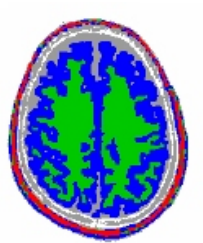

(b)

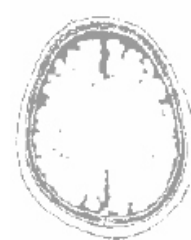

(c)

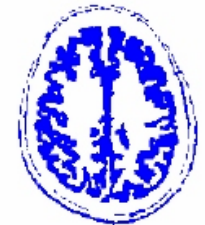

(d)

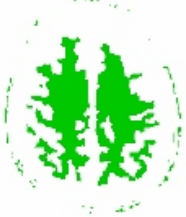

(e)

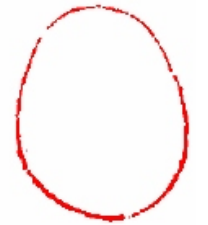

(f)

Figura 2.4: Exemplo de segmentação realizada pela variação do método EM/MPM. (a) imagem original; (b) imagem segmentada em 5 classes; (c) região de classe 1 (fluido cérebro-espinhal); (d) região de classe 2 (massa cinzenta); (e) região de classe 3 (massa branca); (f) região de classe 4 (dura, medula óssea, gordura) (Balan, 2007).

raio-x de tórax objetivando a detecção de nódulos pulmonares para auxílio ao diagnóstico de câncer de pulmão. Já Dy et al. (2003) combinam características de cor, textura e forma para serem utilizadas na recuperação de imagens de tomografia computadorizada do tórax. Siadat \& Soltanian-Zadeh (2005), por sua vez, utilizam a segmentação para identificar o hipocampo em imagens de ressonância magnética, além de utilizar descrições textuais dos laudos para análise de possíveis correlações nos exames para o diagnóstico de epilepsia.

Apesar de inúmeras propostas, a segmentação automática ainda permanece um processo de relativa dificuldade, uma vez que o domínio de imagens reais é amplo e rico em peculiaridades.

\subsubsection{Cor}

As características baseadas em cor são as mais utilizadas na recuperação por conteúdo, especialmente nas abordagens menos recentes. Esta intensa aplicação justificou-se principalmente devido à menor complexidade dos métodos empregados e, conseqüentemente, menor custo computacional e por serem invariantes a rotações e translações das imagens. A identificação de uma imagem por meio da característica relativa à distribuição global de cor é geralmente realizada pela construção de um histograma de cor. No histograma são calculados o número de pixels da imagem para cada cor (ou nível de cinza em imagens monocromáticas). Um tipo de medida é a análise dos tons de cinza, muito utilizada para imagens médicas, onde a imagem é analisada e seu histograma (também conhecido como gray-level histogram ou brightness histogram) é gerado e utilizado para comparação em buscas por similaridade. Para comparar computacionalmente duas imagens, utilizam-se seus respectivos histogramas e a comparação usualmente é realizada por meio da utilização da função de distância $L_{1}$ ou variações da norma $L_{p}$ (ver seção 3.2.1.1). A Figura 2.5 ilustra o histograma de níveis de cinza obtido a partir de uma imagem médica de ressonância magnética do cérebro. 

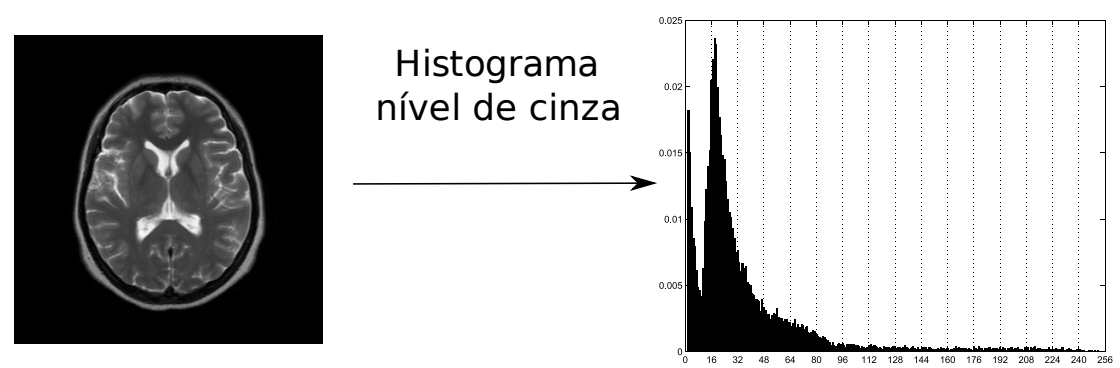

Figura 2.5: Exemplo de um histograma de níveis de cinza obtido a partir de uma imagem médica de ressonância magnética do cérebro.

Em CBIR, o uso de histogramas como passo inicial na seleção de imagens, justificase ainda mais devido aos algoritmos que lidam com outras características intrínsecas textura e forma - apresentarem freqüentemente um custo computacional alto, além de serem dependentes do domínio da aplicação. Histogramas, por outro lado, são obtidos com custo linear em relação ao número de pixels da imagem. Portanto, um procedimento eficiente para recuperação de imagens seria o uso de histogramas para filtrar e reduzir o conjunto de imagens candidatas, como um passo preliminar do processo, seguindo-se de métodos mais precisos e custosos (Alferez et al., 2005).

Entretanto, os histogramas apresentam uma capacidade reduzida de discriminação e não trazem informação sobre a distribuição espacial das cores na imagem. Quando analisadas duas imagens distintas entre si, embora sejam visivelmente diferentes, podem possuir histogramas idênticos, como pode ser observado na Figura 2.6. Diversas técnicas foram propostas para tratar esse problema, incluindo os vetores de coerência de cor (Pass et al., 1996), o correlograma de cor (Huang et al., 1997), o cell histogram (Stehling et al., 2002) e o color distribution entropy (Sun et al., 2006). Além disso, em Chatzichristofis \& Boutalis (2008) foi proposto um descritor denominado "color and edge directivity descriptor" (CEDD) que combina características de cor e textura em um histograma compacto.
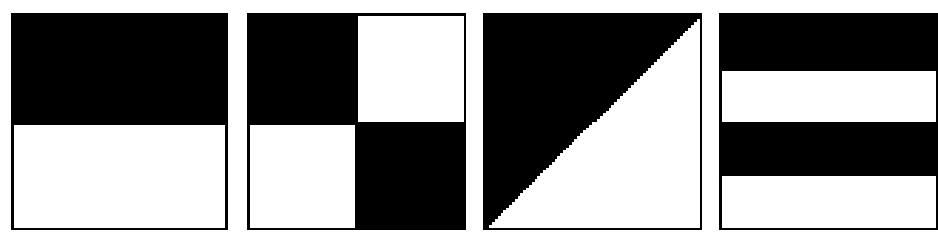

Figura 2.6: Imagens visualmente distintas e com histogramas idênticos.

Um ponto a ser considerado com relação aos histogramas diz respeito à elevada dimensão dos vetores de características gerados, freqüentemente em torno de 256 posições considerando por exemplo uma imagem com 256 níveis de cinza. A elevada dimensionalidade dos vetores propicia o problema da chamada "maldição da alta dimensionalidade" (dimensionality curse) (Beyer et al., 1999; Herrmann et al., 2012; Houle et al., 2010), tornando-se um grande empecilho principalmente para as estruturas de indexação. 


\subsubsection{Textura}

A textura caracteriza-se como um componente chave na percepção visual humana. Da mesma forma que as características de cor, a textura exerce papel preponderante na recuperação de imagens baseada em conteúdo. Qualquer indivíduo pode reconhecer uma determinada textura, por outro lado, defini-la formalmente não é trivial.

Ao contrário da cor, a textura ocorre sobre uma região ao invés de um ponto ( $p i$ xels). Além disso apresenta qualidades como periodicidade e escala. Dessa forma, pode ser descrita em termos de direção, rugosidade, contraste, entre outros (Tamura et al., 1978). É justamente essa natureza multifacetada que torna as características de textura particularmente interessantes e amplamente aplicadas a imagens, gerando uma infinidade de maneiras de extração de características. Em imagens médicas, por exemplo, os extratores baseados em textura têm maior capacidade de discriminar tecidos do que outros extratores (e.g. baseados em cor) e permitem identificar mais facilmente anomalias tais como nódulos e tumores. Portanto, as características de textura são primordiais para discriminação e classificação das imagens (Liu et al., 2007).

Devido à vasta aplicação das técnicas de extração de características baseadas em textura, estas podem ser divididas em três diferentes abordagens:

Abordagem Estatística - considera a distribuição dos tons de cinza e a variação de intensidade dos mesmos em uma dada região de textura. Exemplos de medidas usadas nessa abordagem são: contraste (polarização na distribuição de intensidade de pixels); granularidade (tamanho dos elementos do padrão) e direcionalidade (forma e localização do padrão); Os extratores pertencentes a esta abordagem podem ser classificados de acordo com os métodos estatísticos utilizados, como por exemplo:

- Estatísticas de Primeira Ordem: tais como média e variância dos valores de intensidade dos pixels fornecendo uma mensuração global da distribuição dos pixels na imagem. A partir da combinação das estatísticas de primeira ordem obtém-se características como suavidade e uniformidade da imagem.

- Matrizes de Co-ocorrência: proposta por Haralick (1979) baseadas em estatísticas de segunda ordem que levam em consideração a distribuição de pares de pixels fornecendo uma visão da interação espacial existente entre estes.

Além destes principais métodos existem outras subdivisões. Em (Keller et al., 1989) foram utilizados modelos baseados em fractais para discriminação de texturas. A teoria dos fractais também foi aplicada em Balan et al. (2005) para segmentação baseada em textura de imagens médicas. Já em Picard \& Liu (1994) foi sugerido um novo modelo para mensurar a similaridade perceptual baseada em características de textura embasadas no trabalho desenvolvido por Wold (1953). Em Tamura et al. (1978) foram identificadas 
seis facetas as quais humanos utilizam para diferenciação de texturas, a partir desta identificação foram geradas características que as quantificassem.

Abordagem Estrutural - obtém os elementos de textura presentes na imagem, determinando seus formatos e estimando as regras de posicionamento. As regras de posicionamento descrevem como os elementos de textura são referenciados com relação aos demais. Esta abordagem leva em consideração que texturas são compostas de primitivas organizadas segundo uma dada regularidade e repetição.

Abordagem Espectral - baseia-se em propriedades de espectros de freqüência obtidos por meio de transformadas, tais como a transformada de Fourier (Zhou et al., 2001) a transformada de Wavelets (Arivazhagan \& Ganesan, 2003; Santini \& Gupta, 2001) e filtros de Gabor (Santini \& Jain, 1996; Sastry et al., 2007). No contexto médico, em Ferrari et al. (2004) e Alto et al. (2005) são apresentados métodos para identificação de nódulos em exames de mamografia utilizando respectivamente filtros de Gabor e características de textura de Haralick obtidas a partir dos descritores de Haralick (Haralick, 1979). Já em Soltanian-Zadeh et al. (2004) também são utilizadas wavelets para extração de características de textura para classificação de microcalcificações.

Alguns trabalhos focam a análise das características de textura voltadas para o domínio de imagens médicas. Em Kinoshita et al. (2007) avalia-se uma considerável gama de características utilizadas na recuperação de imagens de mama. Dentre as características utilizadas estão as de forma (área, perímetro, compactness, etc), textura (descritores de Haralick), momentos de $\mathrm{Hu}$, características obtidas a partir da transformada de Radon, e medidas granulométricas. Em Chaddad et al. (2011) os descritores de Haralick são utilizados para a detecção de células cancerosas do cólon.

\subsubsection{Forma}

A extração de características de forma, de maneira geral, envolve processos não triviais, o que leva a um alto custo computacional. No entanto, tais características desempenham um papel fundamental na análise de imagens. Um exemplo de tal importância diz respeito a aplicação no domínio médico. Por exemplo, é extremamente importante a definição do tamanho e forma de nódulos tumorais para classificá-los em benignos ou malignos, visto que nódulos malignos geralmente apresentam espículas, já tumores benignos apresentam certa regularidade (Alto et al., 2005) como pode ser observado na Figura 2.7.

Um requisito das características de forma é que estas sejam invariantes às transformações geométricas (translação, rotação e escala) (Theodoridis \& Koutroumbas, 2006). Para a extração das características as imagens devem ser pré-processadas, por exemplo segmentadas, para evidenciar e detectar as bordas/segmentos dos objetos alvo. No entanto, o processo de detecção de bordas e formas é comprometido em cenas complexas, onde há, além dos ruídos, oclusão parcial de objetos e sombras sobre regiões das imagens. 


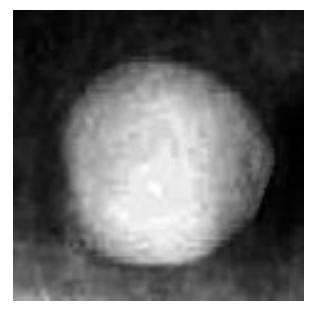

(a) benigno

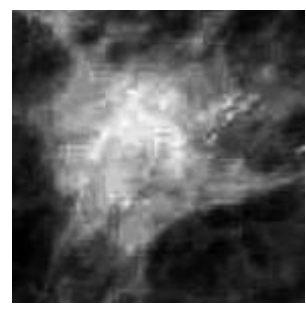

(b) maligno

Figura 2.7: Exemplos de imagens contendo nódulos tumorais: (a) nódulo benigno; (b) nódulo maligno.

Segundo Zhang \& Lu (2004) os métodos de extração de características baseados em forma podem ser classificados em duas vertentes, que são os métodos baseados em região e aqueles baseados em contorno. Os métodos baseados em região levam em consideração o objeto como um todo para a análise e extração das características. Já os baseados em contorno, como o próprio nome já explicita, considera apenas os contornos obtidos para geração dos vetores de características.

Inúmeros métodos para a caracterização de forma foram propostos, tais como os momentos de Zernike (Bin \& Jia-Xiong, 2002; Gu et al., 2002; Kotoulas \& Andreadis, 2005), descritores de Fourier (Chen et al., 2009; Yadav et al., 2008; Zhang \& Lu, 2002), o método curvature scale space (Manjunath et al., 2002; Mokhtarian \& Abbasi, 2002), que tem como principal característica ser invariante a translações, rotações e escalas, as Saliências de Contorno (Torres \& Falcão, 2007), dentre outros, como por exemplo os descritores de forma baseados em Tensor Scale (Saha, 2005; Saha \& Wehrli, 2004) como os propostos em Miranda et al. (2005) e Andaló et al. (2010).

\subsection{Medidas de Similaridade}

Um dos componentes fundamentais para um sistema com a finalidade de armazenamento e manipulação de imagens é a escolha das medidas de similaridade (ou funções de distância). Ao invés de buscas exatas, a recuperação baseada em conteúdo fundamenta-se no cálculo de similaridade entre uma dada imagem de consulta e um conjunto de imagens.

Para a determinação do grau de similaridade entre os objetos, estes podem ser comparados diretamente ou a partir de vetores de características extraídos dos mesmos. Nos dois casos, uma função de distância $d($ ) é definida para calcular o grau de similaridade, retornando um valor numérico que quantifica o quão similar estes objetos são. Esses valores são sempre maiores ou iguais a zero, tendo valores próximos de zero para objetos muito similares (zero para objetos iguais) e valores maiores para objetos menos similares. Esta função é chamada de função de dissimilaridade ou de função de distância e deveria ser sempre definida por um especialista no domínio em questão. 
Na realidade, a função de distância indica a dissimilaridade entre dois objetos. Para simplificar a compreensão de um texto, muitas vezes os autores estabelecem que a função de distância indica a similaridade, já que esta é obtida pela dissimilaridade. No entanto, tais funções de nada servem se as características das imagens (ou objetos complexos) não forem previamente extraídas, pois para o cálculo de similaridade, os objetos são representados por meio de suas características.

Após a realização da extração de características das imagens de um conjunto e da escolha de uma função de distância apropriada, as características extraídas passam a representar cada imagem como um ponto em um espaço métrico (seção 2.3.2) definido pelo domínio das características e por uma função de distância apropriada, definida sobre o conjunto de vetores de características.

\subsubsection{Consultas por Similaridade e Espaços Métricos}

Os Sistemas Gerenciadores de Bases de Dados (SGBDs) tradicionais manipulam domínios de dados que possuem relação de ordem entre os seus elementos (números, textos pequenos, entre outros). Portanto, permitem identificar e organizar elementos por meio de suas grandezas em relação a uma unidade de ordem ou igualdade. Porém, quando se utilizam SGBDs para armazenar dados complexos, os quais na sua grande maioria não possuem relação de ordem, as buscas por igualdade (exemplo: "Procure a cidade cujo nome é Osaka") ou baseadas em ordem (exemplo: "Procure as pessoas que recebem auxílio institucional entre o dia 5 e o dia 20") não se aplicam ou simplesmente têm pouca utilidade. Surge então a questão de como ordenar tais dados complexos (imagens, áudio, vídeo, séries temporais e outros) uma vez que não se consegue estabelecer uma relação de ordem para esses dados (exemplo: "Dadas duas imagens, qual é a "menor" entre elas?"), no entanto pode-se dizer o quanto uma imagem é similar (parecida) com outra imagem.

A busca no domínio de dados complexos, a qual é a base para o processo de recuperação de imagens baseada em conteúdo, é fundamentada no conceito de busca por

similaridade ( similarity search) e surge naturalmente como a maneira mais adequada para realizar consultas sobre tais dados. Esse gênero de consulta é denominado consulta por similaridade.

As consultas por similaridade consistem em procurar por objetos em um conjunto que, segundo algum critério de similaridade, sejam mais "parecidos" ou mais "distintos" com/de um determinado objeto. Em outras palavras, consultas por similaridade consistem na comparação de todos os objetos do conjunto com um objeto escolhido, selecionando apenas os elementos que atendam a um certo critério de similaridade. Por exemplo, visando a obtenção de um diagnóstico mais fidedigno sobre determinado tumor cerebral de um paciente, e até mesmo tentando encontrar subsídios para decidir como encaminhar o tratamento, um médico estaria interessado em encontrar as tomografias de cérebro 
que apresentem um tumor similar àquele em estudo. Esse tipo de consulta, que leva em consideração a informação inerente ao objeto de referência, é chamado de Consulta Baseada em Conteúdo (Content-Based Query), ou seja, a consulta é feita a partir dos dados contidos no objeto, e não a partir de informações descritivas provavelmente associadas aos mesmos.

Para se determinar a similaridade entre os objetos (no caso em questão imagens médicas), estes são comparados a partir de vetores de características extraídos dos mesmos. Nesse caso, uma função de distância $d($ () é definida para calcular o grau de similaridade, retornando um valor numérico que quantifica o quão similar estes objetos são entre si.

Existem vários tipos de consultas por similaridade (Traina \& Traina Jr., 2003), porém as mais comuns são as buscas por abrangência (limitam os resultados a um certo nível de similaridade) e as buscas pelos vizinhos mais próximos (limitam as buscas a um certo número de objetos mais similares). Esses dois tipos de consultas são detalhados nas seções a seguir, bem como o conceito de espaços métricos, primordial para o completo entendimento de tais consultas e outros conceitos que serão introduzidos posteriormente.

\subsubsection{Consulta por Abrangência}

As Consultas por Abrangência (Range query) consistem na busca de objetos que tenham até um determinado nível de similaridade com o objeto de referência. Isto é, dado um conjunto de objetos $O=\left\{o_{1}, o_{2}, o_{3}, \ldots, o_{n}\right\}$ pertencentes a um domínio $\mathfrak{D}$, uma função de distância $d()$, um objeto de consulta $o_{q}$ também pertencente ao domínio e uma distância máxima $r_{q}$, o resultado da busca por abrangência é dado por:

$$
\operatorname{range}\left(o_{q}, r_{q}\right)=A=\left\{a \mid a \in O, d\left(a, o_{q}\right) \leqslant r_{q}\right\}
$$

Indagações tais como "Quais são as nebulosas que diferem até $X$ da Nebulosa de Órion?" e "Quais são as galaxias que ficam até $Y$ anos luz da Via Láctea?" são exemplos desse tipo de consulta.

Na Figura 2.8 (a) é ilustrada uma resposta de uma consulta por abrangência em um domínio bidimensional utilizando a função de distância Euclidiana $\left(L_{2}\right)$ - ver seção 3.2.1.1 do capítulo 3.

\subsubsection{Consulta aos Vizinhos Mais Próximos}

A Consulta aos $k$ Vizinhos mais Próximos ( $k$-Nearest-Neighbor query) consiste na busca dos $k$ objetos mais similares ao objeto de consulta. Ou seja, dado um conjunto de objetos $O=\left\{o_{1}, o_{2}, o_{3}, \ldots, o_{n}\right\}$ pertencentes a um domínio $\mathfrak{D}$, uma função de distância $d()$, um 
objeto de consulta $o_{q}$ também pertencente ao domínio e um número inteiro $k$, o resultado da busca pelos vizinhos mais próximos é dado por:

$$
k-N N\left(o_{q}, k\right)=A=\left\{a\left|a \in O, \forall o \in O-A, d\left(o_{q}, a\right) \leqslant d\left(o_{q}, o\right),\right| A \mid=k\right\}
$$

Indagações tais como "Quais são as $N$ nebulosas mais parecidas com a Nebulosa de Órion?" e "Quais são as $M$ galáxias mais próximas da Via Láctea?" são exemplos desse tipo de consulta. No primeiro, $k$ é igual a $N$ e no segundo $k$ é $M$.

Na Figura 2.8 (b) é ilustrada uma resposta de uma consulta pelos vizinhos mais próximos em um domínio bidimensional empregando a função de distância Euclidiana $\left(L_{2}\right)$.

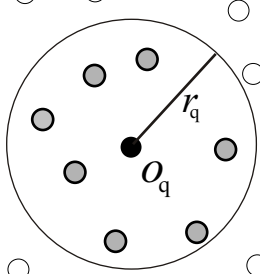

(a)

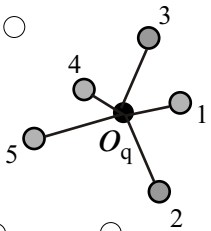

(b)

Figura 2.8: Consultas por similaridade em um domínio de pontos bidimensionais utilizando a função de distância Euclidiana como função de dissimilaridade. O objeto "central" preto $O_{q}$ é o objeto de consulta enquanto os respectivos objetos cinza constituem as respostas. (a) Ilustra uma Consulta por abrangência de raio $r_{q}$ e (b) ilustra uma Consulta pelos 5 vizinhos mais próximos.

\subsubsection{Espaços Métricos}

Um espaço métrico é um par $M=<\mathfrak{D}, d()>$ onde $\mathfrak{D}$ é o domínio dos objetos e $d$ : $\mathfrak{D} \times \mathfrak{D} \rightarrow \Re^{+}$é uma função que associa uma distância a cada par ordenado de elementos $o_{1}, o_{2}, o_{3} \in \mathfrak{D}$. Então, o par $M=<\mathfrak{D}, d()>$ é denominado espaço métrico sempre que a função $d()$ atender aos seguintes axiomas:

1. Simetria: $d\left(o_{1}, o_{2}\right)=d\left(o_{2}, o_{1}\right)$

2. Não negatividade: $0<d\left(o_{1}, o_{2}\right)<\infty$ se $o_{1} \neq o_{2}$ e $d\left(o_{1}, o_{1}\right)=0$

3. Desigualdade Triangular: $d\left(o_{1}, o_{2}\right) \leqslant d\left(o_{1}, o_{3}\right)+d\left(o_{3}, o_{2}\right)$

As condições que definem um espaço métrico, principalmente a desigualdade triangular, possibilitam o desenvolvimento de técnicas de indexação eficientes para responder a consultas por similaridade. 
Os elementos de um espaço métrico podem ser de natureza bastante distintas, tais como números, pontos, vetores, matrizes, funções, conjuntos, entre outros.

A função de distância métrica $d($ ) pode ser interpretada como uma função de cálculo de dissimilaridade entre os objetos do domínio ao qual está inserida, onde, quanto mais similares dois objetos são entre si menor o valor retornado, conseqüentemente valores maiores são retornados para objetos muito distintos, tornando dessa maneira as operações de busca por similaridade naturais dentro de espaços métricos.

Uma importante característica dos espaços métricos é a possibilidade de englobarem os espaços vetoriais, assim como os espaços adimensionais ${ }^{1}$, como por exemplo conjunto de imagens, palavras, sons ou cadeias de DNA, desde que, para isto, haja uma função de distância adequada.

\subsection{Estruturas de Indexação}

Os métodos de acesso (MAs) compreendem estruturas de dados que permitem recuperar rapidamente a informação armazenada. Considerando dados complexos, como imagens por exemplo, os métodos de acesso convencionais e já presentes nos Sistemas Gerenciadores de Bases de Dados (SGBDs) não permitem efetuar recuperação por conteúdo e responder consultas por similaridade. Isso acontece pelo fato de não haver relação de ordem total em tais domínios de dados.

Para domínios de dados complexos como, imagens, vídeos e outros dados multimídia, surgiu a necessidade do desenvolvimento de estruturas de indexação mais adequadas e que permitam a realização de consultas baseadas na similaridade dos dados (descritas na seção 2.3.1).

As primeiras estruturas de indexação foram desenvolvidas para operar em dados onde era apropriada a relação de ordem total, tais como a família de árvores B-tree (Bayer \& McCreight, 1972), (Knuth, 1973), (Comer, 1979), (Folk et al., 1998), ou que tivessem relativamente poucos dados, por exemplo, as estruturas de hashing. As primeiras estruturas de indexação destinadas a suportar dados espaciais foram propostas para espaços de poucas dimensões. Tais estruturas são amplamente descritas na literatura, e são chamadas de Métodos de Acesso Espaciais - SAM (Spatial Access Methods). O desenvolvimento dessas estruturas iniciou-se com o trabalho pioneiro sobre as R-Trees (Guttman, 1984; Manolopoulos et al., 2005) e prosseguiu com numerosas variações e adaptações (Papadias et al., 1999) (Wang \& Perng, 2001) (Sakurai et al., 2002) (Zhuang et al., 2008) (Tzouramanis, 2012). Em Samet (2006, 2010) é apresentada uma ampla descrição e comparação sobre estruturas espaciais. No entanto, para dados em espaços de altas dimensões ou mesmo adimensionais, nenhuma dessas estruturas mostrou-se adequada.

\footnotetext{
${ }^{1}$ Domínios onde os objetos não podem ser identificados por um conjunto de coordenadas em eixos ortogonais
} 
As estruturas de indexação para dados métricos, ou os Métodos de Acesso Métricos - MAM (Metric Access Methods), suportam naturalmente consultas por proximidade ou similaridade, além de serem mais robustas para dados de dimensões altas. Dessa forma, tem-se mostrado bastante apropriado utilizar um MAM para indexar imagens ou, mais propriamente, as características que foram extraídas das imagens suportando busca por similaridade. Tais características, ou descritores, podem ser atributos de forma, textura, histograma de cores (Lew et al., 2006), resultados de transformações como por exemplo singular value decomposition, ou Karhunen-Loeve (Faloutsos, 1996). Utilizando as características extraídas previamente da imagem, um MAM constrói a estrutura de índices calculando as distâncias entre elas, procedimento que deveria corresponder à comparação entre as imagens originais.

As características extraídas de antemão das imagens são utilizadas pelo MAM para construir a estrutura de índices. Durante essa construção são calculadas as distâncias entre tais características a serem inseridas na estrutura. Logo, as características e suas distâncias são basicamente as únicas informações que a árvore necessita das imagens.

O principio básico dos MAMs é a representação de dados complexos em um espaço métrico. Dentre as principais estruturas de indexação para espaços métricos encontradas na literatura consideradas dinâmicas, ou seja, que permitem atualizações nos dados sem a necessidade de reconstrução da estrutura, estão a M-tree (Ciaccia et al., 1997), a Slim-tree (Traina et al., 2000), a DF-tree (Traina et al., 2002), a DBM-tree (Vieira \& Traina Jr., 2004), a OMNI-Family (Traina et al., 2007) e a BP-tree (Almeida et al., 2010).

\subsection{Interação com o Usuário}

Tem se percebido cada vez mais a necessidade de se construir sistemas multimídia centrados no usuário para potencializar a sua aceitação em ambientes reais (Sebe \& Jaimes, 2009).

Um requisito fundamental de sistemas de recuperação de imagens baseada em conteúdo é prover meios para que o usuário consiga especificar o que ele deseja recuperar. As modalidades de consulta de um sistema CBIR incluem: palavras-chave, texto livre, imagem de exemplo, esquema gráfico desenhado pelo usuário, ou uma composição de várias destas formas de consulta (Datta et al., 2008).

Para reduzir o gap semântico, várias técnicas têm sido propostas, com o objetivo de retirar do usuário a difícil tarefa de ajustar manualmente os valores de parâmetros de baixo nível na especificação das consultas, possibilitando o refinamento de consultas envolvendo combinações complexas de parâmetros de forma transparente. Dentre as técnicas utilizadas para a redução do gap semântico em sistemas CBIR, destacam-se os métodos de aprendizado de máquina e as técnicas de realimentação de relevância. 
Os métodos de aprendizado de máquina concentram-se em aplicar algoritmos, supervisionados ou não-supervisionados, para derivar informação semântica a partir de características de baixo nível (Liu et al., 2007). No aprendizado supervisionado, o algoritmo inicialmente passa por uma etapa de treinamento, na qual recebe um conjunto de exemplos pré-classificados e procura identificar os padrões nas características primitivas que diferenciam cada classe de elementos. A recuperação é feita por meio do mapeamento entre os termos do domínio (classes) e o "conhecimento" obtido a partir dos padrões e regras identificados pelo algoritmo. No aprendizado não-supervisionado, por outro lado, não se tem a priori um conjunto de exemplos pré-classificados. A tarefa típica dos algoritmos não-supervisionados é determinar como os exemplos podem ser organizados ou agrupados, minimizando a dissimilaridade entre elementos de um mesmo grupo e maximizando a dissimilaridade entre agrupamentos distintos.

Já as técnicas embasadas em realimentação de relevância envolvem o aprendizado a partir da informação fornecida pela interação do usuário com o sistema.

\subsection{Realimentação de Relevância}

Quando uma consulta baseada em conteúdo é realizada, a quantidade de imagens relevantes a essa consulta, ou seja, que condizem com a expectativa do usuário, em relação ao número total de imagens que deveriam ter sido retornadas, tende a apresentar resultados frustantes principalmente do ponto de vista do usuário, diminuindo assim muitas vezes a aceitação e posterior inclusão de sistemas CBIR em ambientes reais, como por exemplo na prática médica.

Com o intuito de amenizar o problema em questão, inúmeros pesquisadores têm considerado e empregado técnicas de realimentação de relevância (Relevance Feedback - RF) para tornar a recuperação de imagens mais fidedigna em relação à expectativa do usuário.

A realimentação de relevância é uma técnica introduzida na década de 1970, visando a recuperação de documentos de texto. Trata-se de um técnica que visa o refinamento da consulta inicial realizada por determinado usuário, buscando torná-la mais precisa, objetivando retornar somente respostas relevantes e descartar as irrelevantes.

Uma das principais características do processo de realimentação de relevância é que este pode encontrar um conjunto de resultados correlacionados segundo a percepção humana, uma vez que o usuário está diretamente envolvido no processo de busca e refinamento da consulta.

\subsubsection{Sistema CBIR com Realimentação de Relevância}

A realimentação de relevância apresenta uma estratégia de aprendizado em tempo real (on the fly) adaptando a resposta do sistema CBIR por meio das interações com o usuário. 
O usuário pode interagir com o sistema selecionando as imagens mais relevantes (realimentação positiva) e as menos relevantes (realimentação negativa) para um determinado contexto. Portanto, é um processo que efetua um ajuste "automático" de uma consulta existente por meio de informações que são realimentadas ao sistema com relação às respostas retornadas previamente, realizando a adaptação da consulta, objetivando diminuir o gap existente entre o que o usuário deseja e a informação que foi de fato retornada (Yin et al., 2005). É importante salientar que a Realimentação de Relevância por si só não é capaz de preencher a lacuna existente entre as características de baixo nível e a subjetividade da semântica humana, mas sim apresenta-se como um elo de ligação entre tais extremos.

Um panorama característico de realimentação de relevância visando a recuperação de imagens é composto basicamente por três passos (Zhou et al., 2003):

1. O sistema CBIR retorna os resultados iniciais para uma dada consulta com relação a uma dada imagem;

2. O usuário avalia os resultados retornados e especifica um grau de relevância para um conjunto de imagens;

3. Com a realimentação realizada pelo usuário o sistema "aprende", processa a consulta novamente e retorna ao passo 2.

A Figura 2.9 apresenta um diagrama típico e sucinto de um sistema de recuperação de imagens por conteúdo com realimentação de relevância.

As estratégias de recuperação de imagens que incorporam técnicas de realimentação de relevância podem ser classificadas quanto ao refinamento da consulta e quanto ao refinamento das medidas de similaridade (funções de distância) (Doulamis \& Doulamis, 2006). Os passos 2 e 3 do cenário descrito são passivos de repetição até que a expectativa do usuário seja atingida, ou seja, que o mesmo esteja satisfeito com os resultados retornados. Existem diferentes estratégias que podem ser empregadas em tais passos. Para o passo 2, existem algoritmos que assumem a realimentação binária para exemplos positivos e negativos (Ferecatu et al., 2005) (Yin et al., 2005), ou seja, o usuário apenas especifica quais imagens são relevantes e quais são irrelevantes. Existem outros algoritmos que assumem apenas a realimentação positiva (Chen et al., 2001); outros assumem ainda exemplos positivos e negativos permitindo que o usuário especifique certos graus de relevância para as imagens retornadas (Zhou et al., 2005). Para o passo 3, as estratégias que podem ser empregadas dizem respeito a distribuição de pesos nos vetores de características de baixo nível e a movimentação do centro de consulta.

A abordagem de movimentação do centro de consulta (Query Point Movement $Q P M)$, como o próprio nome explicita, consiste em estimar tal centro conforme a interação do usuário, movendo-o no sentido dos exemplos positivos, ou seja, no sentido das 


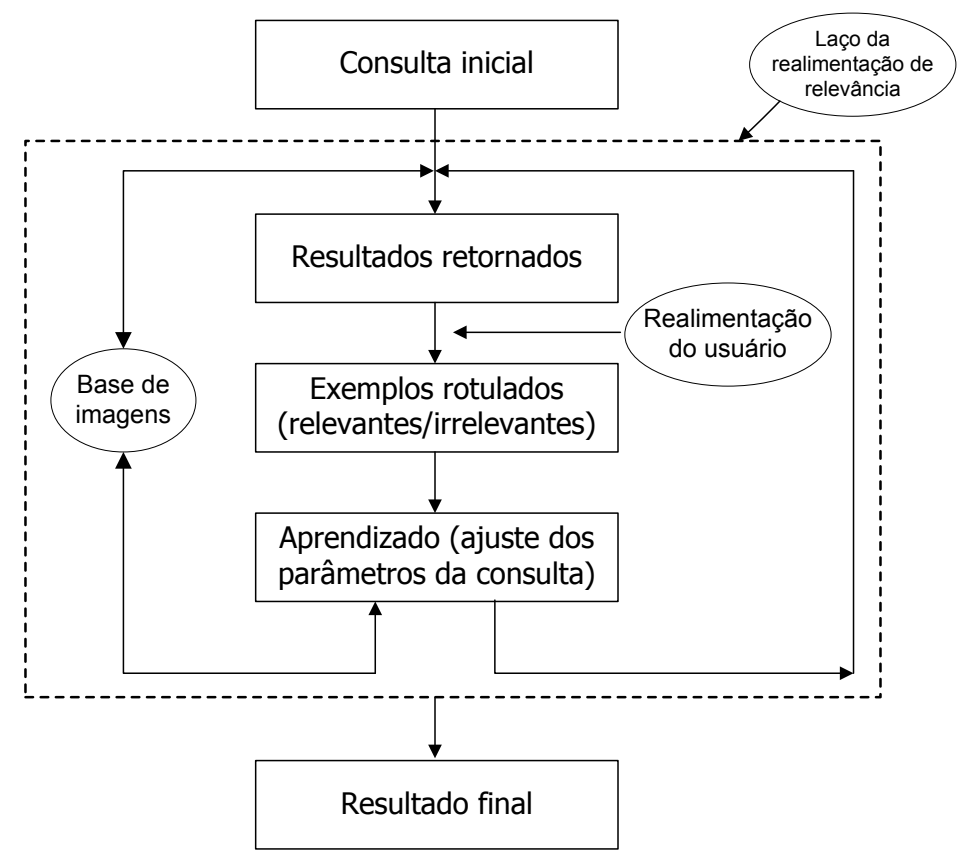

Figura 2.9: Diagrama de um sistema CBIR com realimentação de relevância, explicitando o laço de realimentação (Liu et al., 2007).

imagens selecionadas como relevantes pelo usuário, ao mesmo tempo em que afasta-o dos exemplos negativos (imagens selecionadas como irrelevantes). Dessa forma, a cada interação do usuário um novo centro de consulta "ideal" é estimado no espaço de características. Para tanto, em geral computa-se um novo centro de consulta a partir da média dos vetores de características das imagens selecionadas como relevantes. Devido a tal fato, o novo centro de consulta pode não corresponder necessariamente a uma imagem da base. Diversos trabalhos da literatura empregam tal estratégia (Doulamis \& Doulamis, 2006; Gao \& Guan, 2012; Liu et al., 2009; Nguyen et al., 2010; Rosa et al., 2008; Shirdhonkar \& Kokare, 2011). A Figura 2.10 ilustra um exemplo da técnica de movimentação do centro de consulta.

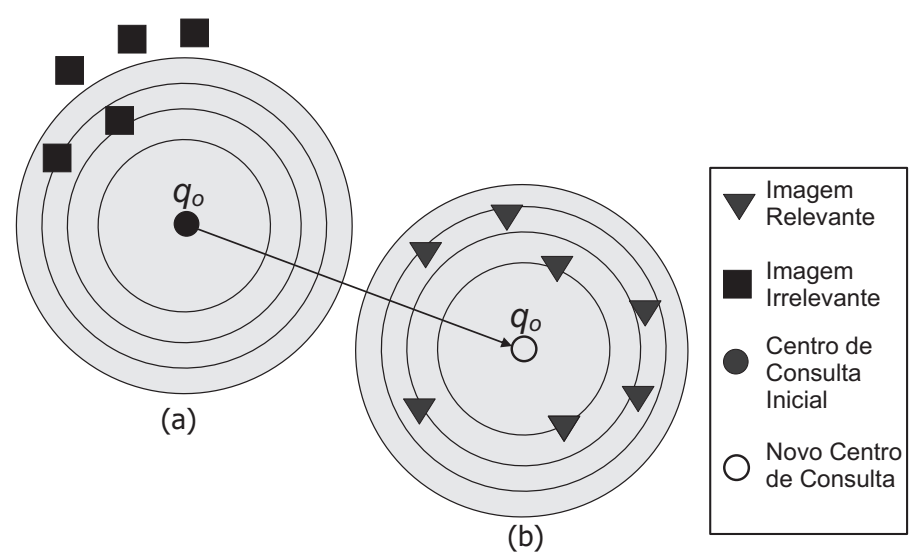

Figura 2.10: Exemplo da técnica de movimentação de centro de consulta. (a) Consulta Inicial (centro de consulta original). (b) Novo centro de consulta movimentado. 
A cada ciclo de realimentação o usuário rotula imagens como relevantes podendo determinar ou não o grau de relevância destas de maneira individual. Dessa forma, para estimar o novo centro (centróide) leva-se em consideração o grau de relevância de cada imagem rotulada pelo usuário.

O trabalho seminal proposto por Rocchio (1971) apresenta a técnica geralmente utilizada para aperfeiçoar iterativamente a estimação do centro de consulta. A denominada fórmula de Rocchio (Rocchio, 1971) é definida pela equação 2.3, onde: $Q$ é o vetor de características original e $Q^{\prime}$ é o vetor de características movimentado; $D_{R}^{\prime}$ e $D_{N}^{\prime}$ são respectivamente os exemplos positivos e negativos realimentados; $N_{R^{\prime}}$ e $N_{N^{\prime}}$ correspondem respectivamente à quantidade de exemplos em $D_{R}^{\prime}$ e $D_{N}^{\prime}$; e $\alpha, \beta$ e $\gamma$ são fatores de ponderação, obtidos experimentalmente.

$$
Q^{\prime}=\alpha Q+\beta\left(\frac{1}{N_{R^{\prime}}} \sum_{i \in D_{R}^{\prime}} D_{i}\right)-\gamma\left(\frac{1}{N_{N^{\prime}}} \sum_{i \in D_{N}^{\prime}} D_{i}\right)
$$

O objetivo desta técnica reside em minimizar a diferença entre o centro de consulta $Q$ e as imagens rotuladas como relevantes $D_{R}^{\prime}$, ao passo em que quando fornecidos exemplos negativos realizar a maximização da diferença entre $Q$ e as imagens rotuladas como irrelevantes $D_{N}^{\prime}$.

Além de tais técnicas existem também aquelas baseadas na movimentação de múltiplos centros de consulta, as quais as principais são as baseadas na expansão da consulta, abordagem Qcluster e abordagem Top- $k$ (Doulamis \& Doulamis, 2006). Da mesma forma, técnicas de aprendizado de máquina também podem ser usadas para o processamento da realimentação de relevância, como por exemplo as Support Vector Machines (SVMs) (Vapnik, 1995), as quais a partir da realimentação realizada pelo usuário tentam definir um hiper-plano separador ótimo entre as imagens rotuladas como relevantes e as irrelevantes (Dagli et al., 2006; Jones \& Shao, 2011).

Existem também métodos que utilizam algoritmos genéticos em conjunto com o processo de realimentação de relevância (Stejić et al., 2003). Em Silva et al. (2006), por exemplo, tal abordagem é aplicada para a aprendizagem de pesos entre diferentes vetores de características (cor, textura e forma) utilizados para cada região da imagem. Já em Ferreira et al. (2008) e Santos et al. (2011) é proposto e empregado um método baseado em programação genética (Koza, 1992; Torres et al., 2009) e realimentação de relevância permitindo diferentes combinações de descritores (Torres \& Falcão, 2006). Em Bulò et al. (2011) é proposta uma nova aplicação de métodos de realimentação de relevância agregados às técnicas de caminhada aleatória (random walking) (Grady, 2006). 


\subsection{Avaliação de Desempenho}

A presente seção discute como mensurar o desempenho de um sistema CBIR. A comunidade de recuperação de texto tem lidado com essa questão há alguns anos e para tanto estabeleceu metodologias para tal avaliação (Salton, 1992; van Rijsbergen, 1979). Na grande maioria dos casos a comunidade de recuperação de imagens utiliza ou adapta tais métodos. Dessa forma, a presente seção pretende fornecer uma visão ampla e aprofundada de um dos métodos de avaliação mais conhecidos e amplamente utilizados, bem como seus pontos fortes e fracos. A próxima subseção irá discutir como avaliar a qualidade dos resultados da recuperação utilizando as medidas de precisão e revocação. Além de tal mensuração é extremamente importante a mensuração do intervalo de tempo entre a consulta realizada pelo usuário e a resposta retornada.

Essas mensurações são essenciais, visto que para ser passível de utilização um sistema CBIR deve não só apresentar boa precisão como também apresentar os resultados em tempo hábil.

\subsubsection{Precisão e Revocação}

Existem diversas maneiras de se analisar a recuperação de dados. A avaliação de performance em um sistema que possui a finalidade de recuperação de dados por conteúdo, é realizada principalmente por gráficos de precisão (precision) versus revocação (recall) (Baeza-Yates \& Ribeiro-Neto, 2011), os quais são também utilizados nos sistemas de recuperação de informação tradicionais.

Além desses gráficos, existem variações que combinam a precisão e a revocação como a medida E e a média harmônica (Baeza-Yates \& Ribeiro-Neto, 2011).

Para uma dada consulta, considera-se que $R$ seja o conjunto de elementos relevantes em uma base de dados e $A$ o conjunto de elementos retornados por tal consulta. Na Figura 2.11 é ilustrado o relacionamento entre os elementos recuperados na consulta (conjunto $A$ ) e os elementos relevantes existentes na base (conjunto $R$ ). A intersecção dos conjuntos $R$ e $A$ compreende os elementos relevantes que foram recuperados em resposta a uma dada consulta. A cardinalidade dos conjuntos $R, A$ e $R \cap A$ é denotada respectivamente como $|R|,|A|$ e $\left|R_{A}\right|$. Pode-se observar que quanto maior é a intersecção entre os conjuntos relevantes e recuperados, $R$ e $A$ respectivamente, maior será a precisão do método.

A medida de revocação (recall) pode ser entendida como a porção do conjunto de elementos relevantes $(R)$ os quais foram recuperados segundo a requisição de uma dada consulta. Já a medida de precisão (precision) é a porção do conjunto de elementos recuperados $(A)$ que são relevantes a uma dada consulta. 


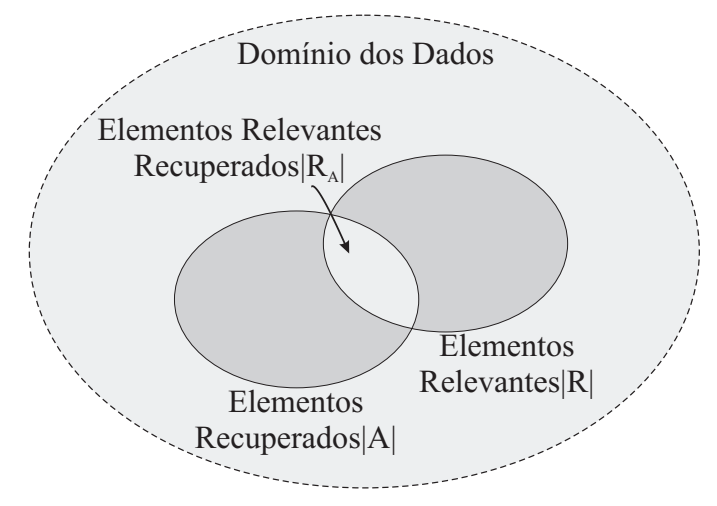

Figura 2.11: Conjunto de resultados possíveis para uma dada operação de busca.

Formalmente as medidas de precision e recall são definidas como:

$$
\begin{gathered}
\text { Recall }=\frac{\left|R_{A}\right|}{|R|} \\
\text { Precision }=\frac{\left|R_{A}\right|}{|A|}
\end{gathered}
$$

Um gráfico que mostra a relação entre precision e recall ilustra a precisão da resposta retornada após uma operação de busca considerando as características do dado complexo e a função de distância utilizada. Uma consulta ideal apresenta $100 \%$ de precisão para todos os valores de revocação.

Existem várias formas de se gerar tais gráficos. Uma delas é gerar para cada consulta seu gráfico de precision e recall, obtendo o gráfico resultante calculando-se a média das precisões (average precision) pela fórmula $\bar{P}(r)=\sum_{i=1}^{N_{q}} \frac{P_{i}(r)}{N_{q}}$, ou seja, a precisão $\bar{P}$ num dado nível de revocação $r$ será a média aritmética das $N_{q}$ precisões $P_{i}(r)$ de cada gráfico daquele nível.

Por exemplo, sejam o conjunto $R=\left\{o_{1}, o_{4}, o_{6}, o_{8}\right\}$ de objetos (imagens) relevantes e, após a execução de uma dada consulta, o conjunto $A=\left\{o_{1}, o_{2}, o_{3}, o_{4}, o_{5}, o_{6}, o_{7}, o_{8}\right\}$ de objetos de fato retornados.

Observando-se o conjunto $A$ dos elementos retornados, verifica-se que o primeiro elemento $\left(o_{1}\right)$, trata-se de um dos elementos pertencentes ao conjunto $R$, portanto relevante à consulta. Nesse caso a medida precision possui valor de $100 \%$ em virtude de todos os elementos analisados, por enquanto apenas o primeiro no caso em questão, serem relevantes à consulta. Por outro lado, neste ponto o valor da medida recall é de $25 \%$ pois um elemento relevante, dentre os quatro elementos relevantes (conjunto $R$ ) pertencentes à base, foi recuperado. O próximo elemento relevante é o quarto $\left(o_{4}\right)$. Nesse ponto, a medida precision da consulta é $50 \%$, pois dois dentre os quatro elementos da base (conjunto $A$ ) foram analisados até o momento e a medida recall é $50 \%$, pois dois dos quatro elementos relevantes da base foram recuperados. A análise prossegue dessa maneira até 
que todos os elementos relevantes sejam verificados. Os valores de precision e recall são então visualizados graficamente, segundo o exemplo ilustrado na Figura 2.12.

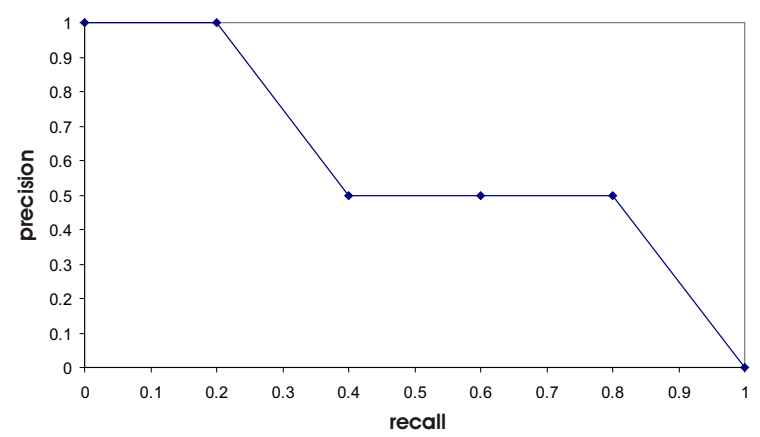

Figura 2.12: Exemplo de um gráfico de medidas precision e recall.

Caso todos os elementos relevantes forem recuperados, o gráfico atinge revocação na marca de 100\%. Como várias consultas geram gráficos com diferentes coordenadas atribuídas, é necessário realizar-se a interpolação em cada gráfico, onde a precisão interpolada em um dado nível de revocação será $P\left(r_{j}\right)=\max _{r_{j} \leqslant r \leqslant r_{j+1}} P(r)$.

Deve-se utilizar medidas que permitam identificar de maneira fidedigna a eficácia da recuperação. Para tanto, tais medidas devem permitir comparar os algoritmos investigados em questão, bem como se os resultados obtidos adequam-se à tarefa realizada pelo usuário. O objetivo final é descobrir como a recuperação pode auxiliar o usuário na tarefa de busca e retornar o resultado desejado pelo mesmo.

As medidas de precisão e revocação fornecem portanto uma visualização do comportamento da recuperação, possibilitando a comparação dos algoritmos empregados. Por exemplo, considerando os gráficos da Figura 2.13, as duas curvas apresentadas, A e B, apresentam aproximadamente a mesma área sob elas, e, portanto têm aproximadamente a mesma média das precisões, cerca de 37\%. Porém, as curvas apresentam diferentes comportamentos, ou seja, os algoritmos aplicados para a recuperação são extremamente diferentes. A curva $A$ apresenta valores altos de precisão para níveis de revocação baixos, fato que geralmente adequa-se melhor a buscas realizadas por usuários que julgam as imagens retornadas, como por exemplo, especialistas médicos, os quais estão interessados em cerca de vinte a trinta imagens relevantes e, portanto, necessitam do maior número de imagens relevantes já no início da recuperação, não importando se todas as imagens relevantes foram recuperadas. Já a curva $B$ apresenta maior precisão que a curva $A$ para níveis altos de revocação. Este comportamento é ideal para um usuário que queira garantir que todas as imagens relevantes foram recuperadas de fato. 


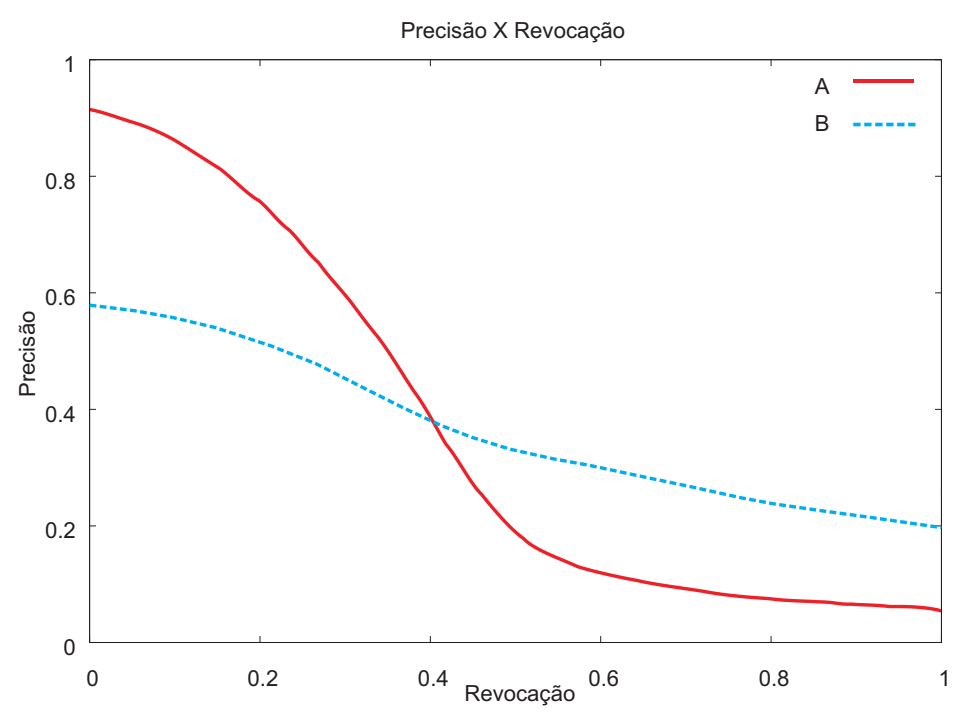

Figura 2.13: Exemplo de gráficos de precisão e revocação.

\subsection{Considerações Finais}

A recuperação de imagens tem sido uma área de pesquisa muito ativa em banco de dados e visão computacional. Devido à crescente utilização de sistemas gerenciadores de bases de dados visando armazenar dados complexos, como informações multimídia, no caso em questão imagens médicas, e à contínua geração de grandes quantidades de imagens, bem como o armazenamento das mesmas, culminaram na necessidade de se responder a consultas embasadas no conteúdo intrínseco de tais dados, nas quais apenas a similaridade entre os objetos pode ser considerada, além do desenvolvimento de métodos que permitissem a recuperação rápida e eficiente de tais dados. Apesar da proposta de muitos sistemas com o intuito de tratar do armazenamento e da recuperação de imagens de forma eficiente, uma solução ótima ainda está longe de ser alcançada.

O presente capítulo apresentou os principais conceitos e processos relacionados à recuperação de imagens baseada em conteúdo (CBIR) incluindo os principais tipos de consulta, cálculo de similaridade, extração de características, métodos de acesso para dados complexos, bem como a interação com o usuário, abordagens para realimentação de relevância e a avaliação de desempenho de consultas com relação à precisão dos resultados retornados para um dado nível de revocação da base de imagens. O trabalho desenvolvido na presente tese está intimamente ligado a todos estes conceitos, sendo que os resultados obtidos foram, muitas vezes, analisados segundo os gráficos de precisão e revocação gerados a partir de consultas por similaridade. 


\section{Capítulo \\ 3 \\ Funções de Distância e Correlações}

\subsection{Introdução}

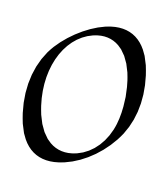

núcleo de qualquer sistema CBIR são as características visuais que foram extraídas das imagens e as funções de distância que são utilizadas para quantificar a similaridade entre estas características. A combinação desses dois componentes conduz o desempenho global do sistema. Além disso, para que resultados satisfatórios sejam retornados considerando uma dada consulta por similaridade é imperativo que seja estudada e analisada qual a melhor integração entre esses dois componentes. O presente capítulo desloca-se para o aprofundamento justamente de um dos aspectos primordiais para a recuperação de imagens baseada em conteúdo que são as funções de distância (medidas de similaridade). Além disso, apresenta estudos realizados com relação à correlação e limites de funções de distância. Tais estudos são importantes uma vez que analisam a abrangência de algumas funções de distância, bem como se estas são homogêneas no espaço de dados.

\subsection{Funções de Distância Consolidadas}

Na literatura, pode-se verificar uma crescente necessidade pelo desenvolvimento de funções de distância, pois estas são empregadas nas mais diversas áreas do conhecimento. Especificamente para a recuperação de imagens com o intuito de atingir a máxima eficácia na recuperação, muitas deixam a desejar com relação ao problema do $\boldsymbol{g a p}$ semântico (Deserno et al., 2008). 
Ao invés da realização de uma equiparação/comparação exata, a busca baseada em conteúdo calcula a similaridade entre uma dada imagem de consulta e imagens contidas em uma base de dados. Em conformidade com tal fato, o resultado retornado pelo processo de recuperação não trata de uma única imagem, mas sim de uma coleção de imagens classificadas em relação aos seus fatores de similaridade com a respectiva imagem de consulta.

Muitas medidas de similaridade têm sido desenvolvidas para recuperação de imagens baseada em estimativas empíricas da distribuição de características. Porém, a escolha das funções de distância empregadas, muitas vezes, é realizada sem critério, ou seja, sem uma fundamentação teórica e não levando em consideração as características explícitas e também implícitas a um determinado contexto específico, como as particularidades semânticas do ambiente ao qual devem ser inseridas, a distribuição estatística intrínseca a este, bem como o modelo de extratores de características e o gênero de dados obtidos por estes, entre outras. Conseqüentemente, diferentes medidas de similaridade e/ou funções de distância poderão afetar de maneira significativa a performance da recuperação de imagens.

Além das funções mais utilizadas como as da família Minkowski - (Lp), existem também algumas outras comumente utilizadas em inúmeros trabalhos (Rubner et al., 2000) (Kokare et al., 2003), as quais também serão introduzidas na presente seção.

Nesta seção são considerados dois vetores de características, de dimensionalidade $n$, $X=\left\{x_{1}, \ldots, x_{n}\right\}$ e $Y=\left\{y_{1}, \ldots, y_{n}\right\}$ onde $X, Y \in G \subset \mathbb{R}^{n}$, respectivamente referentes a uma dada imagem de consulta $X$ e uma imagem $Y$ pertencente a uma base de dados, sendo que a distância entre tais imagens é denotada por $d(X, Y)$.

As funções de distância podem ser classificadas em três categorias de acordo com suas origens teóricas (Liu et al., 2008), conforme discutiremos a seguir.

\subsubsection{Distâncias Geométricas}

As distâncias geométricas tratam os objetos como vetores em um espaço $n$-dimensional e computam a distância entre dois objetos baseadas nas comparações entre pares de dimensões.

\subsubsection{Família de Distâncias Minkowski}

Um aspecto de suma importância pertencente aos espaços métricos diz respeito à capacidade destes englobarem os espaços vetoriais, assim como espaços adimensionais, que não apresentam uma dimensão fixa.

A família de distâncias Minkowski (Wilson \& Martinez, 1997) também conhecida como $L_{p}$, é comumente empregada em espaços multidimensionais. 
Os objetos pertencentes a um espaço multidimensional de dimensão $n$ ( $n$-dimensional) são representados por $n$ coordenadas de valores reais $\left\{x_{1}, \ldots, x_{n}\right\}$. Sendo assim o conjunto de funções de distância $L_{p}$ é definido pela Equação 3.1 .

$$
L_{p}\left(\left(x_{1}, \ldots, x_{n}\right),\left(y_{1}, \ldots, y_{n}\right)\right)=\sqrt[p]{\sum_{i=1}^{n}\left|x_{i}-y_{i}\right|^{p}}
$$

Note que a função de distância Euclidiana é a $L_{2}$. De acordo com o valor atribuído a $p$ obtém-se as variações da família $L_{p}$.

A função de distância $L_{1}$, também denominada City Block ou Manhattan, corresponde ao somatório do módulo das diferenças entre as coordenadas. Nesse caso, o conjunto de pontos eqüidistantes a um dado raio de abrangência $r_{q}$ forma um losango com os diâmetros paralelos aos eixos das coordenadas. A $L_{1}$ é definida formalmente pela Equação 3.2.

$$
d_{L_{1}}(X, Y)=\sum_{i=1}^{n}\left|x_{i}-y_{i}\right|
$$

Calculando-se o limite da Equação 3.1 quando $p$ tende ao infinito, obtém-se a função de distância $L_{\infty}$, conhecida também como Infinity ou Chebychev, na qual o conjunto de pontos eqüidistantes formam um quadrado com os lados paralelos aos eixos das coordenadas. A $L_{\infty}$ é definida formalmente pela Equação 3.3.

$$
L_{\infty}\left(\left(x_{1}, \ldots, x_{n}\right),\left(y_{1}, \ldots, y_{n}\right)\right)=\max _{i=1}^{n}\left|x_{i}-y_{i}\right|
$$

Na Figura 3.1 são ilustradas as formas geométricas das regiões com mesma distância geradas pelas funções $L_{1}$ (Figura 3.1 (a)), $L_{2}$ (Figura 3.1 (b)) e $L_{\infty}$ (Figura 3.1 (c)) em um espaço bidimensional. A sobreposição das representações geométricas das funções na Figura 3.1 (d) distingue os subespaços distintos.

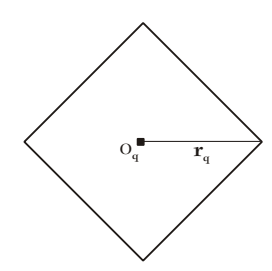

(a)

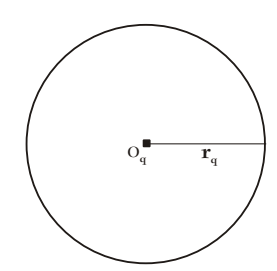

(b)

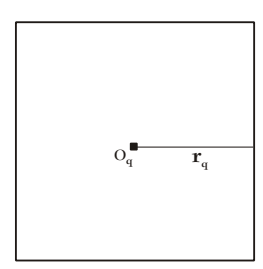

(c)

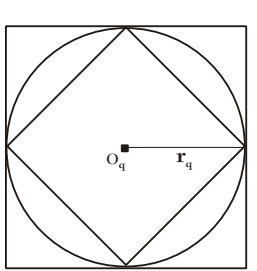

(d)

Figura 3.1: Representação das formas geométricas geradas conforme a distância $L_{p}$ utilizada e em relação aos pontos eqüidistantes à distância $r_{q}$ a partir do objeto centro $o_{q}$.

Além dessas distâncias existem também as fracionárias, onde $0<p<1$. É importante ressaltar que tais distâncias não são métricas visto que violam a propriedade de desigualdade triangular. No entanto, alguns estudos demonstram que a recuperação dos dados 
melhora em muitas circunstâncias quando $p=0.5$ (Howarth \& Rüger, 2005) (Aggarwal, 2001). Por outro lado, outros trabalhos contrapõem tais resultados (François et al., 2007) (Doherty et al., 2004).

\subsubsection{Distância Minkowski Ponderada}

A distância Minkowski ponderada é uma variação da família de Distâncias Minkowski, a qual atribui-se pesos distintos para cada atributo inerente a uma dada imagem. A utilização de um vetor de ponderação dá-se quando houver diferentes influências entre os atributos sobre o resultado da similaridade. Portanto, diferentes vetores de ponderação podem ser estipulados a contextos específicos, exercendo um papel de calibragem da Distância Minkowski para determinados contextos, levando-se em consideração que determinados atributos podem exercer maior ou menor relevância em relação a outros, de acordo com o contexto.

A Distância Minkowski ponderada é definida formalmente pela Equação 3.4.

$$
d_{L_{p}}(X, Y)=\sqrt[p]{\sum_{i=1}^{n} w_{i}\left(x_{i}-y_{i}\right)^{p}}
$$

onde $w$ é o vetor de ponderação $w=\left(w_{1}, w_{2}, \ldots, w_{n}\right)$.

\section{Intersecção de Histogramas}

O histograma de imagem é uma das principais características extraídas das mesmas, devido ao baixo custo computacional. Assim, é interessante exemplificar como comparar duas imagens através de seu histograma.

A intersecção de histogramas pode ser entendida como um caso especial da distância $L_{1}$ (City Block), quando as áreas de dois histogramas são análogas. Tal mensuração é atrativa devido à capacidade de tratar intervalos parciais quando a área de um dado histograma é menor que a de outro.

A intersecção entre dois histogramas é definida formalmente pela Equação 3.5.

$$
d_{\cap}(X, Y)=1-\frac{\sum_{i=1}^{n} \min \left(y_{i}, x_{i}\right)}{\sum_{i=1}^{n} x_{i}}
$$

\section{Distância Mahalanobis}

A distância Mahalanobis é apropriada quando verifica-se a existência de interdependências entre os atributos. Ou seja, o valor de um atributo influencia o valor de outros. Ela difere da distância Minkowski e suas variações, as quais não levam em consideração a correlação entre os atributos. 
Devido à utilização do conceito de correlação entre atributos utilizado na realização do cálculo da distância Mahalanobis, leva-se em consideração a covariância entre os atributos. Intuitivamente, covariância é a mensuração de como duas variáveis, em questão atributos pertencentes a imagens, variam juntamente, diferentemente da variância, a qual mensura o quanto um único atributo varia isoladamente. Se duas variáveis tendem a variar conjuntamente, ou seja, quando uma delas está acima do seu valor esperado, então a outra tende também a estar acima do seu respectivo valor esperado, dessa forma a covariância entre estas duas variáveis será positiva. Por outro lado, quando ocorrer de uma delas estar acima de seu valor esperado, e a outra tender a um valor abaixo do esperado, a covariância entre estas será negativa.

A distância Mahalanobis pode ser denotada formalmente pela Equação 3.6.

$$
d_{M H}(X, Y)=\sqrt{(y-x)^{T} A^{-1}(y-x)}
$$

onde $A$ é a matriz de covariância entre os vetores de atributos $y$ e $x$. Tal matriz é incorporada no cálculo de distância para considerar o efeito da correlação entre os atributos.

A distância Mahalanobis pode ser simplificada caso os atributos sejam independentes entre si. Nesse caso, apenas a variância $\left(v_{i}\right)$ de cada atributo é necessária. Tal simplificação pode ser definida formalmente da seguinte forma:

$$
d_{M H}(X, Y)=\frac{\sum_{i=1}^{n}\left(y_{i}-x_{i}\right)^{2}}{v_{i}}
$$

\section{Distância Quadrática}

A distância Minkowski trata as dimensões do vetor de características de maneira independente, não levando em consideração o fato de que certos pares de dimensões correspondem a características as quais são perceptualmente mais similares do que outros pares. Para solucionar tal problemática a Distância Quadrática é introduzida na Equação 3.8:

$$
d_{A}(X, Y)=\sqrt{(x-y)^{T} A(x-y)}
$$

onde $A=\left[a_{i j}\right]$ é uma matriz $N \times N$ de elementos $a_{i j}$ que denotam a similaridade entre as dimensões $i$ e $j$, e $x$ e $y$ dizem respeito a vetores de atributos (características). O valor de $a_{i j}$ é dado por:

$$
a_{i j}=1-\frac{d_{i, j}}{\max \left[d_{i, j}\right]} \quad \text { onde } \quad d_{i, j}=\left|q_{i}-c_{i}\right|
$$

A Distância Quadrática tem sido utilizada em muitos sistemas de recuperação baseada em conteúdo para histogramas de cores. Foi mostrado que esta distância conduz a resultados perceptualmente mais desejáveis do que a distância Euclidiana e o método de 
Intersecção de Histogramas, pois considera a similaridade entre as dimensões dos vetores de características (Long et al., 2003).

Uma vez que a matriz $A$ seja definida como matriz identidade, a distância quadrática degenera para a distância Euclidiana. Por outro lado, caso tal matriz seja definida diagonal, a distância quadrática degenera para a chamada distância Euclidiana normalizada:

$$
d_{A}(X, Y)=\sqrt{\sum_{i=1}^{n} \frac{\left(x_{i}-y_{i}\right)^{2}}{\sigma_{i}^{2}}}
$$

onde $\sigma_{i}^{2}$ é o desvio padrão da i-ésima dimensão do conjunto de dados.

\section{Distância Canberra}

A distância Canberra pode ser entendida e comparada com a distância Manhattan $\left(L_{1}\right)$, pois na sua computação a diferença absoluta dos valores das características é dividida pela soma absoluta dos mesmos. Isto a torna a distância mais restritiva do que as apresentadas anteriormente, a qual é definida formalmente como:

$$
d_{C}(X, Y)=\sum_{i=1}^{n} \frac{\left|x_{i}-y_{i}\right|}{\left|x_{i}\right|+\left|y_{i}\right|}
$$

Esta distância é muito sensível a pequenas variações, e tem sito empregada em diferentes áreas como por exemplo para seqüências de DNA na bioinformática, assim como para detecção de intrusão (Emran \& Ye, 2001).

\section{Distância Cosseno}

A função de distância Cosseno leva em consideração apenas o ângulo $\theta$ entre dois vetores $R$ e $S$, dispensando a informação de magnitude dos mesmos. Sua definição parte do produto escalar de dois vetores dado por (Zhang \& Lu, 2003):

$$
X \cdot Y=X^{t} Y=|X||Y| \cos \theta
$$

A função de distância Cosseno é definida como:

$$
d_{\cos }(X, Y)=1-\cos \theta=1-\frac{X^{t} Y}{|X||Y|}
$$




\section{Distância Square Chord}

A distância Square Chord obviamente não admite características com valores negativos (Kokare et al., 2003), tal distância é definida formalmente como:

$$
d_{s c}(X, Y)=\sum_{i=1}^{n}\left(\sqrt{x_{i}}-\sqrt{y_{i}}\right)
$$

Em (Zegarra et al., 2009) foi demonstrado a partir de experimentos que a distância Square Chord apresenta bons resultados considerando características de textura obtidas a partir de filtros de Gabor e Wavelets para a recuperação de imagens de impressões digitais.

\subsubsection{Teoria da Informação}

As distâncias classificadas como pertencentes à teoria da informação são aquelas oriundas e derivadas a partir da teoria da entropia de Shannon (Shannon, 2001). Nesse caso os objetos são tratados como distribuições de probabilidade, portanto não são aplicáveis a características com valores negativos.

\section{Divergência de Kullback-Leibler e Divergência de Jeffrey}

A divergência de Kullback-Leibler (DKL) do ponto de vista da teoria da informação, mensura quão ineficiente em média seria codificar um determinado vetor de características a partir de outro, utilizado como referência. No entanto, a DKL é não-simétrica e sensível, por exemplo, à variação da divisão dos bins ${ }^{1}$ de um histograma.

A divergência de Kullback-Leibler é definida formalmente como:

$$
d_{K L}(X, Y)=\sum_{i=1}^{n} y_{i} \log \frac{y_{i}}{x_{i}}
$$

Derivada empiricamente, a partir da DKL, a divergência de Jeffrey (Kim et al., 2010a), é uma modificação desta. Em contraste com a DKL a divergência de Jeffrey é simétrica e apresenta um comportamento numericamente mais estável e robusto em relação a ruídos e ao tamanho dos bins de um dado histograma (Rubner \& Tomasi, 2001).

Tal divergência é definida formalmente como:

$$
d_{J}(X, Y)=\sum_{i=1}^{n}\left(y_{i} \log \frac{y_{i}}{m_{i}}+x_{i} \log \frac{x_{i}}{m_{i}}\right)
$$

onde $m_{i}=\frac{y_{i}+x_{i}}{2}$.

\footnotetext{
${ }^{1}$ Um bin diz respeito à medida de freqüência de cada nível de intensidade mapeado pelo histograma.
} 


\subsubsection{Medidas Estatísticas}

Diferentemente das medidas geométricas, as medidas estatísticas comparam dois vetores de características supondo que os elementos destes são amostras, ou seja, considera os vetores como duas distribuições.

\section{Valor Estatístico $\chi^{2}$}

O valor estatístico $\chi^{2}$ (Skopal \& Bustos, 2011) é calculado encontrando-se a diferença entre cada freqüência observada e teórica para cada resultado possível, elevando-as ao quadrado, e dividindo cada uma pela freqüência teórica, e por fim realizando a soma dos resultados. Para tanto é definida formalmente como:

$$
d_{\chi^{2}}(X, Y)=\sum_{i=1}^{n} \frac{\left(y_{i}-m_{i}\right)^{2}}{m_{i}}
$$

onde novamente $m_{i}=\frac{y_{i}+x_{i}}{2}$.

Essa função valoriza as elevadas discrepâncias existentes entre dois vetores de características comparados, e mensura quão improvável é a distribuição.

\section{Coeficiente de Correlação de Pearson}

A presente distância é derivada a partir do coeficiente de correlação de Pearson e é definida formalmente como:

$$
d_{c c p}(X, Y)=1-|p|
$$

onde

$$
p=\frac{n \sum_{i=1}^{n} x_{i} y_{i}-\left(\sum_{i=1}^{n} x_{i}\right)\left(\sum_{i=1}^{n} y_{i}\right)}{\sqrt{\left[n \sum_{i=1}^{n} x_{i}^{2}-\left(\sum_{i=1}^{n} x_{i}\right)^{2}\right]\left[n \sum_{i=1}^{n} y_{i}^{2}-\left(\sum_{i=1}^{n} y_{i}\right)^{2}\right]}}
$$

Quanto maior o valor de $|p|$, maior a correlação entre os vetores $X$ e $Y$ (Chen \& Chu, 2005), ou seja, maior sua similaridade.

\section{Distância de Kolmogorov-Smirnov}

A distância de Kolmogorov-Smirnov, originalmente proposta por Geman et al. (1990) para segmentação de imagens, mensura a dissimilaridade entre duas distribuições (Rubner \& Tomasi, 2001).

$$
d_{k s}(X, Y)=\max _{1 \leqslant i \leqslant n}\left|F_{X}(i)-F_{Y}(i)\right|
$$


onde $F_{X}(i)$ e $F_{Y}(i)$ são as funções densidade de probabilidade (probability density funcion - $p d f)$ dos vetores de características.

\section{Distância de Cramer-von Misses}

De maneira análoga à distância de Kolmogorov-Smirnov, a distância de Cramer-von Misses (CvM) também baseia-se na função de densidade de probabilidade (Puzicha et al., 1997).

$$
d_{c v m}(X, Y)=\left(F_{X}(i)-F_{Y}(i)\right)^{2}
$$

\subsection{Propostas de Funções de Distâncias}

Na literatura, pode-se verificar uma crescente necessidade pelo desenvolvimento de funções de distância, pois estas são empregadas nas mais diversas áreas do conhecimento. Especificamente para a recuperação de imagens com o intuito de atingir a máxima eficácia na recuperação destas em coerência à similaridade, muitas deixam a desejar com relação ao problema do gap semântico.

Logo, essas funções não captam aspectos particulares das imagens em questão. Como espera-se que os resultados de comparações entre imagens sejam apropriados ao contexto, deve-se também fazer uso de funções ajustadas às características mais específicas do domínio de aplicação, no nosso caso, as imagens médicas.

Uma atividade nessa direção foi realizada pela comunidade de bioengenharia ao definir novas funções de distância para a comparação de cadeias de DNA. A proposta fundamentou-se na adaptação da função de distância $L_{\text {edit }}$ (Euzenat \& Shvaiko, 2007), que compara duas cadeias de caracteres e excelentes resultados foram obtidos (Wang et al., 2000).

Outra proposta de definição de função de distância específica é apresenta em Caballero \& Aranda (2010), a qual realiza o cálculo entre imagens folheares de diferentes espécies de plantas, baseada na curvatura dos contornos das folhas.

O trabalho desenvolvido em (Hiransakolwong et al., 2005) propõe uma distância na qual é realizada uma pré-classificação de cada atributo da imagem em grupos de relevância, irrelevância e neutralidade, sendo fatores considerados no cálculo da distância entre duas imagens.

A Distância Métrica (DM) apresentada em (Traina et al., 2003) efetua a comparação entre as áreas de histogramas métricos, o qual consiste de modificações sobre histogramas tradicionais. O cálculo da similaridade entre duas imagens é feito por meio da diferença entre as áreas de ambos os histogramas métricos. O histograma métrico em relação aos histogramas tradicionais apresentou melhor desempenho com relação à recuperação de imagens. 
Em (Felipe \& Traina, 2005) são propostas algumas funções de distância tais como a Warp Metric Distance (WMD) e a Global Warp Distance (GWD) (Felipe et al., 2005), além de uma nova família de distâncias perceptuais denominada Attribute Interaction Distances (AID) (Felipe et al., 2009). A Warp Metric Distance é uma adaptação da técnica de comparação de duas séries temporais que possuem comportamentos semelhantes, porém defasados em relação ao tempo, denominada Dynamic Time Warping (DTW) (Keogh \& Ratanamahatana, 2005; Keogh et al., 2009; Skopal \& Bustos, 2011) sobre histogramas métricos. Já a Global Warp Distance realiza o cálculo de coeficientes para características globais como simetria, curtose e picos utilizando a WMD ponderada com os respectivos coeficientes calculados.

A família de distâncias AID (Felipe et al., 2009) leva em consideração os efeitos da interação entre os vetores de características extraídos das respectivas imagens, trabalhando com o conceito de interação fraca ou forte entre dois atributos, sendo assim foram propostas duas funções de distância a Weak Attribute Interaction Distance (WAID) e a Strong Attribute Interaction Distance (SAID).

O trabalho desenvolvido em (Stehling et al., 2002) propõe uma distância denominada MiCRoM (Minimum-Cost Region Matching) para a comparação de imagens segmentadas a qual satisfaz os axiomas métricos (ver Seção 2.3.2). Esta distância modela a comparação das regiões de duas imagens baseada na solução do problema dos transportes (Ahuja et al., 1993).

Outros trabalhos analisam o comportamento de diferentes funções de distância, como em (Hsu \& Chen, 2009) onde são demonstradas algumas condições de equivalência para a instabilidade de determinadas funções de distância, ou seja, a partir da verificação de tais condições é possível dizer se a função de distância torna-se instável para espaços de alta dimensionalidade. Já em (Qamra et al., 2005) é proposta uma nova função de distância denominada Dynamic Partial Distance Function (DPF), a qual reduz a dimensionalidade dos vetores de características "escolhendo" dinamicamente um número menor de dimensões.

Já outros trabalhos (Amores et al., 2006; Tian et al., 2004; Yu et al., 2008, 2006) utilizaram a relação entre a distribuição dos dados e algumas funções de distância. Tais trabalhos concluíram que distribuições Gaussianas e Exponenciais resultam nas métricas $L_{2}$ e $L_{1}$ respectivamente. No entanto, distâncias que poderiam adequar-se a outros modelos de distribuição não foram analisadas. Em Yu et al. (2008) foi demonstrado que as distâncias $L_{2}$ e $L_{1}$ não apresentam os melhores casos quando a distribuição das características não é gaussiana nem exponencial. Além disso, a partir dos estudos realizados foi derivado um novo conjunto de distâncias.

Em (Ling \& Okada, 2006) é proposta uma nova distância, denominada "Diffusion Distance", para a comparação de descritores baseados em histogramas. A distância proposta modela a diferença entre dois histogramas como um campo termal, demonstrando que o 
processo de difusão nesse campo lida de maneira eficaz com os efeitos de deformações nos histogramas, bem como os da quantização. Além disso, tal distância é robusta em relação a ruídos e apresenta complexidade linear.

\subsubsection{Funções de Distância Métricas}

Algumas funções de distância utilizadas com o intuito de modelar a percepção humana em relação à similaridade, por muitas vezes contradizem em diferentes maneiras os axiomas métricos (Santini \& Jain, 1999). Em Tversky (1977) e Tversky \& Gati (1982) é apresentada uma análise da percepção humana, na qual acredita-se que os axiomas métricos são extremamente restritivos no contexto de consulta por similaridade, propondo então um modelo de contraste com propriedades diferentes dos axiomas métricos.

Um dos axiomas mais criticados, diz respeito à propriedade da desigualdade triangular, sendo considerado o axioma vital na área de indexação métrica (Samet, 2006), pois este é de extrema importância para o processo de poda nas árvores métricas. Em determinadas situações, a desigualdade triangular não condiz com a percepção que se tem da interrelação entre os objetos. Um exemplo clássico, ilustrado na Figura 3.2, é o distanciamento entre os objetos "homem", "cavalo" e "centauro".

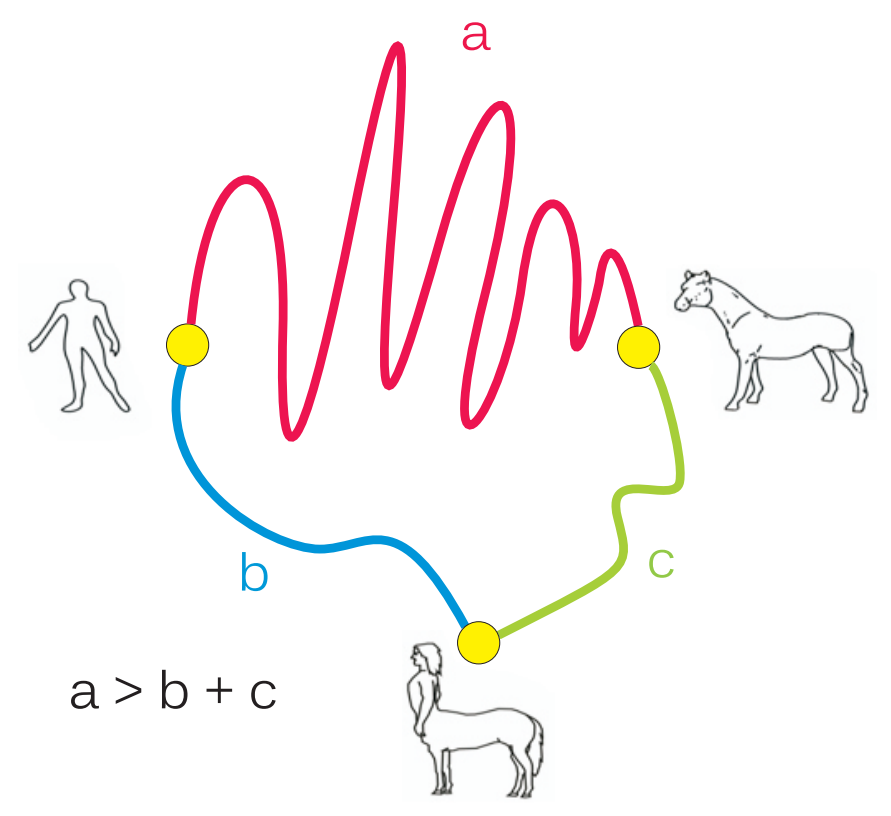

Figura 3.2: Incongruência da desigualdade triangular.

A falha semântica que caracteriza tal efeito consiste na observação de que o centauro está relativamente próximo tanto do cavalo quanto do homem, embora o cavalo e homem não tenham nenhuma característica similar entre si. Dessa forma não seria possível a formação do triângulo entre os três objetos, uma vez que para existir um triângulo, qualquer das combinações possíveis entre os seus três lados tem que obedecer à desigualdade triangular (e.g. $a<b+c)$. Semanticamente, o fato de não existirem atributos comuns entre o 
cavalo e o homem deveria fazer com que a distância entre os mesmos fosse infinitamente grande.

Em Skopal \& Bustos (2011) é apresentada uma extensa revisão sobre a utilização de diversas funções de distância que não contemplam os axiomas métricos, bem como argumenta-se que quanto mais complexa uma função de distância, maior a probabilidade desta não contemplar tais axiomas. Já em Bustos et al. (2012) são apresentados estudos a respeito da utilização de múltiplas métricas em estruturas de indexação, bem como propõe uma metodologia para adaptar tais estruturas com o intuito de permitir a realização de consultas por similaridade baseadas na combinação de múltiplas métricas.

\subsection{Valores Limites de Funções de Distância}

Para que seja possível realizar a troca ou escolha de diferentes funções de distância em MAMs é necessário o estudo da abrangência destas. Considerando as funções de distância que são homogêneas no espaço das características é possível determinar a propriedade de limite inferior (lower bound). Por exemplo, a família de funções Minkowski é homogênea para qualquer $p \geqslant 1$. No entanto, outras funções de distância não preservam a homogeneidade quando o centro de consulta é transladado no espaço, ou quando o raio da consulta é alterado. A função de distância Canberra é um exemplo das que não preservam a propriedade de homogeneidade em tais casos.

Para algumas funções de distância pode-se analisar o conjunto de dados com o intuito de responder se uma dada função de distância é limitada inferiormente por outra. Por exemplo, caso se deseje responder qual a relação de limites entre as funções de distância Canberra e as pertencentes à família Minkowski, deve-se garantir que a relação explicitada pela Equação 3.21 seja satisfeita, aplicando-a no conjunto de dados a ser analisado.

$$
\sum_{i=1}^{n} \frac{\left|x_{i}-y_{i}\right|}{\left|x_{i}\right|+\left|y_{i}\right|} \geqslant\left(\sum_{i=1}^{n}\left|x_{i}-y_{i}\right|^{p}\right)^{1 / p}
$$

porém, caso $p=1$, deseja-se determinar se

$$
\sum_{i=1}^{n} \frac{\left|x_{i}-y_{i}\right|}{\left|x_{i}\right|+\left|y_{i}\right|}-\left|x_{i}-y_{i}\right| \geqslant 0
$$

fato que resulta em:

$$
\sum_{i=1}^{n} \frac{\left|x_{i}-y_{i}\right|\left(1-\left(\left|x_{i}\right|+\left|y_{i}\right|\right)\right)}{\left|x_{i}\right|+\left|y_{i}\right|} \geqslant 0, \forall x_{i}, y_{i} \in S
$$

e uma vez que $d_{L_{1}}>d_{L_{2}}>\ldots>d_{L_{\text {inf }}}$ (e.g. considerando $X=1,2,3$ e $Y=4,5,6$, $d(X, Y)_{L_{1}}=9, d(X, Y)_{L_{2}}=5.2$ e $\left.d(X, Y)_{L_{i n f}}=3\right)$, tal relação vale para qualquer $p \geqslant 1$. 
No entanto, caso se queira definir uma constante para estabelecer os limites inferiores entre as funções, pode-se realizar tal processo majorando uma das distâncias. Por exemplo, caso majoremos a distância Canberra $\left(d_{c}\right)$ :

$$
d_{c} \geqslant \sum_{i=1}^{n} \frac{\left|x_{i}-y_{i}\right|}{c_{\text {lower }}}=\frac{1}{c_{\text {lower }}} \sum_{i=1}^{n}\left|x_{i}-y_{i}\right|=\frac{1}{c_{\text {lower }}} d_{L_{1}}
$$

tem-se, uma vez que o valor das distâncias $d_{L_{1}}>d_{L_{2}}>\ldots>d_{L_{\text {inf }}}$,

$$
\frac{1}{c_{\text {lower }}} d_{L_{p}} \leqslant d_{c}
$$

onde $c_{\text {lower }}=\max \left(\left|x_{i}\right|+\left|y_{i}\right|\right), \forall X, Y \in G$.

Analogamente, o limite superior pode ser obtido minorando a distância Canberra $d_{c}$ :

$$
d_{c} \leqslant \sum_{i=1}^{n} \frac{\left|x_{i}-y_{i}\right|}{c_{\text {upper }}}=\frac{1}{c_{\text {upper }}} \sum_{i=1}^{n}\left|x_{i}-y_{i}\right|=\frac{1}{c_{\text {upper }}} d_{L_{1}}
$$

onde $c_{\text {upper }}=\min \left(\left|x_{i}\right|+\left|y_{i}\right|\right), \forall X, Y \in G$.

Finalmente, temos o limite superior e inferior definidos:

$$
\frac{1}{c_{\text {lower }}} d_{L_{p}} \leqslant d_{c} \leqslant \frac{1}{c_{\text {upper }}} d_{L_{p}}
$$

Dessa forma, conseguimos determinar matematicamente qual função de distância é limitada inferiormente ou superiormente por outra, e em quais condições isso ocorre, de acordo com o conjunto de dados analisado e o centro de consulta especificado. Na Figura 3.3 pode-se visualizar algumas destas funções de distância, onde o centro de consulta ao ser deslocado em cada caso modifica a abrangência da função de distância Canberra em relação às funções da família Minkowski. Analisando a Figura 3.3 (a), considerando um espaço 2-dimensional, pode-se observar que a distância Canberra é mais abrangente que as da família Minkowski. Já o inverso ocorre ao transladar o centro de consulta para um ponto mais próximo da origem do espaço, como observado na Figura 3.3 (b).

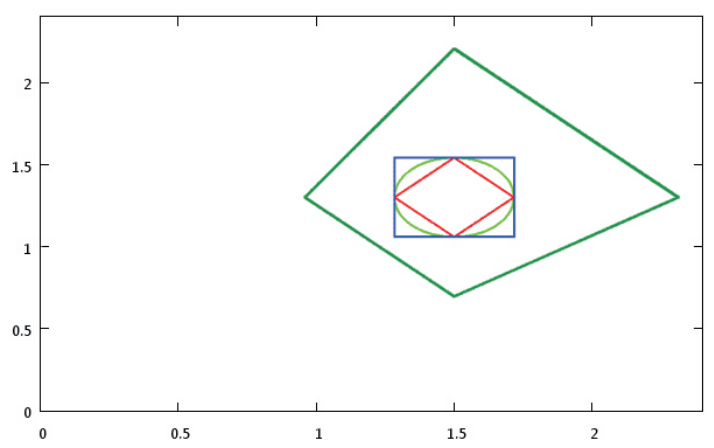

(a)

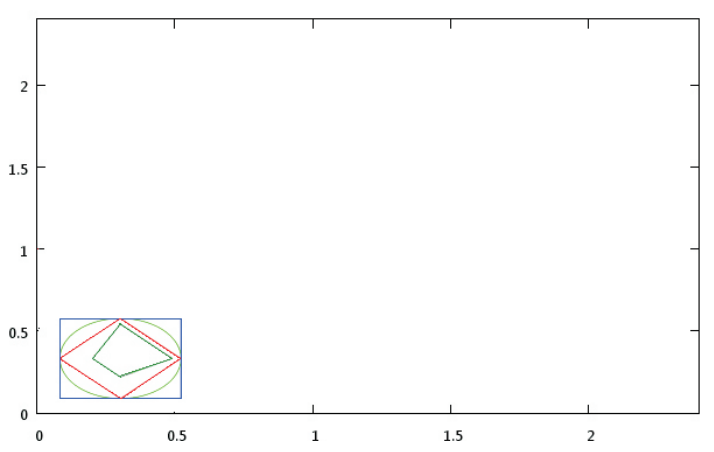

(b)

Figura 3.3: Variação da abrangência das funções de distância de acordo com a translação do centro de consulta. 
O mesmo tipo de comparação pode ser realizado para as métricas da família Minkowski $\left(L_{p}\right)$. Sabe-se que estas são homogêneas no espaço de características. Dessa forma, transformações geométricas como translações não modificam a abrangência entre elas (Samet, 2006). O limite inferior entre as funções de distância da família Minkowski é conhecido e definido como:

$$
L_{\infty} \leqslant \ldots \leqslant L_{2} \leqslant L_{1} \leqslant n L_{\infty}
$$

onde $n$ é o número de dimensões do espaço de características.

Com o intuito de obter um relacionamento dinâmico entre as funções de distância com relação a propriedade de limite inferior, pode-se utilizar a inequação de média generalizada (generalized mean inequality), a qual é definida formalmente como:

$$
\begin{aligned}
& M(\alpha)=\left(\frac{z_{1}^{\alpha}+z_{2}^{\alpha}+\ldots+z_{n}^{\alpha}}{n}\right)^{1 / \alpha} \\
& \alpha \leqslant \beta \Longrightarrow M(\alpha) \leqslant M(\beta)
\end{aligned}
$$

Desenvolvendo-se a equação anterior, tem-se:

$$
\frac{\left(z_{1}^{\alpha}+z_{2}^{\alpha}+\ldots+z_{n}^{\alpha}\right)^{1 / \alpha}}{n^{1 / \alpha}} \leqslant \frac{\left(z_{1}^{\beta}+z_{2}^{\beta}+\ldots+z_{n}^{\beta}\right)^{1 / \beta}}{n^{1 / \beta}}
$$

Finalmente,

$$
\left(z_{1}^{\alpha}+z_{2}^{\alpha}+\ldots+z_{n}^{\alpha}\right)^{1 / \alpha} \leqslant \frac{n^{1 / \alpha}}{n^{1 / \beta}}\left(z_{1}^{\beta}+z_{2}^{\beta}+\ldots+z_{n}^{\beta}\right)^{1 / \beta}
$$

onde $\alpha \leqslant \beta$.

Os relacionamentos entre as métricas $L_{p}$ podem ser obtidos associando-se diferentes valores para $\alpha$ e $\beta$. Por exemplo, caso queira-se comparar o relacionamento entre as funções de distância $L_{p}$ e $L_{p+1}$, tem-se

$$
L_{p+1} \leqslant L_{p} \leqslant \frac{n^{1 / p}}{n^{1 /(p+1)}} L_{p+1}
$$

onde $1 \leqslant p \leqslant \infty$.

\subsection{Considerações Finais}

O presente capítulo, introduziu o conceito de funções de distância, bem como seu estado da arte, visando consultas por similaridade.

Existem diversas funções de distância com o intuito de realizar a mensuração da similaridade entre as características inerentes às imagens. O presente capítulo além dos 
conceitos primordiais ao entendimento e apreciação de funções de distância e suas peculiaridades, também apresentou algumas funções clássicas incluindo a distância Minkowski, distância Mahalanobis, distância Quadrática, entre outras, bem como novas funções de distância encontradas na literatura. Porém, até o momento as distâncias pertencentes à Minkowski são as mais comumente utilizadas para a recuperação de imagens, principalmente a distância Euclidiana.

Por existir uma gama tão ampla de funções de distância na literatura a utilização dessas deve ser analisada e especificamente ajustada para o contexto (e.g. tipos de características extraídas) em que o usuário está inserido e a percepção do mesmo. Como explicitado, algumas das funções de distâncias podem ser derivadas a partir de outras. No entanto, cada uma dessas derivações possuem propriedades específicas que podem ser proveitosas a determinados contextos, melhorando assim consideravelmente a precisão das consultas por similaridade.

Além disso, como discutido, a abrangência de funções de distância demonstra quão genéricas elas são. Dessa forma, identificando a correlação entre as funções pode-se mensurar casos em que uma função será mais abrangente que a outra, e assim, responder quais funções aumentariam ou diminuiriam a generalidade da consulta, ou seja, retornariam um número maior ou menor de elementos. 


\section{Seleção de Características por Demanda Guiada pela Percepção do Usuário}

\subsection{Introdução}

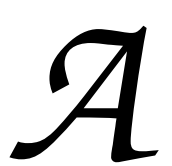

tualmente, com o crescimento exponencial de repositórios de imagens, as técnicas de recuperação de imagens baseada em conteúdo têm sido intensamente pesquisadas. Geralmente as técnicas CBIR utilizam características visuais intrínsecas das imagens (cor, textura e forma), produzindo vetores de características com centenas ou até mesmo milhares de características. Esta elevada cardinalidade das características representa um grande problema, pois leva à chamada maldição da alta dimensionalidade (Hsu \& Chen, 2009), onde as estruturas de indexação degradam-se e o poder de representatividade de cada característica diminui consideravelmente, tornando os processos de indexação e recuperação das imagens muito mais lentos e insatisfatórios. Além disso, freqüentemente muitas características são correlacionadas entre si, trazendo, desse modo, informação redundante, não adicionando nenhuma informação considerável sobre as imagens, deteriorando a habilidade do sistema em distingüi-las de maneira fidedigna.

Com o intuito de evitar o problema da maldição da alta dimensionalidade, as técnicas de seleção de características podem ser empregadas visando a redução do tamanho dos vetores de características. Assim, um dos principais desafios de um sistema CBIR é justamente determinar um subconjunto mínimo de características que melhor representa as imagens. É nessa direção que a presente técnica atua. 
Outro problema considerado é o já citado gap semântico, onde as características de baixo nível extraídas automaticamente das imagens não representam de maneira satisfatória a interpretação semântica destas. Os seres humanos apresentam diferentes percepções com relação à similaridade entre imagens, fato que acarreta a insatisfação destes com os resultados retornados pelo sistema CBIR, diminuindo assim muitas vezes a aceitação e posterior inclusão de tais sistemas em ambientes reais, como por exemplo na prática médica. De fato, existe uma disparidade entre as características de baixo nível extraídas das imagens e a percepção do usuário.

Outro desafio para um sistema CBIR é desenvolver métodos de representação de imagens que estejam em uniformidade com a subjetividade humana. Para captar tal subjetividade é extremamente importante inserir o usuário no processo e, para tanto, inúmeros pesquisadores têm considerado e empregado técnicas de realimentação de relevância (Relevance Feedback - RF) para tornar a recuperação de imagens mais fidedigna em relação à expectativa do usuário.

A realimentação de relevância apresenta uma estratégia de aprendizado em tempo real (on the fly) adaptando a resposta do sistema CBIR por meio das interações com o usuário. O usuário pode interagir com o sistema selecionando as imagens mais relevantes (realimentação positiva) e as menos relevantes (realimentação negativa) para um determinado contexto. Portanto é um processo que realiza um ajuste "automático" de uma consulta existente por meio de informações que são realimentadas ao sistema com relação às respostas retornadas previamente e assim, realizando o ajuste da consulta, objetivando diminuir o gap existente entre o que o usuário deseja e a informação que foi de fato retornada (Deselaers et al., 2008b).

O presente capítulo apresenta um método o qual propõe-se justamente lidar com os dois principais empecilhos encontrados por um sistema CBIR que são a maldição da alta dimensionalidade e o gap semântico. Para tratar tais empecilhos o método utiliza o processo de realimentação de relevância para refinar iterativamente a seleção de características realizada pela mineração de regras de associação estatísticas. Para tanto, o conjunto de treinamento inicial empregado para realizar a mineração de regras de associação é incrementado de acordo com as iterações de realimentação de relevância realizadas pelo usuário, calibrando em tempo de execução o processo de mineração segundo a expectativa do usuário.

Os conceitos necessários para o entendimento da técnica desenvolvida serão apresentados nas próximas seções. Vale ressaltar que a técnica apresentada no presente capítulo foi publicada na forma de artigo científico no IEEE International Conference on Healthcare Informatics, Imaging and Systems Biology (Bugatti et al., 2011b). 


\subsection{Conceitos Relacionados}

\subsubsection{Processo de Mineração de Regras}

A tarefa de associação de características (Agrawal \& Srikant, 1994) é uma das áreas de mineração de dados mais exploradas. Ela foi inicialmente motivada por aplicações comerciais, tais como: análise de mercado, análise de cesta de compras e classificação de clientes. Entretanto, a extração de regras de associação também tem sido intensamente usada em outras aplicações, tais como sumarização e classificação de imagens.

A mineração de imagens demanda a extração de características destas segundo um critério específico. Após extraídas, essas características são submetidas ao processo de mineração. O foco deste trabalho são imagens médicas, mais especificamente sobre os vetores de características utilizados para comparar e recuperar as imagens quanto a sua similaridade. O intuito é selecionar as características de acordo com a contribuição de cada uma para a interpretação semântica, peneirando as características que contêm as informações mais relevantes das imagens, tornando dessa forma o processo de recuperação das mesmas mais eficiente. Um ponto a ser ressaltado é que essa metodologia proposta pode ser diretamente estendida para outros tipos de dados complexos além de imagens, pois consultas por similaridade são empregadas sobre diversos tipos de dados complexos. Como já pudemos observar anteriormente, a similaridade entre imagens é computada por meio da utilização de funções de distância aplicadas aos vetores de características.

Com relação aos processos de redução da dimensionalidade, os quais tratam de outro fator de extrema importância, estes podem ser baseados em técnicas supervisionadas ou não supervisionadas. Enquanto que as técnicas supervisionadas necessitam de um conjunto de treinamento pré-classificado, as técnicas não supervisionadas não necessitam de um conjunto de treinamento. O processo de redução da dimensionalidade também é classificado quanto a métodos de seleção de características (feature selection) ou transformação de características (feature transformation). O ponto chave de diferença entre essas duas técnicas é que a primeira consiste em selecionar um subconjunto das características originalmente extraídas que melhor representem a imagem. Já a segunda técnica consiste em gerar a partir das características originalmente extraídas um novo conjunto de características que melhor representem uma dada imagem. Portanto, o processo de seleção de características não realiza nenhum tipo de transformação sobre as características originais, ele apenas remove aquelas que apresentam certa redundância ou irrelevância, preservando o significado semântico do conjunto de características original. Em (Cheng et al., 2006) foi demonstrado que a seleção automática de características melhora a classificação das imagens médicas.

Na seção subsequente, será explicitada e introduzida a técnica utilizada para realização do processo de mineração de regras de associação empregada na instanciação do 
método proposto. No entanto, é importante ressaltar que a abordagem proposta pode ser estendida para outros métodos de mineração de regras de associação, bem como diferentes métodos de realimentação de relevância.

\section{Regras de Associação Estatísticas}

Tradicionalmente, o problema da mineração de regras de associação consiste em encontrar relacionamentos da forma $A \rightarrow B$, onde $A$ e $B$ são conjuntos de itens, indicando que $A$ e $B$ ocorrem freqüentemente juntos em uma transação do banco de dados. Portanto, se $A$ ocorrer, existe uma grande probabilidade de $B$ também ocorrer. Estes tipos de regras obtêm bons resultados quando se lida com dados categóricos (nominais). Entretanto, quando lidamos com imagens, as quais são representadas por características de baixo nível, que por sua vez são organizadas em vetores de características que as descrevem quantitativamente, ou seja, consistem de dados contínuos, faz-se necessária a utilização de um tipo de regra de associação que considere valores contínuos. Uma classe de regras de associação contínuas que vem sendo pesquisada recentemente são as regras de associação estatísticas, as quais tratam-se de regras geradas por meio da utilização de testes estatísticos.

O método proposto (instanciação) empregou o algoritmo denominado StARMiner proposto em (Ribeiro et al., 2005), o qual faz uso de tais regras de associação baseadas na utilização de testes estatísticos. O objetivo do algoritmo StARMiner é implementar a mineração de regras de associação estatísticas para encontrar as características que melhor discriminam a imagem em categorias, dado um conjunto de treinamento. As regras mineradas são utilizadas pelo método para selecionar as características de acordo com a relevância de cada uma, alcançando dessa forma uma nova e eficiente representação das imagens.

Seja uma base de imagens médicas $T ; x_{j}$ uma categoria de imagens; $T_{x_{j}} \subset T$ o subconjunto de imagens pertencentes a categoria $x_{j}$; e $f_{i}$ a $i$-ésima característica do vetor de características $F$. Sejam $\mu_{f_{i}}(L)$ (equação 4.1) e $\sigma_{f_{i}}(L)$ (equação 4.2), respectivamente, a média e o desvio padrão dos valores da característica $f_{i}$ no subconjunto de imagens $L$ e $\left(f_{i}\right)_{m}$ o valor da característica $f_{i}$ da imagem $m$.

$$
\begin{gathered}
\mu_{f_{i}}(L)=\frac{\sum_{m \in L}\left(f_{i}\right)_{m}}{|L|} \\
\sigma_{f_{i}}(L)=\sqrt{\frac{\sum_{m \in L}\left(\left(f_{i}\right)_{m}-\mu_{f_{i}}(L)\right)^{2}}{|L|}}
\end{gathered}
$$

O algoritmo utiliza três restrições definidas pelo usuário, as quais são: 
- $\Delta \mu_{\text {min }}$ - um parâmetro de entrada que indica a diferença mínima permitida entre a média dos valores de $f_{i}$ para as imagens da categoria $x_{j}$ e a média dos valores de $f_{i}$ para as imagens restantes;

- $\Delta \sigma_{\max }$ - um parâmetro de entrada que indica o máximo de desvio padrão permitido aos valores de $f_{i}$ para as imagens da categoria $x_{j}$;

- $\gamma_{\text {min }}$ - um parâmetro de entrada que indica a confiança mínima com a qual uma hipótese $H_{0}$ deve ser rejeitada.

O objetivo do algoritmo StARMiner é implementar a mineração de regras de associação estatísticas para encontrar as características que melhor discriminam a imagem em categorias. O formato geral da regra é $x_{j} \rightarrow f_{i}$, significando que para a categoria $x_{j}$ a característica $f_{i}$ é relevante. As regras mineradas pelo algoritmo devem satisfazer as seguintes condições:

- A característica $f_{i}$ deve apresentar um comportamento distinto para as imagens da categoria $x_{j}$ em relação às demais imagens;

- A característica $f_{i}$ deve apresentar um comportamento uniforme para todas as imagens da categoria $x_{j}$.

Essas condições são implementadas no algoritmo StARMiner por meio da incorporação das restrições de interesse já discutidas. Portanto, para que o algoritmo StARMiner minere as regras na forma $x_{j} \rightarrow f_{i}$, é necessário satisfazer as condições dadas pelas Equações 4.3, 4.4 e 4.5 .

$$
\begin{gathered}
\mu_{f_{i}}\left(T_{x_{j}}\right)-\mu_{f_{i}}\left(T-T_{x_{j}}\right) \geqslant \Delta \mu_{\min } \\
\sigma_{f_{i}}\left(T_{x_{j}}\right) \leqslant \Delta \sigma_{\max } \\
H_{0}: \mu_{f_{i}}\left(T_{x_{j}}\right)=\mu_{f_{i}}\left(T-T_{x_{j}}\right) \quad \text { e } H_{1}: \mu_{f_{i}}\left(T_{x_{j}}\right) \neq \mu_{f_{i}}\left(T-T_{x_{j}}\right)
\end{gathered}
$$

Na equação 4.5, $H_{0}$ deve ser rejeitada com confiança maior ou igual a $\gamma_{\min }$ em favor da hipótese $H_{1}$. Rejeitando $H_{0}$, com confiança $\gamma_{\text {min }}$, implica que as médias $\mu_{f_{i}}\left(T_{x_{j}}\right)$ e $\mu_{f_{i}}\left(T-T_{x_{j}}\right)$ são estatisticamente diferentes.

Para rejeitar $H_{0}$, o valor $Z$, cujo cálculo é apresentado na Equação 4.6, deve estar na região de rejeição explicitada pela Figura 4.1. Os valores críticos $z 1$ e $z 2$ dependem de $\gamma_{\text {min }}$, como pode ser observado na Tabela 4.2.1.

$$
Z=\frac{\mu_{f_{i}}\left(T_{x_{j}}\right)-\mu_{f_{i}}\left(T-T_{x_{j}}\right)}{\frac{\sigma_{f_{i}}\left(T_{x_{j}}\right)}{\sqrt{\left|T_{x_{j}}\right|}}}
$$




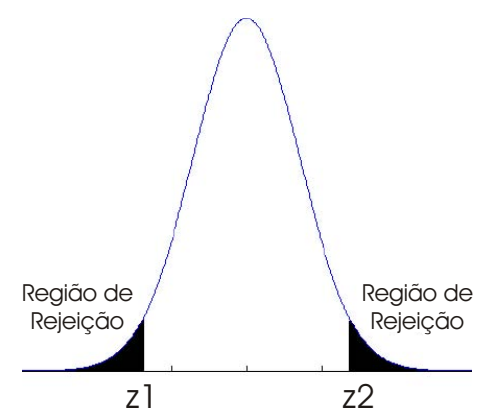

Figura 4.1: Regiões de rejeição (Ribeiro et al., 2005).

Tabela 4.1: Valores Críticos de Z (Ribeiro et al., 2005).

\begin{tabular}{|c|c|c|c|}
\hline$\gamma_{\min }$ & 0.9 & 0.95 & 0.99 \\
\hline \hline$z 1$ & 1.64 & 1.96 & 2.58 \\
\hline$z 2$ & -1.64 & -1.96 & -2.58 \\
\hline
\end{tabular}

Uma regra $x_{j} \rightarrow f_{i}$ é retornada pelo algoritmo, relacionando a característica $f_{i}$ com a classe $x_{j}$, onde valores de $f_{i}$ apresentam um comportamento peculiar em imagens da classe $x_{j}$. Esta propriedade indica que $f_{i}$ é uma característica importante para distinguir imagens pertencentes a classe $x_{j}$ das imagens restantes.

Portanto, o intuito do algoritmo StARMiner é identificar as características que manifestam um alto poder de discriminação, pois estas apresentam um comportamento particular e uniforme em imagens de uma dada categoria. Tal fato é de extrema importância pois as características que apresentam um comportamento uniforme para todas as imagens da base, independentemente da categoria, não contribuem para discriminá-las e devem ser eliminadas. Portanto, as regras geradas pelo StARMiner são muito proveitosas para revelar a relevância das características das imagens.

\subsection{Método Proposto}

O método proposto é uma abordagem supervisionada que lida com os dois principais empecilhos intrínsecos a sistemas CBIR que são como já dito, o gap semântico e a alta dimensionalidade dos vetores de características. Tais problemas são atacados por meio da utilização do processo de realimentação de relevância para construir e calibrar iterativamente o conjunto de treinamento de acordo com a expectativa do usuário, o qual é aplicado ao processo de mineração de regras de associação. Para tanto, o conjunto de treinamento é incrementado de acordo com as iterações da realimentação de relevância realizada pelo usuário.

Dessa forma, o processo de realimentação supre o algoritmo por meio do conjunto de treinamento, atualizando os padrões deste, produzindo a cada ciclo de realimentação um conjunto de regras mais precisas e consequentemente características selecionadas cada vez 
mais condizentes com a expectativa do usuário, uma vez que as regras mineradas são utilizadas para selecionar as características mais relevantes.

Seja $G$ uma base de imagens, composta por imagens de diferentes classes $\left(n_{\text {classes }}\right)$, sendo que cada imagem $g \in G$, a distância entre duas imagens é definida como $d\left(g_{1}, g_{2}\right)$, onde $g_{1}$ é um centro de consulta. Dada uma consulta k-NN inicial, as imagens recuperadas são as mais próximas ao centro da consulta. No entanto, estes resultados podem não atingir a expectativa do usuário, devido ao problema do gap semântico. Portanto, para incluir a expectativa do usuário no processo foi empregada a técnica QPM de realimentação de relevância, onde o usuário rotula as imagens recuperadas em relevantes e irrelevantes (resultado - uma lista ordenada de $k$ imagens mais relevantes pertencentes a $G$ ).

O método proposto é formalizado a seguir nos Algoritmos 1 e 2. O Algoritmo 1 explicita o pipeline do método proposto, enquanto que o Algoritmo 2 descreve o processo de construção incremental do conjunto de treinamento de acordo com a expectativa do usuário, bem como os parâmetros de entrada e saída, definidos como in e out respectivamente.

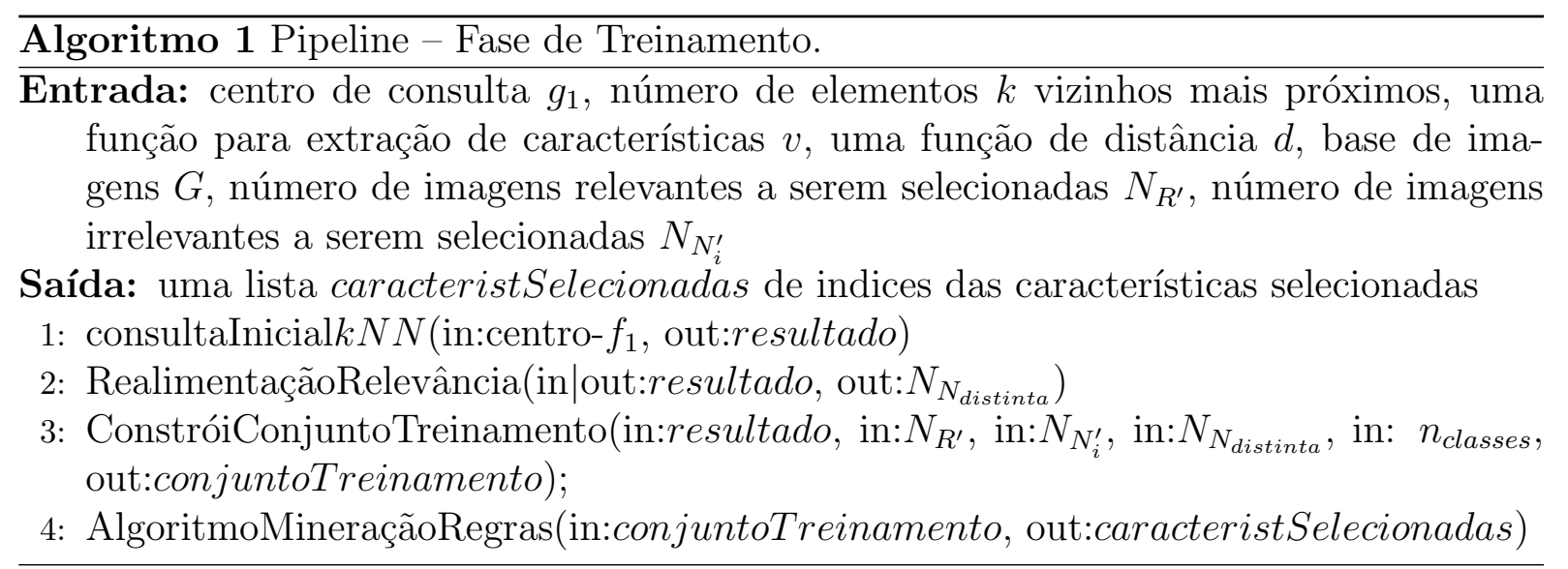

É importante ressaltar que, apesar de no presente capítulo ter sido empregado o algoritmo StARMiner (ver Seção 4.2.1) para realizar o processo de mineração de regras de associação, outros métodos para mineração de regras podem ser aplicados, bem como diferentes métodos de realimentação de relevância, sem perda de generalidade.

Na Figura 4.2 pode-se observar o fluxo de execução do método proposto, explicitando cada um de seus passos. O método é composto de 5 passos principais: (1) consulta inicial, (2) realimentação de relevância (RF loop), (3) mineração das informações da realimentação, (4) mineração de regras de associação, (5) seleção de características, a qual remove características ruidosas e salienta as mais relevantes. Uma vez que o usuário decide finalizar e visualizar o resultado, consultas por similaridade podem ser realizadas com as características selecionadas.

$\mathrm{Na}$ fase de treinamento, inicialmente o conjunto de treinamento utilizado no processo de mineração de regras está vazio. No passo 1 o usuário realiza a consulta por similaridade inicial utilizando para isso uma imagem de consulta (centro de consulta) e então no passo 


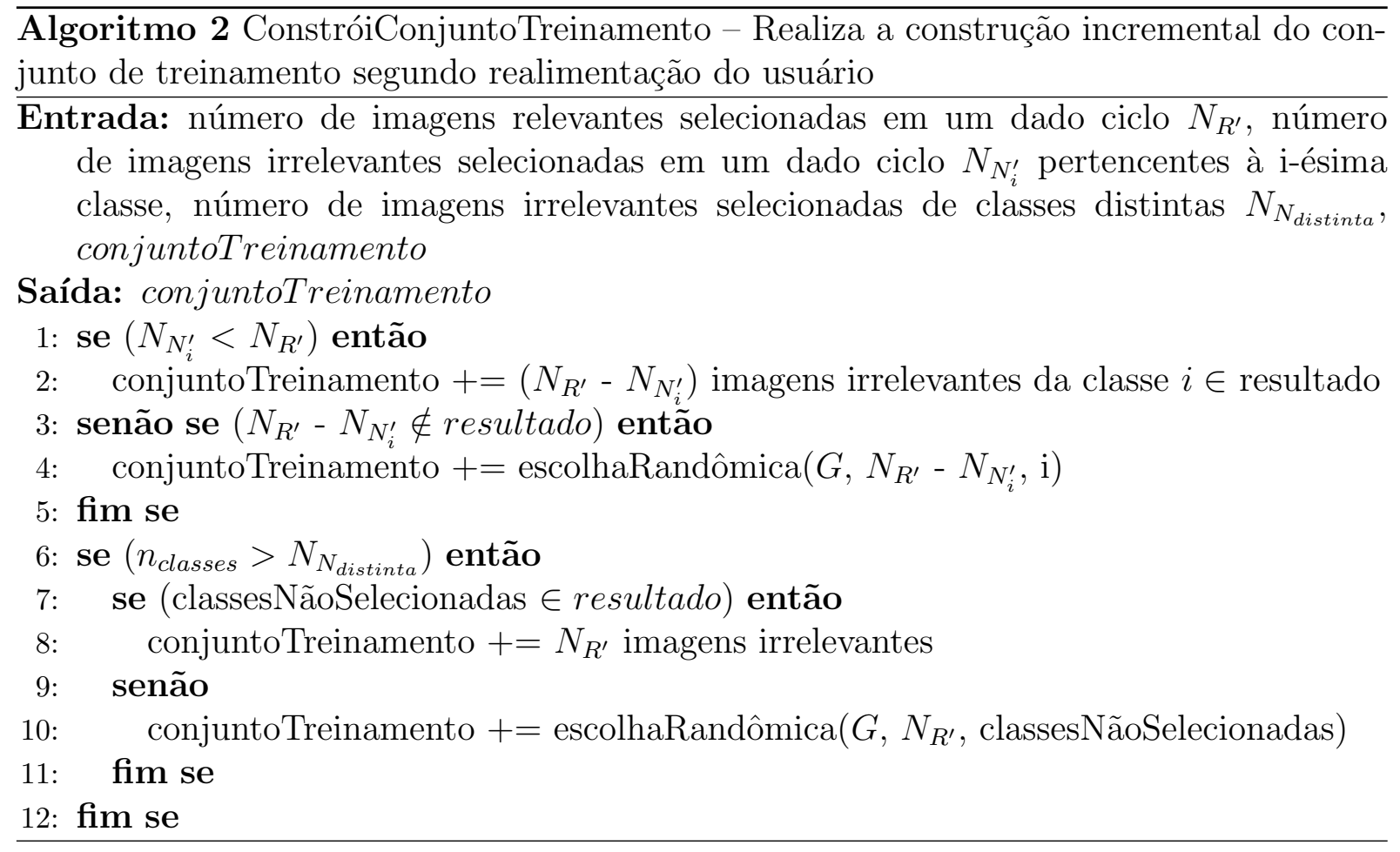

2 rotula as imagens retornadas em relevantes ou irrelevantes. À medida que o usuário rotula tais imagens, estas são incluídas no conjunto de treinamento. Dessa forma, no passo 3 tais informações são organizadas e utilizadas pelo algoritmo 2 para construir o conjunto de treinamento. Já no passo 4 o algoritmo de mineração de regras de associação recebe como entrada o conjunto de treinamento construído de acordo com as expectativas do usuário e inicia o processo de mineração de regras segundo o suporte e confiança definidos. Por fim, no passo 5, as regras de associação geradas são utilizadas no processo de seleção de características com o intuito de selecionar as características mais relevantes. Portanto, a seleção de características é realizada de acordo com a expectativa do usuário, uma vez que o conjunto de treinamento é iterativamente construído durante o processo de realimentação de relevância realizado no passo 2 .

Uma vez que o usuário pode permanecer no laço de realimentação do passo 2 enquanto não estiver satisfeito com os resultados retornados, o conjunto de treinamento aplicado ao processo de mineração de regras continua a ser incrementado até que o processo de realimentação atinja um ponto de saturação. Portanto, a cada ciclo de realimentação o conjunto de treinamento será refinado e consequentemente o processo de seleção de características também.

Dessa forma, o método proposto tem por intuito inserir o conhecimento de alto nível, fornecido pelo usuário a partir do processo de realimentação de relevância, no conjunto de treinamento utilizado no processo de mineração de regras de associação. Portanto, reduz-se o gap semântico ao mesmo tempo em que otimiza-se o processo de seleção de características. Além disso, o método permite a personalização do sistema, uma vez que 


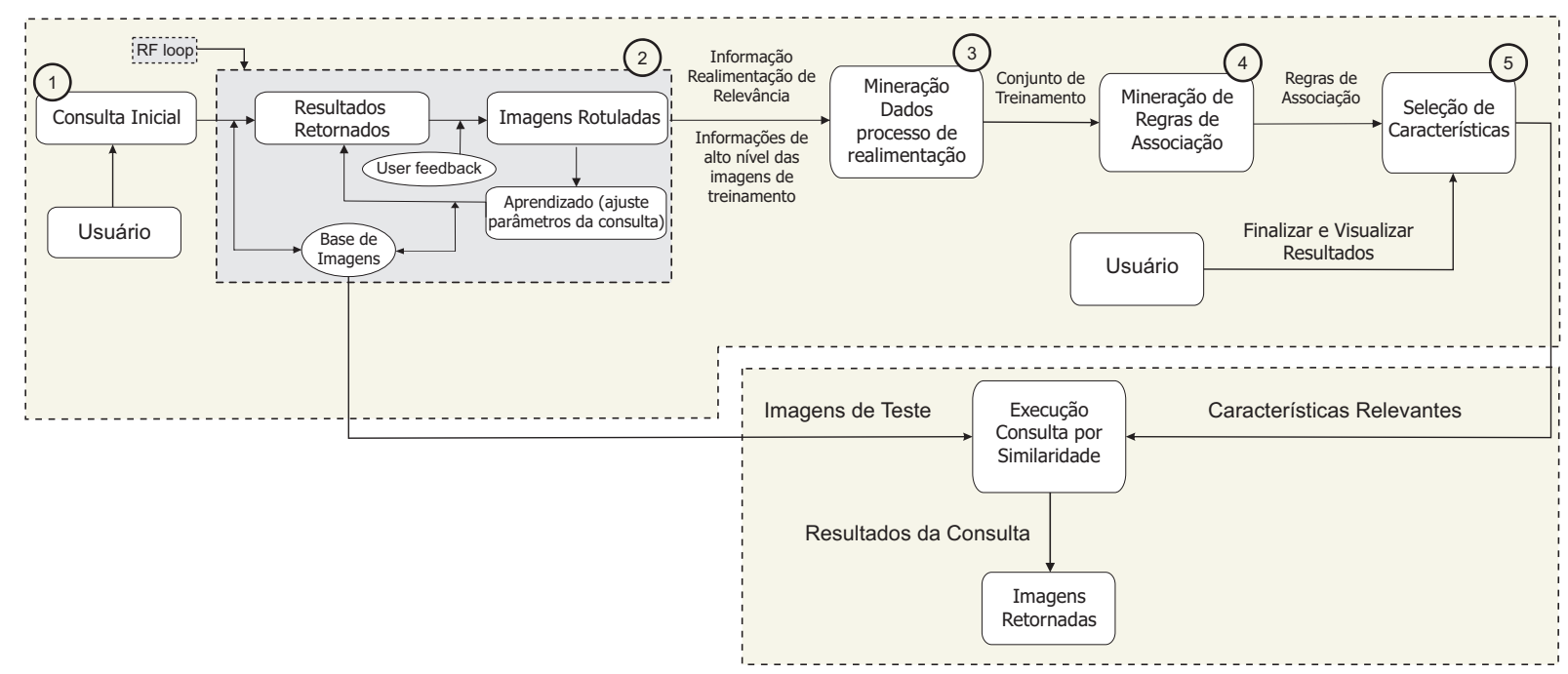

Figura 4.2: Fluxo de Execução do Método Proposto

diferentes usuários podem apresentar diferentes expectativas (ou seja, rotular diferentes imagens como relevantes ou irrelevantes), construindo, dessa forma, diferentes conjuntos de treinamento.

Outro ponto a ser ressaltado diz respeito ao método além de identificar as características mais relevantes de acordo com a expectativa do usuário, também realizar a redução da dimensionalidade dos vetores de características, diminuindo de forma considerável o problema da maldição da dimensionalidade, visto que o vetor de características é modificado a cada ciclo de realimentação por meio do processo de selecionar as características mais significativas e descartar as menos significativas.

\subsection{Experimentos}

Com o intuito de demonstrar a aplicação do método proposto gerou-se uma instância do mesmo, para a qual foi utilizado o método de realimentação de relevância baseado no movimentação de um único centro de consulta.

A presente subseção explicita os resultados obtidos por meio de diversos experimentos empregando o método proposto. Os extratores de características utilizados são os baseados em cor, textura e forma. Os extratores de cor referem-se aos histogramas convencionais de níveis de cinza. Já os extratores de textura dizem respeito à utilização dos descritores de Haralick, baseados na abordagem estatística e obtidos a partir das matrizes de co-ocorrência da imagem, os quais têm sido vastamente utilizados para a representação baseada em textura da imagem (Chaddad et al., 2011). Com relação às características de forma são utilizados os momentos de Zernike (Kejia et al., 2011). As funções de distância 
utilizadas para as consultas por similaridade foram as pertencentes à família Minkowski, dentre elas $L_{1}, L_{2}$, e $L_{\infty}$.

Foram realizados inúmeros testes com algumas bases de imagens e com os extratores de características citados, bem como com diferentes funções de distância. Para a realização dos experimentos foram utilizadas as bases explicitadas na seção subseqüente.

\subsubsection{Descrição das Bases de Imagens}

Visando a realização da análise do método proposto foram utilizadas duas bases de imagens médicas distintas, bem como uma base de dados de domínio público.

A primeira base de imagens utilizada, denominada $M R I$, contém 800 imagens que correspondem a exames de ressonância magnética $(\mathrm{RM})$, obtidas de vários tipos de exames realizados no Hospital das Clínicas de Ribeirão Preto (HCRP). Os exames de ressonância magnética ressaltam melhor os tecidos moles (músculos, gordura, entre outros). A profundidade dos pixels das imagens é de 8 bits, resultando em 256 tons de cinza, e as dimensões das imagens são 256 x 256. A base de imagens foi dividida em 4 classes de acordo com a região do corpo examinada e o tipo de corte especificado.

Na Figura 4.3 podem ser observados exemplos de imagens pertencentes à primeira base de imagens utilizada, oriundas de exames realizados referentes à ressonância magnética de algumas regiões do corpo, como também o corte tomado: (a) corte axial da cabeça; (b) corte coronal da cabeça; $(c)$ corte sagital da cabeça; $(d)$ corte sagital da espinha.

(a) Cabeça Axial

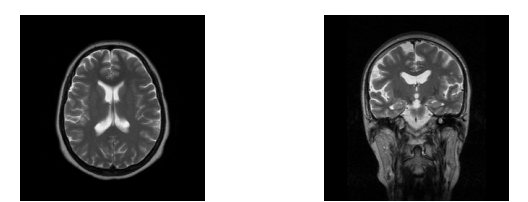

(b) Cabeça Coronal

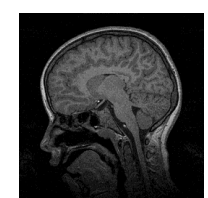

(c) Cabeça Sagital (d) Espinha Sagital

Figura 4.3: Exemplos de imagens de cada classe pertencentes ao conjunto de teste da base de imagens de ressonância magnética $M R I$.

A segunda base de imagens utilizada, denominada CTROIsPulmão, é uma coleção de 3248 imagens de regiões de interesse extraídas de imagens de Tomografia Computadorizada do Tórax, mais especificamente contendo lesões pulmonares. A profundidade dos pixels das imagens é de 8 bits, resultando em 256 tons de cinza, e as dimensões das imagens são 64 x 64 . A base de imagens foi dividida em 6 classes, sendo uma classe de imagens normais (ausência de lesões pulmonares) e 5 classes de padrões anormais que caracterizam lesões pulmonares difusas. É importante salientar que as lesões pulmonares apresentam alterações visuais menos óbvias, onde as possibilidades de dúvidas e as chances de erro na classificação são maiores. Dessa forma é extremamente importante captar o melhor possível a percepção do usuário especialista. A Figura 4.4 ilustra exemplos de imagens pertencentes a cada uma das classes da base de imagens: (a) Normal (590 imagens), (b) 
Consolidação (451 imagens), (c) Enfisema (502 imagens), (d) Espessamento (590 imagens), (e) Favo de Mel (520 imagens) e (f) Vidro Fosco (595 imagens).

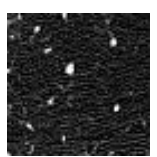

(a) normal

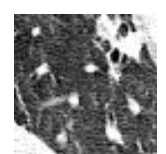

(b) consolidação

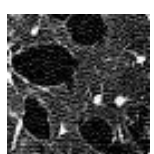

(c) enfisema

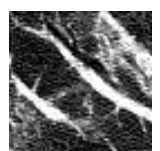

(d) espessamento

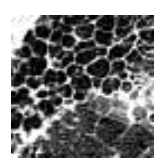

(e) favo de mel

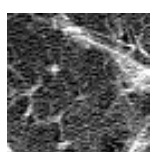

(f) vidro fosco

Figura 4.4: Exemplos de imagens de cada classe pertencentes ao conjunto de teste da base de imagens de ROIs de pulmão oriundas de exames de tomografia computadorizada CTROIsPulmão.

A terceira base utilizada, denominada SatImage, é de domínio público e disponibilizada a partir do repositório da Universidade da Califórnia em Irvine (UCI Machine Learning Repository). ${ }^{1}$ A base é uma coleção de 4435 imagens multiespectrais de satélite, mais especificamente composta por quatro bandas espectrais, duas bandas no intervalo visível do espectro (aproximadamente nas regiões verde e vermelha) e outras duas bandas próximas do infravermelho. Cada pixel das imagens é representado por 8 bits, onde a resolução espacial de cada pixel representa cerca de $80 \mathrm{~m}$ x 80m. As imagens apresentam dimensões de 2340 x 3380 pixels. $^{2}$ A base é dividida em 6 classes, especificadas como red soil, cotton crop, grey soil, damp grey soil, soil with vegetation stubble e very dump grey soil.

\subsubsection{Metodologia Experimental}

As imagens pertencentes às bases utilizadas foram processadas, extraindo suas características gerando os respectivos vetores de características de cada imagem, os vetores obtidos foram indexados utilizando o Método de Acesso Métrico (MAM) Slim-tree. Após a indexação dos vetores de características foram realizadas consultas por similaridade aos $\boldsymbol{k}$-vizinhos mais próximos, mais especificamente aos 80-vizinhos mais próximos e considerando 3 ciclos de realimentação para a construção incremental do conjunto de treinamento. Nessa fase de treinamento do método proposto, foi empregada a técnica de Rocchio fixando a constante de realimentação positiva como $\beta=1.0$ e a de realimentação negativa como $\gamma=0.5$.

Já para a geração dos gráficos de precisão e revocação da fase de teste foram realizadas consultas por similaridade aos $\boldsymbol{k}$-vizinhos mais próximos, utilizando todas as imagens de cada classe como centro de consulta. Dessa forma os gráficos de curvas de precisão e revocação elucidam a média dos resultados obtidos.

Com o intuito de popular de maneira incremental o conjunto de treinamento a partir das iterações do processo de realimentação de relevância, adotou-se uma estratégia particular descrita pelo Algoritmo 2. A cada ciclo de realimentação o usuário foi indagado

\footnotetext{
${ }^{1}$ http://archive.ics.uci.edu/ml/datasets.html

${ }^{2} \mathrm{http}: / /$ archive.ics.uci.edu/ml/datasets/Statlog+\%28Landsat+Satellite\%29
} 
a selecionar um número fixo de imagens relevantes $\left(N_{R^{\prime}}\right)$, bem como um número fixo de imagens irrelevantes $\left(N_{N^{\prime}}\right)$.

Por exemplo, considerando o primeiro ciclo de realimentação (Ciclo1), foi requisitado ao usuário selecionar as 5 imagens mais relevantes (imagens pertencentes à mesma classe da imagem de consulta - $N_{R^{\prime}}=5$ ) e 1 imagem irrelevante (imagem pertencente a classe distinta da imagem de consulta $-N_{N_{i}^{\prime}}=1$, onde $i$ é a i-ésima classe da base de dados). Vale ressaltar que o usuário analisou as 20 primeiras imagens retornadas.

Uma vez que é construído um conjunto de treinamento balanceado, quando o usuário realiza suas escolhas, ou seja, rotula as imagens como relevantes e irrelevantes e realimenta o sistema com tais escolhas, a imagem rotulada como irrelevante é utilizada para selecionar, do conjunto resultante de $k$ imagens, as irrelevantes restantes (e.g. 4 imagens) de mesma classe da rotulada para então compor o conjunto de treinamento. Tal seleção é realizada em ordem inversa da similaridade em relação à imagem de consulta, uma vez que quanto mais distintas as imagens em relação à imagem de consulta maior serão suas distâncias.

Dessa forma, constrói-se um conjunto de treinamento com o mesmo número de tuplas de imagens rotuladas como relevantes e irrelevantes. Esse processo é extrapolado para as diferentes imagens irrelevantes pertencentes às $i$ classes da base de imagens.

Por exemplo, considerando a base de imagens CTROIsPulmão (ver Seção 4.4.1) caso a imagem selecionada como irrelevante pertença à classe "Favo de Mel", serão selecionadas outras 4 imagens de mesma classe para compor o conjunto de treinamento.

No entanto, como pode-se perceber, existem algumas situações a serem consideradas com relação à criação incremental do conjunto de treinamento. Supondo que não existam imagens suficientes pertencentes à mesma classe das imagens rotuladas como irrelevantes no conjunto resultante para completar o número de imagens requeridas $\left(N_{R^{\prime}}-N_{N_{i}^{\prime}}\right)$ para construção de um conjunto de treinamento balanceado. Nesse caso, as imagens pertencentes à mesma classe das irrelevantes selecionadas são selecionadas randomicamente da base de imagens.

O mesmo caso pode ocorrer com relação à imagem de consulta, ou seja, não haver um número suficiente de imagens no conjunto resultante a serem selecionadas como relevantes pelo usuário. Dessa forma, o mesmo procedimento descrito para as imagens irrelevantes é aplicado. No entanto, tal caso poderá ter maior ou menor probabilidade de ocorrência de acordo com o valor especificado ao parâmetro $N_{R^{\prime}}$ e $k$, uma vez que quanto menor $N_{R^{\prime}}$ e maior $k$, menor a probabilidade de tal ocorrência. Como o conjunto de treinamento é inicialmente vazio e construído de maneira incremental a partir das realimentações realizadas, o valor inicial de $N_{R^{\prime}}$ no caso em questão é baixo, no entanto isso não elimina outras variações do método proposto.

Outra situação passível de ocorrência é quando o número de classes de imagens $\left(n_{\text {classes }}\right)$ pertencentes à base é maior que o número de imagens irrelevantes de classes 
distintas selecionadas $\left(N_{N^{\prime} \text { distinta }}\right)$. Nesse caso, as classes de imagens que não foram selecionadas pelo usuário são selecionadas randomicamente do conjunto resultante de $k$ imagens até que seja alcançado o número requerido (i.e. $N_{R^{\prime}}-N_{N_{i}^{\prime}}$ ). Caso o número requerido não seja atingido, as imagens restantes para atingi-lo são selecionadas randomicamente da base de imagens. Por exemplo, considerando a base de imagens CTROIsPulmão, apenas uma imagem da classe "Favo de Mel" tenha sido selecionada como irrelevante, as outras imagens irrelevantes pertencentes às outras classes serão selecionadas de acordo com o processo descrito.

Nos experimentos realizados, na fase de treinamento, no primeiro, segundo e terceiro ciclos de realimentação foram selecionadas, 5, 10 e 15 imagens relevantes respectivamente. Para fins de comparação sempre foram realizados exatamente 3 ciclos de realimentação.

Dessa forma, o primeiro ciclo de realimentação irá gerar sempre um conjunto de treinamento com $5 \times n_{\text {classes }}$, onde $n_{\text {classes }}$ é o número de classes da base de imagens. O segundo ciclo irá gerar um conjunto de treinamento com $15 \times n_{\text {classes }}$, visto que este foi incrementado com 10 novas imagens. Por fim, o terceiro ciclo de realimentação irá gerar um conjunto de treinamento com $30 \times n_{\text {classes }}$ imagens, uma vez que foi incrementado em 15 novas imagens. É importante ressaltar que para os experimentos, foi atribuído um peso $w=-0.5$ às imagens irrelevantes.

\subsubsection{Resultados}

\subsubsection{Estudo de Caso 1}

As curvas de $\mathrm{P} \times \mathrm{R}$ das Figuras 4.5, 4.6 e 4.7 correspondem, respectivamente, aos experimentos realizados utilizando a base de imagens $M R I$ representada pelas características de Haralick, pelos histogramas de níveis de cinza e pelos momentos de Zernike. Nas Figuras 4.5, 4.6 e 4.7, os gráficos (a), (b) e (c) correspondem aos resultados obtidos utilizando as funções de distância $L_{1}, L_{2}$ e $L_{\infty}$, respectivamente, comparando as características originais (i.e. 140 características com relação aos descritores de Haralick e 256 características para histogramas de níveis de cinza e os momentos de Zernike) com o método proposto aplicando os primeiros 3 ciclos de realimentação de relevância na fase de treinamento, fato que realiza a redução do número de características por meio da seleção das imagens relevantes.

A Figura 4.5 ilustra as curvas de $\mathrm{P} \times \mathrm{R}$ obtidas utilizando os descritores de Haralick sobre a base de imagens $M R I$. Analisando o gráfico da Figura 4.5(a), pode-se observar que o método proposto não só claramente obteve um ganho de precisão nas consultas por similaridade, como também realizou uma considerável redução de dimensionalidade dos vetores de características. As precisões obtidas pelas características selecionadas nos ciclos 1, 2 e 3 praticamente empatam, apresentando um ganho de $20 \%$ quando comparadas com 


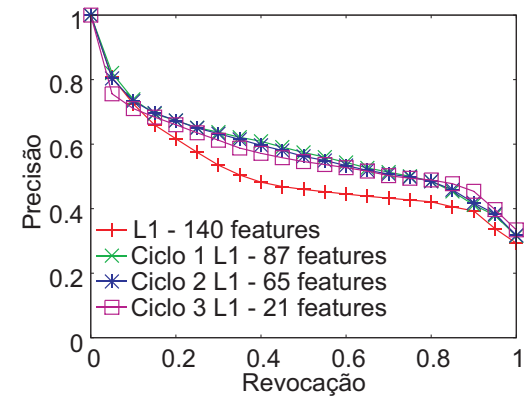

(a)

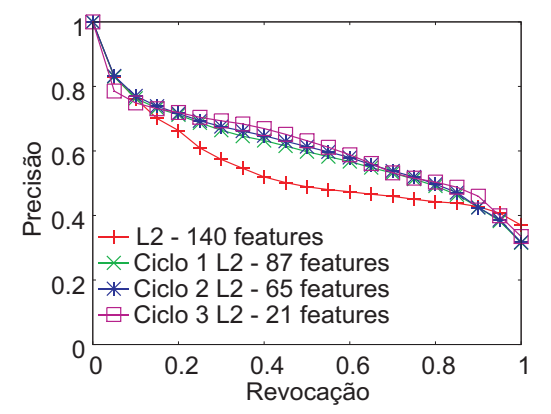

(b)

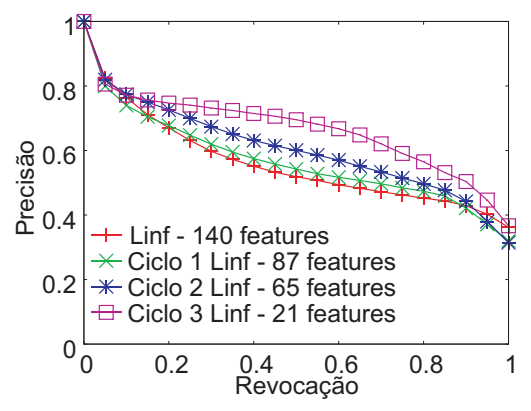

(c)

Figura 4.5: Gráficos de curvas de precisão e revocação, utilizando (a) $L_{1}$, (b) $L_{2}$, e (c) $L_{\infty}$, obtidos a partir da base $M R I$ representada pelos descritores de Haralick comparando o comportamento da recuperação utilizando as características originais com o método proposto utilizando 3 ciclos de realimentação.

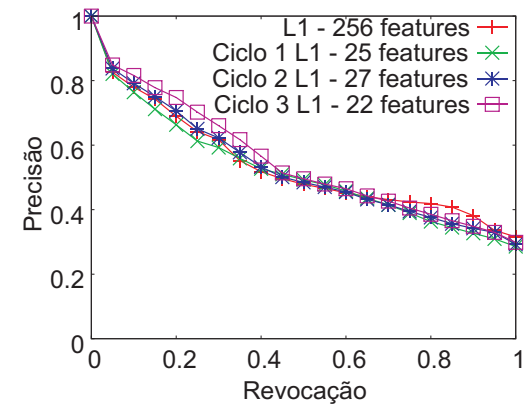

(a)

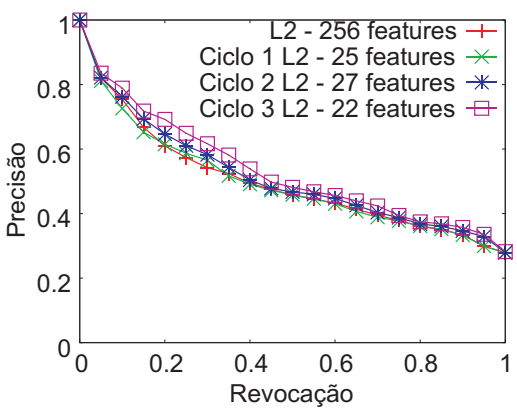

(b)

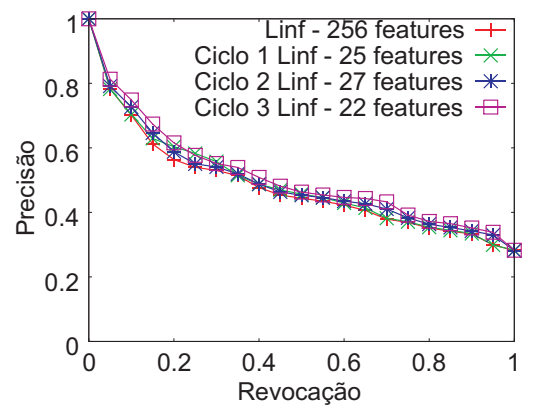

(c)

Figura 4.6: Gráficos de curvas de precisão e revocação, utilizando (a) $L_{1}$, (b) $L_{2}$, e (c) $L_{\infty}$, obtidos a partir da base $M R I$ representada pelo histograma de níveis de cinza comparando o comportamento da recuperação utilizando as características originais com o método proposto utilizando 3 ciclos de realimentação.

a precisão obtida pelas características originais (i.e. 140 características) para um nível de revocação de $40 \%$.

Analisando o gráfico da Figura 4.5(b), observa-se que o método proposto apresentou um ganho de precisão de até $38 \%$ considerando um nível de revocação de $40 \%$ em comparação com as características originais. Observando o gráfico da Figura 4.5(c), nota-se que o método atingiu um ganho de precisão de até $44 \%$ considerando o terceiro ciclo de realimentação para o mesmo nível de revocação, bem como realiza a redução da dimensionalidade dos vetores de características.

É importante ressaltar que o método proposto não só apresentou um ganho considerável de precisão em todos os casos, como também realizou uma redução de até 6.7 vezes menos dimensões no terceiro ciclo de realimentação. Dessa forma, reduzindo o custo de processamento e memória. Tais resultados corroboram que o método proposto melhora consideravelmente a precisão das consultas por similaridade, mesmo quando realiza a redução da dimensionalidade dos vetores de características.

A Figura 4.6 ilustra as curvas de $\mathrm{P} \times \mathrm{R}$ obtidas a partir do emprego dos histogramas de níveis de cinza na representação da base $M R I$. Analisando a Figura 4.6(a), pode-se ob- 
servar que o método proposto apresenta novamente um ganho com relação à precisão das consultas, cerca de $7 \%$ para um nível de revocação de $25 \%$, considerando o terceiro ciclo de realimentação, em comparação com a precisão obtida pelas características originais. A Figura 4.6(b) também ilustra um ganho de precisão do método proposto, aproximadamente de $16 \%$ para um nível de revocação de $20 \%$ em comparação com a precisão obtida pelas características originais. Na Figura 4.6(c), nota-se que no terceiro ciclo de realimentação o método atingiu um ganho de até $13 \%$ na precisão considerando um nível de revocação de 15\%. É importante salientar que nas Figuras 4.6 (a), (b) e (c), a dimensão original dos vetores de características (256 posições) foi reduzida em até 11.6 vezes.

Por fim, a Figura 4.7 ilustra as curvas de $\mathrm{P} \times \mathrm{R}$ obtidas a partir dos momentos de Zernike para a base $M R I$. Analisando a Figura 4.7(a), nota-se que o método proposto alcançou um ganho de até $12 \%$ de precisão quando comparado com as características originais, considerando um nível de revocação de 50\%. Na Figura 4.7 (b) novamente observa-se um ganho na precisão das consultas, cerca de $11 \%$ para um nível de revocação de $60 \%$. Já na Figura 4.7(c) as precisões praticamente empataram. No entanto, em todos os casos a dimensionalidade dos vetores de características foi reduzida em até 2.2 vezes em comparação à dimensionalidade do vetor de caraterísticas original (256 posições).
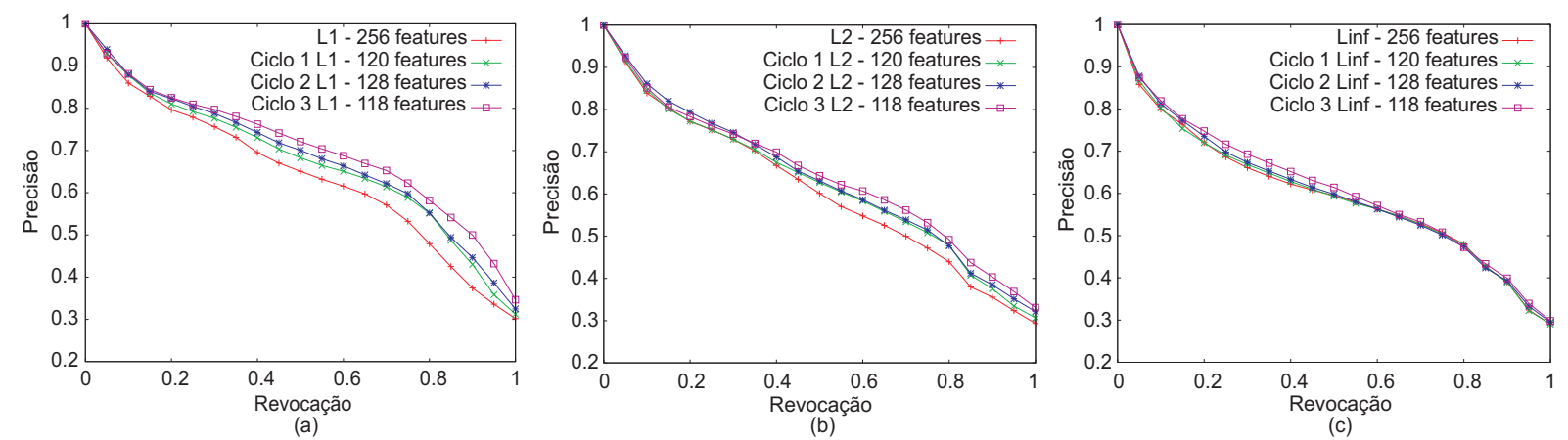

Figura 4.7: Gráficos de curvas de precisão e revocação, utilizando (a) $L_{1}$, (b) $L_{2}$, e (c) $L_{\infty}$, obtidos a partir da base $M R I$ representada pelos momentos de Zernike comparando o comportamento da recuperação utilizando as características originais com o método proposto utilizando 3 ciclos de realimentação.

\subsubsection{Estudo de Caso 2}

As curvas de $\mathrm{P} \times \mathrm{R}$ das Figuras 4.8, 4.9 e 4.10 correspondem, respectivamente, aos experimentos realizados utilizando a base de imagens CTROIsPulmão representadas pelos descritores de Haralick, os histogramas de níveis de cinza e os momentos de Zernike. Analisando os gráficos das Figuras 4.8(a), (b) e (c) nota-se que as precisões obtidas pela seleção de características realizada nos ciclos de realimentação 1, 2 e 3 praticamente empatam. No entanto, tais precisões em todos os casos subjugam as precisões obtidas pelas características originais, ao mesmo tempo em que realiza-se uma considerável redução da dimensionalidade dos vetores de características. Na Figura 4.8(a), o método proposto 
obtém um ganho de até $30 \%$ de precisão para um nível de revocação de $35 \%$ quando comparado com a precisão obtida pelas características originais. Considerando os gráficos das Figuras 4.8(b) e (c), o ganho de precisão obtido pelo método atinge cerca de até $49 \%$ e $72 \%$ respectivamente, considerando um nível de revocação de $35 \%$.

Além disso, o método promove a redução da dimensionalidade dos vetores de características em até 3.8 vezes já na primeira iteração dos ciclos de realimentação quando comparado com a dimensionalidade dos vetores originais. Pode-se observar que no presente experimento o primeiro ciclo de realimentação já alcançou os melhores resultados em termos de precisão e redução da dimensionalidade.
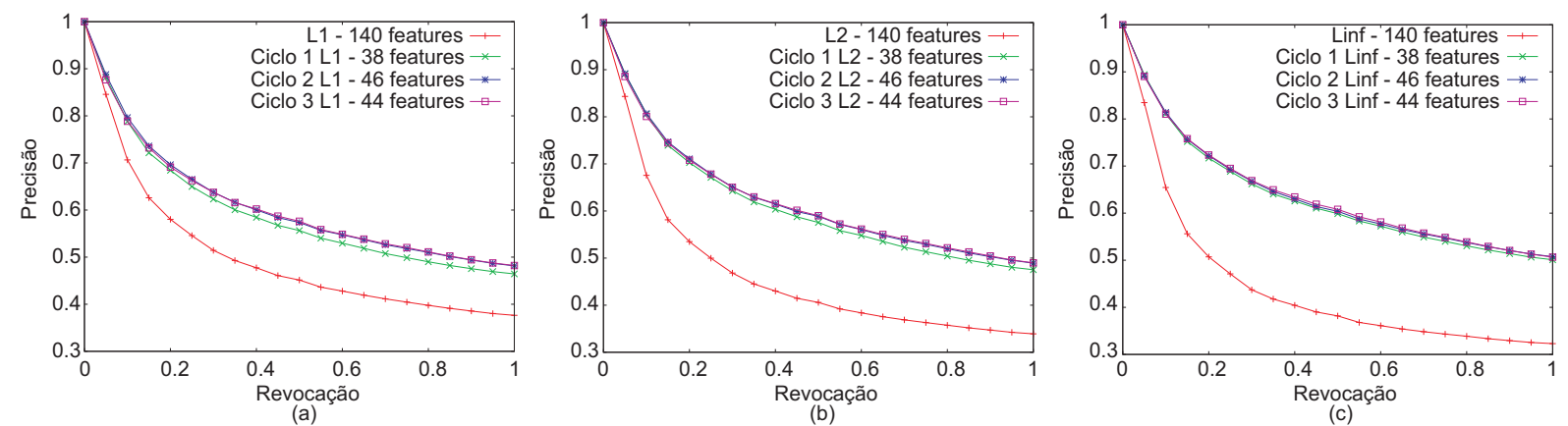

Figura 4.8: Gráficos de curvas de precisão e revocação, utilizando (a) $L_{1}$, (b) $L_{2}$, e (c) $L_{\infty}$, obtidos a partir da base CTROIsPulmão representada pelos descritores de Haralick comparando o comportamento da recuperação utilizando as características originais com o método proposto utilizando 3 ciclos de realimentação.

Já a Figura 4.9 ilustra as curvas de $\mathrm{P} \times \mathrm{R}$ obtidas a partir do emprego das características oriundas dos histogramas de níveis de cinza extraídas a partir da base de imagens CTROIsPulmão. Analisando os gráficos das Figuras 4.9(a), (b) e (c), pode-se constatar que a precisão obtida pelo método proposto praticamente empata com a precisão das características originais, sendo em alguns casos ligeiramente menor, como observa-se nas Figuras 4.9(a) e (b). No entanto, o método alcançou uma notável redução da dimensionalidade de até 2.6 vezes em comparação com a dimensão dos vetores originais (256 características). Tal fato ocorre uma vez que há um ponto de compensação entre a redução da dimensionalidade e o ganho de precisão. Neste caso, o ponto de saturação foi alcançado, ou seja, com uma maior redução da dimensionalidade a precisão apresenta perdas.

A Figura 4.10 ilustra os resultados sobre as características oriundas dos momentos de Zernike. Pode-se observar que apesar das precisões obtidas nos gráficos das Figuras 4.10 (a), (b) e (c) praticamente empatarem, o método proposto alcançou uma considerável redução da dimensionalidade, cerca de 2.2 menos dimensões. O mesmo ponto de compensação citado anteriormente pode ser observado neste caso.

A Figura 4.11 ilustra um exemplo do retorno de uma consulta aos k-vizinhos mais próximos $(k=7)$, utilizando como centro de consulta a imagem no canto superior esquerdo. 


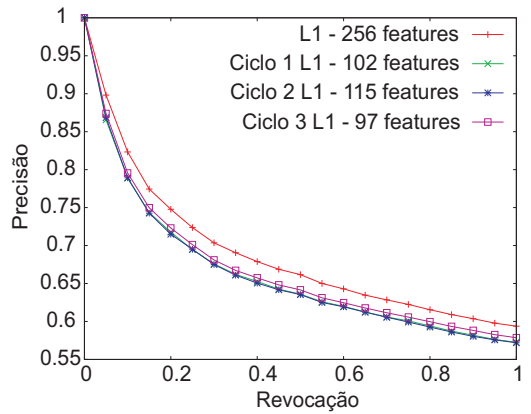

(a)

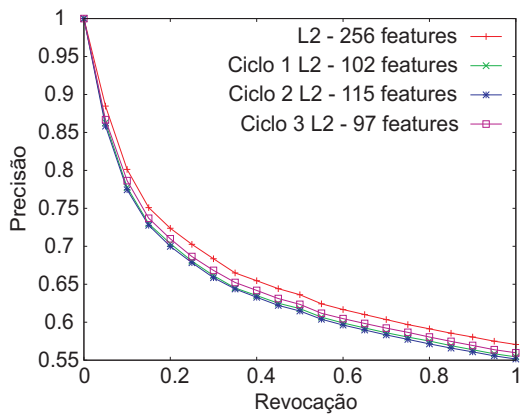

(b)

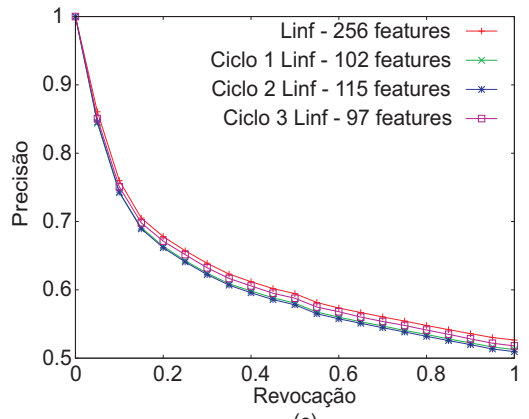

(c)

Figura 4.9: Gráficos de curvas de precisão e revocação, utilizando (a) $L_{1}$, (b) $L_{2}$, e (c) $L_{\infty}$, obtidos a partir da base CTROIsPulmão representada pelo histograma de níveis de cinza comparando o comportamento da recuperação utilizando as características originais com o método proposto utilizando 3 ciclos de realimentação.

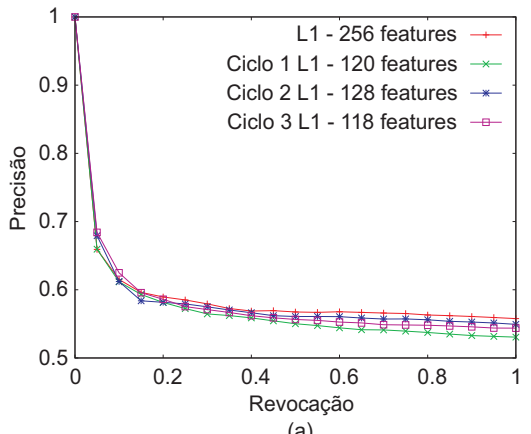

(a)

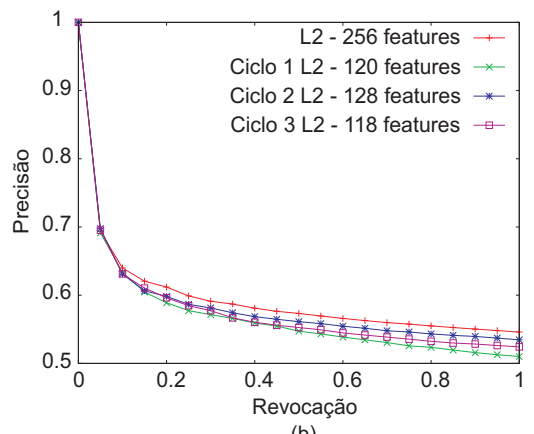

(b)

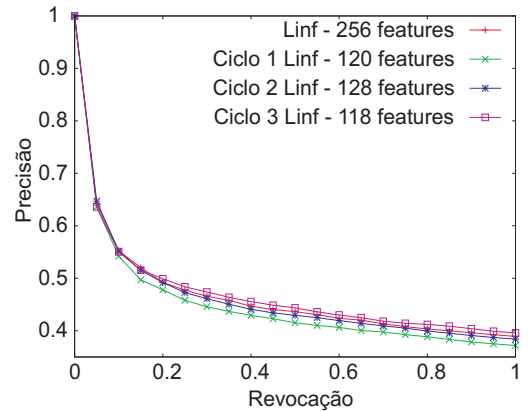

(c)

Figura 4.10: Gráficos de curvas de precisão e revocação, utilizando (a) $L_{1}$, (b) $L_{2}$, e (c) $L_{\infty}$, obtidos a partir da base CTROIsPulmão representada pelos momentos de Zernike comparando o comportamento da recuperação utilizando as características originais com o método proposto utilizando 3 ciclos de realimentação.

A Figura 4.11(a) elucida o resultado obtido utilizando as características originais. Já a Figura 4.11(b) elucida o resultado obtido utilizando o método proposto com um número reduzido de características. As imagens ressaltadas pela borda vermelha são referentes a falsos positivos ${ }^{3}$. Pode-se observar claramente uma significante melhora nos resultados obtidos, com a diminuição de falsos positivos, quando o método proposto é aplicado.

\subsubsection{Estudo de Caso 3}

As curvas de $\mathrm{P} \times \mathrm{R}$ das Figuras 4.12 (a), (b) e (c) ilustram os resultados obtidos a partir da base SatImage de domínio público. Tais gráficos correspondem aos resultados obtidos utilizando as funções de distância $L_{1}, L_{2}$ e $L_{\infty}$, respectivamente, comparando as características originais providas pelo repositório UCI (i.e. 36 características) com o método proposto aplicando os primeiros 3 ciclos de realimentação de relevância.

\footnotetext{
${ }^{3}$ Um falso positivo é uma imagem retornada a qual é pertencente a uma classe que difere da classe da imagem de consulta.
} 

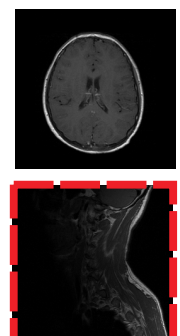
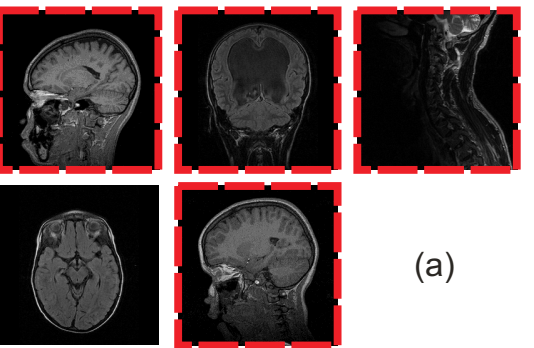
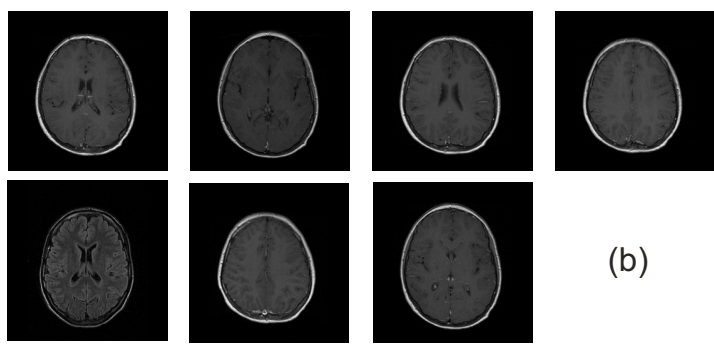

(b)

Figura 4.11: Exemplo da execução de uma consulta $k$-NN $(k=7)$, utilizando a imagem no canto superior esquerdo como centro de consulta. (a) Utilizando as características originais. (b) Utilizando o método proposto. As imagens ressaltadas pela borda vermelha dizem respeito a falsos positivos.

Analisando os gráficos da Figura 4.12 (a), utilizando a distância $L_{1}$, nota-se que as precisões obtidas pelo método nos diferentes ciclos apresentam valores próximos. No primeiro ciclo a precisão apresenta ligeira queda, quase imperceptível, quando comparada com a precisão obtida pelas características originais. Nos ciclos posteriores as precisões praticamente igualam-se às obtidas pelas características originais. No entanto, é importante salientar que a dimensionalidade dos vetores de características foi reduzida das 36 iniciais para 14, 26 e 25 considerando, respectivamente, os ciclos 1, 2 e 3.

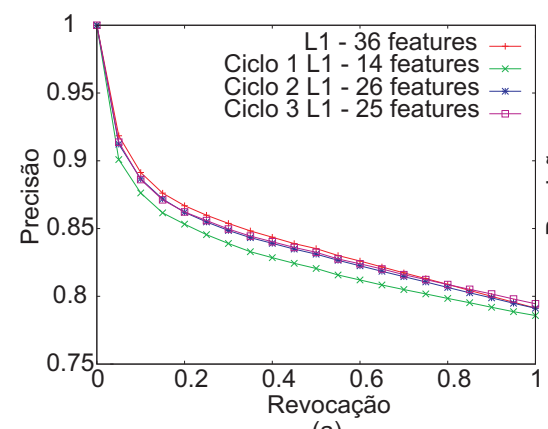

(a)

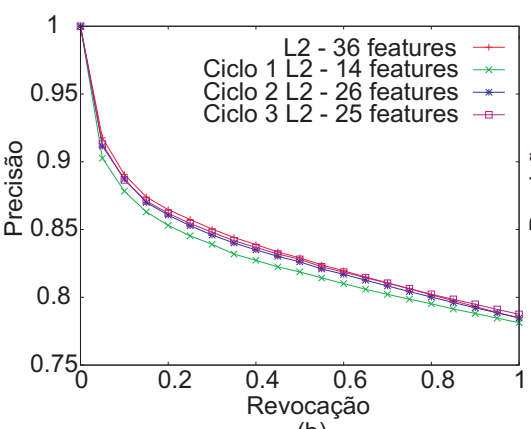

(b)

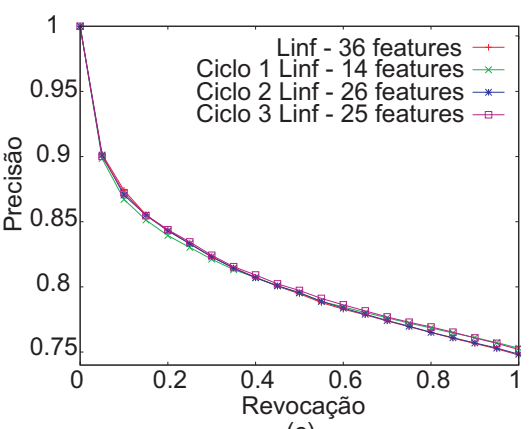

(c)

Figura 4.12: Gráficos de curvas de precisão e revocação, utilizando (a) $L_{1}$, (b) $L_{2}$, e (c) $L_{\infty}$, obtidos a partir da base SatImage comparando o comportamento da recuperação utilizando as características originais com o método proposto utilizando 3 ciclos de realimentação.

O mesmo comportamento foi observado nos gráficos da Figura 4.12 (b) utilizando a distância $L_{2}$. Já para os gráficos das Figura 4.12 (c) pode-se observar que a precisão obtida pelas características selecionadas pelo primeiro ciclo (i.e. 14 dimensões) praticamente empatam com a precisão obtida pelas característica iniciais. A partir dos resultados explicitados a partir da base SatImage demonstrasse novamente a eficiência e eficácia do método proposto, bem como a extensibilidade do mesmo para outros domínios de imagens. 


\subsubsection{Estudo de Caso 4}

Foram realizadas também análises baseadas nos requisitos de tempo para a execução das consultas por similaridade, uma vez que o método proposto reduz de maneira considerável a dimensionalidade dos vetores de características. Todos os valores apresentados foram obtidos por meio da média de 680 consultas por similaridade utilizando o conjunto de imagens $M R I$ com valor de $k$ fixado em 200. Os experimentos foram realizados utilizando o sistema operacional Windows Vista 32 bits, em um máquina com processador Intel Core 2 Duo $2.00 \mathrm{GHz}$, 3GB de memória RAM e HD SATA de 320GB e 5.400RPM. A Figura 4.13 apresenta os resultados de tais experimentos considerando: (a) características de textura (descritores de Haralick), (b) características obtidas por meio dos histogramas de níveis de cinza e (c) características de forma (momentos de Zernike).

Analisando as curvas da Figura 4.13 (a), pode-se notar que o método proposto realizou consultas por similaridade aproximadamente 6 vezes mais rápido, considerando, para tanto, as características selecionadas no terceiro ciclo de realimentação em comparação com o tempo obtido pelas características originais. Já a Figura 4.13 (b) ilustra um maior ganho no tempo de execução das consultas, cerca de 10 vezes mais rápido quando comparado com o tempo de execução requerido pelas características originais. Finalmente, na Figura 4.13 (c) o método proposto novamente alcança um ganho considerável com relação ao tempo de execução das consultas por similaridade, cerca de 4.1 vezes mais rápido em comparação com o tempo requerido pelas características originais.

Dessa forma, a partir dos resultados obtidos pode-se observar que o método proposto alcançou resultados consideráveis não só em termos da precisão das consultas por similaridade, como também em relação ao tempo de execução de tais consultas.

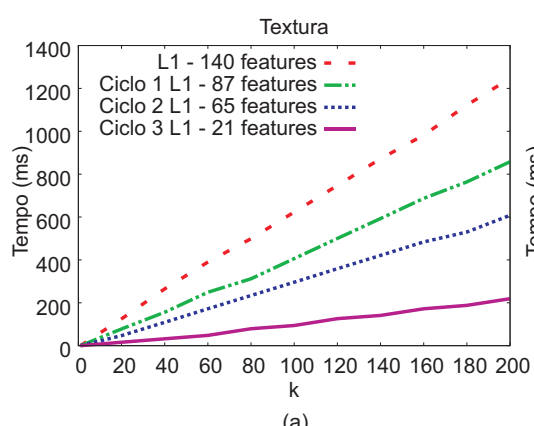

(a)

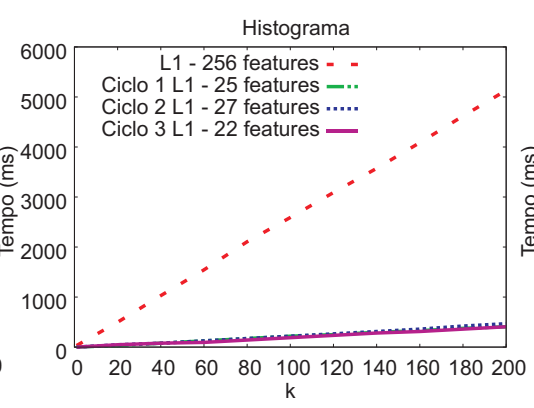

(b)

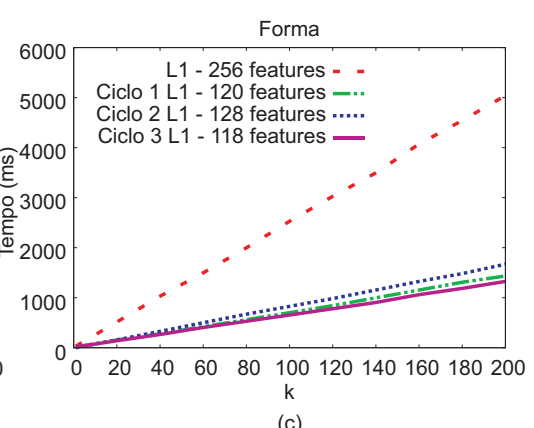

(c)

Figura 4.13: Gráficos ilustrando o tempo de execução das consultas k-NN utilizando a distância $L_{2}$ obtido sobre o conjunto de imagens $M R I$ representado pelas características oriundas dos extratores de (a) Haralick; (b) histograma de níveis de cinza; e (c) momentos de Zernike, comparando o tempo de execução das consultas utilizando as características originais e o método proposto empregando os 3 primeiros ciclos de realimentação.

É importante ressaltar que selecionando as características de acordo com a percepção do usuário é possível detectar que características são mais relevantes para determinados 
grupos de usuários. Dessa forma, introduzindo maior semântica ao processo, bem como auxiliando na criação/modificação de extratores de características mais adequados à percepção do usuário. Tal fato é de extrema importância, uma vez que inúmeros trabalhos na área de CBIR propõem e aplicam métodos para seleção de características. Porém, tais trabalhos não levam em consideração a aplicação de tais métodos segundo a percepção do usuário.

Dessa forma, o presente método também possibilita a aplicação de diversas técnicas de seleção de características de acordo com a percepção do usuário, bem como a demanda do mesmo. A partir de tal fato, torna-se possível identificar quais técnicas de seleção de características adequam-se melhor a diferentes contextos e percepções, introduzindo assim maior semântica ao processo de seleção de características.

\subsection{Considerações Finais}

No presente capítulo foi proposto um novo método, com o intuito de melhorar a precisão de consultas por similaridade em imagens, o qual lida com os dois principais problemas intrínsecos a CBIR que são o gap semântico e a alta dimensionalidade dos vetores de características.

A partir da junção dos processos de realimentação de relevância e mineração foi possível maximizar a acurácia da mineração de regras de associação utilizada na seleção de características, inserindo o usuário no processo. A seleção de características realizada permitiu a redução dos vetores de características em até 6.7 vezes menos dimensões quando comparado com os vetores originais, calibrando o processo de mineração de acordo com a expectativa do usuário. Os experimentos realizados demonstraram que o método proposto melhorou a precisão das consultas de maneira efetiva, contribuindo para a diminuição do gap semântico, alcançando um ganho de precisão de até $72 \%$. Além disso, o método proposto permite a instanciação de outras categorias de técnicas de realimentação de relevância, bem como, outras técnicas de mineração de regras de associação e, consequentemente diferentes técnicas de seleção de características.

É importante ressaltar que o presente método não tem por intuito o tratamento de ruídos inseridos nas iterações de realimentação de relevância, como por exemplo, um dado usuário rotular como relevantes imagens extremamente distintas da imagem de consulta (i.e. não pertencentes à mesma classe da imagem de consulta), fato que pode levar a subespaços de interesse distintos daqueles pertencentes à classe da imagem de consulta. 
Capítulo

5

\section{Integrando Perfis de Usuário em sistemas CBIR médicos para responder consultas por similaridade perceptuais}

\subsection{Introdução}

écnicas relacionadas a CBIR têm sido extensivamente exploradas devido ao ace-
lerado crescimento do volume de imagens geradas e capturadas em diversas apli-
cações e ambientes distintos, bem como a necessidade de recuperação eficiente destas. O ambiente médico é um exemplo específico que produz diariamente um grande fluxo de informações, especialmente imagens digitais empregadas para diagnósticos.

No entanto, uma questão que ainda permanecia sem solução, diz respeito a como alcançar a similaridade perceptual. Para que seja possível realizar uma recuperação eficaz, deve-se caracterizar e quantificar a similaridade perceptual de acordo com a percepção do especialista da área em questão. Portanto, um sistema CBIR ideal deve retornar imagens que satisfaçam a expectativa dos usuários, e deve mensurar a similaridade entre as imagens de maneira consistente com a percepção humana. Entretanto, as medidas de similaridade em sua grande maioria não são perceptualmente consistentes com as expectativas de um dado usuário.

Dessa forma, o método proposto no presente capítulo foi concebido justamente para preencher esta lacuna, criando um suporte consistente para realizar consultas por similaridade em imagens médicas, mantendo a semântica da consulta desejada pelo usuário. 
O princípio de que usuários diferentes em momentos diferentes podem definir a relevância de resultados de maneira distinta (Aboulmagd et al., 2009) indica que o tratamento do gap semântico deva ser realizado individualmente para cada usuário, ou até mesmo, para um mesmo usuário porém em tempos distintos, visto que, um mesmo usuário pode definir diferentes relevâncias ao longo do tempo, uma vez que a percepção humana é baseada em conceitos e experiências adquiridas.

Trabalhos na área de consultas baseadas em textos vislumbram tal rumo (Ioannidis \& Koutrika, 2005; Koutrika \& Ioannidis, 2005; Wang et al., 2006; Zhou \& Aggarwal, 2004), o qual é definido na literatura como personalização de consultas. A personalização de consultas (query personalization) baseia-se no aperfeiçoamento dinâmico de uma consulta fundamentado nas preferências armazenadas em um perfil de usuário (user profile) (Poo et al., 2003), com o intuito de fornecer respostas personalizadas para cada usuário.

No presente capítulo é introduzido um novo método eficaz para o levantamento de perfis de usuário, o qual é empregado para ajustar a avaliação de similaridade, identificando as funções de distância que melhor se adequam com a percepção do usuário. O método proposto captura de maneira interativa a intenção dos usuários de acordo com a similaridade entre imagens médicas durante mecanismos de realimentação de relevância, com o intuito de auxiliar o especialista a recuperar imagens que contemplem suas expectativas. É importante ressaltar que o método é integrado de maneira transparente ao processo de recuperação de imagens baseada em conteúdo, melhorando consideravelmente a eficácia da recuperação com o mínimo de esforço por parte do usuário.

Vale enfatizar que o presente método, bem como respectivos resultados foram publicados na forma de artigo científico na SPIE Medical Imaging Conference: Computer-Aided Diagnosis (Bugatti et al., 2011a).

\subsection{Conceitos Relacionados}

\subsubsection{Análise de Imagens na Área Médica}

Um fator extremamente importante e que deve ser considerado na prática clínica do diagnóstico por imagem diz respeito à modalidade dos exames radiológicos. Dentre os mais comuns estão: Raio X (RX), Tomografia Computadorizada (CT) e Ressonância Magnética (MR). Cada um desses exames geram imagens digitais. Porém, os princípios físicos e computacionais de formação dessas imagens são muito distintos. Esses princípios físicos por sua vez trazem consigo uma semântica, uma informação sobre determinadas características de cada tecido representado na imagem. Por exemplo, imagens de CT são geradas a partir da quantificação do poder de atenuação (absorção) do tecido frente a um feixe de fótons de Raio-X. Esses raios são atenuados pelos tecidos de acordo com 
suas propriedades, estrutura e densidade. Para maiores detalhes com relação às diferentes modalidades e princípios de formação das imagens médicas ver (Suetens, 2009).

No decorrer de sua formação, os médicos aprendem a discernir tais diferenças e semânticas intrínsecas aos vários exames radiológicos. Tal estudo, denominado semiologia médica, abrange a utilização de metodologias e terminologias para a descrição de lesões (achados radiológicos) encontradas nos exames para então gerar a construção de um raciocínio clínico. Por exemplo, ao laudar um exame, um médico radiologista geralmente procura por possíveis variações nas imagens, tais como:

- Presença de densidades anormais;

- Deslocamento da estrutura normal;

- Aumento de tamanho relativo à estrutura normal;

- Destruição da estrutura normal ou bordas.

Tais critérios estão intimamente relacionados com a densidade do tecido examinado, bordas e contornos (regular ou irregular), formas (esféricas ou espiculares) e tamanho de estruturas pertencentes à imagem. Todos os critérios apresentados dizem respeito a possíveis características visuais apresentadas pelas lesões em imagens.

A partir de questionamentos realizados com radiologistas e residentes do Hospital das Clínicas de Ribeirão Preto (HCRP-USP), pôde-se concluir que alguns critérios presentes na análise de imagens requerem um maior tempo de apreciação quando comparados com outros, uma vez que representam perturbações mais tênues na imagem, ou seja, apresentam alterações visuais menos óbvias. Dessa forma, tais critérios geram maiores incertezas no diagnóstico entre os radiologistas. Tal fato, considerando por exemplo imagens de pulmão, gera a necessidade do desenvolvimento de técnicas para a classificação e identificação de lesões pulmonares (Depeursinge et al., 2008). O mesmo é observado para o domínio de imagens de exames de mamografia.

No entanto, não há na literatura muitos estudos para investigar a correlação entre os resultados de CBIR e a percepção de semelhança dos radiologistas em imagens pulmonares, bem como as oriundas de exames de mamografia. Em (Kim et al., 2010b) é realizado um estudo preliminar utilizando redes neurais com respeito à semântica de similaridade em imagens de pulmão.

Diversas doenças podem ser caracterizadas pela presença de alterações comuns na estrutura normal da região. Essas alterações são denominadas pelos especialistas de "achados clínicos".

Definição: Achados Clínicos - lesões, anormalidades ou alterações na estrutura normal de um tecido observado nas imagens médicas de exames radiológicos. Podem carregar consigo informações sobre manifestações de doenças, disfunções ou outra 
anormalidade que evidencie uma doença. Cada achado está diretamente relacionado a parâmetros visuais característicos.

Dentre os achados clínicos presentes, por exemplo, em imagens de pulmão, os principais estão explicitados na Tabela 5.1, a qual sumariza os aspectos e alterações visuais que tais achados causam nas imagens de pulmão, bem como suas descrições fisiopatológicas ${ }^{1}$ segundo (Souza Jr. et al., 2002). Já considerando imagens de mamografia os, principais achados dizem respeito à presença de calcificação ou massa, os quais por sua vez também apresentam diferentes características visuais (Tang et al., 2009).

Tabela 5.1: Tabela explicitando exemplos de achados clínicos em Tomografia Computadorizada de pulmão.

\begin{tabular}{|c|c|c|c|}
\hline Achado & Descrição Fisiopatoló gica & Descrição Visual & Exemplo \\
\hline 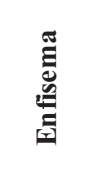 & $\begin{array}{l}\text { Aumento permanente do espaço } \\
\text { aéreo distal ao bronquíolo } \\
\text { terminal, acompanhado de } \\
\text { destruição das paredes alveolares. } \\
\text { Região focal de baixa atenuação, } \\
\text { usualmente sem paredes definidas }\end{array}$ & $\begin{array}{l}\text { - região mais escura (bolha escura) } \\
\text { - sem contornos visíveis } \\
\text { - distribuição não-uniforme }\end{array}$ & \\
\hline 导 & $\begin{array}{c}\text { É a substituição do ar alveolar por } \\
\text { transudato, exudato ou tecido. } \\
\text { Aumento homogêneo da } \\
\text { atenuação do parênquima } \\
\text { pulmonar }\end{array}$ & $\begin{array}{c}\text { - manchas claras } \\
\text { - distribuição homogênea } \\
\text { - contorno es curo nas margens dos } \\
\text { vasos e nas paredes das vias aéreas }\end{array}$ & \\
\hline 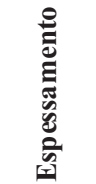 & $\begin{array}{c}\text { Opacidade linear fina que } \\
\text { corresponde ao septo interlobular. } \\
\text { Aumento na espessura do septo } \\
\text { interlobular, usualmente causado } \\
\text { por edema, infiltração celular ou } \\
\text { fibrose }\end{array}$ & $\begin{array}{l}\text { - aumento da espessura do septo } \\
\text { Interlobular com opacidade linear } \\
\text { fina (linha fina e mais clara) }\end{array}$ & \\
\hline 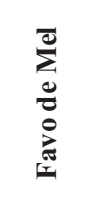 & $\begin{array}{l}\text { Cistos pulmonares de destruição } \\
\text { fibrosados, simbolizando perda } \\
\text { completa da arquitetura acinar e } \\
\text { bronquiolar. Espaços císticos } \\
\text { agrupados, caracterizados por } \\
\text { paredes bem definidas, } \\
\text { geralmente espessas }\end{array}$ & $\begin{array}{l}\text { - Espaços císticos agrupados } \\
\text { - Usualmente com diâmetros } \\
\text { comparáveis, variando de } 0,3 \mathrm{a} 1 \mathrm{~cm} \\
\text { - Contornos bem definidos e } \\
\text { geralmente espessos } \\
\text { - Estrutura similar a um favo de mel }\end{array}$ & \\
\hline 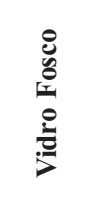 & $\begin{array}{l}\text { Aumento da atenuação pulmonar, } \\
\text { sem obscurecer as margens } \\
\text { brônquicas e vasculares, causado } \\
\text { por preenchimento parcial do } \\
\text { espaço aéreo, espessamento } \\
\text { intersticial ou colapso parcial } \\
\text { alveolar (entre outros) }\end{array}$ & $\begin{array}{l}\text { - Aumento da atenuação pulmonar } \\
\text { (regiões mais claras e com } \\
\text { distribuição não homogênea e não } \\
\text { concentrada) } \\
\text { - apresenta espessamento } \\
\text { intersticial }\end{array}$ & \\
\hline
\end{tabular}

Outro fator extremamente relevante na análise humana de imagens médicas diz respeito à subjetividade da avaliação, uma vez que para cada situação diagnóstica, o radiologista leva em consideração determinadas características visuais em detrimento de outras, ou seja, algumas características apresentam maior relevância perceptual. Tal subjetividade está intimamente relacionada com a experiência e a formação do médico. Dessa forma, é extremamente importante a captura do perfil de cada especialista com o intuito de atender suas expectativas.

\footnotetext{
${ }^{1}$ mecanismo que leva ao aparecimento de doenças.
} 


\subsubsection{Perfis de Usuário}

O primeiro ponto é: Por que utilizar perfis de usuário em sistemas de recuperação de imagens baseada em conteúdo? A resposta é: pois usuários diferentes, em momentos distintos, podem ter interpretações diferentes para uma mesma imagem, ou seja, o resultado obtido é relativo à intenção de cada usuário em um dado momento. Dessa forma é extremamente importante capturar a individualidade de cada usuário.

Portanto, para que seja possível mensurar de maneira eficiente a similaridade perceptual, é necessário o conhecimento prévio do usuário que irá utilizar o sistema, visto que, a similaridade depende dos aspectos que devem ser comparados na imagem que o usuário está buscando, ou seja, o tratamento do gap semântico deve ser realizado isoladamente para cada usuário.

Uma maneira de amenizar o problema de tal gap diz respeito à utilização de técnicas de realimentação de relevância. No entanto, em um ambiente real, é extremamente difícil garantir que um número considerável de usuários realizem tal realimentação voluntariamente. Além disso, a partir de um certo número de iterações, as técnicas de realimentação atingem um ponto de saturação não apresentando ganho de precisão.

Para amenizar tais problemas e possibilitar manter a semântica da consulta desejada por cada usuário individualmente é imperativo capturar e armazenar o perfil de usuários do sistema. A cada realimentação realizada pelo usuário é efetuada a atualização de seu perfil, armazenando sua sessão de consulta (query session).

É importante ressaltar que as interpretações perceptuais de uma dada imagem dependem de cada usuário, do contexto ao qual este está inserido, bem como da aplicação. Dessa forma, não existem modelos genéricos aplicáveis a todos os usuários.

Esse fato também motivou o presente capítulo, visto que, o aprendizado persistente das preferências dos usuários e posterior mineração destas, pode derivar conceitos parametrizados e personalizados para um usuário ou tarefa específica, como por exemplo, a parametrização de funções de distância.

De maneira geral, o levantamento do perfil de usuários pode ser dividido em duas abordagens principais denominadas perfil estático (static profiling) e perfil dinâmico (dynamic profiling) (Poo et al., 2003).

\subsubsection{Perfis de Usuários na Recuperação de Dados}

Um perfil de usuário pode ser visto como uma coleção de informações pessoais (i.e. um modelo do usuário). Dessa forma, tais perfis podem ser utilizados por um sistema com o intuito de explorar as preferências dos usuários. Os perfis de usuários são comumentemente utilizados em máquinas de busca para prover recomendações a partir das preferências de usuários utilizando por exemplo técnicas denominadas collaborative filtering (Adomavi- 
cius \& Tuzhilin, 2005), as quais agrupam e organizam usuários de acordo com interesses similares.

Considerando o domínio médico, o conceito de perfis de usuário pode ser utilizado com o intuito de capturar e manter a semântica de um dado especialista em um domínio específico de imagens. Dessa forma, por exemplo, outros usuários como médicos residentes podem beneficiar-se de tal fato para aprimorar o processo de aprendizado com relação a um domínio de imagens, uma vez que esses podem observar qual foi a percepção do especialista.

A primeira fase do processo de levantamento dos perfis de usuário diz respeito à coleta preliminar de informações dos usuários. Nas subseções subsequentes serão explicitadas as duas principais categorias de perfis de usuário.

5.2.2.1.1 Perfil Estático: A abordagem de perfil estático, como o próprio nome explicita, diz respeito à análise das características estáticas e conhecidas à priori dos usuários. Tais informações geralmente são obtidas e fornecidas diretamente pelos usuários, por meio de formulários (e.g. entrevistas ou preenchimento de questionários) ou registro eletrônico. Por exemplo, informações, tais como o domínio da imagem que o usuário busca (imagens de CT de pulmão, imagens de ressonância magnética do cérebro, entre outros), o grau de experiência do usuário (especialista sênior, médico residente). Considerando tais informações obtidas pelo perfil estático, pode-se capturar o interesse geral do usuário.

No entanto, o perfil estático apresenta algumas desvantagens. Sua natureza estática implica que o perfil possui vida útil limitada, visto que, o usuário pode modificar seus interesses com o passar do tempo. Além disso, o perfil estático não captura o comportamento do usuário (i.e. ações). Dessa forma, a qualidade do perfil estático degrada-se com o decorrer do tempo.

A abordagem de perfil estático pode ser estendida para um perfil estático colaborativo, o qual organiza explicitamente os usuários com preferências similares em grupos de interesse.

5.2.2.1.2 Perfil Dinâmico: A abordagem de perfil dinâmico, ao contrário da abordagem estática, realiza uma análise das atividades e ações do usuário, com intuito de determinar quais são seus interesses, gerando, dessa forma, um perfil comportamental.

O perfil dinâmico reúne as informações com base nas alterações dinâmicas geradas de acordo com o comportamento do usuário durante a tarefa de busca. Posteriormente, tais informações são filtradas, a fim de identificar as mais representativas para geração do perfil do usuário. Para isso, o sistema deve monitorar as ações do usuário e rastrear todo o processo de busca capturando assim os hábitos do mesmo. Outro ponto importante da aplicação dos perfis dinâmicos diz respeito ao fato da grande maioria dos usuários não lembrarem claramente de todos os seus passos realizados no processo de busca. Por esse 
motivo, é vital armazenar um histórico das buscas do usuário, com o intuito de manter a informação de como um determinado usuário alcançou os resultados que tanto almejava.

Apesar das ações do usuário serem coletadas em tempo real, os interesses gerais do usuário não são capturados. Assim, é necessário agregar na mesma arquitetura as vantagens do perfil estático e dinâmico, já que uma complementa a outra. Alguns trabalhos como (Hoi \& Lyu, 2004) propõe a utilização de informações de perfil de usuário para acelerar o processo de realimentação de relevância ou para detectar agrupamentos semânticos no espaço de características (Zhou \& Huang, 2003). Entretanto, tais trabalhos negligenciam a importância de um dos pilares de um sistema CBIR que é a função de distância utilizada na consulta por similaridade em relação à percepção do usuário. Diferentemente destes trabalhos, o presente método propõe estratégias de levantamento de perfis, a fim de encontrar a função de distância mais adequada segundo a percepção do usuário, conforme será descrito na próxima seção.

\subsection{Método CBIR Orientado à Percepção}

A similaridade perceptual depende de qual aspecto da imagem que o usuário está procurando. Por exemplo, uma determinada imagem pode apresentar achados clínicos com padrões visuais distintos. Portanto, diferentes especialistas podem estar interessados em diferentes achados clínicos, empregando, portanto, critérios de similaridade distintos. Para conseguir uma recuperação eficaz que cumpra com as expectativas do usuário, o mecanismo de recuperação deve quantificar e caracterizar adequadamente a similaridade perceptual de cada indivíduo. Para isso, o sistema pode tirar proveito do levantamento de perfis de usuários para capturar e mapear a similaridade perceptual destes.

Por exemplo, em exames de Tomografia Computadorizada (CT) pulmonar, vários tipos de lesões pulmonares exigem diferentes tipos de análises do especialista. Geralmente as mudanças sutis nas lesões são difíceis de identificar. Estes tipos de lesões geram dúvidas entre os radiologistas (Depeursinge et al., 2007).

A presente seção descreve a abordagem proposta para capturar informações que refletem a noção de similaridade do usuário e adapta-se ao processo de busca para melhor atender as expectativas do mesmo. O método proposto compreende o levantamento de perfis de usuários e a adaptação da avaliação de similaridade de acordo com a percepção do usuário capturada. Além disso, o método é integrado de maneira transparente à arquitetura tradicional CBIR.

\subsubsection{Supervisão e Levantamento dos Perfis de Usuários}

No campo da medicina, o conceito de perfis de usuário pode ser utilizado para capturar e manter a semântica de um dado especialista em um determinado domínio de imagem. 
Além disso, outros usuários, como por exemplo, residentes podem beneficiar-se deste conceito para melhorar seu processo de aprendizagem, uma vez que eles podem observar a percepção do especialista sênior (por exemplo um médico radiologista). A estratégia de pesquisa proposta integra o perfil de informações estáticas e dinâmicas obtido do usuário por meio de uma interface típica CBIR.

No que diz respeito ao domínio médico, as informações do perfil estático incluem a especialidade (e.g. tórax, cérebro, etc), o nível de especialização (e.g. médico radiologista, residente, entre outros) e em que tipo de imagem o usuário está interessado. Tais informações são utilizadas para concentrar e focar a busca de um subconjunto específico de imagens armazenadas na base, uma vez que os departamentos de radiologia mantêm usualmente uma base de imagens centralizada provenientes de múltiplos exames, e, portanto de múltiplas especialidades.

Tais dados estáticos são recolhidos por meio da entrada manual de usuários ou importados a partir de registros de usuários existentes. Dessa forma, informações estáticas adicionais podem ser facilmente incluídas aos perfis, de acordo com a necessidade.

Já as informações dinâmicas são obtidas durante o processo de busca por similaridade. Primeiramente, a configuração inicial da consulta é capturada, incluindo o domínio da imagem de consulta. O domínio da imagem de consulta pode ser selecionado para carregar os parâmetros de similaridade global, como por exemplo o extrator de características e as funções de distância que fornecem, na média, a melhor precisão na recuperação das imagens. Posteriormente, a consulta é enviada ao sistema e o conjunto de imagens recuperadas também é armazenado no perfil. Neste ponto, caso o usuário finalize a busca, o sistema "questiona" o usuário se a recuperação foi útil e armazena no perfil a resposta do mesmo. Caso a busca inicial não tenha satisfeito as expectativas do usuário o mesmo pode refiná-la por meio do processo de realimentação de relevância. O único requisito, para tanto, é que o usuário selecione as imagens relevantes em ordem decrescente de acordo com sua percepção, ou seja, da mais similar para a menos similar de acordo com a imagem de consulta.

É importante ressaltar que o método não requer que o usuário forneça o grau de similaridade das imagens rotuladas, uma vez que segundo experimentos realizados em ambiente real, constatou-se tratar de uma alternativa confusa aos usuários, além de cansativa. Os especialistas demonstraram pré-disposição e preferência por uma forma sucinta e rápida para realimentação do sistema, essa consolidou-se como uma tendência em usuários no campo da medicina. Dessa forma, adotou-se a definição da ordem de similaridade das imagens relevantes, uma vez que apresentou boa aceitação por parte dos usuários, além de fornecer uma visão e captura adequada da percepção dos mesmos. A ordem de seleção das imagens relevantes é adicionada ao perfil e o processo de realimentação continua usualmente, até que o usuário esteja satisfeito. Tal processo é ilustrado na Figura 5.1. 


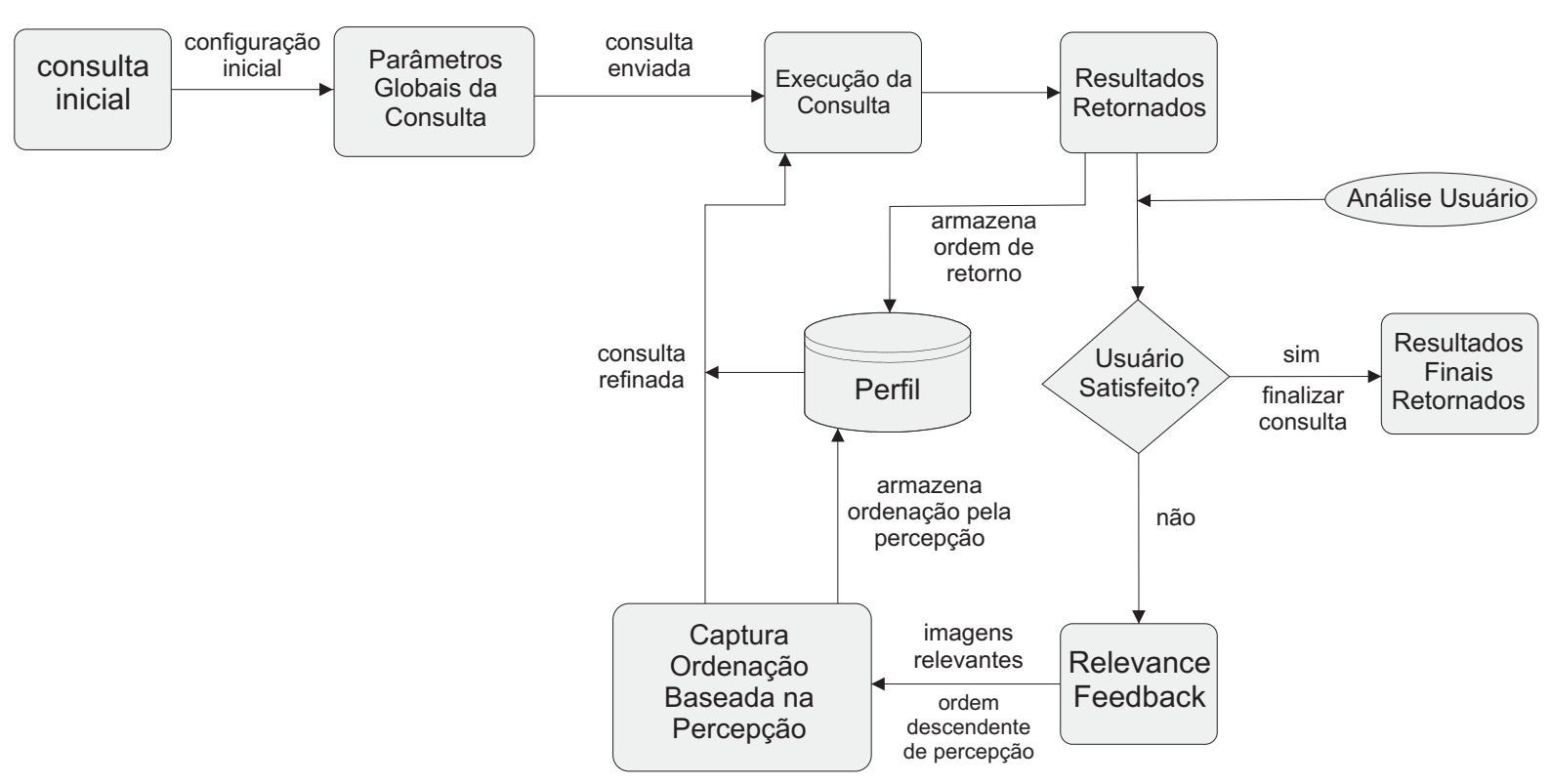

Figura 5.1: Fluxo de execução do processo de levantamento do perfil dinâmico.

É importante ressaltar que tal levantamento é realizado de modo implícito e com mínimo esforço por parte do especialista. Ou seja, o levantamento de tais perfis é realizado de modo automático e interno ao sistema durante o processo de consulta inicial e realimentação de relevância, ao se mapear as escolhas indicadas pelo usuário.

\subsubsection{Avaliação de Similaridade Guiada pela Percepção}

Os perfis de usuário permitem calibrar a avaliação de similaridade de acordo com a percepção de cada usuário. As informações oriundas dos perfis estáticos são utilizadas para identificar o subconjunto de pares função de distância/extrator de características que melhor se adequa ao espaço de busca de um dado usuário. Por exemplo, as características extraídas a partir das imagens de pulmão são distintas daquelas extraídas de imagens do cérebro. Dessa forma, identificar o contexto da busca é extramente importante. No que diz respeito às funções de distância, a seleção da melhor distância dentre as disponíveis para uma determinada situação não é um processo trivial. Tal fato deve-se à não existência de uma concordância geral sobre qual função de distância deve ser utilizada para a grande maioria de extratores de características no campo da medicina. Além disso, usuários distintos podem obter melhores resultados aplicando funções de distância distintas sobre o mesmo conjunto de dados.

O método proposto utiliza também informações do perfil dinâmico para escolher a função de distância que melhor representa a percepção do mesmo. Para atingir tal objetivo foi definido o Fator de Percepção (Perception Factor), que se trata de uma medida para quantificar a percepção do usuário baseada na comparação entre a ordem de retorno da 
consulta e a ordem de seleção das imagens relevantes. Seja $M$ o conjunto de imagens rotuladas pelo usuário como relevantes. O Fator de Percepção de uma imagem $m \in M$ em uma determinada consulta é definido como:

$$
\operatorname{PerceptionFactor}(m, \varphi)=\frac{1}{\epsilon_{m}} \times\left|s_{m}-r_{m}\right|
$$

onde $s_{m}$ é a posição da imagem $m$ na lista de imagens ordenadas pela percepção do usuário (i.e. a ordem de seleção das imagens consideradas relevantes pelo usuário), $r_{m}$ é a posição de retorno de $m$ segundo um dado centro de consulta, bem como de acordo com uma dada função de distância $\varphi$ disponível no sistema (i.e. que vizinho mais próximo do centro de consulta é $m$ de acordo $\operatorname{com} \varphi$ ), e $\epsilon_{m}$ é uma penalidade atribuída à imagem. Tal penalidade prioriza as primeiras imagens selecionadas pelo usuário, uma vez que estas são mais similares à imagem de consulta, segundo a percepção do mesmo. Dessa forma, essa penalidade deve ser uma progressão crescente. Tal progressão pode ser linear, quadrática, e assim por diante. A partir da análise de diferentes progressões foi definido como formulação geral a progressão aritmética no intervalo fechado $[1,|M|]$ com gradiente igual a 1, como segue:

$$
\epsilon_{m}=\frac{|M|}{(|M|+1)-s_{m}}
$$

onde $|M|$ é o número de imagens rotuladas e $s_{m}$ é a posição da imagem $m$ na lista de imagens ordenadas pela percepção do usuário.

Com o intuito de sumarizar o Fator de Percepção de um dada recuperação, considerando-se as imagens selecionadas como relevantes foi proposta uma nova medida denominada Fator de Percepção Médio (Average Perception Factor - APF) de uma dada consulta, que é formalmente definida pela Equação 5.3.

$$
\operatorname{APF}(\varphi)=\frac{1}{|M|} \sum_{m \in M} \text { PerceptionFactor }(m, \varphi)
$$

O Fator de Percepção Médio fornece o nível de similaridade obtido pela consulta, segundo a percepção do usuário. Dessa forma, quanto mais próximo de 0 for o resultado da Equação 5.3, melhor o resultado (melhor a função de distância em relação a percepção do usuário). O APF está ligado à função de distância empregada no seu cálculo. Portanto, pode ser calculado para diversas funções de distância para uma dada consulta, e assim, identificará a função de distância que melhor se adequa à expectativa do usuário. Além disso, uma vez que o APF é baseado nos perfis de usuário, esse provê uma noção individualizada da similaridade, bem como pode ser utilizado para encontrar padrões de percepção entre os usuários. A Figura 5.2 ilustra o exemplo de cálculo do Fator de Percepção para uma dada imagem de consulta. 


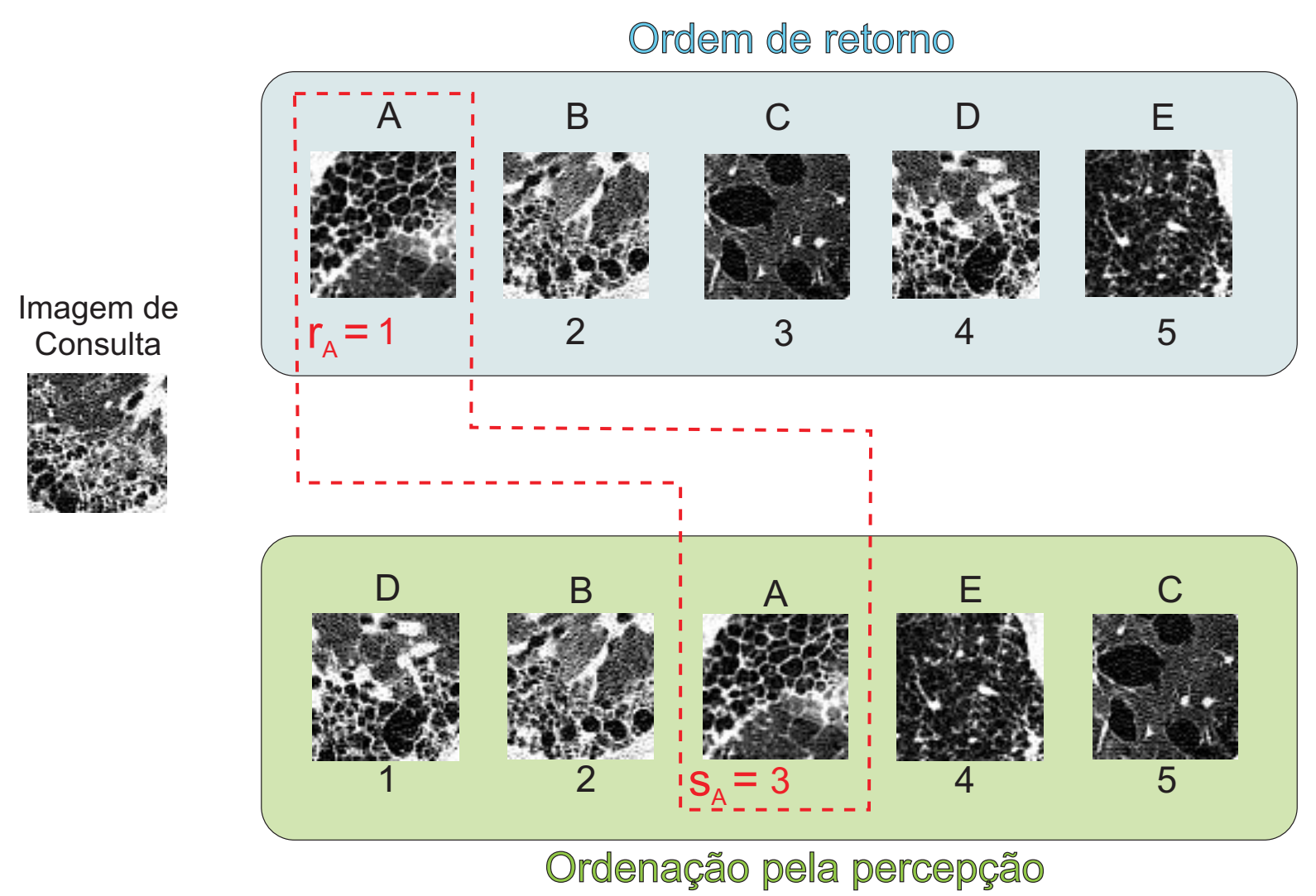

Figura 5.2: Exemplo de cálculo do Fator de Percepção.

\subsubsection{Integração de Perfis de Usuários em Sistemas CBIR}

O método proposto foi concebido para ser integrado de forma transparente a sistemas CBIR. De maneira geral, um sistema CBIR é composto por uma máquina de busca por similaridade, que está no centro do processo de execução da consulta, como ilustrado na Figura 5.3. Imagens pertencentes à base são processadas pelos extratores de características, normalmente em lote, gerando vetores de características que descrevem seu conteúdo intrínseco. Características extraídas das imagens são encaminhadas pela máquina de busca por similaridade para o módulo de funções distância, que também interage com rotinas de realimentação de relevância para refinar a busca, e apresenta as imagens recuperadas ao usuário.

Nesta arquitetura, o método proposto é encapsulado em um agente de perfil, que gerencia os perfis de usuário (em destaque na Figura 5.3). O agente inspeciona a máquina de busca por similaridade para coletar informações. Além disso, o mesmo fornece informações para orientar a avaliação da similaridade com base na percepção do usuário capturada. Tal processo é realizado de forma transparente computando o APF considerando as funções de distância disponíveis durante as consultas do usuário. Caso seja detectado que uma dada função de distância alcançou um APF menor que a distância 


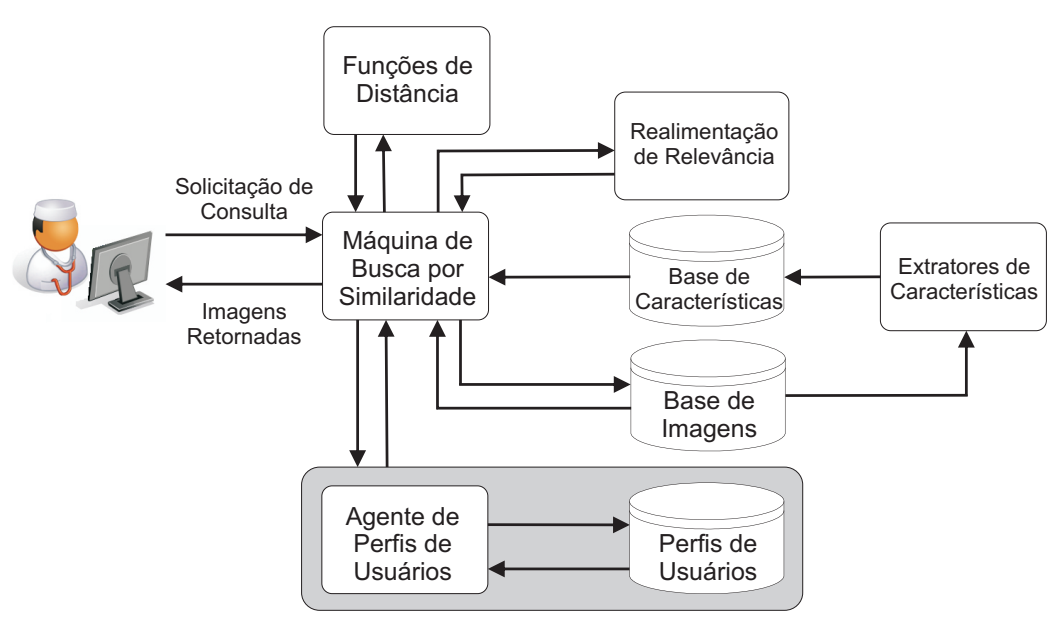

Figura 5.3: Integração da abordagem de perfis de usuários proposta para uma arquitetura típica de sistema CBIR.

corrente em utilização, a máquina de busca modifica dinamicamente a função de distância empregada e continua o processo de busca. Portanto, o método pode orientar a busca por similaridade considerando a percepção do usuário de maneira não intrusiva no ambiente CBIR.

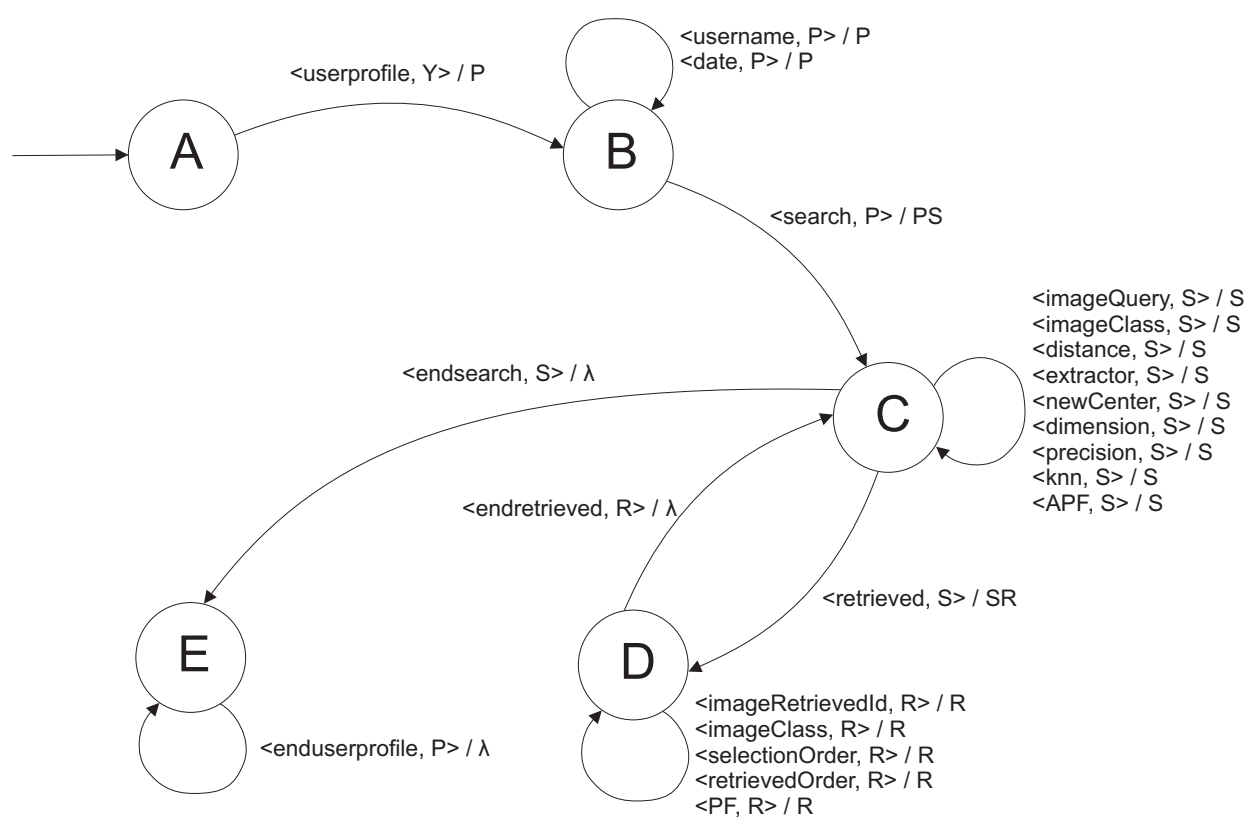

Figura 5.4: Autômato de pilha desenvolvido para o parsing dos perfis de usuário.

Visando manipular e alcançar ampla e acessível extensão dos perfis de usuários, foi desenvolvido um parser como parte integrante do agente de perfil. O parser desenvolvido decompõe a informação oriunda dos perfis em unidades estruturais as quais são organizadas em uma estrutura hierárquica. A Figura 5.4 ilustra a representação formal do autômato de pilha (AP) mapeado para o desenvolvimento do parsing dos perfis. Como pode ser observado foram propostas tags estruturais de abertura e fechamento com o in- 
tuito de definir a informação contida nos perfis em diferentes graus de organização. As tags propostas foram:

- userprofile e enduserprofile que abrangem as informações referentes aos usuários (por exemplo, username, date);

- search e endsearch que abrangem as informações referentes à busca realizada (por exemplo, query id, distance, extractor, APF, new Center, etc);

- retrieved e endretrieved que abrangem as informações referentes às imagens retornadas para uma dada consulta (por exemplo, image id, perceived similarity position, retrieved position, perception factor, etc).

É importante enfatizar que com o desenvolvimento do citado parser a extensão de novas informações a cada uma das tags citadas torna-se intuitiva e acessível. O autômato de pilha proposto para tal feito foi formalmente definido como uma sextupla:

$$
P=<\Sigma, \Gamma, S, S_{0}, \delta, B>
$$

onde $\Sigma$ é o alfabeto de entrada do AP; $\Gamma$ refere-se ao alfabeto da pilha; $S$ é o conjunto finito não vazio de estados do AP; $S_{0}$ é o estado inicial, $S_{0} \in S ; \delta$ é a função de transição de estados, $\delta: S \times(\Sigma \cup \lambda) \times \Gamma \rightarrow S \times \Gamma^{*} ; B$ é o símbolo da base da pilha, $B \in \Gamma$. Portanto, tais definições assumem, respectivamente, valores como:

- $\Sigma=\{$ username, date, distance, extractor, APF, perceived similarity position, perception factor, ... $\}$

- $\Gamma=\{\mathrm{P}, \mathrm{S}, \mathrm{R}, \mathrm{Y}\}$

- $S=\{\mathrm{A}, \mathrm{B}, \mathrm{C}, \mathrm{D}, \mathrm{E}\}$

- $S_{0}=\mathrm{A}$

- $B=\mathrm{Y}$

O funcionamento do autômato de pilha é definido pela função de transição $\delta$. A configuração do autômato é dada por uma tripla $\langle s, x, \alpha>$ na qual $s$ diz respeito ao estado corrente, $x$ refere-se à cadeia que falta ser processada, e $\alpha$ é o conteúdo corrente da pilha. Dessa forma, dado o autômato $P$ proposto e uma dada cadeia $x$ de caracteres (i.e. string) em $\Sigma, x$ é aceito por $P$ sse $\exists s \in S \mid\left\langle S_{0}, x, Y>\stackrel{*}{\rightarrow}<s, \lambda, \lambda\right\rangle$, onde $\lambda$ denota uma string vazia.

O autômato inicia sua execução no estado inicial $S_{0}$ denotado no caso em questão por $A$, e com um símbolo na pilha, denotado por $Y$. Ao consumir a tag estrutural de abertura userprofile o símbolo $P$ é inserido na pilha, substituindo o símbolo base da mesma: $Y$. 
Dessa forma, realiza-se a transição para o estado $B$. No estado $B$, o nome de usuário (username) e a data corrente (date) são consumidas e o conteúdo da pilha é substituído pelo símbolo $P$. O AP permanece no estado $B$ até que uma tag estrutural de abertura search seja consumida. Quando tal fato ocorre, é realizada uma transição para o estado $C$ e o símbolo $S$ é inserido na pilha.

Considerando o estado $C$ o AP consome informações referentes à busca realizada, tais como o $i d$ da imagem de consulta (imageQuery), a classe de tal imagem (imageClass), a dimensão do vetor de característica que a representa (dimension), o valor de $\mathrm{k}$ utilizado para a consulta $k-N N$, o APF calculado para a busca corrente (APF), dentre outros. O AP permanece no estado $C$ inserindo o símbolo $S$ na pilha substituindo o antigo até que uma tag estrutural de abertura retrieved seja consumida. Assim que tal tag é consumida o símbolo $R$ é inserido na pilha e uma transição para o estado $D$ é realizada.

O AP permanece no estado $D$ consumindo informações a respeito das imagens que retornadas segundo uma dada consulta, tais como o id da imagem retornada (imageRetrievedId), a ordem de seleção da imagem (selectionOrder), a posição de retorno da mesma (retrievedOrder), o fator de percepção (PF), dentre outros. No estado D, caso uma tag estrutural de fechamento endsearch seja consumida pelo AP, uma transição de retorno para o estado $C$ ocorre e um símbolo $R$ é removido da pilha. A partir do estado $C$, caso um tag estrutural de fechamento endsearch seja consumida, uma transição para o estado $E$ é realizada e um símbolo $S$ é removido da pilha. Por fim, o estado $E$ cumpre a tarefa de consumir a tag estrutural de fechamento enduserprofile.

Portanto, pode-se observar que os símbolos pertencentes ao alfabeto da pilha $(P, S$ e $R)$ são utilizados, respectivamente, para controlar as tag estruturais de abertura/fechamento userprofile/enduserprofile, search/endsearch e retrieved/endretrieved. É importante salientar que por meio da utilização do AP proposto a extensão do parser desenvolvido para o tratamento de novas informações que possam ser armazenadas nos perfis torna-se trivial.

\subsection{Experimentos}

Esta seção apresenta os resultados experimentais da utilização do método proposto, com o intuito de melhorar o processo de recuperação de imagens similares segundo uma dada imagem de consulta em uma dada base de imagens, por meio da captura das intenções do usuário, ou seja, da semântica de consulta desejada por um determinado especialista.

\subsubsection{Descrição das Bases de Imagens}

Para os experimentos foi utilizada a base de imagens CTROIsPulmão, descrita na Seção 4.4.1. Foram vários os motivos que levaram a escolher esse tipo de imagem. Especialistas médicos e pesquisadores do Hospital das Clínicas de Ribeirão Preto (HCRP-USP), campo 
de estudo desse trabalho, demonstraram interesse em estudar padrões de lesões difusas de pulmão. Além disso, os exames que abrangem o Tórax são um dos mais realizados no ambiente hospitalar, por ser um excelente mecanismo de triagem e abranger diferentes tecidos. Além disso, como mencionado, as lesões pulmonares apresentam alterações visuais menos óbvias, onde as possibilidades de dúvidas e as chances de erro na classificação são maiores, dessa forma é extremamente importante captar o melhor possível a percepção do usuário especialista.

A segunda base de imagens utilizada para os experimentos foi denominada MamaROIs, a qual compreende 2892 imagens de ROIs oriundas de exames de Mamografia. O conjunto de imagens é dividido em duas classes de achados clínicos: calcificação e massa. As imagens foram obtidas a partir do repositório público Digital Database for Screening Mammography (DDSM) ${ }^{2}$ (Yaffe, 2011).

Na Figura 5.5 pode-se observar o exemplo de cada uma das classes de imagens. A presente base de imagens foi utilizada uma vez que exames de mamografia são os principais exames realizados para uma precoce detecção de achados clínicos com relação à mama. Além disso, esse tipo de imagem representa um grande desafio, uma vez que a performance do diagnóstico decresce significativamente devido a variabilidade da percepção dos usuários. Dessa forma, é extremamente importante captar a percepção destes no domínio em questão.

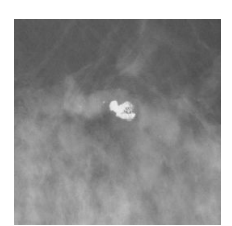

(a) Calcificação

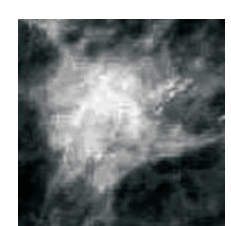

(b) Massa

Figura 5.5: Exemplos de cada classe de imagens da base MamaROIs: (a) calcificação, (b) massa.

\subsubsection{Metodologia Experimental}

Para os experimentos foram utilizadas as bases de imagens CTROIsPulmão e MamaROIs, descritas na Seção 5.4.1. As imagens pertencentes a tais bases utilizadas foram processadas, extraindo suas características e gerando os respectivos vetores de características de cada imagem. Para a realização dos experimentos foram empregados para a base CTROIsPulmão dois extratores de características: (a) um extrator baseado em textura e (b) histogramas tradicionais de níveis de cinza. O extrator baseado em textura utilizado faz uso dos descritores de Haralick (Haralick, 1979), obtidos a partir das matrizes de co-ocorrência oriundas do conjunto de imagens utilizado. Os descritores de Haralick utilizados para os experimentos foram variância, entropia, energia, homogeneidade, momento

\footnotetext{
${ }^{2}$ http://marathon.csee.usf.edu/Mammography/Database.html.
} 
de $3^{a}$ ordem, variância inversa e step. Todos esses descritores foram combinados gerando um vetor de características composto de 140 elementos.

Considerando o extrator de histogramas convencionais de níveis de cinza, os vetores de características gerados apresentam 256 posições, uma vez que as imagens pertencentes à base utilizada para experimentos possuem pixels de profundidade de 8 bits, resultando portanto em 256 tons de cinza, o que leva a histogramas possuindo 256 bins.

Já para a base MamaROIs foram extraídas também características de forma, obtidas a partir dos momentos de Zernike, além das características baseadas em textura e histogramas de níveis de cinza já citadas. Tal extração gerou um vetor de características de 256 dimensões.

Antes de iniciar o processo de rotulação das imagens realizado pelos usuários especialistas, bem como a coleta e levantamento de informações para seus perfis, foram realizados experimentos para definir a melhor função de distância para cada extrator. Para isso, foram realizadas consultas por similaridade aos $\boldsymbol{k}$-vizinhos mais próximos, $k$-NN ( $k$ nearest neighbor), variando aleatoriamente as imagens de consulta. Para a análise de tais experimentos foi utilizado o cálculo de precisão e revocação $(P \times R)$ (Baeza-Yates \& Ribeiro-Neto, 2011). Para sumarizar os resultados foi utilizada a precisão média (MAP Mean Average Precision), conforme definido em (Baeza-Yates \& Ribeiro-Neto, 2011).

Foram avaliadas diversas funções de distância com relação aos extratores de características explicitados. Considerando, para ambas as bases de imagens, as características obtidas por meio dos descritores de Haralick e dos momentos de Zernike, a função de distância que apresentou os melhores resultados foi a Canberra, ou seja, foram aquelas que apresentaram maiores valores de MAP. Já para as características oriundas dos histogramas de níveis de cinza a melhor distância foi a $L_{1}$.

Para os experimentos, considerando a base de imagens CTROIsPulmão, foram realizadas consultas por similaridade com 7 radiologistas (médicos residentes em diferentes níveis de residência, médicos radiologistas com larga experiência e técnicos em radiologia) do Hospital das Clínicas (HC) da Faculdade de Medicina de Ribeirão Preto da Universidade de São Paulo (FMRP-USP) e utilizando como centro de consulta imagens pertencentes a três classes representativas da base (Espessamento, Vidro-Fosco e Favo de Mel), com o intuito de capturar a percepção de tais especialistas em relação a essas imagens. Para tanto, foi solicitado a cada um dos especialistas realizar no sistema uma consulta k-NN utilizando como centro de consulta uma imagem suspeita, ou seja, contendo possíveis lesões pulmonares. Após a recuperação das imagens mais similares em relação ao centro de consulta, foi solicitado a cada um dos especialistas analisarem cada uma das imagens retornadas e rotular 5 destas como relevantes em ordem da mais similar para a menos similar, de acordo com a percepção de cada um.

$\mathrm{O}$ valor de $k$ para as consultas $\mathrm{k}-\mathrm{NN}$ foi fixado em 20 (i.e. 20 imagens retornadas) e o número de imagens a serem rotuladas em 5 , visto que, uma cardinalidade maior tornaria 
o processo cansativo e em desacordo com a prática comumente empregada no diagnóstico por imagem.

A estratégia proposta para o levantamento do perfil estático e dinâmico do usuário explicitada na Seção 5.3 foi empregada para acumular informações e gerar cada perfil de usuário. Em seguida, foi calculado o APF, de acordo com a ordenação das imagens realizada baseada na percepção de cada usuário em comparação com a ordem de retorno das imagens obtidas por cada uma das funções de distância providas pelo sistema, que foram as pertencentes à norma $L_{p}\left(L_{1}, L_{2}\right.$ e $\left.L \infty\right)$ e a distância Canberra. Como mencionado, o APF indica a função de distância que mais se aproxima à percepção de cada um dos usuários, ou seja, a que melhor se aproxima do ranking baseado na percepção do usuário que está armazenado em seu perfil.

A mesma metodologia foi aplicada para a base de imagens MamaROIs. Foram realizadas consultas por similaridade com 6 radiologistas do HC da FMRP-USP, utilizando como centro de consulta imagens pertencentes às duas classes da base (Calcificação e Massa).

\subsubsection{Resultados}

\subsubsection{Estudo de Caso 1}

As Figuras 5.6 e 5.7 ilustram as funções de distância que melhor se ajustam à percepção de cada usuário com base em seus perfis, utilizando para isso o cálculo do APF e a base de imagens CTROIsPulmão considerando os achados: (a) Espessamento, (b) Vidro Fosco e (c) Favo de Mel. Para isso, foram extraídas, do conjunto de imagens, características de textura baseadas nos descritores de Haralick e matrizes de co-ocorrência e histogramas de níveis de cinza, que são representadas, respectivamente, pelas Figuras 5.6 e 5.7.

Analisando os resultados da Figura 5.6 (a), pode-se notar que os especialistas apresentam um padrão nas funções de distância que melhor se adequam às suas percepções. Pode-se observar que quanto menor o valor APF mais adequada a distância. Considerando os resultados da Figura 5.6 (b), os especialistas apresentam algumas variações em suas percepções, quando comparados com os obtidos pela classe espessamento, mas ainda é possível estabelecer um padrão em suas percepções. No entanto, ao analisar os resultados considerando a classe favo de mel (Figura 5.6 (c)) é difícil definir um padrão na função de distância que melhor se adequa à percepção dos usuários, devido a variação no APF. Lembrando que a função de distância mais adequada à percepção do usuário é aquela que apresenta menor valor de APF.

Pode-se observar o mesmo comportamento quando analisados os gráficos da Figura 5.7 (a), (b) e (c), referentes às características oriundas dos histogramas de níveis de cinza. Considerando o achado espessamento (Figura 5.7 (a)), observa-se um padrão bem definido com relação à percepção dos especialistas. Tal padrão, ainda que mais sutil e com maiores variações, pode ser observado para o achado vidro fosco (Figura 5.7 (b)). 
(a) Textura - Espessamento

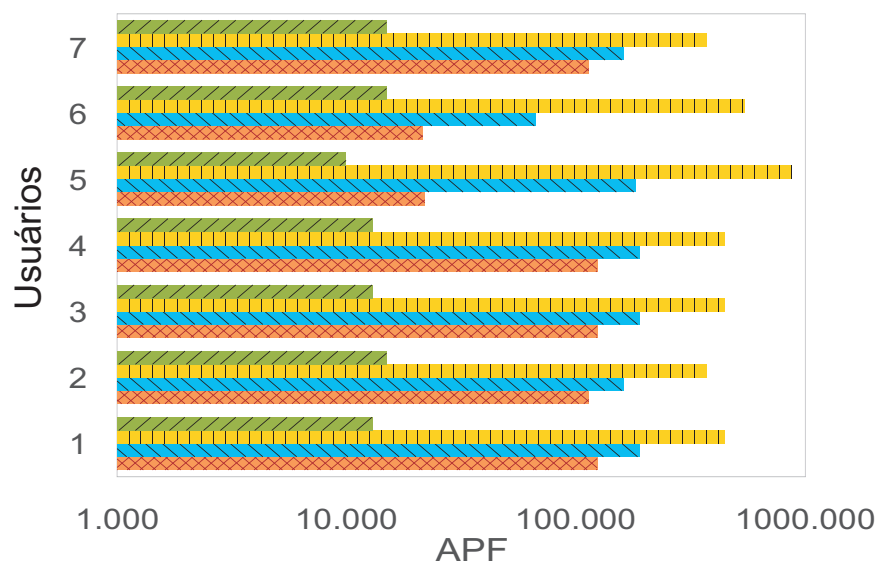

$\otimes \mathrm{L} 1\|\mathrm{~L} 2\| \mathrm{Linf} \geq \operatorname{Canberra}$

(b) Textura - Vidro Fosco

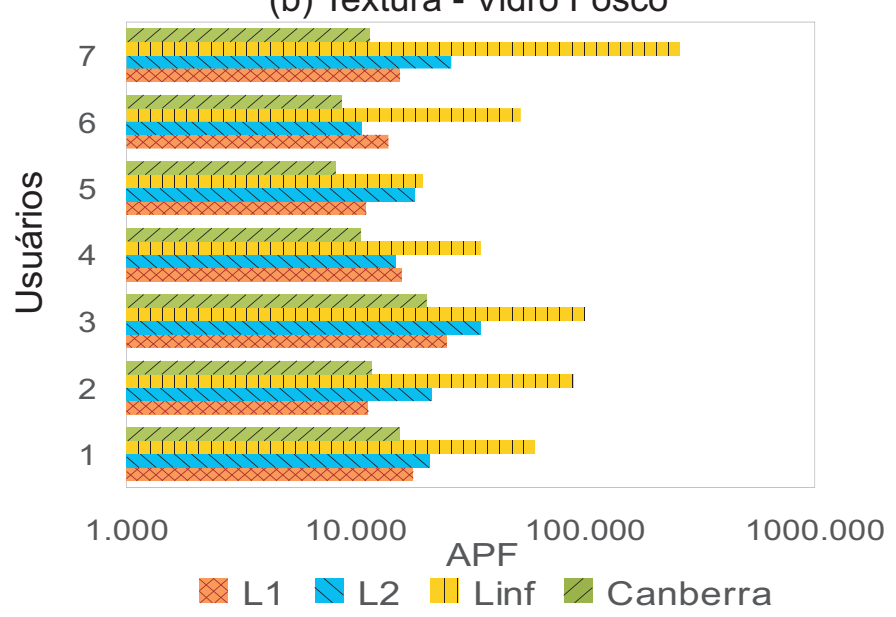

(c) Textura - Favo de Mel

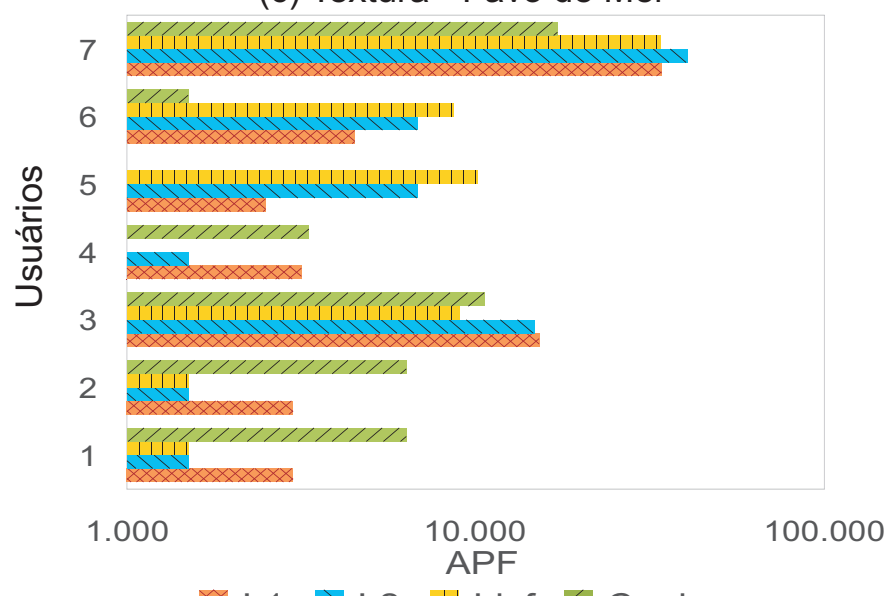

L1 \& L2 || Linf $/ 4$ Canberra

Figura 5.6: Gráficos ilustrando e comparando o comportamento das funções de distância que melhor se ajustam à percepção de cada usuário com base em seus perfis utilizando o APF, considerando os achados (a) Espessamento; (b) Vidro Fosco e (c) Favo de Mel. Quanto menor o valor do APF, mais adequada a função de distância à percepção do usuário. 
Tabela 5.2: Tabela comparando a precisão das consultas por similaridade e o APF em relação ao número de características visuais de um dado achado clínico representadas pelas características de textura, considerando a base CTROIsPulmão.

\begin{tabular}{|c|c|c|c|}
\hline Achado & Características Visuais & MAP(\%) & Desvio Padrão APF \\
\hline espessamento & aumento da espessura do septo interlobular & 60 & 1.81 \\
\hline \multirow[t]{2}{*}{ vidro fosco } & aumento da atenuação pulmonar & \multirow[t]{2}{*}{80} & \multirow[t]{2}{*}{4.28} \\
\hline & espessamento intersticial & & \\
\hline \multirow{3}{*}{ favo de mel } & espaços císticos agrupados & \multirow{3}{*}{84} & \multirow{3}{*}{5.88} \\
\hline & variação no diâmetro dos cistos & & \\
\hline & Contornos bem definidos e geralmente espessos & & \\
\hline
\end{tabular}

Porém, ao analisar os resultados para o achado favo de mel ((Figura 5.7 (c)), novamente não é trivial definir um padrão com relação à percepção dos usuários, como observado nos achados anteriores.

A partir dos resultados, pôde-se constatar que quanto maior o número de possíveis características visuais que está sendo comparado pelos especialistas, maior é a diferença entre a percepção dos mesmos, consequentemente, também entre a escolha das distâncias que melhor se adequam às suas percepções. Isso ocorre porque quando se trata de uma classe de imagem que apresenta um número maior de características visuais (por exemplo, favo de mel), a probabilidade de um usuário dar mais ênfase a uma característica do que as outras é maior. Por exemplo, o espessamento apresenta apenas uma característica visual, que é o aumento da espessura dos septos interlobulares, enquanto o achado vidro fosco apresenta duas, que são o aumento da atenuação pulmonar e o espessamento do interstício. Por outro lado, o achado favo de mel apresenta três principais características visuais que são os agrupamentos císticos, a variação de seus diâmetros, variando de 0,3 a $1 \mathrm{~cm}$, e as paredes bem definidas, geralmente espessas. Dessa forma, percebe-se que existe um relacionamento entre o padrão de percepção apresentado pelos especialistas e o número de características visuais apresentado por cada achado clínico.

Outro fator interessante observado nos resultados, diz respeito ao comportamento dos gráficos de $P \times R$ gerados para escolher a função de distância inicial para o processo de rotulação das imagens realizado pelos usuários. Pôde-se observar a partir de tais resultados que a maior precisão foi obtida quando utilizadas as imagens pertencentes à classe favo de mel como centros de consulta. Já a segunda melhor precisão foi obtida utilizando as imagens da classe vidro fosco como centros de consulta, e a pior precisão foi obtida com as imagens da classe espessamento. Dessa forma, pode-se notar que quanto maior o número de características visuais de uma dada classe de imagens, maior o poder de discriminação das lesões, portanto, maior é a precisão das consultas. Por exemplo, considerando as imagens pertencentes à classe espessamento, que contém apenas uma característica visual, a precisão obtida pelas consultas foi a menor.

Este resultado influencia diretamente o comportamento dos usuários ao gerar seus perfis, uma vez que quanto maior a precisão das consultas, maior a similaridade entre as 
(a) Histograma - Espessamento

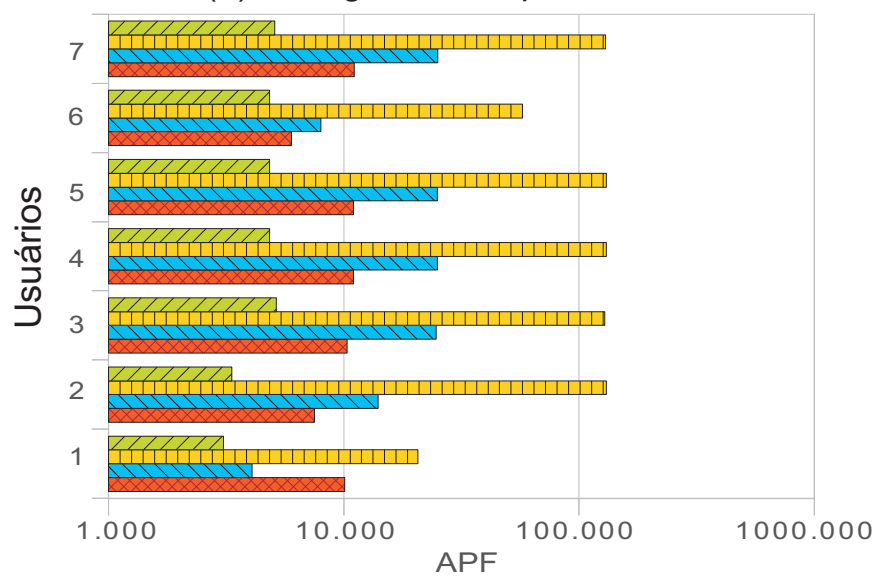

L1 $\ \mathrm{~L} 2 \quad \| \mathrm{Linf} \geq \mathrm{C}$ Canberra

(b) Histograma - Vidro Fosco

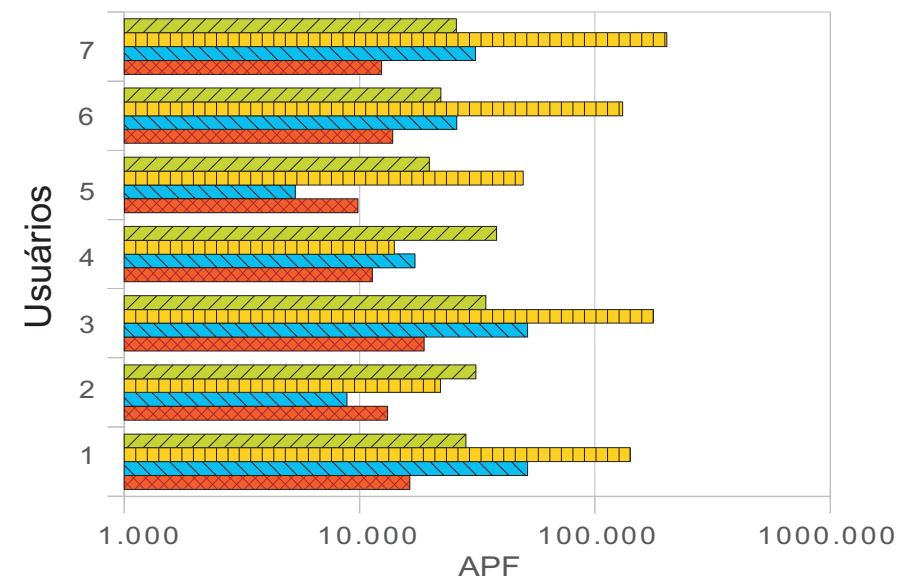

L1 $\$$ L2 || Linf $V /$ Canberra

(c) Histograma - Favo de Mel

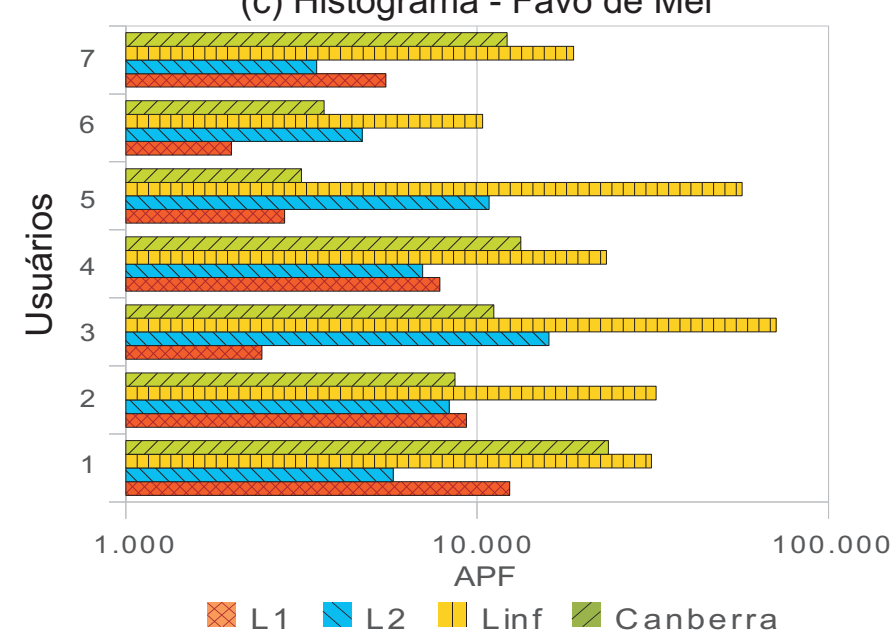

Figura 5.7: Gráficos ilustrando e comparando o comportamento das funções de distância que melhor se ajustam à percepção de cada usuário com base em seus perfis utilizando o APF, considerando os achados (a) Espessamento; (b) Vidro Fosco e (c) Favo de Mel. Quanto menor o valor do APF, mais adequada a função de distância à percepção do usuário. 
Tabela 5.3: Tabela comparando a precisão das consultas por similaridade e o APF em relação ao número de características visuais de um dado achado clínico representadas pelas características de histogramas de níveis de cinza, considerando a base CTROIsPulmão.

\begin{tabular}{|c|c|c|c|}
\hline Achado & Características Visuais & MAP(\%) & Desvio Padrão APF \\
\hline espessamento & aumento da espessura do septo interlobular & 52 & 2.01 \\
\hline \multirow{2}{*}{ vidro fosco } & aumento da atenuação pulmonar & 67 & \multirow{2}{*}{3.03} \\
\cline { 2 - 2 } & espessamento intersticial & & \multirow{2}{*}{70} \\
\cline { 2 - 2 } favo de mel & espaços císticos agrupados & \multirow{2}{*}{4.00} \\
\cline { 2 - 2 } & variação no diâmetro dos cistos & \\
\cline { 2 - 2 } & Contornos bem definidos e geralmente espessos & & \\
\hline
\end{tabular}

imagens retornadas. Assim, maior a dificuldade do especialista em discriminar a diferença perceptual entre elas, como pode-se observar nas Tabelas 5.2 e 5.3, comparando-se os valores de precisão média (MAP) obtidos, com o desvio padrão dos valores de APF dos usuários especialistas.

Vale enfatizar novamente que quanto menor o valor do APF de uma dada função de distância, mais adequada e condizente à percepção de um dado usuário esta será. Por exemplo, na Figura 5.7(a) a função de distância Canberra foi a mais adequada segundo a percepção dos usuários, uma vez que apresentou os menores valores de APF.

Pode-se observar que a partir dos resultados obtidos, o método proposto foi capaz de encontrar a função de distância que melhor captura a intenção de um dado usuário. Além disso, evidencia fatores de extrema relevância, como a relação entre o número de características visuais e a precisão das consultas realizadas, e o quanto tais fatores influenciam na percepção do usuário.

Todos esses resultados demonstram a grande importância dos perfis de usuário para manter a semântica da consulta por similaridade, com o intuito de alcançar a percepção do usuário, e portanto, permitir a realização de consultas por similaridade perceptuais e ao mesmo tempo não onerando o usuário, ou seja, sem adicionar esforço extra por parte do mesmo em tal processo, uma vez que o método proposto realiza todo o processo implicitamente e de maneira transparente ao usuário.

\subsubsection{Estudo de Caso 2}

Além de tais experimentos com a base CTROIsPulmão, foram também realizados experimentos com a base MamaROIs, como descrito anteriormente. As Figuras 5.8 (a), (b) e (c) ilustram as funções de distância que melhor se ajustam à percepção de cada usuário com base em seus perfis, utilizando para isso o cálculo do APF e a base de imagens MamaROIs, considerando os achados Massa e Calcificação, para os quais foram extraídas características utilizando respectivamente: (a) histogramas tradicionais de níveis de 
Tabela 5.4: Tabela comparando a precisão das consultas por similaridade e o APF em relação ao número de características visuais de um dado achado clínico representadas pelas características de histogramas de níveis de cinza, considerando a base MamaROIs.

\begin{tabular}{|c|c|c|c|}
\hline Achado & Características Visuais & MAP (\%) & Desvio Padrão APF \\
\hline \multirow{2}{*}{ calcificação } & Forma (puntiforme, amorfa, pleomórfica, esférica, etc) & \multirow{2}{*}{55} & 8,72 \\
\cline { 2 - 2 } & Distribuição (agrupados, linear, segmental, difusa, etc) & & \\
\hline \multirow{3}{*}{ massa } & Forma (redonda, oval, lobulada, irregular) & \multirow{2}{*}{67} & \multirow{2}{*}{10,66} \\
\cline { 2 - 2 } & Contorno (cincunscrito, microlobulado, espiculado, etc) & & \\
\cline { 2 - 3 } & Densidade (alta, constante, baixa, gordurosa) & & \\
\hline
\end{tabular}

cinza, (b) descritores de Haralick (características de textura) (c) momentos de Zernike (características de forma).

Considerando os resultados ilustrados pelas Figuras 5.8 (a), (b) e (c) em relação ao achado calcificação, pode-se observar que os especialistas apresentaram um padrão bem definido em relação às funções de distância que melhor adequaram-se às suas percepções, quando comparadas com o achado massa. Analisando os resultados obtidos pelas características oriundas dos momentos de Zernike (Figura 5.8 (c)) para o achado massa, nota-se que tais características em conjunto com a distância Canberra apresentou a combinação mais adequada (menor valor de APF) segundo a percepção dos usuários. Tal fato ocorre para este respectivo achado uma vez que as características de forma são as que mais atraem a atenção dos usuários no decorrer da análise, logo depois apresentam-se as características de textura oriundas dos descritores de Haralick.

Por outro lado, considerando-se o achado calcificação, os histogramas tradicionais de níveis de cinza (Figura 5.8 (a)), um método trivial, em combinação com a distância $L_{1}$ também apresentou bons resultados. Isto ocorre pois os achados de calcificações nos exames de mamografia são evidenciados como regiões com maior intensidade (i.e. maior brilho) devido à atenuação do Raio-X ao deparar-se com o elemento cálcio, em comparação com a intensidade do tecido mamário normal.

Com relação aos valores de $\mathrm{P} \times \mathrm{R}$ obtidos a partir de tais experimentos pôde-se observar novamente que quanto maior o número de características visuais de uma dada classe de imagens, maior é a precisão obtida. Por exemplo, considerando-se as imagens oriundas da classe calcificação, a qual apresenta duas principais características visuais, a precisão das consultas foi menor quando comparada com a precisão obtida pela classe massa, a qual apresenta três características visuais bem definidas. As Tabelas 5.4, 5.5 e 5.6 demonstram as comparações entre os valores de precisão média (MAP), com o desvio padrão dos valores de APF dos usuários especialistas, considerando, respectivamente, as características obtidas pelos histogramas de níveis de cinza, os descritores de Haralick e os momentos de Zernike. 
(a) Histograma - Calcificação

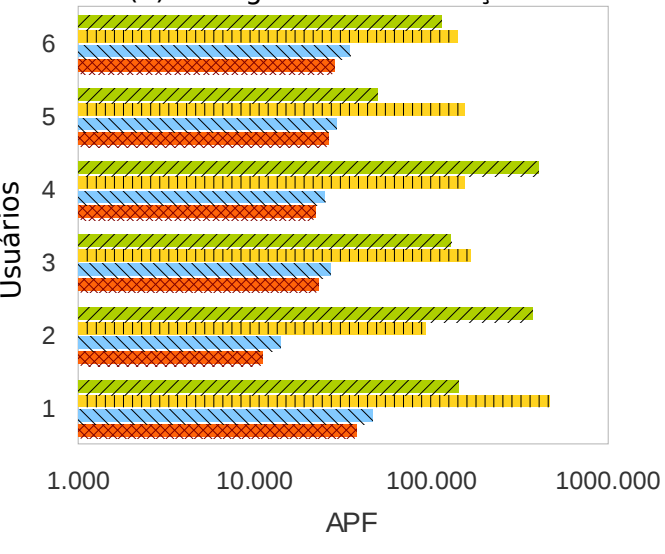

L1 L2

(b) Textura - Calcificação

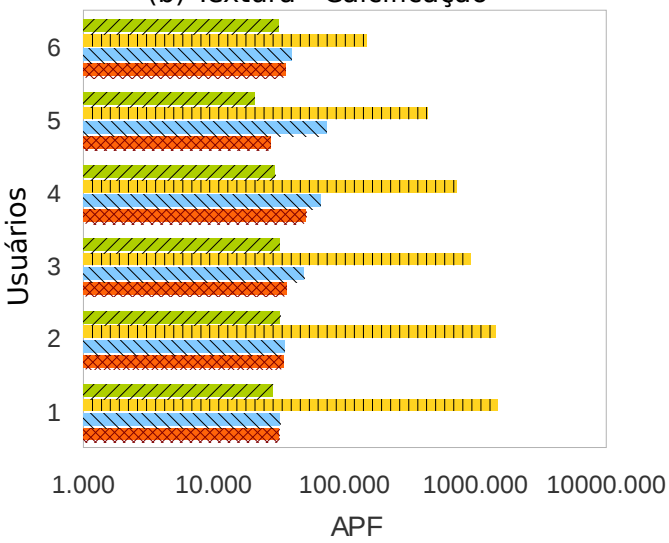

L1 L2 II Linf $\geq$ Canberra

(c) Zernike - Calcificação

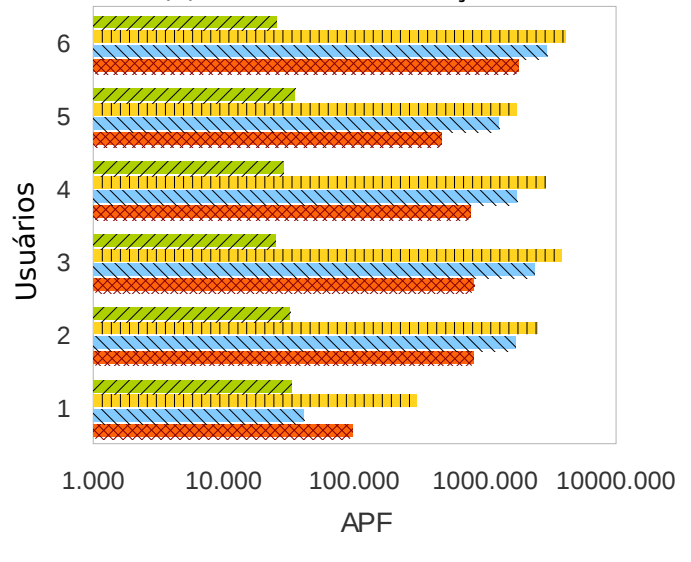

L1 L2 || Linf प Canberra (a) Histograma - Massa

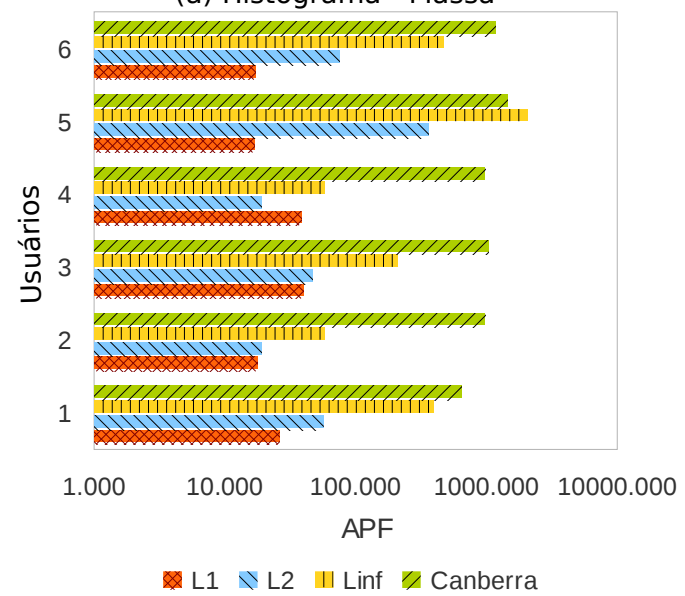

(b) Textura - Massa

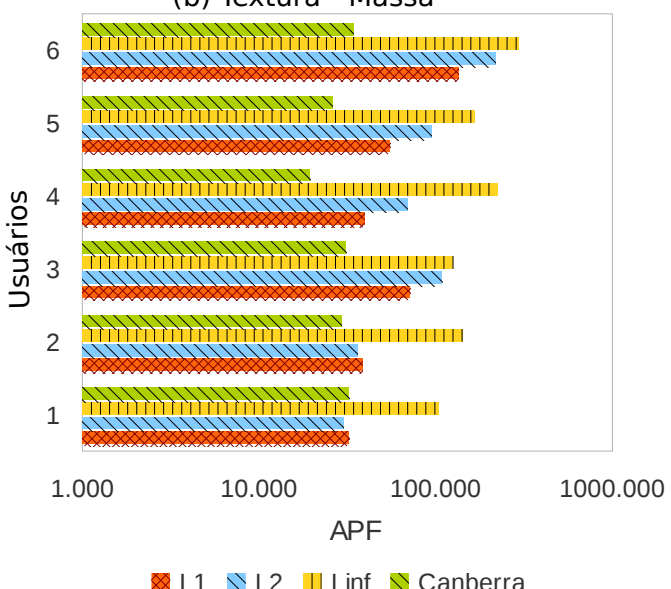

(c) Zernike - Massa

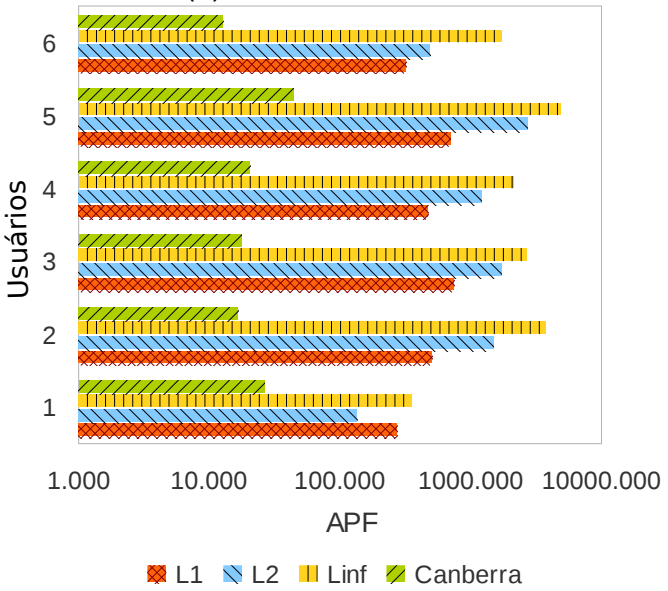

Figura 5.8: Gráficos ilustrando e comparando o comportamento das funções de distância que melhor se ajustam à percepção de cada usuário com base em seus perfis utilizando o APF, considerando os achados Calcificação e Massa descritos pelos: (a) histogramas de níveis de cinza, (b) descritosres de Haralick e (c) momentos de Zernike. Quanto menor o valor do APF, mais adequada a função de distância à percepção do usuário. 
Tabela 5.5: Tabela comparando a precisão das consultas por similaridade e o APF em relação ao número de características visuais de um dado achado clínico representadas pelos descritores de Haralick, considerando a base MamaROIs.

\begin{tabular}{|c|c|c|c|}
\hline Achado & Características Visuais & MAP (\%) & Desvio Padrão APF \\
\hline \multirow{2}{*}{ calcificação } & Forma (puntiforme, amorfa, pleomórfica, esférica, etc) & \multirow{2}{*}{54} & 4,35 \\
\cline { 2 - 2 } & Distribuição (agrupados, linear, segmental, difusa, etc) & & \\
\hline \multirow{3}{*}{ massa } & Forma (redonda, oval, lobulada, irregular) & \multirow{2}{*}{65} & \multirow{2}{*}{5,32} \\
\cline { 2 - 2 } & Contorno (cincunscrito, microlobulado, espiculado, etc) & & \\
\cline { 2 - 3 } & Densidade (alta, constante, baixa, gordurosa) & & \\
\hline
\end{tabular}

Tabela 5.6: Tabela comparando a precisão das consultas por similaridade e o APF em relação ao número de características visuais de um dado achado clínico representadas pelos momentos de Zernike, considerando a base MamaROIs.

\begin{tabular}{|c|c|c|c|}
\hline Achado & Características Visuais & MAP (\%) & Desvio Padrão APF \\
\hline \multirow{2}{*}{ calcificação } & Forma (puntiforme, amorfa, pleomórfica, esférica, etc) & 54 & 4,23 \\
\cline { 2 - 2 } & Distribuição (agrupados, linear, segmental, difusa, etc) & & \\
\hline \multirow{2}{*}{ massa } & Forma (redonda, oval, lobulada, irregular) & \multirow{2}{*}{71} & \multirow{2}{*}{7,99} \\
\cline { 2 - 2 } & Contorno (cincunscrito, microlobulado, espiculado, etc) & \multirow{2}{*}{ Densidade (alta, constante, baixa, gordurosa) } & \\
\cline { 2 - 2 } & & \\
\hline
\end{tabular}

\subsubsection{Estudo de Caso 3}

Além das análises apresentadas, foi observado também o impacto de um dado par função de distância/extrator de características na percepção global do usuário. As Figuras 5.9 (a) e (b) elucidam tal impacto, ilustrando o APF global (média de APFs dos usuários) obtido, considerando os extratores aplicados a cada uma das bases de imagens citadas, CTROIsPulmão e MamaROIS, respectivamente, com relação as quatro funções de distância empregadas $\left(L_{1}, L_{2}, L_{\infty}\right.$ e Canberra).

Considerando os gráficos da Figura 5.9 (a) pode-se notar o impacto considerável que uma determinada função distância pode causar na percepção dos usuários. Ao analisar os resultados obtidos pela utilização da distância $L_{\infty}$ em combinação com os histogramas de níveis de cinza (i.e. pior combinação), obtém um APF global aproximadamente 10 vezes maior que o APF global obtido utilizando a distância $L_{1}$, a qual trata-se da melhor combinação pois alcançou o menor APF global. Analisando-se as outras distâncias, $L_{2}$ e Canberra, contra a melhor combinação, os níveis de APF global foram de aproximadamente duas vezes maiores.

Com relação aos descritores de Haralick, tal impacto apresentou-se ainda mais evidente. O pior desempenho foi obtido com a distância $L_{\infty}$, na qual o APF global foi 18.5 vezes maior do que o APF global alcançado pela distância Canberra (melhor combinação). A vantagem da distância Canberra também foi elevada em relação às outras distâncias, uma vez que os níveis de APF global obtidos com a $L_{1}$ e $L_{2}$ foram, respectivamente, mais do que 3.5 e 6 vezes superiores ao obtido pela combinação com a Canberra.

Analisando os gráficos da Figura 5.9 (b) com relação aos níveis de APF global segundo a base MamaROIs, observa-se claramente o impacto gerado pela escolha correta de uma dada função de distância na percepção dos usuários. Considerando a distância $L_{1}$ em combinação com as características dos histogramas de níveis de cinza (melhor com- 

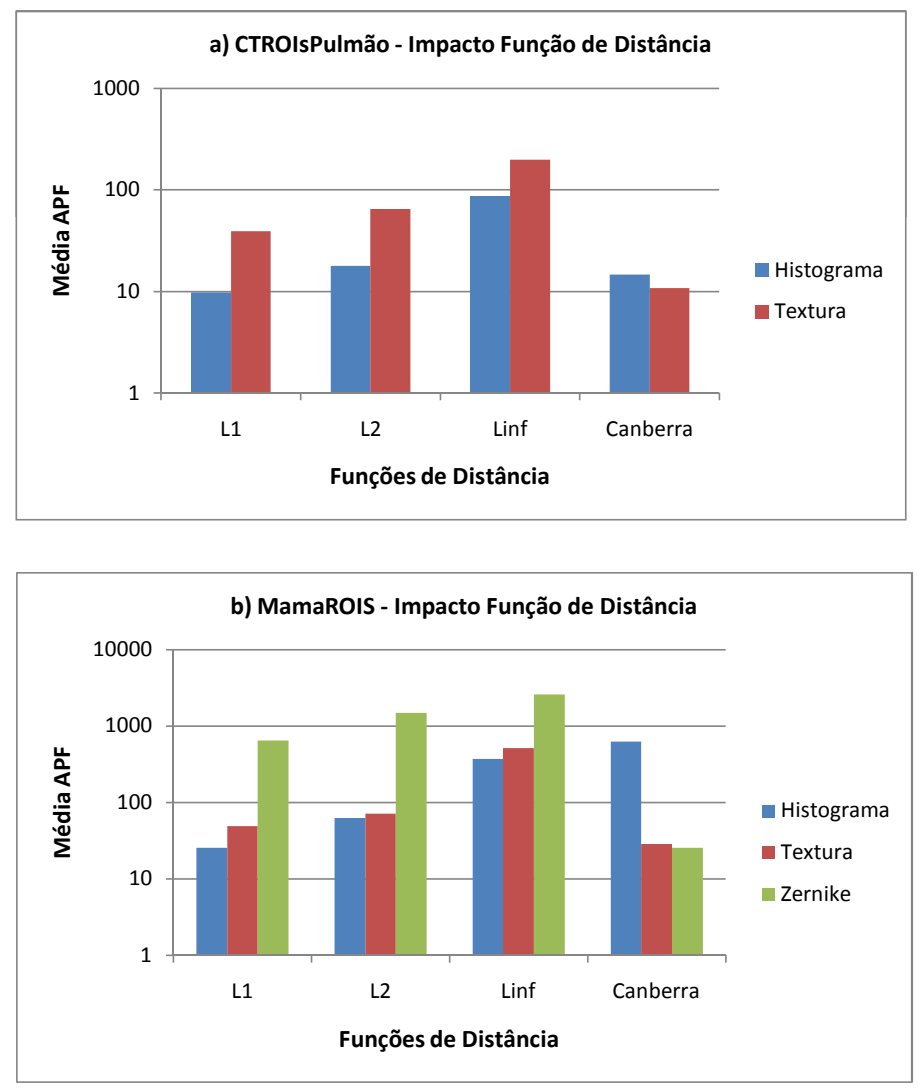

Figura 5.9: Gráficos comparando o impacto gerado pelas funções de distância com relação à percepção dos usuários, calculado agregando informações dos perfis de usuários, considerando as características obtidas a partir das bases CTROIsPulmão e MamaROIs em junção com as distâncias $L_{1}, L_{2}, L_{\infty}$ e Canberra.

binação), o nível de APF global de tal combinação apresentou-se, respectivamente, 2.5, 14.5 e 24.5 vezes menor do que os níveis obtidos pelas distâncias $L_{2}, L_{1}$ e Canberra. Já com relação às características de textura oriundas dos descritores de Haralick a melhor combinação foi obtida com a distância Canberra, alcançando um nível de APF global de até $1.7,2.5$ e 18 vezes menor do os obtidos pelas distâncias $L_{1}, L_{2}$ e $L_{\infty}$.

Por fim, foi observado também um grande impacto na percepção dos usuários utilizando as características oriundas dos momentos de Zernike combinados com a distância Canberra (melhor combinação), uma vez que o nível de APF global de tal combinação foi, respectivamente, 25, 58 e 100 vezes menor do que o níveis de APF global obtidos pelas distâncias $L_{1}, L_{2}$ e $L_{\infty}$.

Observa-se a partir dos resultados obtidos que o método proposto foi capaz de encontrar e prover a função de distância que melhor captou a intenção do(s) usuário(s). Dessa forma, tais resultados corroboram novamente a importância do perfil do usuário para manutenção da semântica da consulta por similaridade, com o intuito de alcançar a percepção do mesmo e, assim, realizar consultas por similaridade perceptuais de maneira transparente ao usuário. Além disso, como demonstrado, o método foi capaz de elucidar 
padrões úteis de comportamento dos especialistas, trazendo conclusões extremamente relevantes e úteis sobre a percepção do(s) usuário(s) no campo da medicina, foco central da presente tese.

Além de tais análises, uma vez que o método proposto realiza o levantamento e armazenando de informações nos perfis de usuário obteve-se um fator de Ciclos Salvos na execução das consultas, visto que um dado usuário não mais necessita executar novamente diversas realimentações de relevância, mas apenas carregar a sessão armazenada no perfil. Dessa forma, aumentando o fator de Ciclos Salvos concomitantemente aumenta-se o que foi denominado como fator de Objetos Salvos, ou seja, aqueles objetos, no caso em questão imagens, para os quais não foi mais necessária sua recuperação. Tal fator foi formalmente definido como: ObjetosSalvos $_{i}=$ CiclosSalvos $_{i} * k$, onde $k$ diz respeito à quantidade de imagens recuperadas no $i$-ésimo ciclo de realimentação. De forma trivial o Fator Médio de

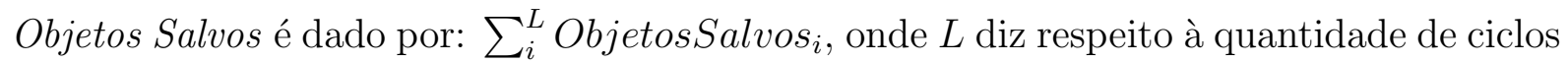
de realimentação realizados. Considerando, por exemplo, uma consulta 30-NN (k=30), e que determinado usuário realizou 5 ciclos de realimentação de relevância mantendo tal valor de k constante, o valor do Fator Médio de Objetos Salvos para tal caso seria de 150 objetos salvos.

É importante também ressaltar que embasado na sessão de consulta armazenada nos perfis dos usuários capturou-se também a quantidade de vezes que uma determinada imagem foi selecionada como primeira relevante no processo de realimentação de relevância. Dessa forma, caso uma imagem tenha sido selecionada várias vezes como a primeira relevante pela grande maioria dos usuários, esta apresenta-se como um bom representante para o achado em questão, segundo a percepção do usuário ou um grupo destes. Assim, gerando agrupamentos implícitos baseados na intenção do usuário.

A partir das técnicas apresentadas e discutidas, verifica-se que estas originam um grande número de possibilidades para o emprego e exploração do método proposto com relação à percepção do usuário, levando a novas perspectivas no campo de CBIR.

\subsection{Considerações Finais}

No presente capítulo foi apresentada uma nova abordagem para diminuir o problema do gap semântico em sistemas CBIR. A abordagem proposta obtém dos usuários seus interesses gerais, bem como, suas intenções durante a realização das consultas por similaridade e efetua o levantamento e a alimentação dos perfis de usuário, por meio da estratégia proposta.

A estratégia proposta de supervisão e levantamento do perfil combina perfis estáticos e dinâmicos que são incorporados ao ciclo de realimentação de relevância, portanto, não exigem um esforço extra por parte do usuário. 
A abordagem também é capaz de responder e definir qual a função de distância que melhor se adequa à percepção de um dado usuário. Para tanto, foram definidas duas novas medidas para quantificar a similaridade perceptual de um dado usuário segundo um determinado centro de consulta. Tais medidas foram denominadas Perception Factor e Average Perception Factor as quais são os principais mecanismos para vincular a avaliação de similaridade baseada na percepção do usuário com os pares de função de distância/extrator de características. Com base em tais medidas foi desenvolvido um agente capaz de ser integrado de maneira transparente a sistemas CBIR, o qual permite definir dinamicamente a função de distância que melhor se adapte à percepção de um determinado usuário.

Vale ressaltar que uma vez que tais informações foram armazenadas nos perfis de usuários obteve-se o citado fator de Ciclos Salvos na execução das consultas. Portanto, o método proposto também obtém ganho em termos de eficiência utilizando o perfil, ou seja, "pulando" fases de realimentação.

Além disso, considerando um ambiente clínico, a abordagem proposta pode ser utilizada como um treinamento do sistema feito por um especialista em um determinado domínio de imagem, uma vez que os perfis de usuário armazenam informações que elucidam o comportamento intrínseco dos especialistas na tarefa de busca baseada em conteúdo. Portanto, outros usuários, como os médicos residentes, podem se beneficiar deste trabalho, para melhorar seu processo de aprendizagem, uma vez que podem observar a percepção do especialista e assim carregar esse perfil como base de comparação (ground truth) para o aprendizado. 


\section{Capítulo 6 \\ Novas Políticas para Escolha de
Funções de Distância}

\subsection{Introdução}

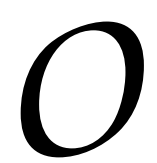

s sistemas CBIR, como o próprio nome os especifica, tem por intuito recuperar as imagens mais similares em relação a uma dada imagem de consulta baseada em comparações de características visuais (automaticamente extraídas a partir das imagens). Para realizar tal tarefa, os sistemas CBIR baseiam-se em dois principais pilares que são as características extraídas das imagens e uma medida de similaridade utilizada para compará-las. Dentre as características comumentemente utilizadas para a representação de imagens em CBIR estão as denominadas como primitivas (Deselaers et al., 2008a), as quais são derivadas dos principais elementos básicos de uma imagem: cor, textura e forma.

Com relação ao segundo pilar de sustentação, embora por quase uma década, pesquisas têm sido realizadas com o intuito de explorar a área de CBIR, a maioria destas, foca na proposta de novos extratores de características e acabam negligenciando o relacionamento entre as características extraídas das imagens e as funções de distâncias utilizadas na comparação destas. Dessa forma, fazem uso das mais conhecidas e amplamente utilizadas funções de distância.

Apesar dos recentes esforços de pesquisa, a tarefa de recuperação de imagens baseada em conteúdo continua a ser uma tarefa difícil e desafiadora, devido principalmente ao problema do gap semântico (Deserno et al., 2008), já citado anteriormente. 
Na última década, técnicas de realimentação de relevância têm recebido grande atenção e relativo sucesso, quando empregadas em conjunto com sistemas CBIR, principalmente devido à sua capacidade em reduzir os principais inconvenientes intrínsecos à recuperação de imagens baseada em conteúdo, por meio de interações com o usuário, construindo uma ponte de ligação entre os dois extremos que são a percepção humana e a descrição das imagens realizada pela máquina. Dessa forma, caracterizam-se como um poderoso instrumento, quando atreladas aos sistemas CBIR.

Apesar da existência de uma infinidade de diferentes técnicas propostas para a realização da realimentação de relevância em CBIR, a grande maioria destas, principalmente as baseadas na movimentação de um único centro de consulta, query point movement - QPM (Doulamis \& Doulamis, 2006), não focam na importância de uma escolha cuidadosa de uma dada função de distância com relação a um tipo específico de características em cada ciclo de realimentação. Dessa forma, a técnica proposta na presente seção tem por intuito demonstrar que a modificação de funções de distância em cada ciclo de realimentação gera resultados melhores.

O presente capítulo visa introduzir uma técnica que agrega novas políticas para realizar a melhor escolha de uma dada função de distância para um ciclo específico em conjunto com o mecanismo de realimentação de relevância (movimentação de um único centro de consulta), apresentando, portanto, melhorias com relação à precisão das consultas por similaridade baseadas nas expectativas dos usuários. Para tanto, foi proposto um mediador para realizar o controle e o emprego de tais políticas.

O presente método, bem como os respectivos resultados foram publicados na forma de artigo científico no IEEE International Symposium on Computer-Based Medical Systems (Bugatti et al., 2011c).

\subsection{Método Proposto}

O método proposto embasa-se na abordagem de avaliação da possibilidade de junção da modificação de funções de distância, em tempo de execução, em cada iteração dos ciclos de realimentação, propiciando, dessa forma, novos rumos para a melhoria dos paradigmas utilizados.

Uma pergunta que surge diz respeito a como realizar essa mudança "on the fly", de acordo com as intenções do usuário. Que informações do perfil do usuário utilizar para realizar tal mudança?

Primeiramente, foram realizados experimentos baseados na combinação de diferentes funções de distância de maneira aleatória e analisando-se os resultados obtidos. A partir da análise de tais resultados e da viabilidade da mudança dinâmica de funções de distância em ciclos de realimentações específicos, derivou-se a proposta de uma política para a escolha de funções de distância embasada em novas informações acrescidas no perfil dos usuários. 
Tal modificação de funções de distância, em cada ciclo de realimentação, não pode ser realizada a esmo, pois para que seja possível atingir a melhor combinação seria necessária uma verificação exaustiva, como a realizada nos experimentos explicitados na seção 6.3, para corroborar a viabilidade de mudança "on the fly" nos ciclos de realimentação.

Agregado a tal fato, sabe-se que uma dada base de imagens possui um par extrator e função de distância que melhor se adequam a esta. No entanto, nessa mesma base de imagens existem diferentes classes de imagens, podem apresentar funções de distâncias distintas da denotada para a base como um todo. Esse fato não é levado em consideração pelos trabalhos encontrados na literatura. Dessa forma, caso um dado usuário realize uma busca por similaridade em uma determinada base de imagens, existirá para esta uma configuração do melhor par extrator/função de distância. No entanto, ao acoplar a isso o processo de realimentação de relevância, a mesma função de distância é mantida para todos os ciclos de realimentação sem nenhuma forma de análise.

Dessa forma, é justamente nessa direção que o método proposto visa contribuir, aplicando uma política de escolha para funções de distância, de acordo com a classe de imagens desejada pelo usuário no processo de realimentação de relevância, integrando, assim, a modificação dinâmica de funções de distância à intenção do usuário.

Experimentos iniciais foram conduzidos para responder qual o melhor par extrator de características e função de distância, para a base como um todo, bem como para cada classe de imagens dessa mesma base. Tais informações foram armazenadas nos perfis de usuários. De acordo com a realimentação inicial, realizada pelo usuário, o método proposto verifica a classe majoritária das imagens selecionadas como relevantes e realiza uma "busca" nos perfis de usuário para responder qual é a melhor função de distância, de acordo com a intenção do usuário no ciclo de realimentação corrente. Para a realização de tal processo e escolha da política de modificação adotada, foi desenvolvido um mediador, dividido em alguns módulos, que são:

1. Agente Analisador da Rotulação: efetua a análise da rotulação realizada pelo usuário no processo de realimentação de relevância, verificando a classe de imagens majoritária rotulada pelo usuário;

2. Agente de Tradução e Mediação: traduz as informações passadas pelo Agente Analisador da Rotulação e realiza uma busca no perfil de usuários, para recuperar e intermediar o processo de escolha de qual a melhor função de distância, de acordo com a rotulação das imagens realizada pelo usuário;

3. Agente Transformador da Consulta: a partir dos parâmetros definidos pelo Agente de Tradução e Mediação, realiza a transformação da consulta original, aplicando os parâmetros de modificação da função de distância, reescrevendo tal consulta. 
A Figura 6.1 ilustra os passos de execução do método proposto. No passo 1, o usuário realiza uma consulta por similaridade inicial, dada uma imagem de consulta, a qual não se conhece a classe e a melhor função de distância, definida para tal base de imagens. Após tal consulta, são retornadas as imagens mais similares, de acordo com a imagem de consulta. No passo 2, o usuário analisa as imagens e inicia o processo de rotulação das imagens em relevantes, e caso queira, em irrelevantes também. Já no passo 3, o processo de rotulação é finalizado e as imagens rotuladas são, então, passadas ao próximo passo.

O passo 4 caracteriza-se pelo início da atuação do módulo mediador desenvolvido. Nesse passo, entra em ação o Agente Analisador da Rotulação já descrito, o qual, a partir das imagens rotuladas oriundas do passo 3, analisa tal processo, gera e organiza informações, tais como, o número distinto de classes rotuladas pelo usuário e repassa tal informação ao passo 5. No passo 5, entra em ação o Agente de Tradução e Mediação, o qual obtém as informações repassadas a ele, as traduz, obtendo qual a classe majoritária rotulada como relevante pelo usuário e realiza uma busca no perfil dos usuários para obter qual a função de distância que melhor adequa-se a tal classe de imagens majoritária.

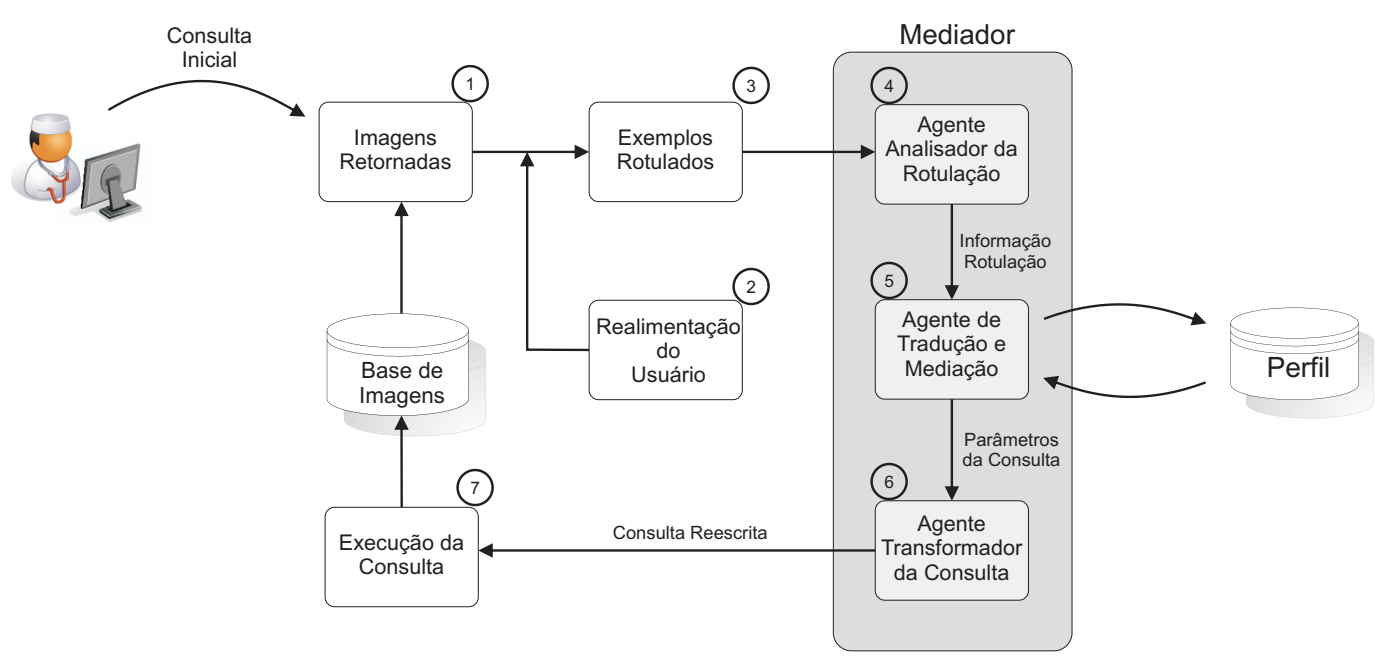

Figura 6.1: Arquitetura do método proposto.

A partir da obtenção da resposta do passo 5, por meio do Agente de Tradução e Mediação, são definidos novos parâmetros para a consulta, baseados na intenção do usuário. Tais parâmetros são, então, passados ao Agente Transformador da Consulta incluso no passo 6, o qual obtém tais parâmetros e transforma a consulta original a partir destes, reescrevendo a consulta e definindo a função de distância que melhor se adequa.

No passo 7, é realizada a execução da consulta transformada e tratada pelo mediador proposto e então são retornadas novas imagens para o usuário analisá-las e rotulá-las. Esse processo pode permanecer em um ciclo de execução até que o usuário esteja satisfeito.

Por exemplo, o usuário realiza uma consulta aos k-vizinhos mais próximos e, a partir do retorno da consulta seleciona as 5 imagens mais relevantes. Após essa seleção, entra em cena o mediador desenvolvido, o método então verifica a classe das 5 imagens selecionadas 
e retorna, a partir do perfil, a melhor configuração (e.g. função de distância, custo computacional) para a classe com maior número de imagens selecionadas pelo usuário. Caso seja verificado que a melhor função de distância da classe não coincide com a melhor da base utilizada na consulta inicial, a consulta é reescrita, caso contrário a consulta permanece inalterada. Nesse caso, nos próximos ciclos, o mediador não necessariamente precisa entrar em ação, uma vez que as distâncias coincidiram. No entanto, ainda considerando o mesmo caso, pode existir uma função de distância com melhor custo computacional e com resultados muito próximos ou praticamente empatados com a melhor função de distância para uma determinada classe, essa função de distância, de menor custo, é escolhida em substituição da anterior e a consulta é reescrita.

Informações dos ciclos de realimentação também são armazenadas nos perfis, à medida que consultas são realizadas. Dessa forma, pode-se dizer, no caso de empate, por exemplo, qual função de distância apresenta uma saturação mais rápida no processo de realimentação em relação a outra e assim realizar uma melhor escolha, ou seja, de acordo com o contexto e intenção do usuário, decidir pela função que apresenta menor saturação com relação ao ganho de precisão nos ciclos de realimentação decorrentes.

É importante ressaltar que todo esse processo é executado de maneira transparente ao usuário e sem requerer esforço qualquer por parte do mesmo, uma vez que este apenas rotula as imagens no processo de realimentação. Dessa forma, a arquitetura de mediação desenvolvida no método facilita e automatiza o processo de transformação da consulta, o qual pode ser aplicado em diversas circunstâncias.

A Figura 6.2 ilustra duas possíveis situações de utilização da política de escolha de funções de distância. A primeira situação diz respeito a uma consulta realizada pelo Usuário 1, nela é escolhida uma dada imagem de consulta (e.g. imagem A), a qual não se conhece a classe, e realizada uma consulta aos 7 vizinhos mais próximos. Dessa forma, 7 imagens mais similares, de acordo com o centro de consulta, são retornadas. O Usuário 1 então analisa tais imagens e rotula as que ele considera relevantes, que, nesse exemplo, foram as imagens de B a E. Todas as imagens rotuladas pelo usuário são da classe Crânio Coronal, dessa forma, o mediador irá entrar em ação, utilizar a política de escolha de funções de distância desenvolvida, ou seja, definir a melhor distância para essa classe de imagens e transformar a consulta.

Já no caso do Usuário 2, este selecionou além das imagens B, C, D e F, outras imagens não tão similares à imagem de consulta (e.g. E e G), introduzindo ruídos na consulta. $\mathrm{O}$ método proposto analisa a classe majoritária de rotulação, uma vez que leva em consideração a intenção do usuário. Dessa forma, nesse caso, o mediador seleciona novamente a melhor função de distância, de acordo com a classe majoritária. Caso o usuário introduza uma magnitude considerável de ruídos no processo de rotulação, o mediador irá atuar segundo a intenção do mesmo. 


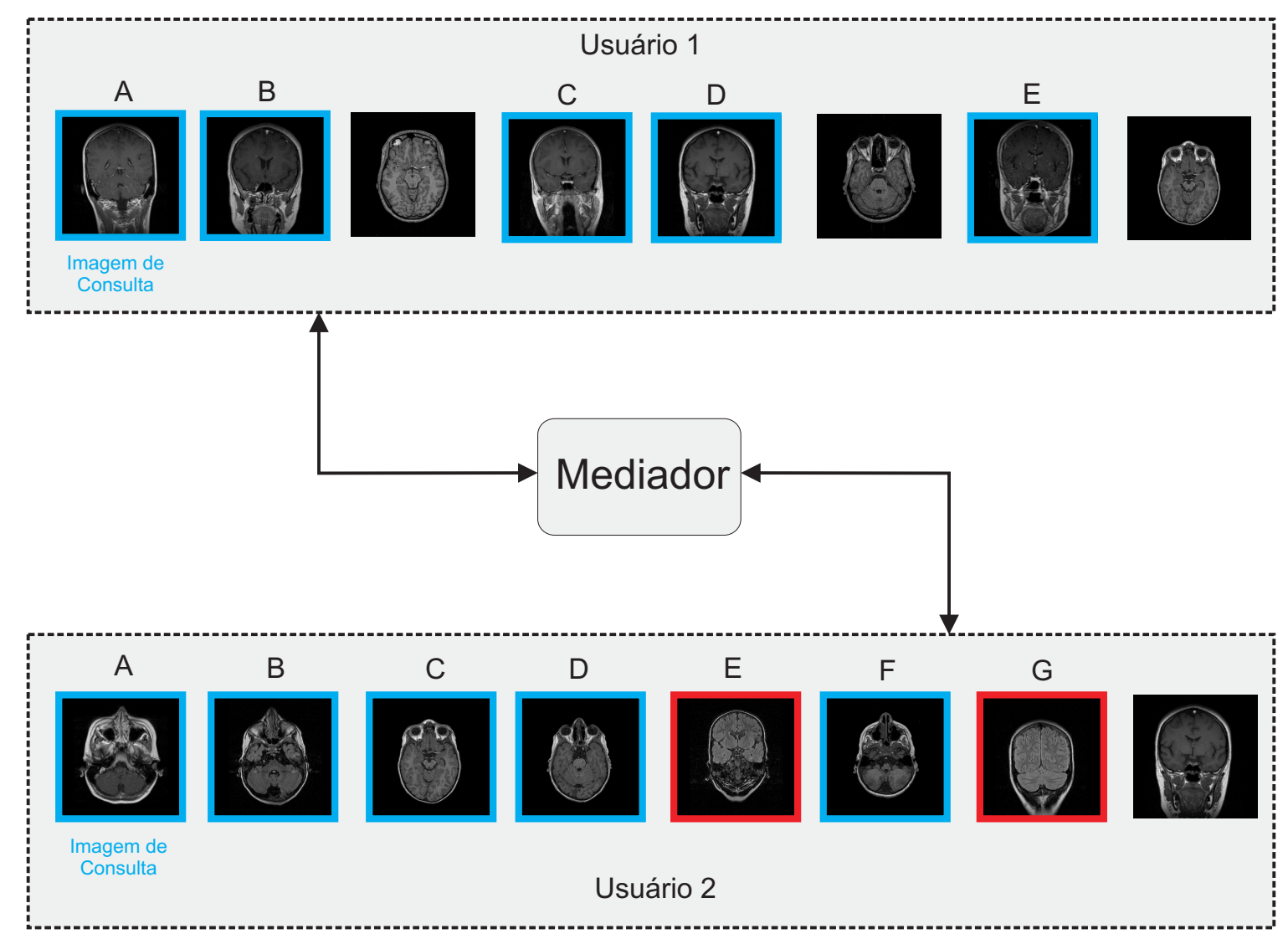

Figura 6.2: Exemplo do funcionamento da política proposta.

\subsection{Experimentos}

A presente seção apresenta os resultados experimentais da utilização do método proposto. Para os experimentos, foram utilizadas as bases de imagens MRI e CTROIsPulmão, ambas descritas na Seção 4.4.1. Além de tais bases foi utilizada a base de imagens Corel $^{1}$, contendo 1000 imagens, classificada em 10 classes, sendo que cada uma das classes possui 100 imagens. As classes da base Corel utilizadas foram: (a) Africa; (b) Beach; (c) Buildings; (d) Buses; (e) Dinosaurs; (f) Elephants; (g) Flowers; (h) Food; (i) Horses e (j) Mountains. Na Figura 6.3, podem ser observados exemplos de imagens pertencentes à base de imagens Corel, referentes a cada uma de suas classes.

A base Corel foi utilizada também, uma vez que é disponibilizada para a comunidade científica, além de já ter sido utilizada em uma gama considerável de experimentos na literatura, por representar um conjunto heterogêneo de imagens. Para os experimentos, as imagens da base foram pré-processadas e transformadas para escala de níveis de cinza.

\footnotetext{
${ }^{1}$ http://wang.ist.psu.edu/docs/related/
} 


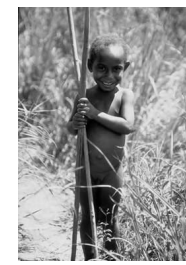

(a) Africa

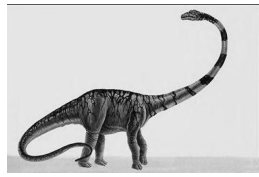

(e) Dinosaurs

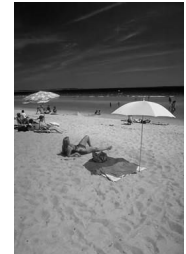

(b) Beach

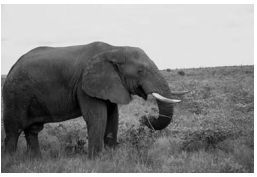

(f) Elephants

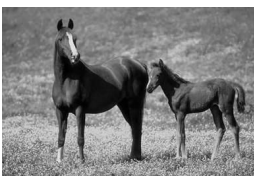

(i) Horses

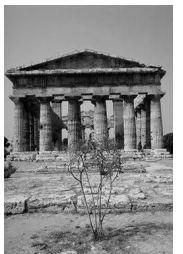

(c) Buildings

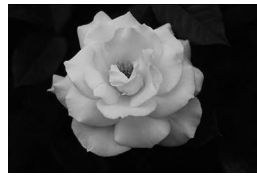

(g) Flowers

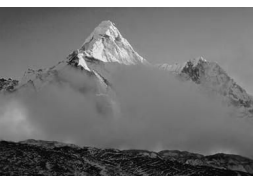

(j) Mountains

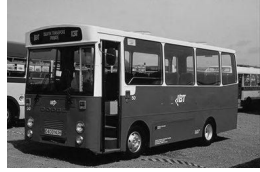

(d) Buses

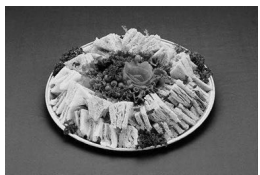

(h) Food

Figura 6.3: Exemplos de imagens de cada classe pertencentes ao conjunto de teste da base de imagens Corel: (a) Africa; (b) Beach; (c) Buildings; (d) Buses; (e) Dinosaurs; (f) Elephants; (g) Flowers; (h) Food; (i) Horses e (j) Mountains.

\subsubsection{Resultados}

Inúmeros métodos de realimentação de relevância podem levar a mínimos locais ótimos permanecendo presos a tais subespaços, tal problema é denominado na literatura como local optimum traps (Liu et al., 2009). Uma vez que os centros de consulta no processo de realimentação de relevância são modificados e movimentam-se no espaço para diferentes regiões antes de atingirem subespaços que contenham as imagens de fato relevantes para o usuário, é possível que, nesse processo, o método fique preso nessas regiões intermediárias.

A Figura 6.4 ilustra esse possível cenário, onde o Cluster 2 contém as imagens mais relevantes. Como resultado de uma consulta $3-N N$, utilizando $Q$ como centro de consulta, foram retornadas as imagens $P_{1}$ e $P_{2}$, além do próprio centro de consulta. Sendo $P_{1}$ e $P_{2}$ imagens relevantes rotuladas pelo usuário, o novo centro de consulta refinado para a próxima consulta $3-N N$ seria $Q^{\prime}$, visto que, é o centróide de ambas. No entanto, pode-se observar que, nesse caso, mesmo com a modificação do centro de consulta, seriam retornadas as mesmas 3 imagens. Em outras palavras, o processo apresenta-se preso nessa região, visto que, a recuperação satura-se com a seleção das mesmas imagens, a cada ciclo de realimentação.

Embora seja possível "escapar" de tal "armadilha" (região do espaço), aumentando o valor de $k$, a escolha de um limiar não é trivial. Por exemplo, considerando o caso da Figura 6.4, o limiar para $k$ seria 14. Consequentemente, o usuário pode nem mesmo detectar que está preso em uma região do espaço referente a mínimos locais. 


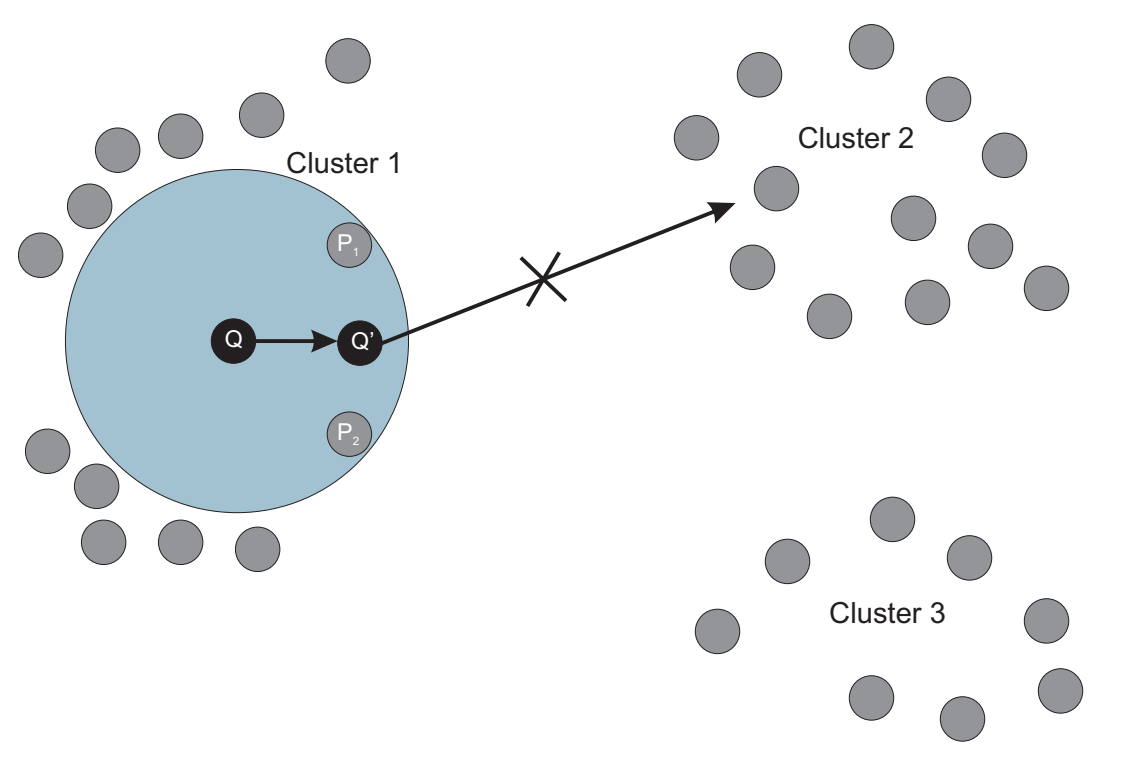

Figura 6.4: Fenômeno local optimum trap (Liu et al., 2009).

Tais explicitações do fenômeno local optimum traps são passíveis de ocorrência no processo de realimentação de relevância. Modificando-se a função de distância utilizada em cada ciclo de realimentação de relevância modifica-se também o espaço de busca, fazendo, dessa forma, com que a distribuição dos dados também mude. Portanto, uma vez que a distribuição dos dados é modificada, isso possibilita o retorno de diferentes imagens para a rotulação do usuário e então a possibilidade de "escapar" do mínimo local, ao qual estava preso.

\subsubsection{Estudo de Caso 1}

Partindo para a análise dos experimentos realizados com relação à combinação aleatória de funções de distância, com o intuito de demonstrar a viabilidade da modificação dinâmica de distâncias em diferentes ciclos, as Figuras 6.5 e 6.6 ilustram as curvas de P\&R, obtidas realizando a modificação dinâmica de funções de distância em diferentes ciclos de realimentação. O eixo das abscissas representa as iterações de realimentação de relevância, ou seja, os diferentes ciclos. Já os eixos das ordenadas dizem respeito à precisão média obtida em cada um dos diferentes ciclos. Para os experimentos, foram realizadas 3 iterações de realimentação de relevância, nesses experimentos foi utilizada a base $M R I$. O método de realimentação de relevância utilizado foi o baseado na movimentação de um único centro de consulta (query point movement - QPM). Já com relação às funções de distância, foram utilizadas as pertencentes à família Minkowski, bem como, as distâncias Canberra e $\chi^{2}$. Tais funções de distância são explicitadas, em maiores detalhes, no capítulo 3.

Nos experimentos, o processo de realimentação de relevância foi realizado de maneira automática, simulando as escolhas de usuários, uma vez que seria inviável realizar todas as 
combinações possíveis entre as diferentes funções de distância, analisadas para cada ciclo de realimentação. Tal processo é amplamente utilizado na literatura para a corroboração da proposta de novos métodos, bem como, comparação destes. Dessa forma, as imagens retornadas que possuíam a mesma classe da imagem de consulta foram consideradas como relevantes no processo.

Os gráficos das Figuras 6.5 (a), (b), (c) e (d) ilustram os resultados obtidos, respectivamente, utilizando imagens de consulta pertencentes às classes: cabeça axial; cabeça coronal; espinha sagital; cabeça sagital.

As legendas de tais gráficos elucidam as funções de distâncias utilizadas em cada ciclo, em ordem crescente. Por exemplo uma legenda da forma $L_{1}-L_{\infty}-L_{1}-L_{1}$ significa que para a consulta inicial foi utilizada a função distância $L_{1}$, são então retornadas determinadas imagens, sendo que algumas são rotuladas como relevantes e então modifica-se a distância para $L_{\infty}$ e realiza-se uma nova consulta utilizando as imagens rotuladas, ou seja, referente ao primeiro ciclo de realimentação, posteriormente, novas imagens são retornadas e então novamente algumas são rotuladas como relevantes, modifica-se a distância para $L_{1}$ e realiza-se a consulta caracterizando o segundo ciclo de realimentação. Por fim, no terceiro ciclo de realimentação é realizado o mesmo procedimento porém mantém-se a função $L_{1}$.

Analisando as curvas da Figura 6.5 (a), nota-se que caso o usuário inicie a busca inicial com a distância $L_{\infty}$ e mantenha a mesma distância para os ciclos de realimentação posteriores, obtém-se uma precisão de aproximadamente $64 \%$, considerando o terceiro ciclo de realimentação. Já realizando a busca inicial com a distância $L_{\infty}$ e nos ciclos de realimentação modificando para a distância $L_{1}$ e mantendo-a, obtém-se uma precisão de até $82 \%$, ou seja, modificando as distâncias dinamicamente em cada ciclo de realimentação, obteve-se um ganho de cerca de $28 \%$ na precisão. Dessa forma, é possível notar que o método proposto na seção 6.2, em conjunto com os perfis de usuário, é passível de aplicação.

É importante observar, ainda com relação às curvas da Figura 6.5 (a), que fixando-se a distância $L_{1}$ para a busca inicial e mantendo-a para os ciclos de realimentação, obtémse uma precisão de aproximadamente $76 \%$, ou seja, abaixo da precisão obtida, quando inicia-se com a distância $L_{\infty}$ e modifica-se, nos ciclos de realimentação, para a distância $L_{1}$. As curvas da Figura 6.5 (b) apresentam comportamentos semelhantes ao descrito.

Observando os gráficos da Figura 6.5 (c), é possível constatar que iniciando a busca inicial com a distância $L_{\infty}$ e mantendo-a nos ciclos de realimentação posteriores, obtémse uma precisão de aproximadamente $65 \%$, considerando o terceiro ciclo. Já iniciando a busca com a distância $L_{\infty}$ e nos ciclos de realimentação modificando para a distância $L_{1}$ e mantendo esta, obtém-se uma precisão de cerca de $98 \%$, ou seja, um ganho considerável na precisão das buscas. O mesmo comportamento pode ser observado para a distância $L_{2}$ fixa para todos os ciclos em comparação com a modificação dinâmica para a distância $L_{1}$ 

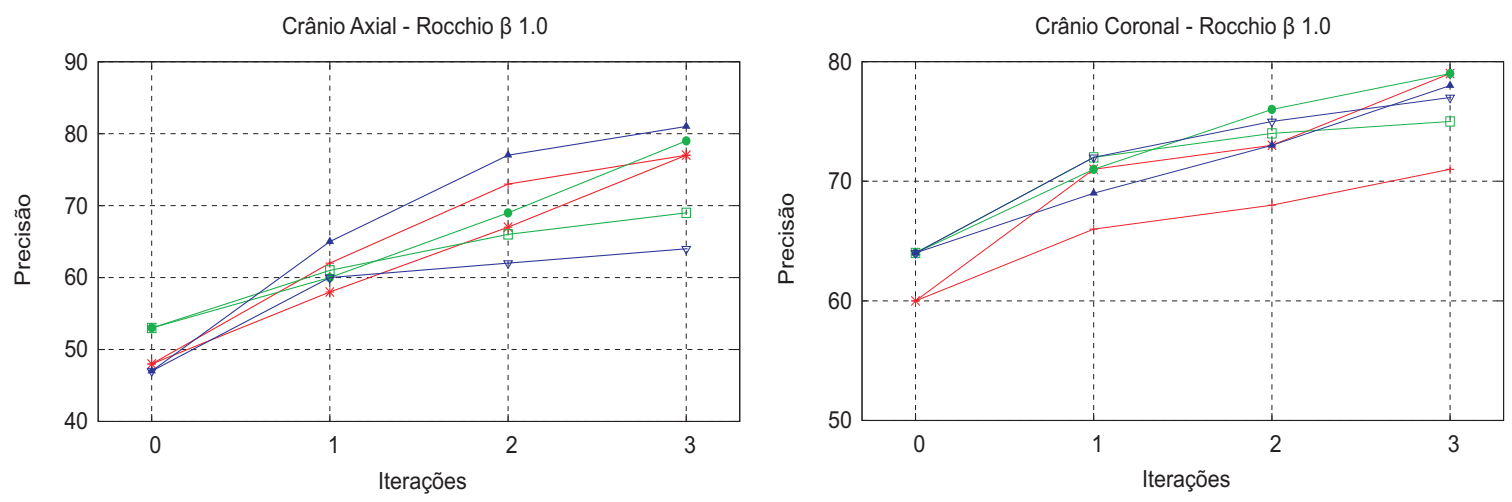

(a)

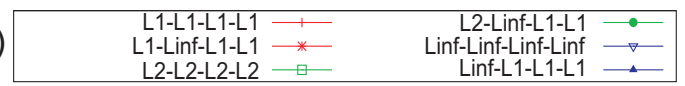

(b)
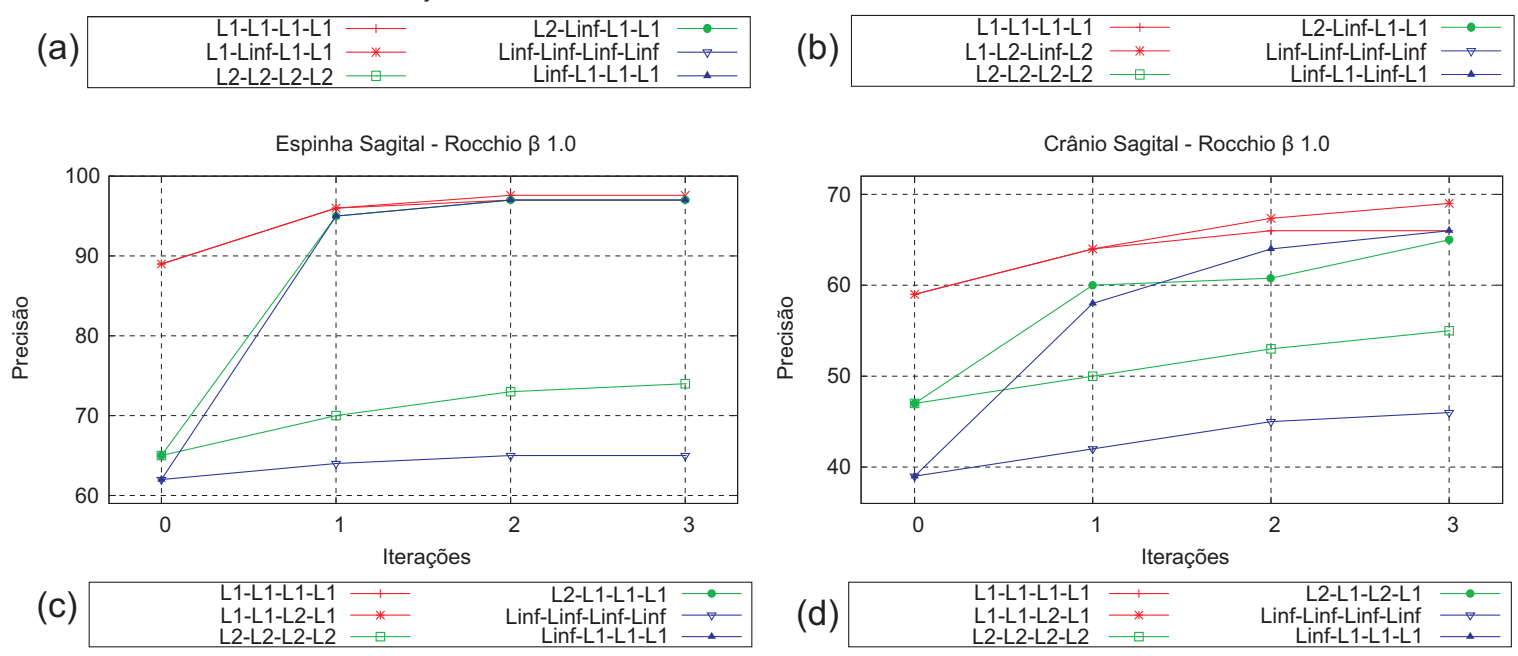

(c)

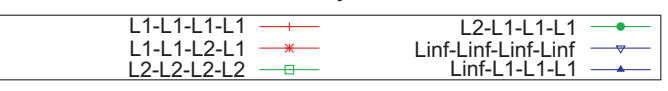

(d)

Figura 6.5: Gráficos de curvas de precisão média, gerados a partir de consultas aos kvizinhos mais próximos e dos primeiros 3 ciclos de realimentação sobre a base de imagens $M R I$, comparando a utilização da técnica QPM com distâncias estáticas e QPM com a abordagem de mudança dinâmica de funções de distância proposta. Realimentação positiva, utilizando funções de distância da família Minkowski. (a) Cabeça Axial (b) Cabeça Coronal (c) Espinha Sagital (d) Cabeça Sagital.

nos outros ciclos. Nota-se também que mantendo-se a distância $L_{1}$, tanto na busca inicial, quanto para todos os ciclos de realimentação, obtém-se uma precisão de aproximadamente $98 \%$.

Comportamentos similares são apresentados nas curvas da Figura 6.5 (d). No entanto, é interessante observar que, mantendo a distância $L_{1}$ fixa para a busca inicial e os posteriores ciclos de realimentação, obteve-se a segunda melhor precisão, cerca de $65 \%$. Já mantendo a distância $L_{1}$ para busca inicial e o primeiro ciclo de realimentação, e então modificando para a distância $L_{2}$ no segundo ciclo, e no terceiro ciclo retornando para a distância $L_{1}$, obtém-se a melhor precisão, cerca de $69 \%$. Uma possível explicação para tal fato é a modificação da distribuição das distâncias, levando o processo a "escapar" de um possível mínimo local em direção a imagens de maior relevância, como descrito na Figura 6.4. O mesmo comportamento pode ser observado para a distância $L_{2}$ e modificando-a.

Foram também realizados experimentos com as distâncias Canberra e $\chi^{2}$, compondoas às funções da família Minskowski. A partir da observação das curvas P\&R das Figura 
6.6 (a), (b), (c) e (d), pôde-se observar que alternar entre famílias de funções de distância diferentes obteve-se ganho considerável de precisão, considerando o terceiro ciclo de realimentação em praticamente todos os casos, em comparação com a manutenção da mesma distância em todos os ciclos. Esse fato pode demonstrar o escape de um possível mínimo local, ao qual o processo estava preso, fato o qual gerava a saturação da precisão das consultas, em que um grande número de imagens iguais eram repetidamente rotuladas como relevantes nos diferentes ciclos.
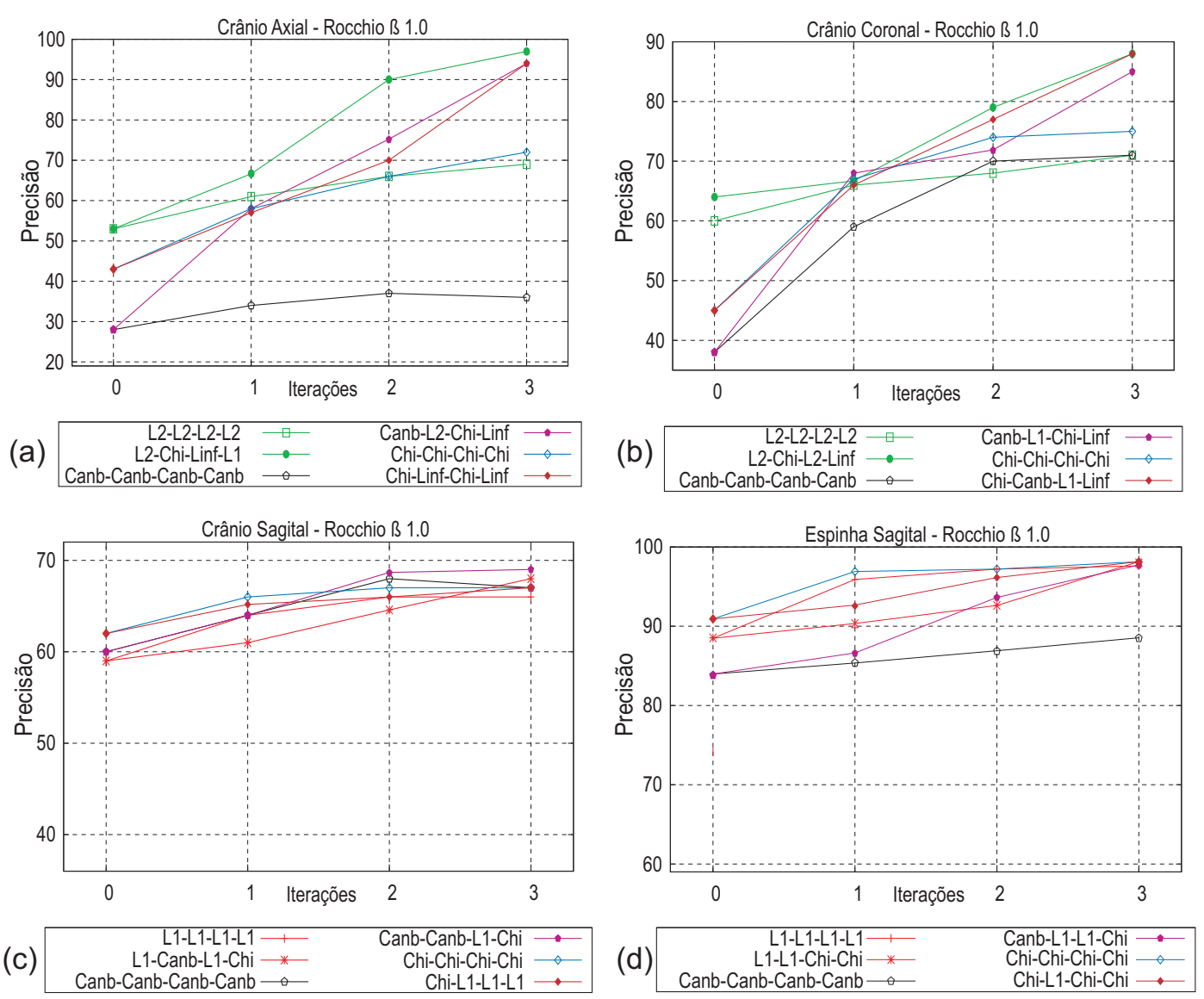

(c)

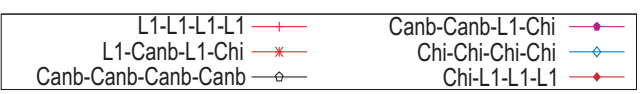

Chi-L1-L1-L1

Figura 6.6: Gráficos de curvas de precisão média, gerados a partir de consultas aos kvizinhos mais próximos e dos primeiros 3 ciclos de realimentação sobre a base de imagens $M R I$, comparando a utilização da técnica QPM com distâncias estáticas e QPM com a abordagem de mudança dinâmica de funções de distância proposta. Realimentação positiva, utilizando funções de distância da família Minkowski, Canberra e $\chi^{2}$. (a) Cabeça Axial (b) Cabeça Coronal (c) Cabeça Sagital (d) Espinha Sagital.

Os experimentos realizados, no sentido de modificação aleatória de funções de distância em diferentes ciclos de realimentação, apresentou resultados interessantes, uma vez que corroboraram possibilidades para o desenvolvimento de diferentes técnicas, principalmente relacionadas a políticas para a escolha de funções de distância. Dessa forma, é justamente nessa direção que os próximos experimentos foram realizados, aplicando o método desenvolvido, uma vez que a modificação de funções de distância em cada ciclo de 
realimentação não pode ser realizada a esmo, pois para que seja possível atingir a melhor combinação seria necessária uma verificação exaustiva.

\subsubsection{Estudo de Caso 2}

As Figuras 6.7 e 6.8 ilustram os resultados obtidos a partir do emprego do método proposto em comparação com a manutenção estática da melhor função de distância para a base como um todo. Para tanto, foi utilizada a base $M R I$ representada pelas características oriundas dos histogramas de níveis de cinza e dos momentos de Zernike, respectivamente. Considerando as características obtidas pelos histogramas de níveis de cinza, a melhor função de distância para a base como um todo, foi a $L_{1}$ e para as características obtidas a partir dos momentos de Zernike foi a distância Canberra.

Posteriormente, foi então verificada para cada uma das classes da base de imagens $M R I$, qual a distância que melhor adequava-se a cada uma dessas e então tal informação foi armazenada no perfil.

Nas Figuras 6.7 (a), (b) e (c) pode-se observar os resultados obtidos, respectivamente, nos três primeiros ciclos de realimentação, considerando para tanto, a classe de imagens Crânio Coronal, a qual apresenta como melhor função de distância a $L_{2}$ e como segunda melhor função de distância a $L_{\infty}$, porém com resultados muito próximos da $L_{2}$, chegando praticamente a um empate.

Analisando os gráficos da Figura 6.7 (a), nota-se que a distância $L_{2}$, que melhor adequa-se à classe, apresenta um ganho de até 36\% com relação à precisão das consultas por similaridade em comparação com a distância $L_{1}$ (melhor da base), considerando um nível de revocação de $70 \%$. Já realizando a mesma análise para a distância $L_{\infty}$, obtevese um ganho de até $25 \%$ na precisão para um nível de revocação de $65 \%$. Tais ganhos aumentam com o decorrer dos ciclos de realimentação. Observando as Figuras 6.7 (b) e (c), a distância $L_{2}$ apresentou ganhos de até $46 \%$ de precisão para um nível de revocação de $70 \%$ e $48 \%$ para um nível de $65 \%$ de revocação, respectivamente. Já considerando a distância $L_{\infty}$, os ganhos de precisão foram de até $39 \%$ e $48 \%$, respectivamente, ambos para um nível de revocação de $65 \%$.

Com relação aos gráficos das Figuras 6.8 (a), (b) e (c) referentes à classe Crânio Coronal representadas pelos momentos de Zernike, a melhor função de distância foi a $L_{\infty}$ para essa classe, praticamente equiparada com a distância $L_{2}$. Analisando os ganhos de precisão em relação à melhor função da base (i.e. Canberra) para tais características, explicitados pela Figura 6.8 (a), estes alcançaram níveis de até $60 \%$ utilizando a distância $L_{\infty}$ e $54 \%$ considerando a distância $L_{2}$, ambas para um nível de revocação de $50 \%$. Já observando os resultados da Figura 6.8 (b) referentes à precisão do segundo ciclo de realimentação, a distância $L_{\infty}$ obteve um ganho de até $83 \%$ na precisão das consultas, já a distância $L_{2}$ alcançou um ganho de $77 \%$, considerando, para ambas, um nível de revocação de $55 \%$. 


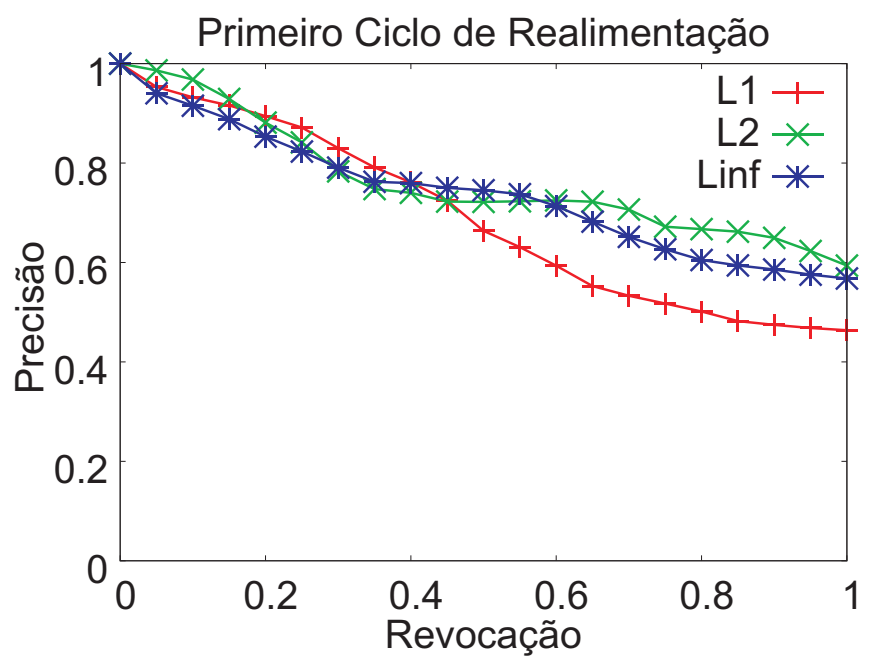

(a)

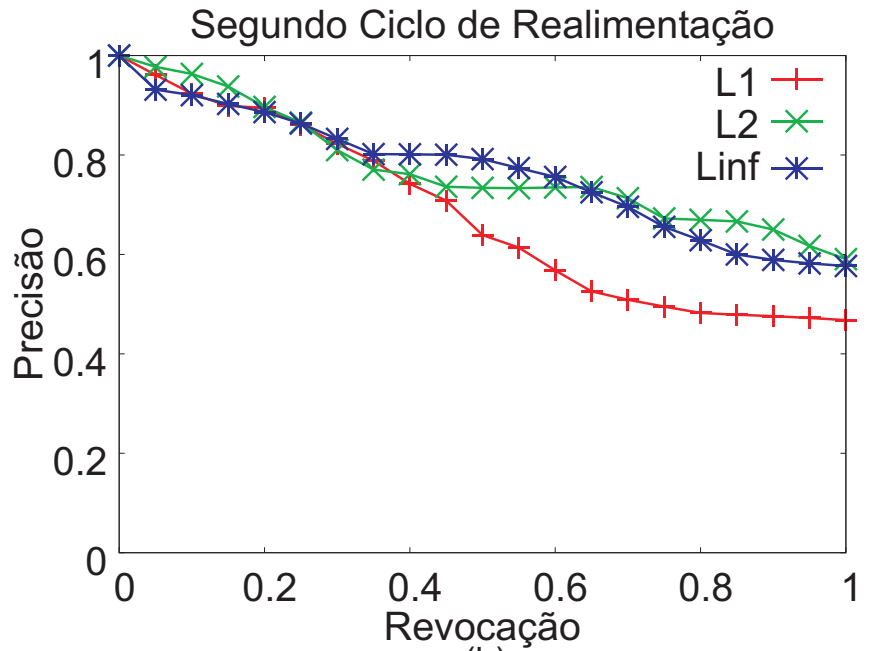

(b)

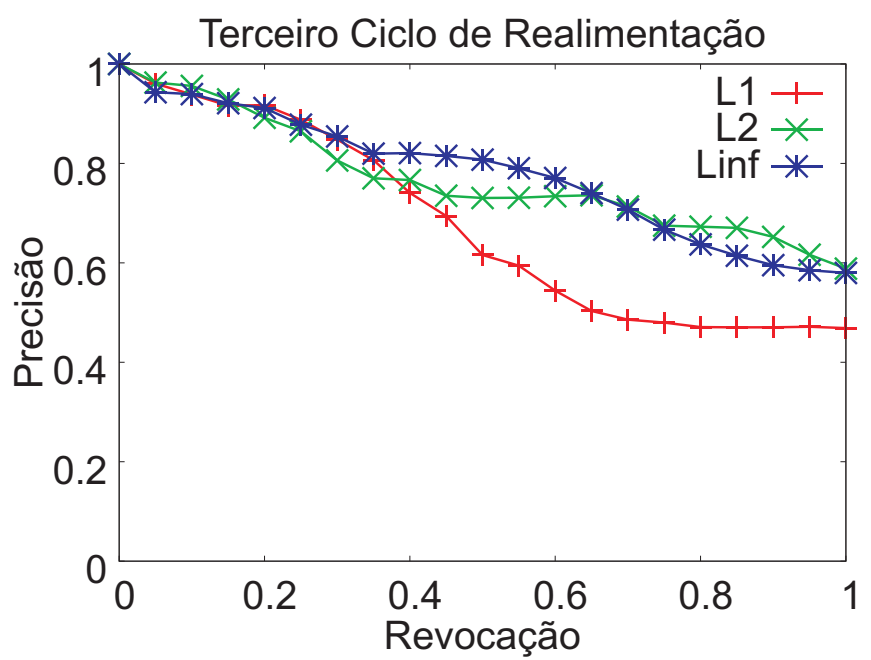

(c)

Figura 6.7: Gráficos de curvas de precisão e revocação, gerados a partir de consultas aos k-vizinhos mais próximos sobre imagens da classe Crânio Coronal da base de imagens $M R I$ representadas por características de histogramas de níveis de cinza, comparando a política proposta em relação a manutenção da melhor distância da base. 
Com relação aos gráficos da Figura 6.8 (c), pode-se observar novamente um ganho em relação a precisão, aplicando o método proposto. A distância $L_{\infty}$ obteve um ganho de até $84 \%$ quando comparada com a distância Canberra, para um nível de revocação de $50 \%$ enquanto que a distância $L_{2}$ alcançou um ganho de até $81 \%$ segundo a mesma comparação, considerando um nível de revocação de $55 \%$.

Nas Figuras 6.8 (a), (b) e (c), pode-se observar os resultados obtidos considerando, respectivamente, os três primeiros ciclos de realimentação, utilizando, para tanto, a classe de imagens Crânio Coronal, sendo que esta apresenta como melhores funções de distância a $L_{\infty}$ e $L_{2}$ praticamente empatadas com relação à precisão média. No caso de empate a política adotada foi a da escolha da função de distância com menor custo computacional, nesse caso a $L_{\infty}$.

As Figuras 6.9 e 6.10 ilustram o comportamento da precisão média, em relação as iterações do processo de realimentação de relevância. O eixo das abscissas representa as iterações de realimentação de relevância, ou seja, os diferentes ciclos. Já o eixo das ordenadas diz respeito à precisão média, obtida em cada um dos diferentes ciclos.

Analisando o gráfico da Figura 6.9, pode-se perceber que, ao empregar o método proposto, obteve-se um ganho com relação à precisão média de aproximadamente $14 \%$, em todos os ciclos de realimentação, uma vez que a distância $L_{1}$ (melhor da base) foi substituída pela distância $L_{2}$ (melhor da classe Crânio Coronal). Já considerando a segunda melhor distância da classe, $L_{\infty}$, o método proposto apresentou um ganho de $9 \%, 10 \%$ e $14 \%$, considerando, respectivamente, os ciclos 1, 2 e 3 de realimentação.

Já com relação ao gráfico da Figura 6.10, é possível observar que a distância $L_{\infty}$ apresentou ganhos de aproximadamente $24 \%, 28 \%$ e 30\%, em comparação com a precisão média, obtida pela distância Canberra, considerando, respectivamente, os ciclos 1, 2 e 3 do processo de realimentação. Já a distância $L_{2}$ apresentou ganhos de $20 \%, 24 \%$ e $24 \%$ com relação à mesma comparação com a distância Canberra. Nota-se a partir de tais resultados, que a distância $L_{\infty}$ apresentou menor saturação durante o processo de realimentação, quando comparada com a distância $L_{2}$.

As Figuras 6.11 (a), (b) e (c), ilustram os resultados obtidos utilizando a classe Espinha Sagital da base de imagens $M R I$, descrita pelas características obtidas a partir dos histogramas de níveis de cinza, para os 3 primeiros ciclos de realimentação, respectivamente, comparando o método proposto com a manutenção da melhor distância para a base toda. A melhor função de distância para a base, nesse caso, foi a $L_{1}$, como já mencionando anteriormente. Já a melhor função de distância para a classe de imagens Espinha Sagital foi a $\chi^{2}$.

Observando o gráfico da Figura 6.11 (a), o método proposto obteve um ganho de 11\%, para um nível de revocação de $75 \%$, ou seja, pela modificação da função $L_{1}$ (melhor da base) para a função $\chi^{2}$ (melhor da classe Espinha Sagital). Já observando as Figuras 6.11 


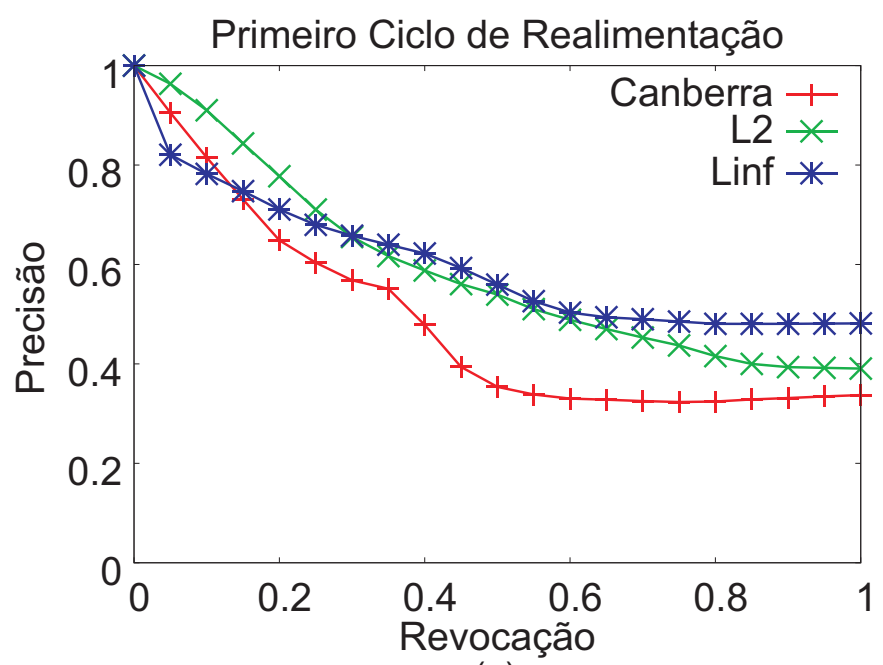

(a)

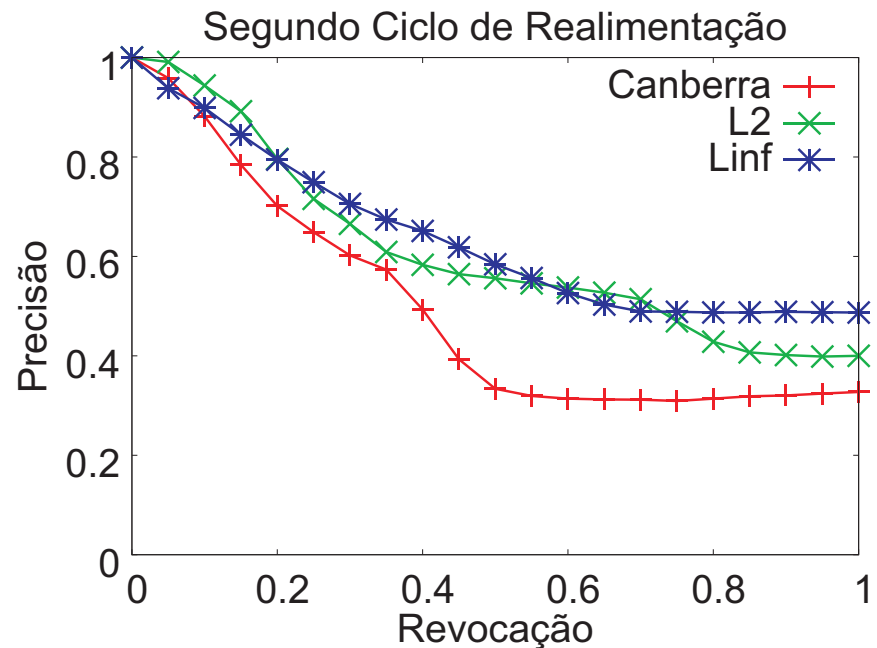

(b)

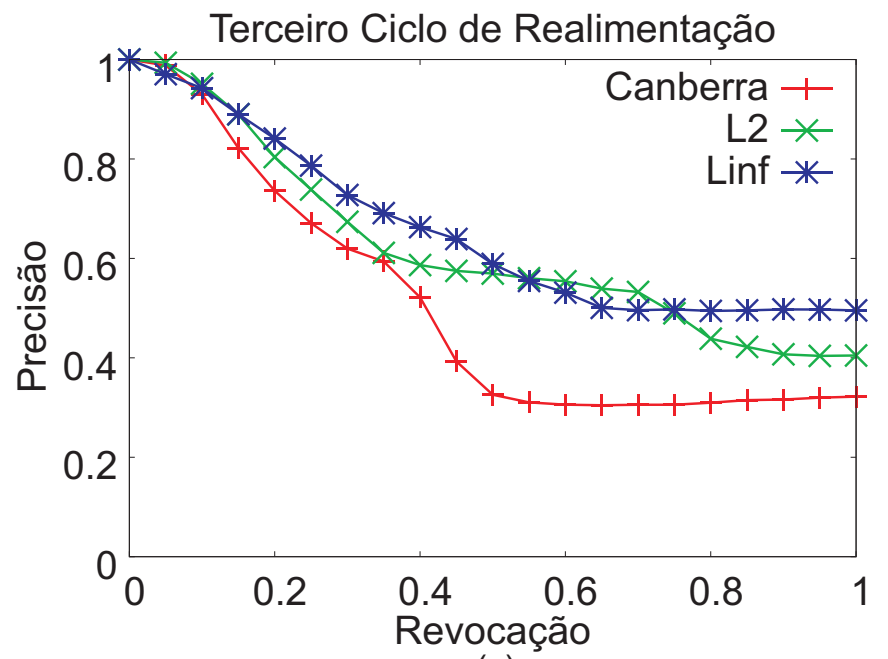

(c)

Figura 6.8: Gráficos de curvas de precisão e revocação, gerados a partir de consultas aos k-vizinhos mais próximos sobre imagens da classe Crânio Coronal da base de imagens $M R I$ representadas por características oriundas dos momentos de Zernike, comparando a política proposta em relação a manutenção da melhor distância da base. 


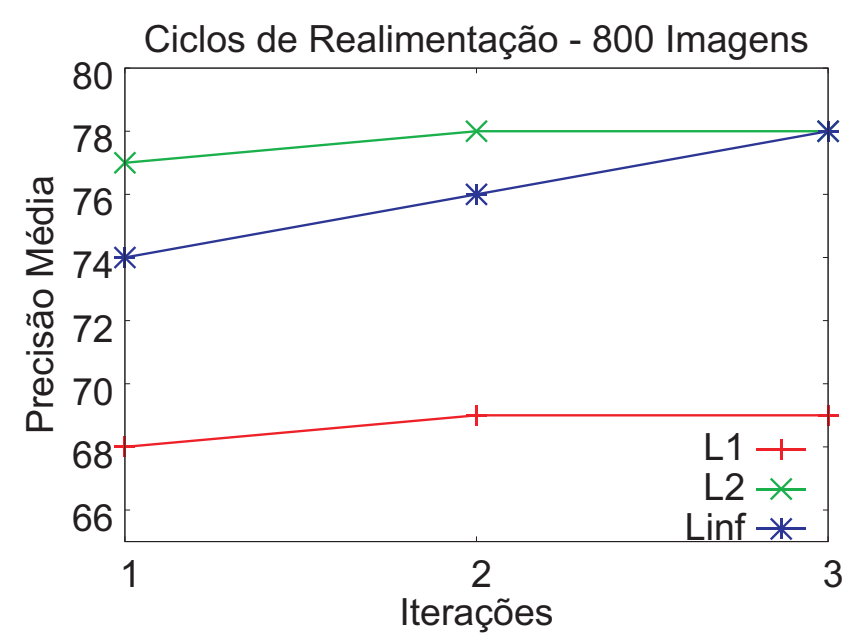

Figura 6.9: Gráficos de curvas de precisão média, gerados a partir de consultas aos kvizinhos mais próximos e dos primeiros 3 ciclos de realimentação sobre imagens da classe Crânio Coronal da base de imagens $M R I$, representadas por características de histogramas de níveis de cinza, comparando a política proposta em relação a manutenção da melhor distância da base.

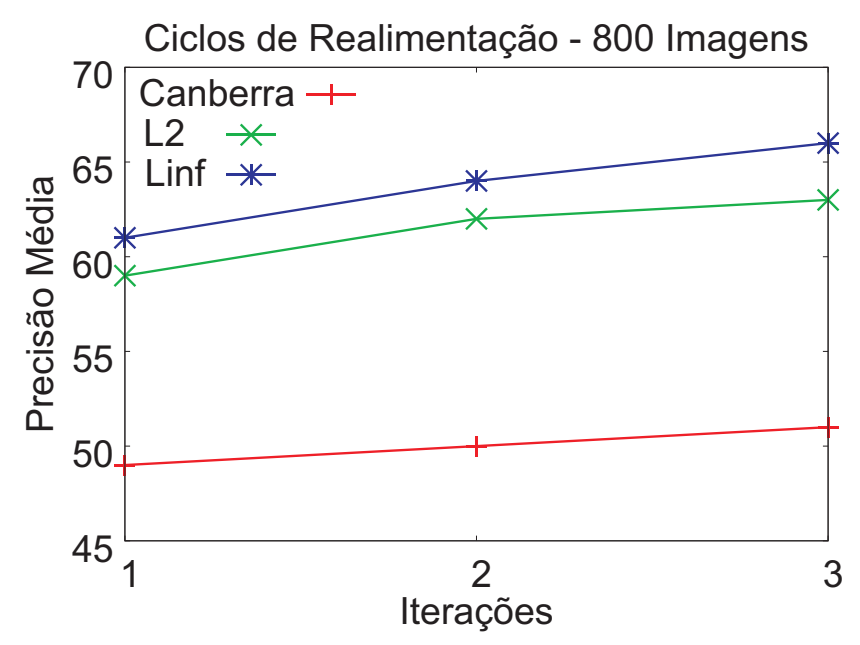

Figura 6.10: Gráficos de curvas de precisão média, gerados a partir de consultas aos kvizinhos mais próximos e dos primeiros 3 ciclos de realimentação sobre imagens da classe Crânio Coronal da base de imagens $M R I$, representadas por características oriundas dos momentos de Zernike, comparando a política proposta em relação a manutenção da melhor distância da base.

(b) e (c), o método alcançou ganhos de até $14 \%$ e 15\%, respectivamente, com relação à precisão, considerando, para ambos os casos, um nível de revocação de $80 \%$.

\subsubsection{Estudo de Caso 3}

As Figuras 6.12 e 6.13 ilustram os resultados obtidos utilizando o método proposto em comparação novamente com a abordagem tradicional de manutenção de uma mesma função de distância em todos os ciclos de realimentação, considerando a base de imagens 


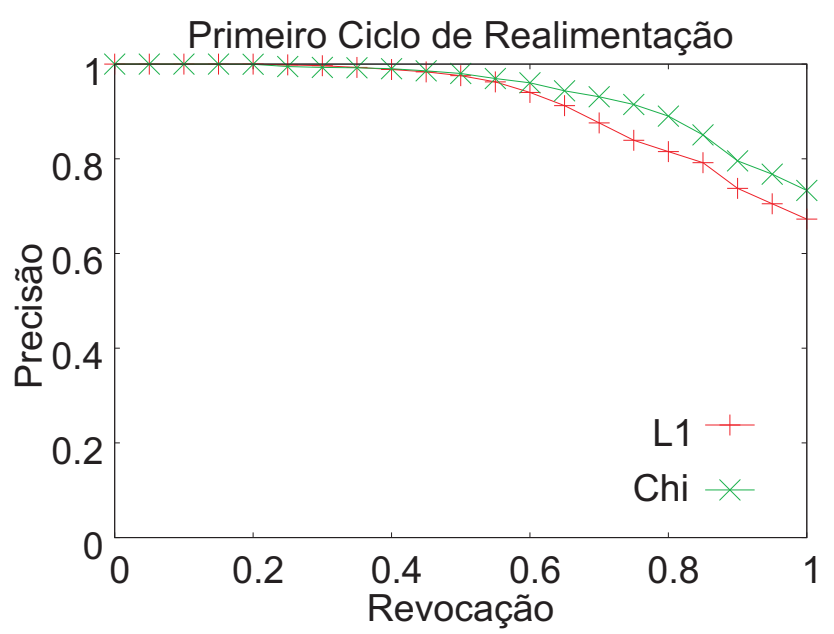

(a)

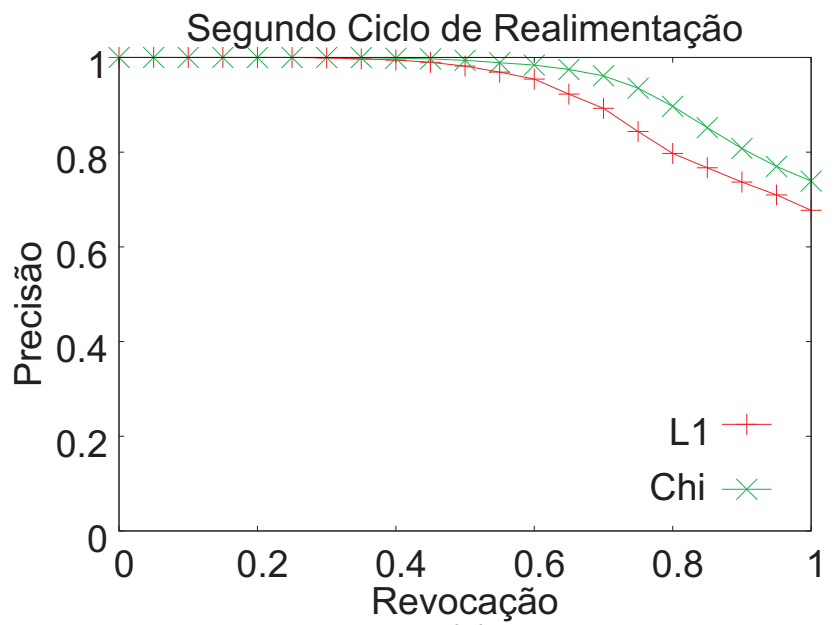

(b)

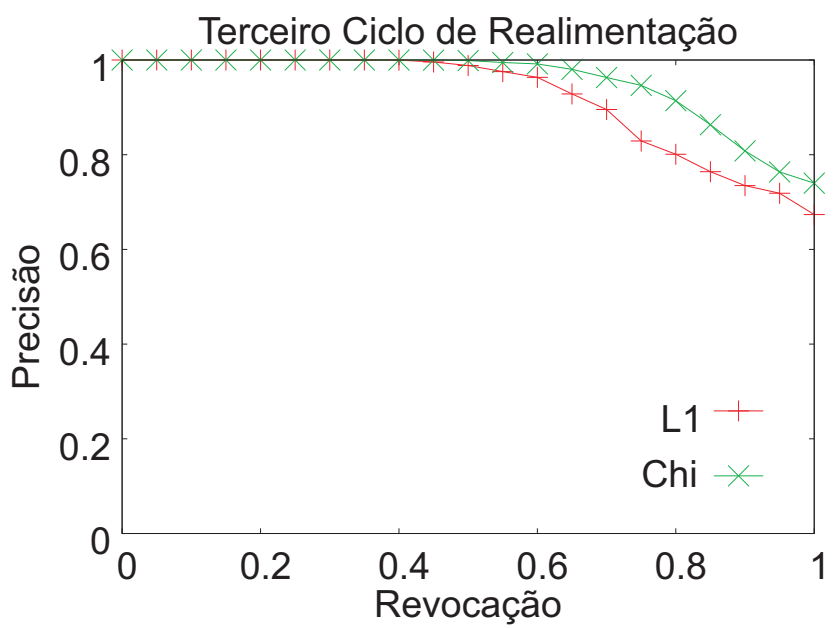

(c)

Figura 6.11: Gráficos de curvas de precisão e revocação, gerados a partir de consultas aos k-vizinhos mais próximos e dos primeiros 3 ciclos de realimentação sobre imagens da classe Espinha Sagital da base de imagens $M R I$, representadas por características oriundas dos momentos de Zernike, comparando a política proposta em relação a manutenção da melhor distância da base. 
CTROIsPulmão representada por características oriundas dos descritores de Haralick e dos momentos de Zernike, respectivamente. É importante salientar que para as características oriundas dos descritores de Haralick, a função de distância que apresentou melhor precisão para a base de dados como um todo foi a distância Canberra. Já para os momentos de Zernike a função de distância que apresentou melhor precisão foi a $L_{1}$. Dessa forma, as distâncias Canberra e $L_{1}$ foram respectivamente utilizadas como ponto inicial para ambos os tipos de características. Posteriormente verificou-se para cada classe de imagens da base CTROIsPulmão qual a distância que atingiu a maior precisão para cada uma dessas classes, tal informação foi então armazenada no perfil.

As Figuras 6.12 (a), (b) e (c) elucidam os resultados obtidos empregando três ciclos de realimentação de relevância, respectivamente, considerando a classe de imagem Enfisema representada pelas características oriundas dos descritores de Haralick. É importante destacar que a classe Enfisema apresentou a distância $L_{\infty}$ como a melhor, e a distância $L_{2}$ como segunda melhor, diferentemente da distância Canberra a qual apresentou a melhor precisão para a base como um todo. Ambas as distâncias, $L_{\infty}$ e $L_{2}$ apresentaram resultados muito próximos.

Analisando os gráficos da Figura 6.12 (a) nota-se que a distância $L_{\infty}$, ou seja, a que apresentou melhor precisão para a classe Enfisema, alcançou um ganho de precisão de até $22 \%$ em relação às consultas por similaridade utilizando a distância Canberra (a qual obteve melhor precisão para o conjunto como um todo) considerando um nível de revocação de $70 \%$. Ao analisar os resultados obtidos pela distância $L_{2}$ observa-se que esta obteve um ganho de precisão de até $12 \%$ para o mesmo nível de revocação quando comparada com a distância Canberra.

Tais ganhos aumentam continuamente com os posteriores ciclos de realimentação de relevância. Considerando, por exemplo, as Figuras 6.12 (b) e (c), pode-se notar que a distância $L_{\infty}$ apresenta um ganho de precisão de até $26 \%$ e $29 \%$, para níveis de revocação de $65 \%$ e 70\%, quando comparada com a distância Canberra. Já com relação à distância $L_{2}$ esta alcançou ganhos de precisão de até $15 \%$, para um nível de revocação de $65 \%$, para consultas sobre a classe Enfisema.

As Figuras 6.13 (a), (b) e (c) elucidam os resultados obtidos considerando a classe de imagens Consolidação representada pelos momentos de Zernike. A melhor função de distância para tal classe de imagens foi a Canberra, a qual praticamente empatou a distância $\chi^{2}$. É importante relembrar que a distância $L_{1}$ foi a que apresentou melhores resultados para a base como um todo considerando os momentos de Zernike.

Na Figura 6.13 (a) nota-se que ao aplicar a arquitetura mediadora proposta e modificando a função de distância, as distâncias Canberra e $\chi^{2}$ praticamente empatam, alcançando um ganho de precisão de até 37\% para um nível de revocação de $40 \%$ quando comparadas com a distância $L_{1}$. Analisando os resultados ilustrados pela Figura 6.13 (b), ambas as distâncias, Canberra e $\chi^{2}$, obtiveram aproximadamente um ganho de precisão 


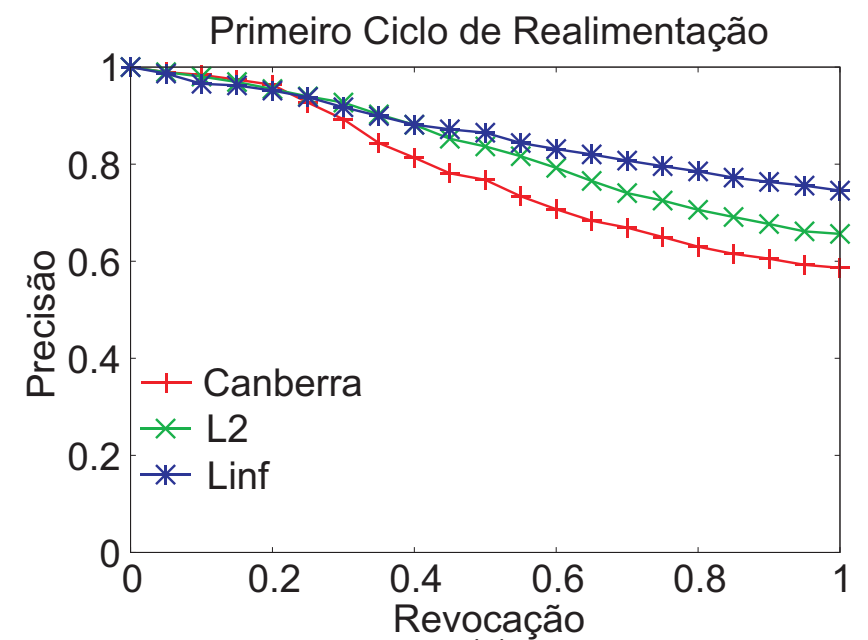

(a)

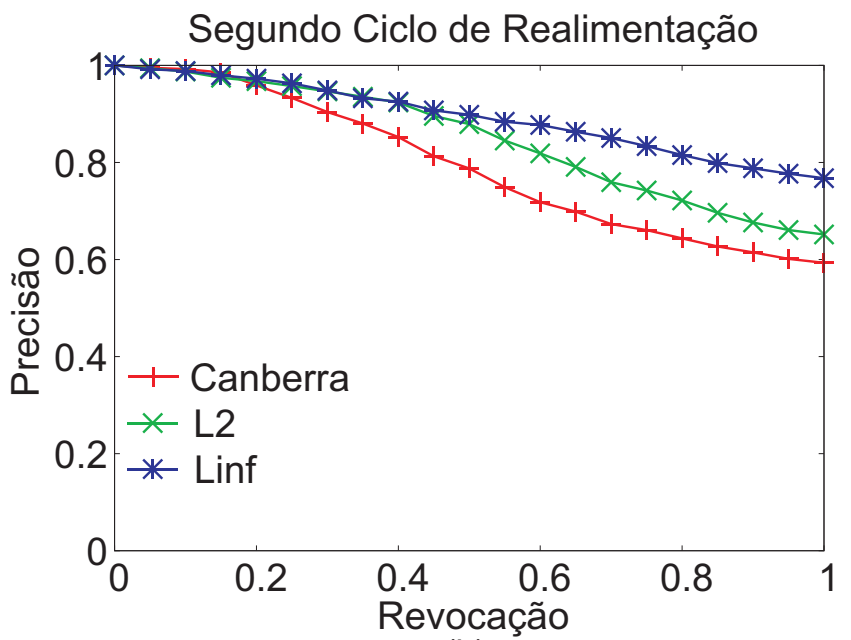

(b)

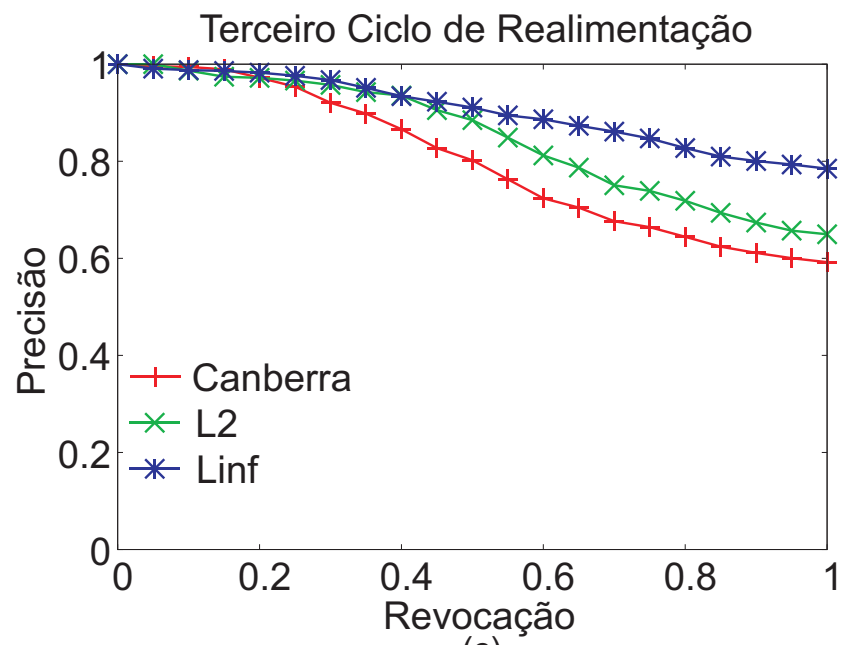

(c)

Figura 6.12: Gráficos de curvas de precisão e revocação gerados a partir de consultas aos k-vizinhos mais próximos e os primeiros 3 ciclos de realimentação sobre imagens da classe Enfisema da base de imagens CTRoisPulmão representadas por características oriundas dos descritores de Haralick aplicados às matrizes de co-ocorrência, comparando a política proposta em relação a manutenção da melhor distância da base. 


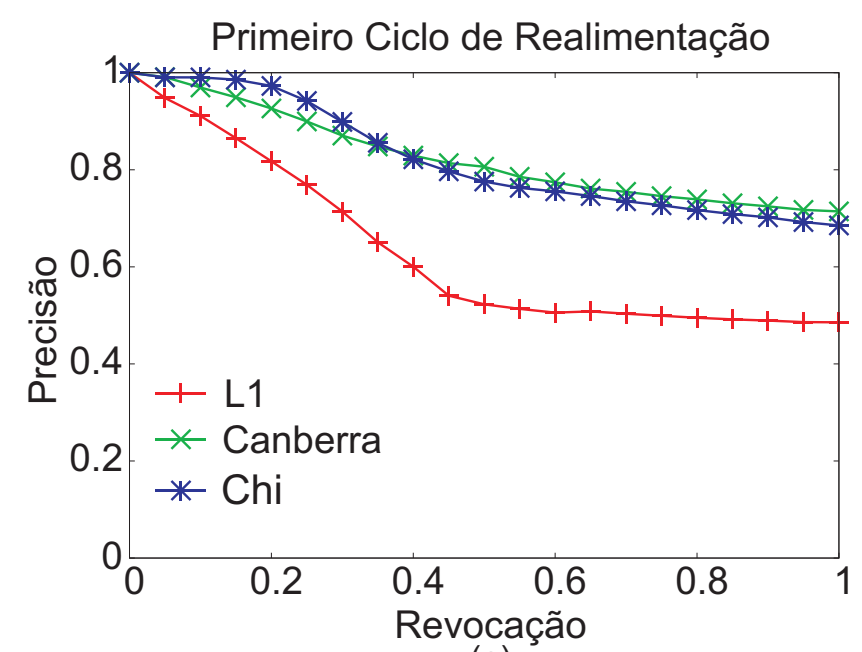

(a)

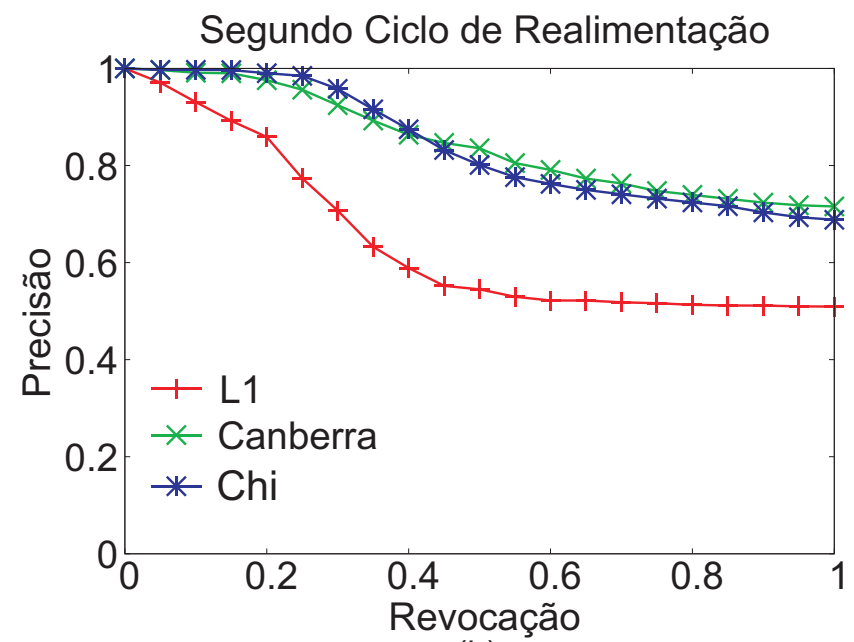

(b)

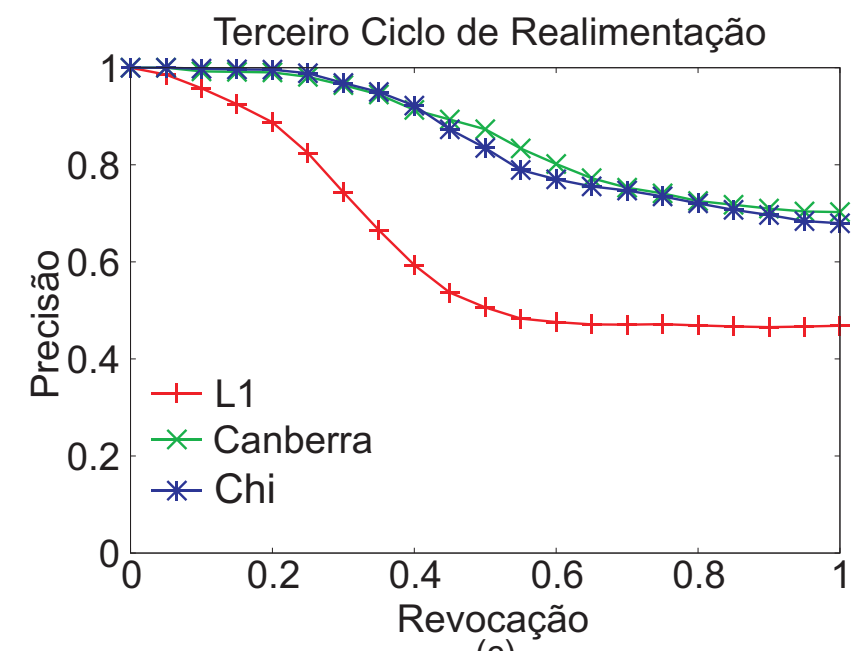

(c)

Figura 6.13: Gráficos de curvas de precisão e revocação gerados a partir de consultas aos k-vizinhos mais próximos e os primeiros 3 ciclos de realimentação sobre imagens da classe Consolidação da base de imagens CTRoisPulmão representadas por características oriundas dos momentos de Zernike, comparando a política proposta (Canberra e Chi) em relação a manutenção da melhor distância da base $\left(L_{1}\right)$. 
de até $56 \%$ e 49\%, respectivamente, para um nível de revocação de 50\%, para consultas sobre as imagens de Consolidação.

No que diz respeito aos gráficos da Figura 6.13 (c) nota-se novamente um ganho de precisãoA distância Canberra obteve um ganho de precisão de até $74 \%$ em comparação com a distância $L_{1}$, considerando um nível de revocação de $50 \%$. Já a distância $\chi^{2}$ atingiu um ganho de precisão de até $64 \%$ sobre a mesma comparação, para um nível de revocação de $45 \%$.

É importante enfatizar que na ocorrência de um empate de precisões obtidas pelas distâncias, o método proposto adota a política de escolher a distância que apresenta menor custo computacional. Por exemplo, se as distâncias $L_{1}$ e $L_{2}$ praticamente empatassem em relação à precisão obtida, a distância $L_{1}$ é selecionada. Tal fato ocorre com a classe Consolidação, na qual a distância Canberra e $\chi^{2}$ praticamente empatam, porém a Canberra apresenta menor custo computacional.

Outro fato a ser destacado a partir dos resultados é com relação à distância $L_{\infty}$ apresentar uma menor taxa de saturação durante o processo de realimentação de relevância quando comparada com a distância $L_{2}$. Portanto, tais políticas são aplicadas com base não apenas sobre o ganho de precisão, mas também na combinação entre as taxas de ganho de saturação e custo computacional.

Pode-se notar a partir dos resultados obtidos que a abordagem proposta foi capaz de atingir ganhos consideráveis em relação à precisão de consultas por similaridade em imagens médicas. Além disso, a arquitetura mediadora proposta aplica de maneira bem sucedida as políticas desenvolvidas para escolher a distância mais adequada a uma classe de imagens desejada, de acordo com a intenção do usuário. Portanto, abrindo novos caminhos para melhorar a aceitação de sistemas CBIR principalmente na área médica.

\subsubsection{Estudo de Caso 4}

Além das bases MRI e CTRoisPulmão, foram realizados experimentos utilizando a base de imagens Corel, descrita na Seção 6.3, as quais foram representadas pelas características oriundas dos histogramas de níveis de cinza. Para essa base, a melhor função de distância foi a Canberra.

As Figuras 6.14 (a), (b) e (c) descrevem os resultados obtidos para os 3 primeiros ciclos de realimentação, apresentando o método proposto em comparação com a manutenção da melhor função de distância para a base, referente à classe de imagens Africa. Para tal classe, a função de distância que melhor adequou-se foi a $\chi^{2}$.

Analisando os resultados explicitados pelas Figuras 6.14 (a), (b) e (c), pode-se observar que o método proposto apresentou um ganho de até $29 \%, 38 \%$ e 39\%, respectivamente, considerando para todos os casos um nível de revocação de $75 \%$.

Já as Figuras 6.15 (a), (b) e (c) ilustram os resultados obtidos segundo a classe Elephants da base Corel. Para essa classe de imagens, a função de distância $\chi^{2}$ apre- 


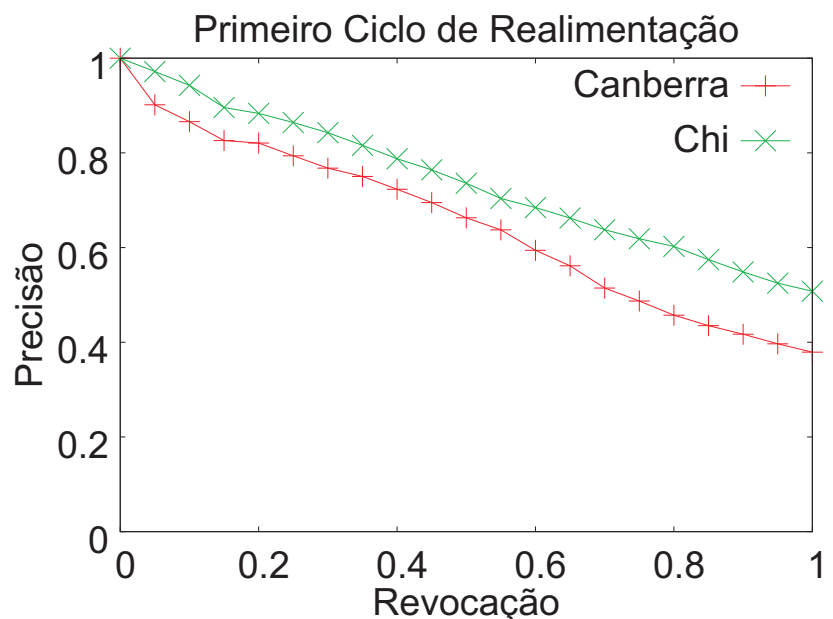

(a)

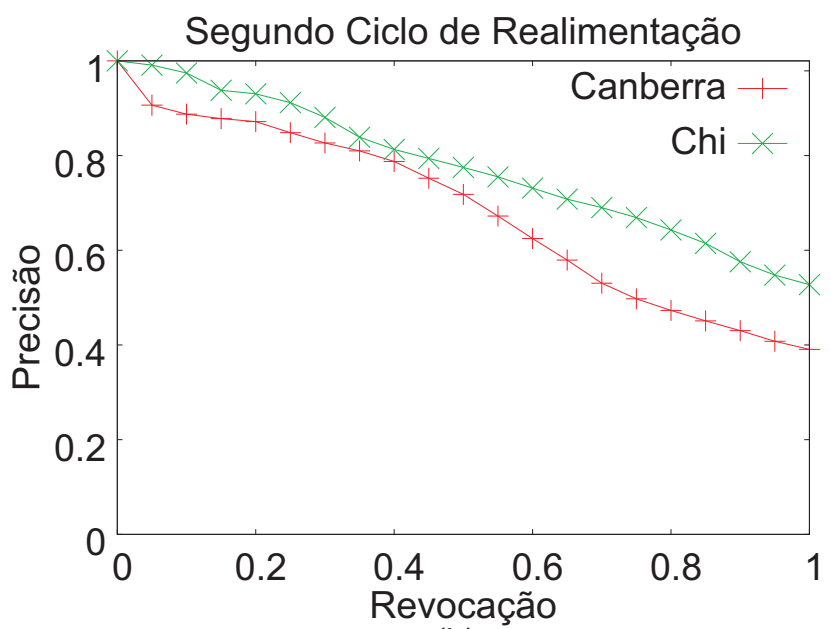

(b)

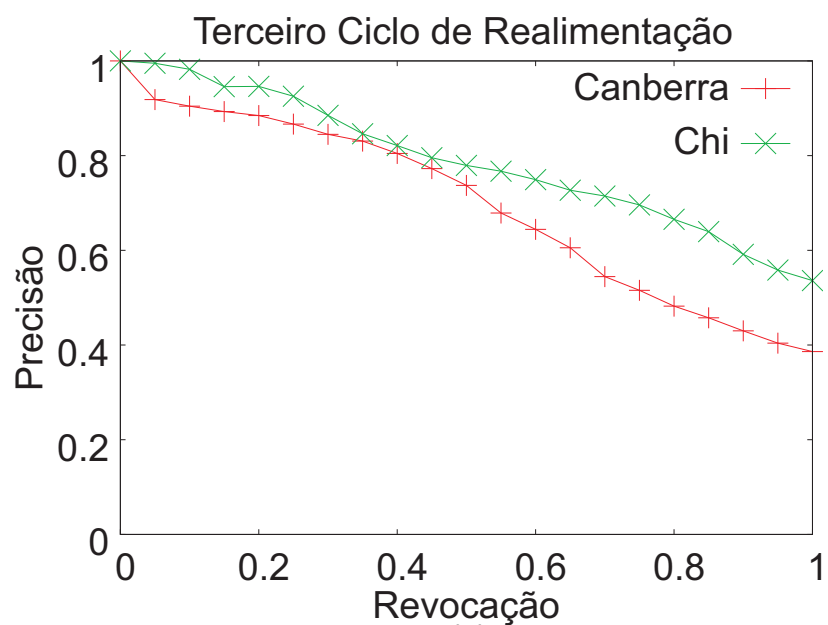

(c)

Figura 6.14: Gráficos de curvas de precisão e revocação gerados a partir de consultas aos k-vizinhos mais próximos e os primeiros 3 ciclos de realimentação sobre imagens da classe Africa da base de imagens Corel representadas por características oriundas dos histogramas de níveis de cinza, comparando a política proposta em relação a manutenção da melhor distância da base. 


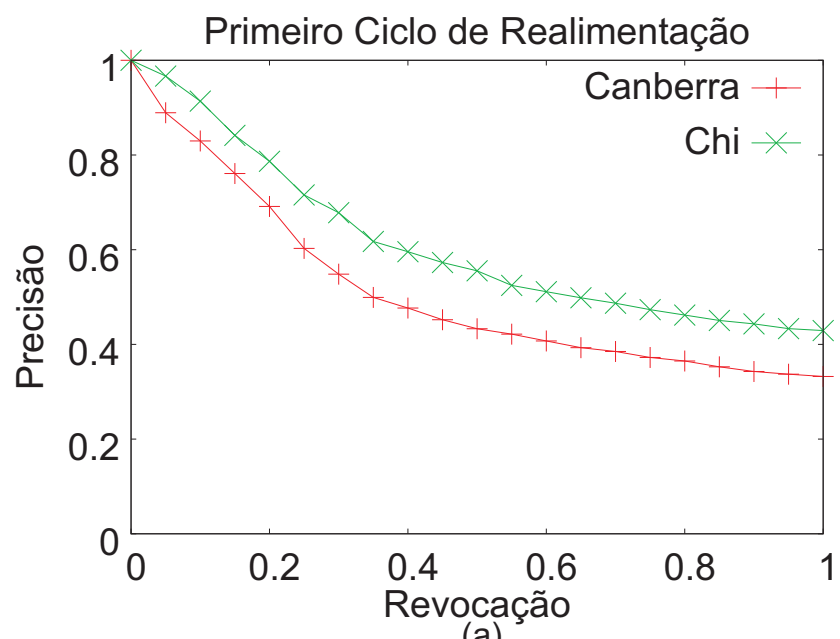

(a)

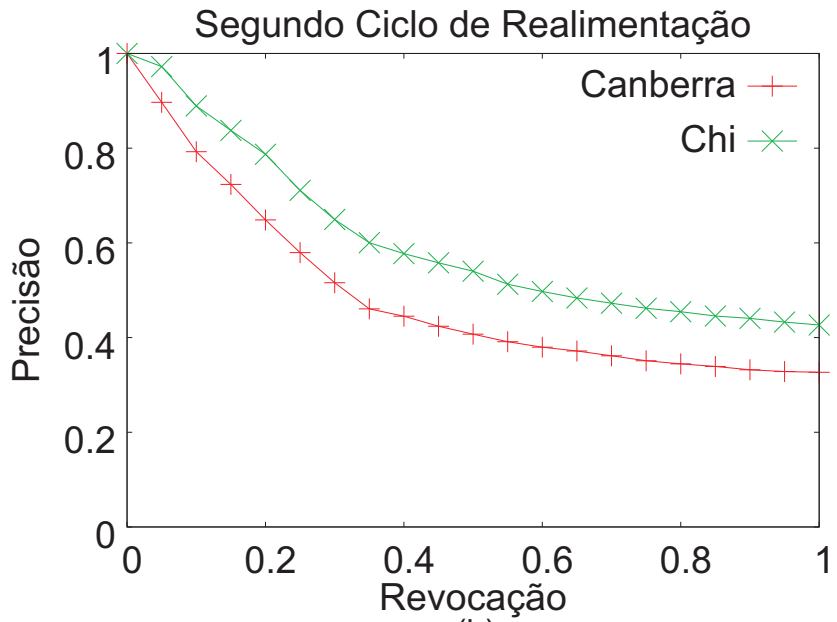

(b)

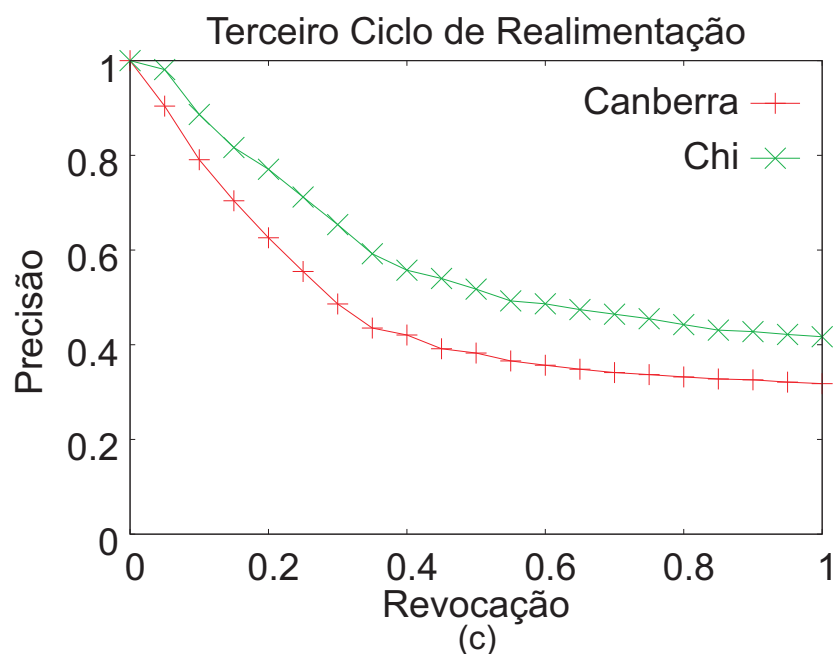

Figura 6.15: Gráficos de curvas de precisão e revocação gerados a partir de consultas aos k-vizinhos mais próximos e os primeiros 3 ciclos de realimentação sobre imagens da classe Elephants da base de imagens Corel representadas por características oriundas dos histogramas de níveis de cinza, comparando a política proposta em relação a manutenção da melhor distância da base. 


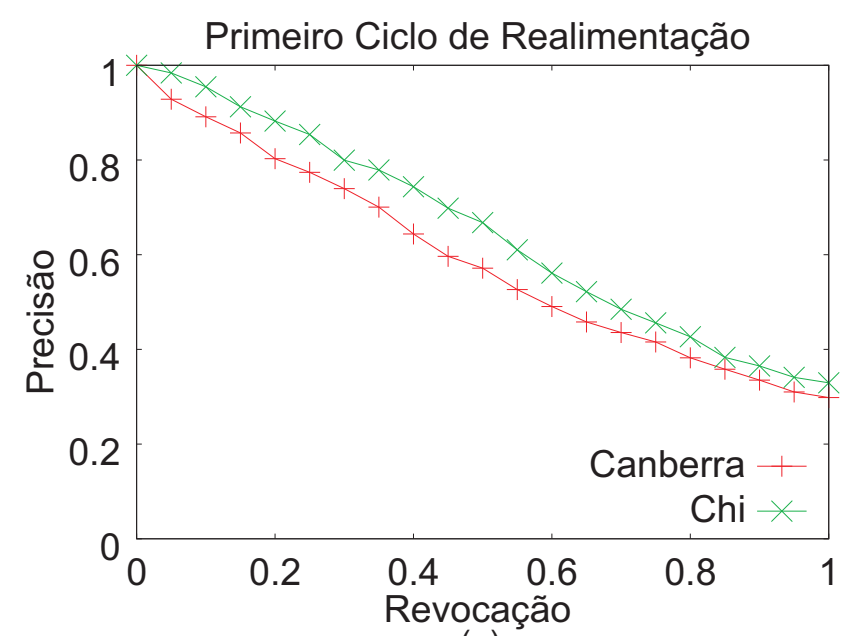

(a)

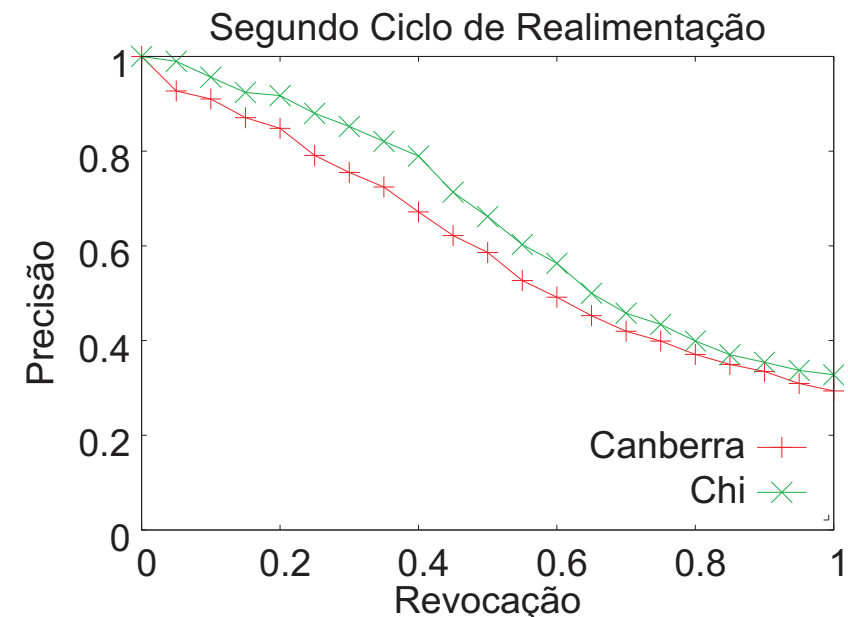

(b)

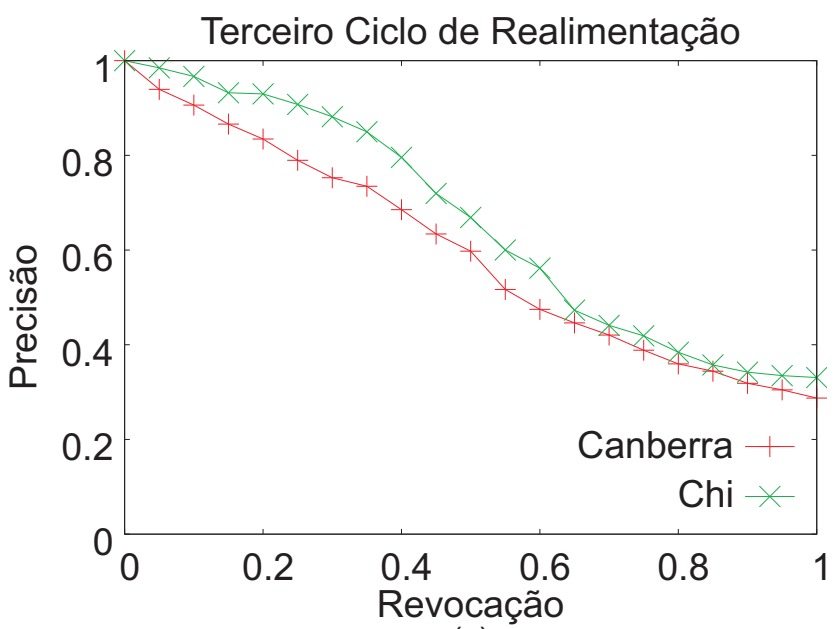

(c)

Figura 6.16: Gráficos de curvas de precisão e revocação gerados a partir de consultas aos k-vizinhos mais próximos e os primeiros 3 ciclos de realimentação sobre imagens da classe Horses da base de imagens Corel representadas por características oriundas dos histogramas de níveis de cinza, comparando a política proposta em relação a manutenção da melhor distância da base. 
sentou os melhores resultados. O método proposto novamente apresentou ganhos de precisão, cerca de até $27 \%, 31 \%$ e 37\%, considerando um nível de revocação de 35\%, respectivamente, para as Figuras 6.15 (a), (b) e (c).

As Figuras 6.16 (a), (b) e (c) explicitam os resultados obtidos, considerando a classe Horses da base Corel. Novamente a distância $\chi^{2}$ apresentou os melhores resultados para a presente classe. O método apresentou um ganho de precisão de até $17 \%$ e $19 \%$ para um nível de revocação de 40\%, considerando, respectivamente, os resultados explicitados pelas Figuras 6.16 (a) e (b). O mesmo pôde ser observado a partir da análise dos resultados ilustrados pela Figura 6.16 (c), em que o método obteve um ganho de aproximadamente $20 \%$ para um nível de revocação de $30 \%$.

Dessa forma, a partir dos resultados obtidos, pode-se observar que o método proposto alcançou resultados consideráveis em termos da precisão das consultas por similaridade. Além disso, o processo de escolha das políticas de funções de distância que melhor se adequam-se a uma determinada classe, de acordo com a intenção do usuário, é realizado de maneira transparente ao mesmo, por meio do mediador proposto, bem como, não requer que o usuário despenda esforço para a realização de tal processo.

\subsection{Considerações Finais}

Os experimentos realizados mostram que as funções de distância apresentam diferentes desempenhos na recuperação das imagens. Para cada ciclo de realimentação, a montagem do novo centro de consulta depende de quais imagens relevantes foram retornadas no ciclo atual. Como a qualidade da consulta é determinada, em parte, pela escolha da melhor função de distância, a troca das funções em cada ciclo foi determinante para análise do desempenho da realimentação nos ciclos posteriores. As possibilidades de otimização da consulta em cada ciclo contaram não só com a mudança do centro de consulta, mas também com a mudança do espaço de busca, onde as características estão imersas. Essa mudança no espaço de busca, caracterizada pela mudança da função de distância utilizada na consulta, fez com que a distribuição dos dados também se alterasse.

No entanto, a modificação de funções de distância em cada ciclo de realimentação não pode ser realizada a esmo, uma vez que para atingir a melhor combinação seria necessária uma verificação exaustiva. Dessa forma, o presente capítulo apresentou também uma nova abordagem, bem como uma nova política agregada a esta, para a escolha de funções de distância nos ciclos de realimentação, baseada tanto em informações a priori da base de imagens, bem como, na percepção do usuário no processo das consultas por similaridade. Os experimentos realizados, nessa direção, demonstraram a eficácia do método proposto, o qual melhora consideravelmente a precisão das consultas por similaridade, além de incluir a intenção do usuário no processo. 
Além disso, o método proposto pode ser aplicado com o intuito de mitigar o problema denominado cold-start. Tal problema ocorre quando não se tem praticamente conhecimento algum a respeito das preferências do usuário quando aplicado a sistemas de recomendação. O mesmo problema ocorre quando transportado para sistemas CBIR, ou seja, quando um novo especialista realiza consultas, não existem informações sobre quais pares função de distância/extrator de características melhor se adequam à percepção deste, ou mesmo com relação a definição do contexto da consulta. Dessa forma, a partir da aplicação da técnica proposta no presente capítulo é possível atenuar o problema de cold-start em sistemas CBIR. 


\section{Capítulo \\ 7 \\ Arquitetura CBIR agregada a Perfis}

\subsection{Introdução}

$\mathcal{A}$

partir das abordagens descritas foi definida e implementada uma arquitetura para desenvolvimento de sistemas CBIR agregados a perfis de usuário, possibi-

litando a captura da semântica da consulta desejada pelo usuário. A presente arquitetura aplica técnicas específicas para a interligação, interação dos módulos desenvolvidos e definição da topologia da arquitetura de um CBIR guiado pela intenção do usuário, bem como faz uso de padrões de projeto para o mesmo. Dessa forma, torna-se possível a reutilização de tal conhecimento para posteriores desenvolvimentos que também captem e insiram novas técnicas baseadas na intenção do usuário na recuperação de imagens baseada em conteúdo. Portanto, definiu-se uma arquitetura geral para a criação dos mesmos reduzindo também a quantidade de informações a serem assimiladas num novo projeto, bem como diminuindo o esforço para a implementação e entendimento do mesmo.

A partir do conjunto de características desejadas à arquitetura determinou-se a aplicação principalmente de dois estilos arquiteturais para o desenvolvimento da mesma. Os dois principais estilos aplicados foram os estilos pipes and filters e blackboard degenerado (Bass et al., 2003). Com a utilização de tais estilos e padrões de projeto evita-se consideravelmente a rigidez, fragilidade, imobilidade e viscosidade no desenvolvimento (Dong et al., 2009; Freeman et al., 2004). 
A rigidez diz respeito à tendência do software apresentar dificuldades com relação a mudanças mesmo em suas partes mais simples, gerando um efeito cascata em módulos dependentes. A fragilidade é a tendência do software "quebrar" em muitos locais a cada modificação necessária, onde geralmente tais "quebras" ocorrem em segmentos que não possuem relacionamento conceitual com o código que foi alterado. Já a imobilidade, como o próprio nome descreve, diz respeito à incapacidade de reutilização de partes do software desenvolvido em outros projetos. Por fim, a viscosidade ocorre quando o desenvolvedor depara-se com diferentes formas de modificação do software, porém as que preservam a arquitetura do projeto são mais difíceis de serem realizadas, do que as que burlam tal premissa.

\subsection{Estilos Arquiteturais e Padrões de Projeto}

O estilo arquitetural de pipes and filters de maneira geral considera a existência de um fluxo de dados que caminham de uma extremidade (origem) à outra (destino). O fluxo de dados se dá por meio de pipes e tais dados são processados nos filters e sofrem transformações. Dessa forma, é possível definir uma sequência de pipes and filters na qual os filters extraem, transformam e/ou incrementam os dados oriundos de alguma fonte e os pipes interligam dois filtros ou uma fonte/receptor de dados a um filtro.

Pode-se observar que os vários estágios de processamento (e.g. módulos propostos) podem ser interligados, onde cada estágio caracteriza-se por um filtro, o qual recebe dados de alguma fonte e gera dados de saída canalizados ao próximo estágio via um conjunto de pipes. No entanto, a arquitetura desenvolvida possui também um repositório central de dados compartilhados entre os diversos módulos, que refere-se aos perfis de usuários e o respectivo agente controlador do mesmo, fatos esses que caracterizam uma arquitetura blackboard degenerada, visto que não é necessário um árbitro para escalonar diversos agentes de resolução do problema, mas sim apenas o agente do perfil. Dessa forma a presente arquitetura desenvolvida é um híbrido entre os estilos pipes and filters com o estilo blackboard degenerado.

Com relação aos padrões de projeto, considerando os módulos de Extratores de Características, Funções de Distância e Realimentação de Relevância, estes foram agregados ao padrão de projeto denominado Abstract Factory (Dong et al., 2009; Freeman et al., 2004; Gamma et al., 1994). Tal padrão foi utilizado visto que fornece uma maneira útil de criação de "fábricas" de objetos.

Dessa forma, esse padrão fornece uma interface para criar diferentes famílias de "produtos", o que em questão dizem respeito a diferentes famílias de Extratores de Características 
(Forma, Textura, Cor, entre outros), Funções de distância (Geométricas, Estatísticas) e Mecanismos de Realimentação de Relevância (Movimentação de Centro, Ponderação, entre outros). Portanto, desvincula-se o código da fábrica real que cria, por exemplo, os diferentes extratores de características. Tal fato possibilita implementar uma variedade de fábricas que fazem produtos para contextos diferentes. Além disso, mantém o encapsulamento de tais informações.

Já para o agente do perfil, explicitado no método do capítulo 5, foi utilizado o padrão de projeto Singleton (Freeman et al., 2004) uma vez que garante a existência de apenas uma instância do agente do perfil, mantendo um ponto global de acesso ao seu objeto, visto que tal agente é responsável pela coleta, manutenção e aplicação dos perfis armazenados. Dessa forma, garantindo o acesso à sua instância e ainda interceptando as requisições para criação de novas instâncias do mesmo tipo, garantindo assim que nenhuma outra instância seja criada.

Considerando a máquina de busca por similaridade utilizou-se o padrão Façade (Bayley \& Zhu, 2010; Freeman et al., 2004), oferecendo uma interface única de nível mais elevado que torna o sistema mais fácil de utilização. Dessa forma, o cliente não precisa conhecer muitos detalhes do subsistema para utilizá-lo. Tal fato, permite que objetos individuais cuidem de uma única tarefa, deixando que a fachada se encarregue de divulgar suas operações. Como por exemplo, quando um dado usuário escolhe uma dada imagem para consulta e realiza uma consulta por similaridade, a fachada se encarrega de divulgar quais operações são necessárias para realizar tal tarefa (extração de características, cálculos de distância, etc), ou seja, delegando aos objetos apropriados para cada tarefa.

Já considerando o método proposto no capítulo 6 embasado no mediador, o padrão de projeto utilizado para tal desenvolvimento foi o Mediator (Freeman et al., 2004; Gamma et al., 1994; Thung et al., 2010) visto que tal padrão define um objeto que encapsula a forma como um conjunto de objetos interagem, permitindo que um grupo de objetos comunique-se entre si. Dessa forma o padrão encapsula toda a comunicação entre o grupo de objetos que o compõe. O mediador então recebe requisições dos remetentes e repassa as requisições aos destinatários. Dessa forma, a política de comunicação está presente e centralizada no mediador.

Vale ressaltar que os padrões de projeto são conceitos que apresentam uma solução para determinado problema em um determinado contexto. A utilização de tais estilos arquiteturais e padrões apresenta importância para a posterior reutilização e disseminação do conhecimento. 


\subsection{Arquitetura Desenvolvida}

A presente seção visa explicitar o pipeline da arquitetura desenvolvida a partir dos conceitos explicitados na seção anterior com relação aos estilos arquiteturais e padrões de projeto adotados. A Figura 7.1 ilustra o diagrama esquemático de tal arquitetura no qual pode-se observar claramente a topologia híbrida da arquitetura composta pelo estilo arquitetural de pipes and filters em junção com o blackboard degenerado.

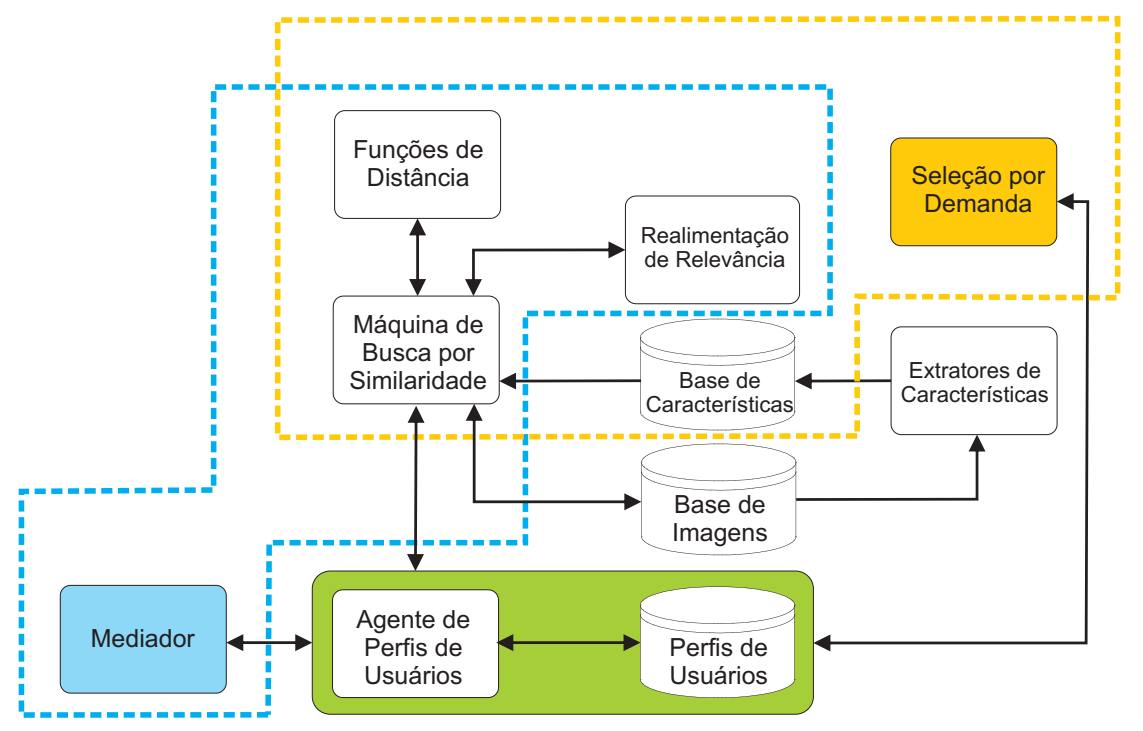

Figura 7.1: Diagrama Esquemático da Arquitetura Proposta.

A primeira etapa para execução da arquitetura diz respeito ao método proposto no capítulo 6 o qual utiliza-se da política de escolha de funções de distâncias iniciais que também tratam o problema de cold-start. Posteriormente o controle é repassado à realimentação de relevância a qual captura a ordenação do usuário de acordo com a intenção do mesmo (método proposto no capítulo 5), concomitantemente é construído o conjunto de treinamento para um dado usuário (método proposto no capítulo 4). O ciclo de processamento continua com a execução até que o usuário esteja satisfeito com as imagens retornadas.

\subsection{Descrição do Sistema}

A interface do sistema é simples e clara. A Figura 7.2 ilustra um screenshot da mesma. Tal interface é composta pelos seguintes componentes principais:

1. corresponde à área de listagem das imagens pertencentes à uma dada base, possibilitando a escolha de imagens a serem utilizadas como centro de consulta;

2. diz respeito à área de visualização da imagem de consulta, a qual pode ser modificada segundo uma dada escolha via o componente 1, o qual lista as imagens da base; 


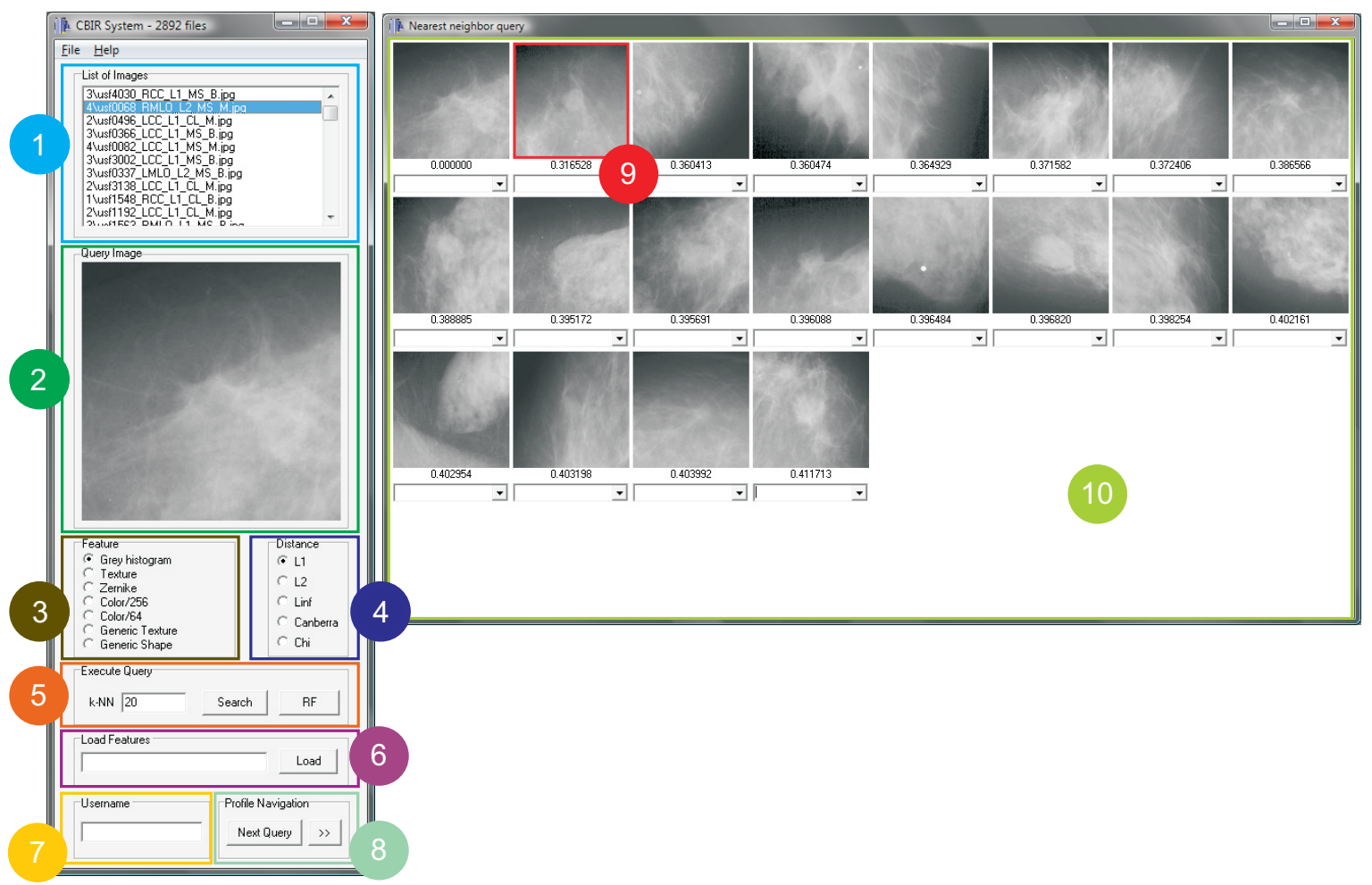

Figura 7.2: Interface do sistema.

3. permite a escolha do tipo de característica a ser utilizado nas consultas por similaridade (por exemplo, histogramas de níveis de cinza, histogramas de cores, momentos de Zernike, descritores de Haralick, entre outros);

4. permite a escolha da função de distância a ser utilizada (por exemplo, $L_{1}, L_{2}$, Canberra, entre outras) para execução de uma dada consulta;

5. refere-se à área de execução das consultas por similaridade; permite a definição do número de vizinhos mais próximos a serem retornados pela consulta. Além disso, agrega os botões para execução da consulta inicial (botão Search) e posteriores realimentações de relevância (botão $R F$ );

6. diz respeito ao campo para carregamento de características a partir de arquivos; uma alternativa caso o usuário não queira utilizar os extratores fornecidos pela ferramenta;

7. área de inserção do nome/id do usuário que utilizará o sistema; tal id é utilizado para armazenamento do perfil do usuário e posterior recuperação e carregamento do mesmo;

8. permite a navegação no perfil do usuário previamente carregado; o botão Next Query permite carregar e visualizar a(s) imagem(ns) de consulta utilizada(s) e informações 
agregadas à(s) mesma(s), já o botão >> permite a visualização dos respectivos ciclos de realimentação realizados para as determinadas imagens de consulta;

9. diz respeito a uma dada imagem selecionada como relevante; ao ser rotulada como relevante pelo usuário, a imagem é visualizada com um invólucro em cor vermelha;

10. corresponde à área em que os k-vizinhos mais próximos são retornados pela consulta por similaridade. O usuário pode, realizar a escolha das imagens mais relevantes para posterior realimentação. O sistema realiza automaticamente a captura da ordenação de tais escolhas, da imagem mais relevante perceptualmente para a menos relevante em relação à imagem de consulta. Além disso, foi fornecido ao usuário também uma opção de ToolTip, quando o mesmo posiciona o ponteiro do mouse sobre uma determinada imagem. Tal ToolTip explicita algumas informações sobre a dada imagem, como por exemplo seu id e o tipo da lesão (classe da imagem).

A Figura 7.3 ilustra o menu da ferramenta, a partir do qual carrega-se o perfil de um dado usuário, bem como permite realizar os cálculos de APF para o mesmo. Como já mencionado, após a execução de consultas e possíveis realimentações realizadas por um dado usuário, o perfil do mesmo é coletado e armazenado. Dessa forma, após tal processo a ferramenta permite o carregamento do perfil de um dado usuário. Na Figura 7.3 o marcador 1 diz respeito ao menu File, o qual possui a opção Load Profile (marcador 2), que ao clicar na mesma essa abrirá uma janela (marcador 3), na qual o usuário poderá escolher qual perfil deseja carregar. Vale ressaltar que por definição os arquivos de perfis gerados possuem a extensão .prl. Ao selecionar um perfil desejado, entra em ação o parser, citado na seção 5.3.3, que irá tratar das informações contidas no mesmo, sendo que tais informações são carregadas e visualizadas via interface.

\subsubsection{Validação em Ambiente Real}

Para validação do sistema foram realizados testes com especialistas (6 usuários), médicos radiologistas e médicos residentes abrangendo R3 a R5, do Hospital das Clínicas da Faculdade de Medicina de Ribeirão Preto (HC-FMRP). O sistema também foi avaliado por usuários comuns (10 usuários) considerando imagens não médicas.

Solicitou-se aos usuários que comparassem os resultados da busca inicial simples com a busca utilizando a ferramenta proposta, segundo suas respectivas intenções, e os mesmos opinassem se o resultado da busca com a ferramenta foi "muito pior", "um pouco pior", "similar/neutro", "um pouco melhor" ou "muito melhor" do que o da busca simples inicial. 


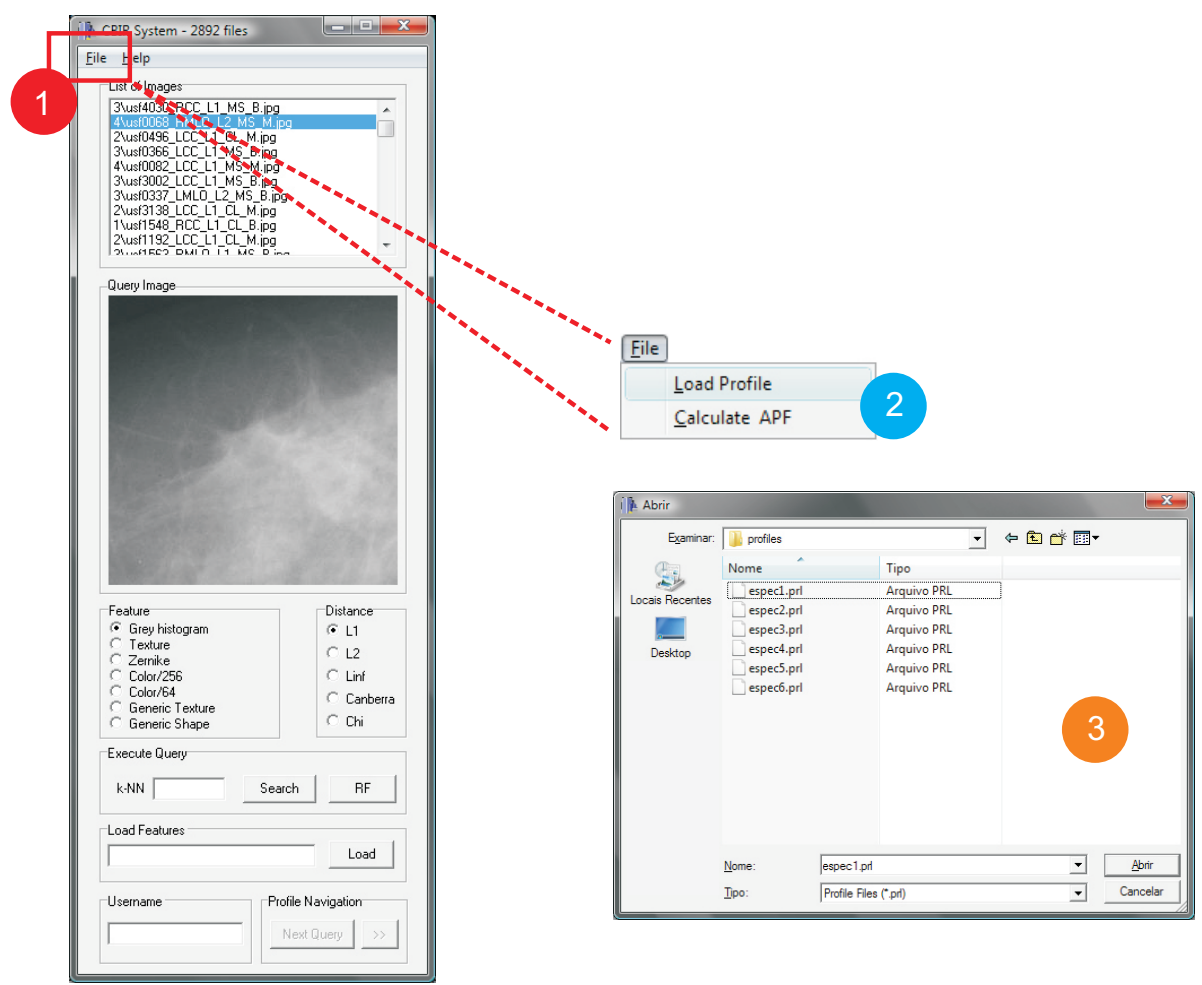

Figura 7.3: Interface do sistema - Menu.

Os gráficos da Figura 7.4 ilustram a porcentagem de votação dos usuários segundo as 5 escalas de satisfação adotadas, tanto para as avaliações realizadas com os usuários especialistas (Figura 7.4 (a)), quanto as realizadas com usuários comuns (Figura 7.4 (b)). Ao analisar o gráfico da Figura 7.4 (a) pode-se observar que na maioria dos casos (cerca de $69 \%$ ), dentre um total de 6 usuários e 36 consultas, os mesmos apresentaram boa satisfação com o emprego do sistema. Analisando o gráfico da Figura 7.4 (b), que referese aos usuários comuns, na maioria dos casos (cerca de 78\%), dentre um total de 10 usuários e 60 consultas, os usuários também apresentaram boa satisfação.

(a) Avaliação Sistema - Especialistas

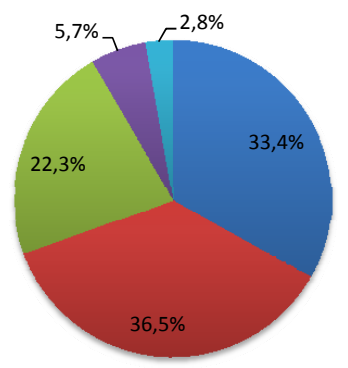

(b) Avaliação Sistema - Usuários Comuns

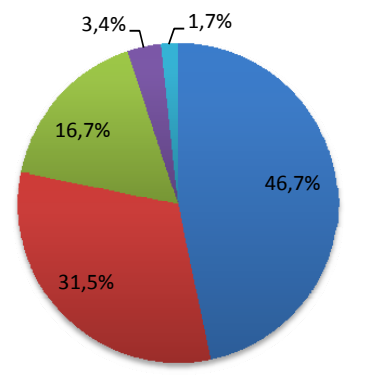

Muito Melhor -Um Pouco Melhor - Similar/Neutro - Um Pouco Pior - Muito Pior

Figura 7.4: Porcentagem de casos onde os usuários responderam que o sistema apresentou resultados de acordo com cinco escalas de satisfação: muito melhor, um pouco melhor, neutro/similar, um pouco pior e muito pior. (a) Usuários Especialistas; (b) Usuários Comuns. 


\subsection{Considerações Finais}

O presente capítulo apresentou uma nova contribuição para a implementação de sistemas CBIR tanto tradicionais, quanto baseados na captura da intenção/percepção do usuário, permitindo interligar as técnicas propostas na presente tese. Para tanto, foi utilizada a mescla de dois diferentes estilos arquiteturais, os quais são embasados na teoria de arquitetura de software, bem como fez-se uso de padrões de projeto.

Dessa forma, a partir da definição da presente arquitetura estabelece-se uma terminologia comum para o desenvolvimento em equipe o qual requer um vocabulário comum, bem como um ponto de vista comum do problema. Assim, permite-se que se interaja em um nível mais alto de abstração, bem como tornando mais fácil a compreensão do sistema. Com o emprego dos estilos arquiteturais e padrões de projeto foi possível fornecer um ponto comum de referência para as posteriores análises e elaborações de projetos CBIR que visam agregar a intenção do especialista. 


\section{Capítulo \\ 8 \\ Conclusões}

\subsection{Considerações Finais}

$\mathcal{A}$ proposta do presente trabalho de Doutorado foi contribuir principalmente para a área de recuperação por conteúdo de imagens médicas, no qual o ponto focal da presente tese esteve relacionado com o alcance de consultas por similaridade que atendam às expectativas do usuário, ou seja, prover ao sistema CBIR a manutenção da semântica de consulta desejada pelo usuário. Para tanto foram desenvolvidos três principais métodos. Dessa forma, criou-se um suporte consistente para a realização de consultas por similaridade perceptuais em imagens médicas.

O primeiro método visou a seleção de características por demanda baseada na intenção do usuário, possibilitando dessa forma a agregação de semântica ao processo de seleção de características. O segundo método culminou no desenvolvimento de técnicas para coleta e agregação de perfis de usuário, bem como novas formulações para quantificar a similaridade perceptual dos usuários, permitindo definir dinamicamente a função de distância que melhor adapta-se à percepção de um determinado usuário.

O terceiro método teve por objetivo a modificação dinâmica de funções de distância em diferentes ciclos de realimentação. Para tanto foram definidas políticas para realizar tal modificação, as quais foram baseadas na junção de informações a priori da base de imagens, bem como, na percepção do usuário no processamento das consultas por similaridade. Além disso, a presente tese definiu uma arquitetura para o desenvolvimento de sistemas CBIR agregados a perfis de usuário. 


\subsection{Principais Contribuições}

Na presente tese foram propostos métodos embasados em diversos conceitos oriundos da recuperação de imagens baseada em conteúdo visando atender a percepção do usuário. Resumidamente, as principais contribuições do presente trabalho para a área de CBIR são descritas a seguir:

- Estudo e aprofundamento relativos à importância das funções de distância. Por meio dos estudos realizados com relação à correlação e limites de funções de distância foi possível demonstrar que funções de distâncias podem ser derivadas a partir de outras. No entanto, cada uma dessas derivações possuem propriedades específicas que podem ser proveitosas a determinados contextos, melhorando assim consideravelmente a precisão das consultas por similaridade;

- Um novo método para realização de seleção de características por demanda guiada pela percepção do usuário, visando lidar com os dois principais empecilhos encontrados por um sistema CBIR que são a maldição da alta dimensionalidade e o gap semântico. Para tratar tais empecilhos utilizou-se o processo de realimentação de relevância para refinar iterativamente a seleção de características realizada pela mineração de regras de associação estatísticas, calibrando em tempo de execução o processo de mineração segundo a expectativa do usuário;

- Um novo método o qual obtém dos usuários seus interesses gerais, bem como, suas intenções durante a realização das consultas por similaridade e efetua o levantamento e a alimentação dos perfis de usuário, por meio da estratégia proposta, diminuindo o problema do gap semântico em sistemas CBIR. A estratégia proposta de supervisão e levantamento do perfil combina perfis estáticos e dinâmicos que são incorporados ao ciclo de realimentação de relevância, portanto, não exigem um esforço extra por parte do usuário. Para tanto foi proposto e desenvolvido formalmente um parsing maleável para tal processo. A abordagem também é capaz de responder e definir qual a função de distância que melhor se adequa à percepção de um dado usuário por meio de duas novas medidas propostas, Perception Factor e Average Perception Factor, as quais quantificam a similaridade perceptual de um dado usuário segundo um determinado centro de consulta. Além disso, o método proposto uma vez que coleta e armazena os perfis de usuários, ao mesmo tempo gera informações que elucidam o comportamento intrínseco dos especialistas na tarefa de busca baseada em conteúdo.

- Um novo método para a modificação dinâmica de funções de distância em diferentes ciclos de realimentação. Para tanto foram desenvolvidas novas políticas para realizar a melhor escolha de uma dada função de distância em um dado ciclo de realimentação 
de relevância específico de maneira dinâmica. Tais políticas foram baseadas tanto em informações a priori da base de imagens, bem como, na percepção do usuário no processo das consultas por similaridade, apresentando, portanto, melhorias com relação à precisão das consultas por similaridade baseadas nas expectativas dos usuários. Além disso, o método proposto pode ser aplicado com o intuito de mitigar o problema denominado cold-start;

- Definição de uma arquitetura para desenvolvimento de sistemas CBIR agregados a perfis de usuário, possibilitando a captura da semântica da consulta desejada pelo usuário.

\subsection{Publicações}

Além das contribuições geradas pela presente tese, as publicações geradas na mesma também foram importantes para a sua validação, consolidação e disseminação das técnicas propostas. Tais publicações são listadas a seguir:

\section{Conferências Internacionais - Artigos Completos}

[1] BUGATTI, Pedro Henrique; KASTER, Daniel Santos; PONCIANO-S, Marcelo; TRAINA, Agma Juci Machado Traina; TRAINA JR., Caetano. "Integrating user profile in medical CBIR systems to answer perceptual similarity queries". In: SPIE Medical Imaging Conference, 2011, Lake Buena Vista. Proceedings of the SPIE-MI. Orlando: SPIE, 2011. v. 1. p. 79630Q-1-79630Q-12.

[2] BUGATTI, Pedro Henrique; RIBEIRO, Marcela Xavier; TRAINA, Agma Juci Machado; TRAINA JR, Caetano. "Feature Selection Guided by Perception in Medical CBIR Systems". In: IEEE International Conference on Healthcare Informatics, Imaging and Systems Biology, 2011, San Jose, California, USA. Proceedings of the IEEE HISB. Los Alamitos : IEEE Computer Press, 2011. v. 1. p. 323-330.

[3] BUGATTI, Pedro Henrique; Traina, Agma Juci Machado; TRAINA JR, Caetano. "Improving Content-Based Retrieval of Medical Images through Dynamic Distance on Relevance Feedback". In: 24th IEEE International Symposium on Computer-Based Medical Systems, 2011, Bristol, England. Proceedings of the CBMS 2011. Los Alamitos : IEEE Computer Society, 2011. v. 1. p. 92-97.

[4] BUGATTI, Pedro Henrique; PONCIAnO-S., Marcelo; TRAINA, Agma Juci Machado; TRAINA JUNIOR, Caetano; MARQUES, Paulo Mazzoncini Azevedo. Content- 
Based Retrieval of Medical Images: from Context to Perception. In: 22nd IEEE International Symposium on Computer-Based Medical Systems, 2009, Albuquerque, New Mexico, USA. Procceddings of the CBMS 2009. Los Alamitos: IEEE Computer Society, 2009. v. 1. p. $9-15$.

[5] KASTER, Daniel Santos; BUGATTI, Pedro Henrique; PONCIANO-S., Marcelo; TRAINA, Agma Juci Machado; TRAINA JR, Caetano. "MedFMI-SiR: A Powerful DBMS Solution for Large-scale Medical Image Retrieval". In: 2nd International Conference on Information Technology in Bio- and Medical Informatics, 2011, Toulouse. Lecture Notes in Computer Science (LNCS). Berlin : Springer-Verlag, 2011. v. 6865. p. 16-30.

\section{Conferências Nacionais - Artigos Completos}

[1] BEDO, Marcos Vinicius Naves; PONCIANO-S., Marcelo; KASTER, Daniel Santos; BUGATTI, Pedro Henrique; TRAINA, Agma Juci Machado; TRAINA JUNIOR, Caetano. Higiia: A Perceptual Medical CBIR System Applied to Mammography Classification. In: Demo and Applications Session of the XXVII Brazilian Symposium on Databases (SBBD), 2012, São Paulo, SP, Brazil. Proceedings of the SBBD 2012. Porto Alegre: Brazilian Computer Society, 2012. v. 1. p. 13-18.

[2] KASTER, Daniel Santos; BUGATTI, Pedro Henrique; TRAINA, Agma Juci Machado; TRAINA JUNIOR, Caetano. Incorporating Metric Access Methods for Similarity Searching on Oracle Database. In: XXIV Simpósio Brasileiro de Banco de Dados (SBBD), 2009, Fortaleza, CE, Brasil. Anais do SBBD 2009. Porto Alegre : SBC - Sociedade Brasileira de Computação, 2009. p. 1-15.

[3] SILVA, Carolina Yukari Veludo Watanabe; BUGATTI, Pedro Henrique; RIBEIRO, Marcela Xavier; TRAINA, Agma Juci Machado; TRAINA JR., Caetano. (2008) "Improving CBIR Using Feature Extraction Based on Wavelet Transform". In: XIV Simpósio Brasileiro de Sistemas Multimedia e Web (WebMedia 2008), 2008, Vila Velha. Anais do WebMedia 2008. Porto Alegre : Sociedade Brasileira de Computação. v.1. p. 9-15.

\section{Periódicos Internacionais}

[1] BUGATTI, Pedro Henrique; KASTER, Daniel Santos; PONCIANO-S, Marcelo; TRAINA, Agma Juci Machado Traina; TRAINA JR., Caetano; MARQUES, Paulo Maz-

zoncini Azevedo. "PRoSPer: Perceptual Similarity Queries in Medical CBIR Systems 
through User Profiles". Computers in Biology and Medicine, v. 1, p. 1-35, 2012. (artigo submetido)

[2] RIBEIRO, Marcela Xavier; BUGATTI, Pedro Henrique; TRAINA JR., Caetano; MARQUES, Paulo Mazzoncini Azevedo; ROSA, Natália Abdala; TRAINA, Agma Juci Machado. "Supporting content-based image retrieval and computer-aided diagnosis systems with association rule-based techniques". Data \& Knowledge Engineering, v. 1, p. $1-13,2009$.

[3] KASTER, Daniel Santos; BUGATTI, Pedro Henrique; TRAINA, Agma Juci Machado; TRAINA JR., Caetano. "FMI-SiR: A Flexible and Efficient Module for Similarity Searching on Oracle Database". In: Journal of Information and Data Management, v. 1, p. 229-244, 2010.

\section{Capítulo de Livro Internacional}

[1] TRAINA, Agma Juci Machado; TRAINA JR., Caetano; BALAN, Andre Guilherme Ribeiro; RIBEIRO, Marcela Xavier; BUGATTI, Pedro Henrique; SILVA, Carolina Yukari Veludo Watanabe; MARQUES, Paulo Mazzoncini Azevedo. "Feature Extraction and Selection for Decision Making over Medical Images". In: Thomas Deserno. (Org.). Biomedical Image Processing - Methods and Applications. 1 ed. Berlin: Springer-Verlag, 2011, v.1 , p. 181-209.

\section{Capítulo de Livro Nacional}

[1] TALARICO NETO, Americo; FORTES, Renata Pontin Mattos; TEIXEIRA, Fabiano Costa; ALVES, Luis Cezar D.; BUGATTI, Pedro Henrique; CARVALHO Jr., Osvaldo A. Interfaces Multimodais Dinâmicas Utilizando J2EE. In: Marcos Roberto da Silva Borges; José Gonçalves Pereira Filho. (Org.). Mini-cursos WebMedia 2008. 1 ed. Vila Velha - ES: Sociedade Brasileira de Computação SBC, 2008, v. 1, p. 1-48.

\subsection{Propostas para Trabalhos Futuros}

A seguir estão apresentadas algumas sugestões de tópicos que podem ser abordados em estudos futuros.

- Aplicação de algoritmos de mineração de dados em conjunto com as informações referentes a ordenação de relevância realizada pelo usuário e armazenadas no perfil; 
- Aplicação de funções de agregação de rankings em conjunto com as técnicas de modificação dinâmica de funções de distância e os perfis de usuário;

- Extensão da técnica APF para formulação e detecção de clusters baseados na percepção dos usuários;

- Definição de novos métodos para interação do usuário com relação aos métodos de realimentação de relevância; 


\section{Referências Bibliográficas}

Aboulmagd, H., El-Gayar, N., e Onsi, H. (2009). A new approach in content-based image retrieval using fuzzy. Telecommunication Systems, 40:55-66.

Adomavicius, G. e Tuzhilin, A. (2005). Toward the next generation of recommender systems: A survey of the state-of-the-art and possible extensions. IEEE Transactions on Knowledge and Data Engineering, 17:734-749.

Aggarwal, C. C. (2001). Re-designing distance functions and distance-based applications for high dimensional data. ACM SIGMOD Records, 30(1):13-18.

Agrawal, R. e Srikant, R. (1994). Fast algorithms for mining association rules. In International Conference on Very Large Databases (VLDB), p. 487-499, Santiago de Chile, Chile.

Ahuja, R. K., Magnanti, T. L., e Orlin, J. B. (1993). Network Flows: Theory, Algorithms, and Applications. Prentice Hall, Englewood Cliffs, NJ.

Akgül, C. B., Rubin, D. L., Napel, S., Beaulieu, C. F., Greenspan, H., e Acar, B. (2011). Content-based image retrieval in radiology: Current status and future directions. Journal of Digital Imaging, 24(2):208-222.

Alferez, R., Wang, Y.-F., e Jiao, L. (2005). An affine-invariant tool for retrieving images from homogeneous databases. Multimedia Tools and Applications Journal (MTAJ), 25(1):133-159.

Almeida, J., Torres, R. S., e Leite, N. J. (2010). Bp-tree: an efficient index for similarity search in high-dimensional metric spaces. In Proceedings of the 19th ACM Conference on Information and Knowledge Management, p. 1365-1368.

Alto, H., Rangayyan, R. M., e Desautels, J. E. L. (2005). Content-based retrieval and analysis of mammographic masses. Journal of Electronic Imaging, 14(2):1-17.

Amores, J., Sebe, N., e Radeva, P. (2006). Boosting the distance estimation. Pattern Recognition Letters, 27(3):201-209.

Andaló, F. A., Miranda, P. A. V., Torres, R. S., e Falcão, A. X. (2010). Shape feature extraction and description based on tensor scale. Pattern Recognition, 43(1):26-36. 
Arivazhagan, S. e Ganesan, L. (2003). Texture classification using wavelet transform. Pattern Recognition Letters, 24:1513-1521.

Bach, J. R., Fuller, C., Gupta, A., Hampapur, A., Horowitz, B., Humphrey, R., Jain, R., e Shu, C.-F. (1996). Virage image search engine: An open framework for image management. In Storage and Retrieval for Image and Video Databases (SPIE), p. 76-87.

Baeza-Yates, R. A. e Ribeiro-Neto, B. A. (2011). Modern Information Retrieval - the concepts and technology behind search, Second edition. Pearson Education Ltd., Harlow, England.

Balan, A. G. R. (2007). Métodos adaptativos de segmentação aplicados à recuperação de imagens por conteúdo. Tese de doutorado, Universidade de São Paulo.

Balan, A. G. R., Traina, A. J. M., Traina Jr., C., e Marques, P. M. A. (2005). Fractal analysis of image textures for indexing and retrieval by content. In 18th IEEE International Symposium on Computer-Based Medical Systems (CMBS 2005), p. 22-24, Dublin, Ireland. IEEE Computer Society.

Bass, L., Clements, P., e Kazman, R. (2003). Software Architecture in Practice. AddisonWesley Longman Publishing Co., Inc., Boston, MA, USA, 2 edition.

Bayer, R. e McCreight, E. M. (1972). Organization and maintenance of large ordered indices. In ACM SIGFIDET Workshop on Data Description and Access, p. 107-141, Houston, Texas. ACM Press.

Bayley, I. e Zhu, H. (2010). Formal specification of the variants and behavioural features of design patterns. Journal of Systems and Software, 83(2):209 - 221.

Beyer, K., Godstein, J., Ramakrishnan, R., e Shaft, U. (1999). When is "nearest neighbor"meaningful? In Beeri, C. e Buneman, P., editors, International Conference on Database Theory (ICDT), v. 1540 of Lecture Notes in Computer Science, p. 217-235, Jerusalem, Israel. Springer Verlag.

Bin, Y. e Jia-Xiong, P. (2002). Invariance analysis of improved zernike moments. Journal of Optics A: Pure and Applied Optics, 4:606-614.

Bueno, J. M., Chino, F., Traina, A. J. M., Traina Jr., C., e Marques, P. M. A. (2002). How to add content-based image retrieval capability in a pacs. 15th IEEE International Symposium on Computer-Based Medical Systems (CMBS 2002), 00:321.

Bugatti, P. H., Kaster, D. S., Ponciano-Silva, M., Traina, A. J. M., e Traina Jr., C. (2011a). Integrating user profile in medical cbir systems to answer perceptual similarity queries. In Medical Imaging 2011: Computer-Aided Diagnosis, v. 7963, p. 79630Q-1-79630Q12. SPIE.

Bugatti, P. H., Ribeiro, M. X., Traina, A. J. M., e Traina Jr., C. (2011b). Feature selection guided by perception in medical cbir systems. In IEEE International Conference on Healthcare Informatics, Imaging and Systems Biology, p. 323-330. IEEE Computer Society. 
Bugatti, P. H., Traina, A. J. M., e Traina Jr., C. (2011c). Improving content-based retrieval of medical images through dynamic distance on relevance feedback. In International Symposium on Computer-Based Medical Systems, p. 1-6. IEEE Computer Society.

Bulò, S. R., Rabbi, M., e Pelillo, M. (2011). Content-based image retrieval with relevance feedback using random walks. Pattern Recognition, 44(9):2109-2122.

Bustos, B., Kreft, S., e Skopal, T. (2012). Adapting metric indexes for searching in multi-metric spaces. Multimedia Tools and Applications, 58:467-496.

Caballero, C. e Aranda, M. C. (2010). Plant species identification using leaf image retrieval. In Proceedings of the ACM International Conference on Image and Video Retrieval, p. 327-334, New York, NY, USA. ACM.

Chaddad, A., Tanougast, C., Dandache, A., Al Houseini, A., e Bouridane, A. (2011). Improving of colon cancer cells detection based on haralick's features on segmented histopathological images. In IEEE International Conference on Computer Applications and Industrial Electronics, p. $87-90$.

Chatzichristofis, S. A. e Boutalis, Y. S. (2008). Cedd: Color and edge directivity descriptor: A compact descriptor for image indexing and retrieval. In International Conference on Computer Vision Systems, p. 312-322.

Chen, C.-C. e Chu, H.-T. (2005). Similarity measurement between images. Annual International Computer Software and Applications Conference, 2:41-42.

Chen, C.-S., Yeh, C.-W., e Yin, P.-Y. (2009). A novel fourier descriptor based image alignment algorithm for automatic optical inspection. J. Vis. Comun. Image Represent., 20(3):178-189.

Chen, Y., Zhou, X., e Huang, T. S. (2001). One-class SVM for learning in image retrieval. In International Conference on Image Processing (ICIP), p. 34-37, Thessaloniki, Grécia. IEEE.

Cheng, T.-H., Wei, C.-P., e Tseng, V. S. (2006). Feature selection for medical data mining: Comparisons of expert judgment. In the 19th IEEE International Symposium on Computer-based Medical Systems, p. 165-170, Salt Lake City, Utah, USA. IEEE Computer Society.

Ciaccia, P., Patella, M., e Zezula, P. (1997). M-tree: An efficient access method for similarity search in metric spaces. In International Conference on Very Large Data Bases (VLDB), p. 426-435, Athens, Greece. Morgan Kaufmann.

Comer, D. (1979). The ubiquitous b-tree. ACM Computing Surveys, 11(2):121-137.

Comer, M. L. e Delp, E. J. (2000). The EM/MPM algorithm for segmentation of textured images: Analysis and further experimental results. IEEE Transactions on Image Processing, 9(10):1731-1744.

Dagli, C. K., Rajaram, S., e Huan, T. S. (2006). Leveraging active learning for relevance feedback using an information theoretic diversity measure. In Proceedings of the 5th international Conference on Image and Video Retrieval, p. 123-132, Berlin, Heidelberg. Springer-Verlag. 
Datta, R., Joshi, D., Li, J., e Wang, J. Z. (2008). Image retrieval: Ideas, influences, and trends of the new age. ACM Computer Survey, 40(2):1-60.

Depeursinge, A., Iavindrasana, J., Cohen, G., Platon, A., Poletti, P.-A., e Müller, H. (2008). Lung tissue classification in hrct data integrating the clinical context. IEEE Symposium on Computer-Based Medical Systems, 0:542-547.

Depeursinge, A., Sage, D., Hidki, A., Platon, A., Poletti, P. A., Unser, M., e Müller, H. (2007). Lung tissue classification using Wavelet frames. In Proceedings of the Internatioanl Conference of the IEEE Engineering in Medicine and Biology Society, p. 6259-6262. IEEE Computer Society.

Deselaers, T., Keysers, D., e Ney, H. (2008a). Features for image retrieval: An experimental comparison. Information Retrieval, 11(2):77-107.

Deselaers, T., Paredes, R., Vidal, E., e Ney, H. (2008b). Learning weighted distances for relevance feedback in image retrieval. In 19th International Conference on Pattern Recognition, p. 1-4.

Deserno, T. M., Antani, S., e Long, R. (2008). Ontology of gaps in content-based image retrieval. Journal of Digital Imaging, p. 1-14.

Doherty, K. A. J., Adams, R. G., e Davey, N. (2004). Non-euclidean norms and data normalisation. In Proceedings of the European Symposium on Artificial Neural Networks, p. 181-186, Bruges, Belgica.

Dong, J., Zhao, Y., e Peng, T. (2009). A review of design pattern techniques. International Journal of Software Engineering and Knowledge Engineering, 19(06):823-855.

Doulamis, N. e Doulamis, A. (2006). Evaluation of relevance feedback schemes in contentbased in retrieval systems. Signal Processing: Image Communication, 21(4):334 - 357.

Dy, J. G., Brodley, C. E., Kak, A., Broderick, L. S., e Aisen, A. M. (2003). Unsupervised feature selection applied to content-based retrieval of lung images. IEEE Transactions on Pattern Analysis and Machine Intelligence, 25(3):373-378.

Emran, S. M. e Ye, N. (2001). Robustness of canberra metric in computer intrusion detection. In IEEE Workshop on Information Assurance and Security, West Point, NY, USA.

Euzenat, J. e Shvaiko, P. (2007). Ontology matching. Springer.

Faggioni, L., Neri, E., Castellana, C., Caramella, D., e Bartolozzi, C. (2011). The future of pacs in healthcare enterprises. European Journal of Radiology, 78(2):253-258.

Faloutsos, C. (1996). Searching Multimedia Databases by Content. Kluwer Academic Publishers, Boston, MA.

Felipe, J. C., Jr., C. T., e Traina, A. J. M. (2009). A new family of distance functions for perceptual similarity retrieval of medical images. Journal Digital Imaging, 22(2):183201. 
Felipe, J. C. e Traina, A. J. M. (2005). Desenvolvimento de métodos para extração, comparação e análise decaracterísticas intrínsecas de imagens médicas, visando à recuperação perceptual por conteúdo. Tese de doutorado, Universidade de São Paulo, Instituto de Ciências Matemáticas e de Computação, São Carlos, Brasil.

Felipe, J. C., Traina, A. J. M., e Traina Jr., C. (2005). Global warp metric distance: Boosting content-based image retrieval through histograms. In Tsai, J. J. P., Muhlhauser, M., e Takizawa, M., editors, IEEE International Symposium on Multimedia, page 8, Irvine, CA. IEEE Press.

Ferecatu, M., Crucianu, M., e Boujemaa, N. (2005). Improving performance of interactive categorization of images using relevance feedback. IEEE International Conference on Image Processing (ICIP), 1:1197-1200.

Ferrari, R. J., Rangayyan, R. M., Desautels, J. E. L., Borges, R. A., e Frère, A. F. (2004). Automatic identification of the pectoral muscle in mammograms. IEEE Transactions on Medical Imaging, 23(2):232-245.

Ferreira, C. D., S. Torres, R., Gonçalves, M. A., e Fan, W. (2008). Image retrieval with relevance feedback based on genetic programming. In SBBD '08: Proceedings of the 23rd Brazilian symposium on Databases, p. 120-134, Porto Alegre, Brazil, Brazil. Sociedade Brasileira de Computaç ao.

Flickner, M., Sawhney, H., Niblack, W., Ashley, J., Huang, Q., Dom, B., Gorkani, M., Hafner, J., Lee, D., Petkovic, D., Steele, D., e Yanker, P. (1995). Query by image and video content: The qbic system. IEEE Computer, 28(9):23-32.

Folk, M. J., Zoellick, B., e Riccardi, G. (1998). File structures: An Object-Oriented Approach with $\mathrm{C}++$. Addison-Wesley, Reading, USA, 3 edition.

François, D., Wertz, V., e Verleysen, M. (2007). The concentration of fractional distances. IEEE Transactions on Knowledge and Data Engineering, 19(7):873-886.

Freeman, E., Freeman, E., Bates, B., e Sierra, K. (2004). Head First Design Patterns. O' Reilly \& Associates, Inc.

Gamma, E., Helm, R., Johnson, R., e Vlissides, J. (1994). Design Patterns: Elements of Reusable Object-Oriented Software. Addison-Wesley Professional, 1 edition.

Gao, G. e Guan, S. (2012). Text categorization based on improved rocchio algorithm. In International Conference on Systems and Informatics, p. 2247-2250.

Geman, D., Geman, S., Graffigne, C., e Dong, P. (1990). Boundary detection by constrained optimization. IEEE Transactions on Pattern Analysis and Machine Intelligence, 12(7):609-628.

Ghosh, P., Antani, S., Long, L. R., e Thoma, G. R. (2011). Review of medical image retrieval systems and future directions. In 24th IEEE International Symposium on Computer-Based Medical Systems, p. 1-6. IEEE Computer Society.

Gonzalez, R. C. e Woods, R. E. (2008). Digital Image Processing (5th Edition). PrenticeHall, Inc. 
Grady, L. (2006). Random walks for image segmentation. IEEE Transactions on Pattern Analysis and Machine Intelligence, 28(11):1768-1783.

Gu, J., Shu, H. Z., Toumoulin, C., e Luo, L. M. (2002). A novel algorithm for fast computation of zernike moments. Pattern Recognition, 35(12):2905-2911.

Guttman, A. (1984). R-tree : A dynamic index structure for spatial searching. In $A C M$ International Conference on Data Management (SIGMOD), p. 47-57, Boston, MA. ACM PRess.

Hains, I. M., Georgiou, A., e Westbrook, J. I. (2012). The impact of pacs on clinician work practices in the intensive care unit: a systematic review of the literature. Journal of the American Medical Informatics Association, p. 1-8.

Haralick, R. M. (1979). Statistical and structural approaches to texture. Proceedings of the IEEE, 67(5):786-804.

Herrmann, F. J., Friedlander, M. P., e Yilmaz, Ö. (2012). Fighting the curse of dimensionality: Compressive sensing in exploration seismology. IEEE Signal Processing Magazine, 29(3):88-100.

Hiransakolwong, N., Hua, K. A., Koompairojn, S., Vu, K., e Lang, S.-D. (2005). An adaptive distance computation technique for image retrieval systems. In $S A C$ '05: Proceedings of the 2005 ACM symposium on Applied computing, p. 1195-1199, New York, NY, USA. ACM Press.

Hoi, C.-H. e Lyu, M. R. (2004). A novel log-based relevance feedback technique in contentbased image retrieval. In ACM International Conference on Multimedia (MULTIMEDIA), p. 24-31, New York, NY, USA. ACM Press.

Horii, S. C. e Ratib, O. M., editors (2006). Content-based image retrieval in picture archiving and communication systems, v. 6145, San Diego, CA, USA. SPIE.

Houle, M. E., Kriegel, H.-P., Kröger, P., Schubert, E., e Zimek, A. (2010). Can sharedneighbor distances defeat the curse of dimensionality? In 22nd International Conference Scientific and Statistical Database Management, p. 482-500. Springer.

Howarth, P. e Rüger, S. M. (2005). Fractional distance measures for content-based image retrieval. In 27 th European Conference on IR Research Advances in Information Retrieval, p. 447-456.

Hsu, C.-M. e Chen, M.-S. (2009). On the design and applicability of distance functions in high-dimensional data space. IEEE Transactions on Knowledge and Data Engineering,, 21(4):523-536.

Huang, H. (2011). Short history of pacs (part i: Usa). European Journal of Radiology, $78(2): 163-176$.

Huang, J., Kumar, S. R., Mitra, M., Zhu, W.-J., e Zabih, R. (1997). Image indexing using color correlograms. In IEEE Conference on Computer Vision and Pattern Recognition (CVPR), p. 762-768, San Juan, Puerto Rico. IEEE. 
Ioannidis, Y. e Koutrika, G. (2005). Personalized systems: models and methods from an ir and db perspective (VLDB Tutorial). In International Conference on Very Large Data Bases (VLDB), p. 1365-1365, Trondheim, Norway. VLDB Endowment.

Jing, F., Li, M., Zhang, L., Zhang, H., e Zhang, B. (2003). Learning in region-based image retrieval. In International Conference on Image and Video Retrieval (CIVR), v. 2728 of Lecture Notes in Computer Science, p. 198-207. Springer.

Jones, S. e Shao, L. (2011). Action retrieval with relevance feedback on youtube videos. In Proceedings of the Third International Conference on Internet Multimedia Computing and Service, p. 42-45, New York, NY, USA. ACM.

Kass, M., Witkin, A., e Terzopoulos, D. (1987). Snakes: Active countour models. International Journal of Computer Vision, 1(4):321-331.

Kejia, W., Honggang, Z., Lunshao, C., Ying, H., e Ping, Z. (2011). A comparative study of moment-based shape descriptors for product image retrieval. In International Conference on Image Analysis and Signal Processing, p. 355 -359.

Keller, J. M., Chen, S., e Crownover, R. M. (1989). Texture description and segmentation through fractal geometry. Computer Vision, Graphics, and Image Processing, 45(2):150-166.

Keogh, E. e Ratanamahatana, C. A. (2005). Exact indexing of dynamic time warping. Knowledge and Information Systems, 7(3):358-386.

Keogh, E., Wei, L., Xi, X., Vlachos, M., Lee, S.-H., e Protopapas, P. (2009). Supporting exact indexing of arbitrarily rotated shapes and periodic time series under euclidean and warping distance measures. The VLDB Journal, 18(3):611-630.

Kim, R., Dasovich, G., Bhaumik, R., Brock, R., Furst, J. D., e Raicu, D. S. (2010a). An investigation into the relationship between semantic and content based similarity using lidc. In Proceedings of the international conference on Multimedia information retrieval, p. 185-192, New York, NY, USA. ACM.

Kim, R., Dasovich, G., Bhaumik, R., Brock, R., Furst, J. D., e Raicu, D. S. (2010b). An investigation into the relationship between semantic and content based similarity using lidc. In MIR '10: Proceedings of the international conference on Multimedia information retrieval, p. 185-192, New York, NY, USA. ACM.

Kinoshita, S. K., Azevedo-Marques, P. M. d., Jr, R. R. P., Rodrigues, J. A. H., e Rangayyan, R. M. (2007). Content-based retrieval of mammograms using visual features related to breast density patterns. Journal of Digital Imaging, 20(2):172-190.

Knuth, D. E. (1973). The Art of Computer Programming - Sorting and Searching, v. 3. Addison-Wesley, Reading, USA.

Kokare, M., Chatterji, B., e Biswas, P. (2003). Comparison of similarity metrics for texture image retrieval. In Conference on Convergent Technologies for Asia-Pacific Region, v. 2, p. 571-575.

Kotoulas, L. e Andreadis, I. (2005). Real-time computation of zernike moments. IEEE Transactions on Circuits and Systems for Video Technology, 15(6):801-809. 
Koutrika, G. e Ioannidis, Y. (2005). Personalized queries under a generalized preference model. In International Conference on Data Engineering (ICDE), p. 841-852. IEEE Computer Society.

Koza, J. R. (1992). Genetic programming: on the programming of computers by means of natural selection. MIT Press, Cambridge, MA, USA.

Lemke, H. U. (2011). Short history of pacs (part ii: Europe). European Journal of Radiology, 78(2):177 - 183.

Lew, M. S., Sebe, N., Djeraba, C., e Jain, R. (2006). Content-based multimedia information retrieval: State of the art and challenges. ACM Trans. Multimedia Comput. Commun. Appl., 2(1):1-19.

Ling, H. e Okada, K. (2006). Diffusion distance for histogram comparison. In CVPR '06: Proceedings of the 2006 IEEE Computer Society Conference on Computer Vision and Pattern Recognition, p. 246-253, Washington, DC, USA.

Liu, D., Hua, K. A., Vu, K., e Yu, N. (2009). Fast query point movement techniques for large cbir systems. IEEE Transactions on Knowledge and Data Engineering, 21(5):729 -743 .

Liu, H., Song, D., Rüger, S. M., Hu, R., e Uren, V. S. (2008). Comparing dissimilarity measures for content-based image retrieval. In Li, H., Liu, T., Ma, W.-Y., Sakai, T., Wong, K.-F., e Zhou, G., editors, 4th Asia Infomation Retrieval Symposium (AIRS), v. 4993 of Lecture Notes in Computer Science, p. 44-50, Harbin, China. Springer.

Liu, Y., Zhang, D., Lu, G., e Ma, W.-Y. (2007). A survey of content-based image retrieval with high-level semantics. Pattern Recognition Letters, 40:262 - 282. Elsevier Ltd.

Long, F., Zhang, H., e Feng, D. D. (2003). Multimedia Information Retrieval and Management - Technological Fundamentals and Applications, Capitulo "Fundamentals of Content-Based Image Retrieval". Springer.

Ma, W. e Manjunath, B. (1997). NeTra: a toolbox for navigating large image databases. In International Conference on Image Processing, v. 1, p. 568-571.

Manjunath, B. S., Salembier, P., e Sikora, T. (2002). Introduction to MPEG-\%: Multimedia Content Description Interface. Wiley, New York.

Manolopoulos, Y., Nanopoulos, A., Papadopoulos, A. N., e Theodoridis, Y. (2005). RTrees: Theory and Applications (Advanced Information and Knowledge Processing). Springer-Verlag New York, Inc., Secaucus, NJ, USA.

Marsh, A. (1997). Euromed - the creation of a telemedical information society. In 10' IEEE Symposium on Computer Based Medical Systems, p. 86-91, Maribor, Slovenia.

Miranda, P. A., Torres, R. S., e Falcão, A. X. (2005). Tsd: A shape descriptor based on a distribution of tensor scale local orientation. Computer Graphics and Image Processing, Brazilian Symposium on, 0:139-146.

Mokhtarian, F. e Abbasi, S. (2002). Shape similarity retrieval under affine transfmorms. Pattern Recognition, 35(1):31-41. 
Müller, H., Michoux, N., Bandon, D., e Geissbuhler, A. (2004). A review of content-based image retrieval systems in medical applications - clinical benefits and future directions. International Journal of Medical Informatics, 73(1):1-23.

Nguyen, N.-V., Boucher, A., Ogier, J., e Tabbone, S. (2010). Clusters-based relevance feedback for cbir: A combination of query movement and query expansion. In IEEE International Conference on Computing and Communication Technologies, Research, Innovation, and Vision for the Future, p. 1-6.

Otsu, N. (1979). A thresholding selection method from graylevel histogram. IEEE Transactions on Systems, Man and Cybernetics, 9:62-66.

Papadias, D., Mamoulis, N., e Theodoridis, Y. (1999). Processing and optimization of multiway spatial joins using r-trees. In ACM Symp. on Principles of Database Systems (PODS), p. 44-55, Philadelphia, PA. ACM Press.

Pass, G., Zabih, R., e Miller, J. (1996). Comparing images using color coherence vectors. In ACM International Conference on Multimedia, p. 65-73, Boston, Massachusetts. ACM Press.

Penatti, O. A. B., Valle, E., e Torres, R. S. (2012). Comparative study of global color and texture descriptors for web image retrieval. Journal of Visual Communication and Image Representation, 23(2):359-380.

Pentland, A., Picard, R. W., e Sclaroff, S. (1996). Photobook: content-based manipulation of image databases. International Journal of Computer Vision, 18(3):233-254.

Picard, R. W. e Liu, F. (1994). A new wold ordering for image similarity. In Proceedings of IEEE Conference on Acoustics Speech and Signal Processing, p. 129-132.

Poo, D., Chng, B., e Goh, J.-M. (2003). A hybrid approach for user profiling. Hawaii International Conference on System Sciences, 4:103b.

Puzicha, J., Hofmann, T., e Buhmann, J. M. (1997). Non-parametric similarity measures for unsupervised texture segmentation and image retrieval. IEEE Computer Society Conference on Computer Vision and Pattern Recognition, 0:267.

Qamra, A., Meng, Y., e Chang, E. Y. (2005). Enhanced perceptual distance functions and indexing for image replica recognition. IEEE Transactions on Pattern Analysis and Machine Intelligence, 27(3):379-391.

Qian, W., Mao, F., Sun, X., Zhang, Y., Song, D., e Clarke, R. A. (2002). An improved method of region grouping for microcalcification detection in digital mammograms. Computerizes Medical Imaging and Graphics, 26(6):361-368.

Ribeiro, M. X., Balan, A. G. R., Felipe, J. C., Traina, A. J. M., e Jr, C. T. (2005). Mining statistical association rules to select the most relevant medical image features. In IEEE International Workshop on Mining Complex Data (MCD), p. 91-98, Houston, USA. IEEE.

Rocchio, J. J. (1971). Relevance Feedback in Information Retrieval. The SMART Retrieval System: Experiments in Automatic Document Processing. Prentice-Hall, Englewood Cliffs, New Jersey. 
Rosa, N. A., Felipe, J. C., Traina, A. J. M., Traina, C., Rangayyan, R. M., e AzevedoMarques, P. M. (2008). Using relevance feedback to reduce the semantic gap in contentbased image retrieval of mammographic masses. In International Conference of the IEEE Engineering in Medicine and Biology Society, p. 406-409.

Rubner, Y. e Tomasi, C. (2001). Perceptual Metrics for Image Database Navigation. The Kluwer International Series in Engineering and Computer Science. Kluwer Academic Publishers.

Rubner, Y., Tomasi, C., e Guibas, L. J. (2000). The earth mover's distance as a metric for image retrieval. International Journal of Computer Vision, 40(2):99-121.

Saha, P. K. (2005). Tensor scale: A local morphometric parameter with applications to computer vision and image processing. Computer Vision and Image Understanding, 99(3):384-413.

Saha, P. K. e Wehrli, F. W. (2004). A robust method for measuring trabecular bone orientation anisotropy at in vivo resolution using tensor scale. Pattern Recognition, 37(9):1935-1944.

Sahoo, P. K., Soltani, S., Wong, A. K., e Chen, Y. C. (1988). A survey of thresholding techniques. Computer Vision, Graphics, and Image Processing, 41(2):233-260.

Sakurai, Y., Yoshikawa, M., Uemura, S., e Kojima, H. (2002). Spatial indexing of highdimensional data based on relative approximation. The VLDB Journal, 11(2):93-108.

Salton, G. (1992). The state of retrieval system evaluation. Information Processing and Management: an International Journal, 28(4):441-449.

Samet, H. (2006). Foundations of Multidimensional and Metric Data Structures (The Morgan Kaufmann Series in Computer Graphics and Geometric Modeling). Morgan Kaufmann Publishers Inc., San Francisco, CA, USA.

Samet, H. (2010). Sorting in space: multidimensional, spatial, and metric data structures for computer graphics applications. In ACM SIGGRAPH ASIA 2010 Courses, Siggraph Asia '10, p. 3:1-3:52, New York, NY, USA. ACM.

Santini, S. e Gupta, A. (2001). A wavelet data model for image databases. In IEEE International Conference on Multimedia and Expo (ICME), p. 345-348. IEEE.

Santini, S. e Jain, R. (1996). Gabor space and the development of preattentive similarity. In International Conference on Pattern Recognition, p. 40-44, Vienna, Austria.

Santini, S. e Jain, R. (1999). Similarity measures. IEEE Transactions on Patterns Analysis and Machine Intelligence, 21(9).

Santos, J. A., Ferreira, C. D., Torres, R. S., Gonçalves, M. A., e Lamparelli, R. A. C. (2011). A relevance feedback method based on genetic programming for classification of remote sensing images. Information Sciences, 181(13):2671-2684.

Sastry, C. S., Ravindranath, M., Pujari, A. K., e Deekshatulu, B. L. (2007). A modified gabor function for content based image retrieval. Pattern Recogn. Lett., 28(2):293-300. 
Schilham, A. M. R., van Ginneken, B., e Loog, M. (2006). A computer-aided diagnosis system for detection of lung nodules in chest radiographs with an evaluation on a public database. Medical Image Analysis, 10(2):247-258.

Sebe, N. e Jaimes, A. (2009). Human-centered Computing: Application to Multimedia. Springer US.

Shannon, C. E. (2001). A mathematical theory of communication. SIGMOBILE Mob. Comput. Commun. Rev., 5(1):3-55.

Shirdhonkar, M. e Kokare, M. (2011). Document image retrieval using signature as query. In International Conference on Computer and Communication Technology, p. 66-70.

Siadat, M.-R. e Soltanian-Zadeh, H. (2005). Content-based image database system for epilepsy. Computer Methods and Programs in Biomedicine, 79(3):209-226.

Silva, S. F., Barcelos, C. A. Z., e Batista, M. A. (2006). An image retrieval system adaptable to user's interests by the use of relevance feedback via genetic algorithm. In WebMedia '06: Proceedings of the 12th Brazilian symposium on Multimedia and the web, p. 45-52, New York, NY, USA. ACM.

Skopal, T. e Bustos, B. (2011). On nonmetric similarity search problems in complex domains. ACM Computing Surveys, 43(4):34:1-34:50.

Smeulders, A. W. M., Worring, M., Santini, S., Gupta, A., e Jain, R. (2000). Contentbased image retrieval at the end of the early years. IEEE Transactions on Patterns Analysis and Machine Intelligence, 22(12):1349-1380.

Smith, J. R. e Chang, S.-F. (1996). Visualseek: a fully automated content-based image query system. In ACM Multimedia '96, p. 87-98, Boston, MA. ACM Press.

Soltanian-Zadeh, H., Rafiee-Rad, F., e Pourabdollah-Nejad, S. (2004). Comparison of multiwavelet, wavelet, haralick, and shape features for microcalcification classification in mammograms. Pattern Recognition, 37(10):1973-1986.

Souza Jr., A. S., Araujo Neto, C. d., Jasinovodolinsky, D., Marchiori, E., Kavakama, J., Irion, K. L., Nobre, L. F., Funari, M., Chaves, M., Terra Filho, M., e Daltro, P. (2002). Terminologia para Descrição de Tomografia Computadorizada do Tórax (Sugestões iniciais para um consenso brasileiro). Radiologia Brasileira, 35:125 - 128.

Stehling, R. O., Nascimento, M. A., e Falcão, A. X. (2002). A compact and efficient image retrieval approach based on border/interior pixel classification. In International Conference on Information and Knowledge Management (CIKM), p. 102-109, McLean, Virginia, USA. ACM Press.

Stejić, Z., Takama, Y., e Hirota, K. (2003). Genetic algorithm-based relevance feedback for image retrieval using local similarity patterns. Inf. Process. Manage., 39(1):1-23.

Suetens, P. (2009). Fundamentals of Medical Imaging. Cambridge University Press, 2nd edition edition.

Sun, J., Zhang, X., Cui, J., e Zhou, L. (2006). Image retrieval based on color distribution entropy. Pattern Recognition Letters, 27(10):1122-1126. 
Sung, M., Kim, M., Sung, M.-W., Kim, E., e Yoo, J. (2000). Comed: A real-time collaborative medicine system. In 13th IEEE International Symposium on ComputerBased Medical Systems (CMBS 2000), Houston, Texas. IEEE Computer Society.

Tamura, H., Mori, S., e Yamawaki, T. (1978). Textural features corresponding to visual perception. IEEE Transactions on Systems, Man and Cybernetics, 8(6):460-472.

Tang, J., Rangayyan, R., Xu, J., El Naqa, I., e Yang, Y. (2009). Computer-aided detection and diagnosis of breast cancer with mammography: Recent advances. IEEE Transactions on Information Technology in Biomedicine, 13(2):236 -251.

Theodoridis, S. e Koutroumbas, K. (2006). Pattern Recognition - Third Edition. Elsevier.

Thung, P. L., Ng, C. J., Thung, S. J., e Sulaiman, S. (2010). Improving a web application using design patterns: A case study. In International Symposium in Information Technology, v. 1, p. 1-6.

Tian, Q., Xue, Q., Yu, J., Sebe, N., e Huang, T. (2004). Toward an improved error metric. In International Conference on Image Processing, v. 4, p. 2199-2202.

Torres, R. S. e Falcão, A. X. (2007). Contour salience descriptors for effective image retrieval and analysis. Image Vision Computing, 25(1):3-13.

Torres, R. S., Falcão, A. X., Gonçalves, M. A., Papa, J. P., Zhang, B., Fan, W., e Fox, E. A. (2009). A genetic programming framework for content-based image retrieval. Pattern Recognition, 42(2):283 - 292. Learning Semantics from Multimedia Content.

Torres, R. S. e Falcão, A. X. (2006). Content-based image retrieval: Theory and applications. Revista de Informática Teórica e Aplicada (RITA), 13(2):161-185.

Traina, A. J. M. e Traina Jr., C. (2003). Similarity search in multimedia databases. In Furht, B. e Marques, O., editors, Handbook of Video Databases - Design and Applications, v. 1, p. 711-738. CRC Press.

Traina, A. J. M., Traina-Jr, C., Bueno, J. M., Chino, F. J. T., e Marques, P. M. A. (2003). Efficient content-based image retrieval through metric histograms. World Wide Web Journal, 6(2):157-185.

Traina, Caetano, J., Santos Filho, R. F., Traina, A. J. M., Vieira, M. R., e Faloutsos, C. (2007). The omni-family of all-purpose access methods: A simple and effective way to make similarity search more efficient. The International Journal on Very Large Databases, 16(4):483-505.

Traina, Caetano, J., Traina, A. J. M., Santos, Roberto Figueira, F., e Faloutsos, C. (2002). How to improve the pruning ability of dynamic metric access methods. In Proceedings of the 11th International Conference on Information and Knowledge Management (CIKM), p. 219-226, McLean, USA. ACM Press.

Traina, Caetano, J., Traina, A. J. M., Seeger, B., e Faloutsos, C. (2000). Slim-trees: High performance metric trees minimizing overlap between nodes. In Zaniolo, C., Lockemann, P. C., Scholl, M. H., e Grust, T., editors, International Conference on Extending Database Technology (EDBT), v. 1777 of Lecture Notes in Computer Science, p. 51-65, Konstanz, Germany. Springer. 
Tversky, A. (1977). Features of similarity. Psychological Review, 84(4):327-352.

Tversky, A. e Gati, I. (1982). Similarity, separability and the triangle inequality. Psychological Review, 89(1):123-154.

Tzouramanis, T. (2012). History-independence: a fresh look at the case of r-trees. In Proceedings of the 27th Annual ACM Symposium on Applied Computing, p. 7-12, New York, NY, USA. ACM.

van Rijsbergen, C. J. (1979). Information Retrieval. Butterworth.

Vapnik, V. N. (1995). The nature of statistical learning theory. Springer-Verlag New York, Inc., New York, NY, USA.

Vieira, M. R. e Traina Jr., C. (2004). DBM-tree: Método de acesso métrico sensível à densidade local. Dissertação de mestrado, Universidade de São Paulo, Instituto de Ciências Matemáticas e de Computação, São Carlos, Brasil.

Wang, D., Huang, X., Kim, Y.-S., Lim, J. S., Han, M.-M., e Lee, B.-W. (2006). A structure-based approach for multimedia information filtering. Multimedia Tools and Applications, 29(1):73-89.

Wang, H. e Perng, C.-S. (2001). The s2-tree: An index structure for subsequence matching of spatial objects. In Proceedings of the 5th Pacific-Asia Conference on Knowledge Discovery and Data Mining, p. 312-323, London, UK, UK. Springer-Verlag.

Wang, J. T.-L., Ma, Q., Shasha, D., e Wu, C. H. (2000). Application of neural networks to biological data mining: a case study in protein sequence classification pages. In $A C M$ Int'l Conf. on Knowledge Discovery and Data Mining (KDD), p. 305-309, Boston, MA.

Wang, J. Z., Li, J., , e Wiederhold, G. (2001). SIMPLIcity: Semantics-sensitive integrated matching for picture libraries. IEEE Transactions on Pattern Analysis and Machine Intelligence, 23(9):947-963.

Wilson, D. R. e Martinez, T. R. (1997). Improved heterogeneous distance functions. Journal of Artificial Intelligence Research, 6:1-34. Morgan Kaufmann Publishers.

Wold, H. (1953). A Study in the Analysis of Stationary Time Series. Alqvist and Wiksell Intenational, Stockholm.

Wong, K.-M., Cheung, K.-W., e Po, L.-M. (2005). Mirror: an interactive content based image retrieval system. In IEEE International Symposium on Circuits and Systems, p. 1541-1544.

Yadav, R. B., Nishchal, N. K., Gupta, A. K., e Rastogi, V. K. (2008). Retrieval and classification of objects using generic fourier, legendre moment, and wavelet zernike moment descriptors and recognition using joint transform correlator. Optics $\&$ Laser Technology, 40(3):517-527.

Yaffe, M., editor (2011). The Digital Database for Screening Mammography. Medical Physics Publishing. 
Yin, P.-Y., Bhanu, B., Chang, K.-C., e Dong, A. (2005). Integrating relevance feedback techniques for image retrieval using reinforcement learning. IEEE Transactions on Pattern Analysis and Machine Intelligence (PAMI), 27(10):1536-1551.

Yu, J., Amores, J., Sebe, N., Radeva, P., e Tian, Q. (2008). Distance learning for similarity estimation. IEEE Transactions on Pattern Analysis and Machine Intelligence, 30(3):451-462.

Yu, J., Tian, Q., Amores, J., e Sebe, N. (2006). Toward robust distance metric analysis for similarity estimation. In IEEE Computer Society Conference on Computer Vision and Pattern Recognition, v. 1, p. 316-322.

Zegarra, J. A. M., Leite, N. J., e Torres, R. S. (2009). Wavelet-based fingerprint image retrieval. Journal of Computational and Applied Mathematics, 227(2):294 - 307. Special Issue on Emergent Applications of Fractals and Wavelets in Biology and Biomedicine.

Zhang, D. e Lu, G. (2002). Shape-based image retrieval using generic fourier descriptor. Signal Processing: Image Communication, 17(10):825-848.

Zhang, D. e Lu, G. (2003). Evaluation of similarity measurement for image retrieval. In Proceedings of the 2003 International Conference on Neural Networks and Signal Processing, v. 2, p. 928-931.

Zhang, D. e Lu, G. (2004). Review of shape representation and description techniques. Pattern Recognition, 37(1):1-19.

Zhou, F., Feng, J. F., e Shi, Q. Y. (2001). Texture feature based on local fourier transform. In Proceedings International Conference on Image Processing, v. 2, p. 610-613.

Zhou, M. X. e Aggarwal, V. (2004). An optimization-based approach to dynamic data content selection in intelligent multimedia interfaces. In ACM Symposium on User Interface Software and Technology (UIST), p. 227-236, Santa Fé, NM, USA. ACM Press.

Zhou, Q., Ma, L., Celenk, M., e Chelberg, D. M. (2005). Content-based image retrieval based on roi detection and relevance feedback. Multimedia Tools and Applications, $27(2): 251-281$.

Zhou, X., Wang, G., Yu, J. X., e Yu, G. (2003). $\mathrm{M}^{+}$-tree: A new dynamical multidimensional index for metric spaces. In 4th Australasian Database Conference, p. 1-8, Adelaide, Australia.

Zhou, X. S. e Huang, T. S. (2003). Relevance feedback in image retrieval: A comprehensive review. Multimedia Systems, 8(6):536 - 544.

Zhuang, Y., Zhuang, Y., Li, Q., Chen, L., e Yu, Y. (2008). Indexing high-dimensional data in dual distance spaces: a symmetrical encoding approach. In Proceedings of the 11th international Conference on Extending Database Technology: Advances in Database Technology, p. 241-251, New York, NY, USA. ACM. 
Este documento foi preparado com o formatador de textos $\mathrm{AT}_{\mathrm{E} X}$. 